\title{
DE LA SUERTE, EL JUEGO, Y OTROS AZARES
}
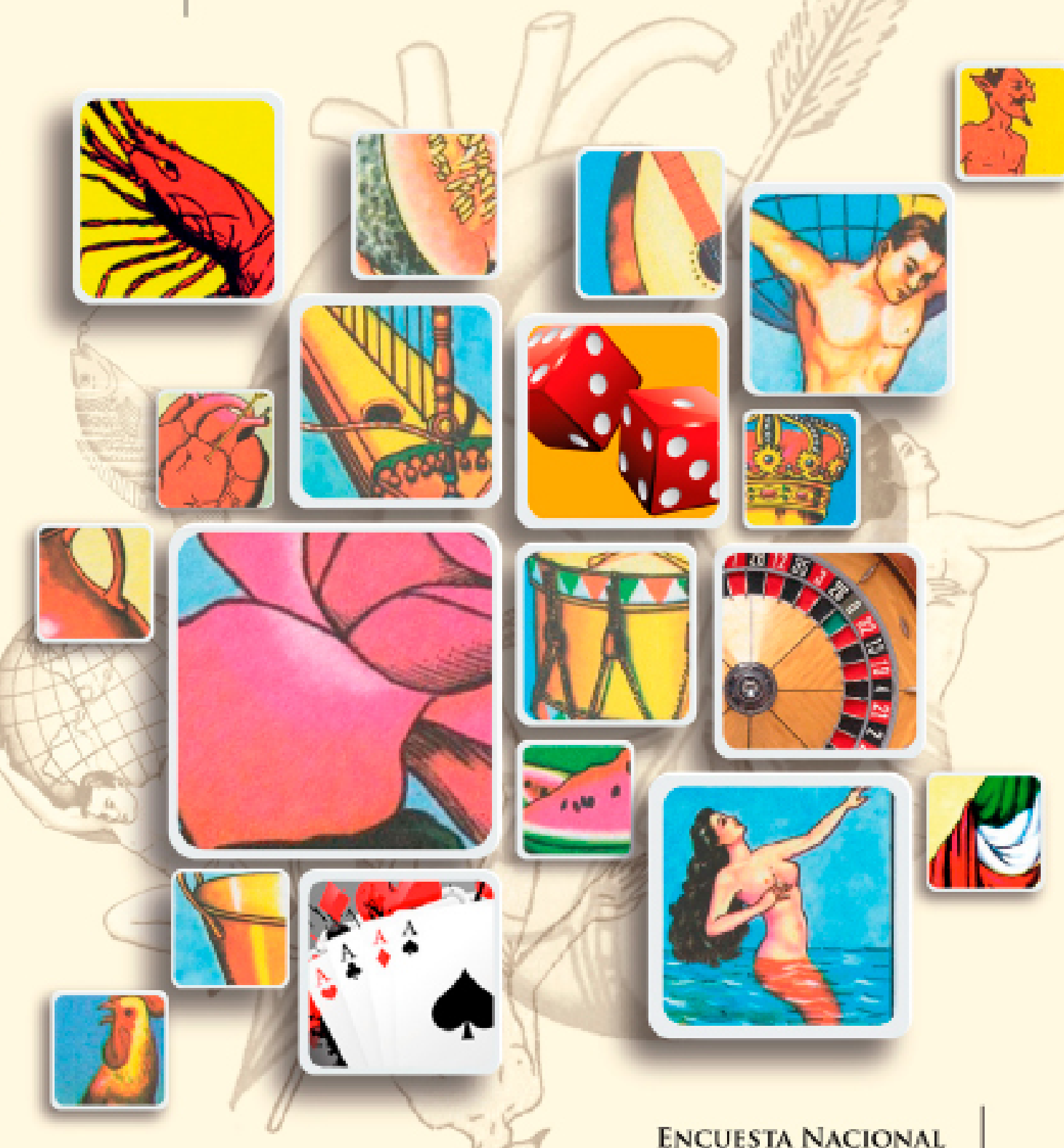

ENCUESTA NACIONAL DE PERCEPCIONES SOCIALES DE LOS JUEGos DE AZAR EN MÉXICO 
Percepciones, pobreza, desigualdad

Encuesta Nacional de Pobreza

El mercado de trabajo en México.

La opinión social sobre la precariedad laboral

Encuesta Nacional de Economía y Empleo

Educación. Las paradojas

de un sistema excluyente

Encuesta Nacional de Educación

Una reflexión crítica sobre la salud de los mexicanos

Encuesta Nacional de Salud

¡Qué familia!

La familia en México en el siglo XXI

Encuesta Nacional de Familia

Conocimientos, ideas y representaciones acerca de niños, adolescentes y jóvenes. ¿Cambio o continuidad?

Encuesta Nacional de Niños,

Adolescentes y Jóvenes

Realidades y expectativas

frente a la nueva vejez

Encuesta Nacional de Envejecimiento

Géneros asimétricos. Representaciones y percepciones del imaginario colectivo Encuesta Nacional de Género

Ser indígena en México.

Raíces y derechos

Encuesta Nacional de Indígenas

Imaginarios de la migración

internacional en México.

Una mirada a los que se van

y a los que llegan

Encuesta Nacional de Migración

Sentimientos y resentimientos

de la nación

Encuesta Nacional de Identidad y Valores
Estado laico en un país religioso

Encuesta Nacional de Religión,

Secularización y Laicidad

Cultura, lectura y deporte.

Percepciones, prácticas, aprendizaje

y capital intercultural

Encuesta Nacional de Cultura,

Lectura y Deporte

Cómo viven los mexicanos.

Análisis regional de las condiciones de habitabilidad de la vivienda

Encuesta Nacional sobre las Condiciones

de Habitabilidad de la Vivienda

Entre mi casa y mi destino.

Movilidad y transporte en México

Encuesta Nacional de Movilidad

y Transporte

La dimensión ambiental

en los albores del siglo XXI.

Miradas desde la diversidad

Encuesta Nacional de Medio Ambiente

Ciencia y tecnología:

una mirada ciudadana

Encuesta Nacional de Ciencia

y Tecnología

La otra brecha digital. La sociedad de la información y el conocimiento Encuesta Nacional de Sociedad de la Información

México en la globalización.

Dilemas y paradojas

Encuesta Nacional de Globalización

La sociedad mexicana

y los derechos humanos

Encuesta Nacional de Derechos Humanos,

Discriminación y Grupos Vulnerables

Entre un buen arreglo y un mal pleito

Encuesta Nacional de Justicia 
Percepción del desempeño de las instituciones de seguridad y justicia

Encuesta Nacional de Seguridad Pública

Percepciones sobre el federalismo en México

Encuesta Nacional de Federalismo

La corrupción en México:

percepción, prácticas y sentido ético

Encuesta Nacional de Corrupción

y Cultura de la Legalidad
El déficit de la democracia en México

Encuesta Nacional de Cultura Política

Inventario de México en 2015

\section{Los mexicanos y su Constitución}

Encuesta Nacional de Cultura Constitucional 


\section{DE LA SUERTE, EL JUEGO Y OTROS AZARES}

Encuesta Nacional de Percepciones Sociales de los Juegos de Azar en México

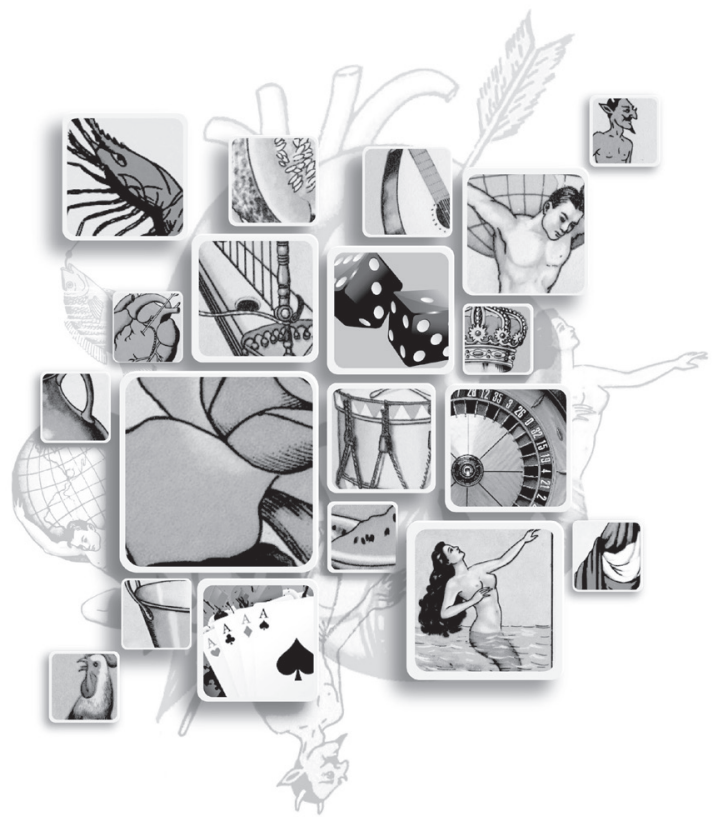


UNIVERSIDAD NACIONAL AUTÓNOMA DE MÉXICO

Rector

Enrique Graue Wiechers

INSTITUTO DE INVESTIGACIONES JURÍDICAS

Director

Pedro Salazar Ugarte

Coordinación editorial

Raúl Márquez Romero

Wendy Vanesa Rocha Cacho

Departamento de Investigación

Aplicada y Opinión

Julia Isabel Flores Dávila

Investigadores del Departamento

Azucena Rojas Parra

Agustín Morales Mena

Liliana Huerta Rodríguez

Investigación y Estadística

Miguel Tonatiuh Santiago Martínez

Eduardo Daniel Hernández Gaona

Yesenia Asunción García Cruz

Patricia Itzel Díaz Soto

Luis Ángel Ubaldo Fuentes

Sandra Hernández Cortés

Actuarios del Departamento

Diana Domínguez Sánchez

Andrés Garduño Gómez

Oscar Arturo Bringas López

Informática del Departamento

Mauricio Daniel Patlán Hernández

Apoyo Logístico del Departamento

Navorina Díaz Pineda

Angélica González Castañón 


\section{DE LA SUERTE, EL JUEGO Y OTROS AZARES}

ENCUESTA NACIONAL DE PERCEPCIONES SOCIALES

DE LOS JUEGOS DE AZAR EN MÉXICO

Biblioteca Los mexicanos vistos por sí mismos Los grandes temas nacionales

COORDINADORES

JULIA ISABEL FLORES

RUBÉN HERNÁNDEZ CID

AZUCENA ROJAS PARRA

PATRICIA NOEMÍ VARGAS

PATRICIA ITZEL DÍAZ SOTO

SILVIA KARLA FERNÁNDEZ MARÍN

MIGUEL ÁNGEL GARCÍA OLIVO

YESENIA ASUNCIÓN GARCÍA CRUZ

EDUARDO DANIEL HERNÁNDEZ GAONA

LILIANA HUERTA RODRÍGUEZ

AGUSTÍN MORALES MENA

MIGUEL TONATIUH SANTIAGO MARTÍNEZ

\section{codere}

UNIVERSIDAD NACIONAL AUTÓNOMA DE MÉXICO

INSTITUTO DE INVESTIGACIONES JURÍDICAS

CODERE 
De la suerte, el juego y otros azares. Encuesta Nacional de Percepciones Sociales de los Juegos de Azar en México / Coordinación de Julia Isabel Flores, Rubén Hernández Cid, Azucena Rojas Parra, Patricia Noemí Vargas. Primera edición. Ciudad de México : Universidad Nacional Autónoma de México, Instituto de Investigaciones Jurídicas, Codere : 2018.

318 páginas.- (Los mexicanos vistos por sí mismos, Los grandes temas nacionales ; 28)

ISBN 978-607-02-6987-5 (colección rústica)

ISBN 978-607-30-0563-0 (rústica)

1. Juego - Leyes y legislación - México. 2. Casinos - Leyes y legislación - México. I. Flores, Julia Isabel, editor de la compilación. II. Hernández Cid, Rubén, editor de la compilación. III. Rojas Parra, Azucena, editor de la compilación. IV. Vargas, Patricia Noemí, editor de la compilación. V. Serie KGF3528.S84 2018 F850.113 / F598D

Primera edición: 29 de junio de 2018

D.R. (C) Universidad Nacional Autónoma de México

Instituto de Investigaciones Jurídicas

Circuito Maestro Mario de la Cueva s/n

Ciudad de la Investigación en Humanidades

Ciudad Universitaria, 04510 Ciudad de México

D.R. (C) CODERE

Av. Industria Militar s/n, Acceso A

Col. Residencial Militar, Miguel Hidalgo

11600 Ciudad de Mexico

ISBN 978-607-02-6987-5 (colección rústica)

ISBN 978-607-30-0563-0 (rústica)

Esta edición y sus características son propiedad de la Universidad Nacional Autónoma de México.

Prohibida su reproducción parcial o total por cualquier medio, sin autorización escrita del titular de los derechos patrimoniales.

Hecho e impreso en México. 


\section{CONTENIDO}

Biblioteca Los mexicanos vistos por sí mismos.

Los grandes temas nacionales

Enrique Graue Wiechers

Prefacio

Pedro Salazar Ugarte

Presentación

Julia Isabel Flores

Prólogo

José Ignacio Cases

Introducción

Metodología

CAPÍTULO 1

La azarosa historia de los juegos de azar en México

Introducción

Antecedentes

El azar en la Colonia

El régimen porfirista y la influencia extranjera: de las carreras de caballos a los hipódromos 
Loterías, juegos de azar, casinos e hipódromos en México

desde el siglo XX

La Lotería Nacional en el siglo XX

Los casinos a inicios del siglo XX: del porfiriato

al presidente Lázaro Cárdenas

56

El regreso de los casinos a nuestro país

60

El surgimiento de los juegos de apuesta y los sorteos en línea

CAPÍTULO 2

\section{Religiones, creencias y prácticas tradicionales}

Las creencias religiosas en México

El azar, la suerte y los milagros

Prácticas y creencias tradicionales

La creencia en la suerte

Las representaciones sociales de la suerte en México

Supersticiones y rituales

Las protecciones: talismanes, amuletos y fetiches

Las denominaciones religiosas y la práctica de los juegos

de azar en México

Creencias tradicionales y prácticas de juego

El bienestar subjetivo y el azar

Control sobre la vida, locus de control y percepción del futuro

Percepción e imagen del futuro: sueños y deseos

El significado del éxito

Aislamiento social y emocional

Conclusiones

Las creencias religiosas en México

Creencias y prácticas tradicionales

Bienestar subjetivo

CAPÍTULO 3

El juego como actividad social

Introducción

Evaluación económica y política del país 
Evaluación de la situación económica familiar y personal

Aporte económico al hogar y transparencia de las finanzas

Mentalidad económica

Uso del tiempo libre

Apuestas y juegos de azar

Actitudes hacia los juegos de apuestas

Percepción de la legalidad de los juegos de azar y apuestas

Imaginarios y asociaciones de los casinos

Políticos, empresarios y narcotraficantes

Asistencia a casinos

Asistencia a casinos durante el último año

Formas de pago en los casinos

Conclusiones

Situación del país

Tiempo libre

Imaginarios de los casinos

Legalidad y regulación de los casinos

Asistencia a los casinos

CAPÍTULO 4

\section{Los jugadores en México. Una primera aproximación}

Algunos rasgos sociales de los jugadores en México

¿Quiénes juegan?

¿A qué se juega?

Participación en juegos tradicionales

Lotería Nacional y pronósticos

Salas de juego

¿Quiénes participan en múltiples juegos?

Frecuencia de juego

¿Quiénes apuestan?

Aproximación analítica a los jugadores en México

¿Cómo se identificó a los jugadores en México?

¿Quiénes juegan en México? 
Escolaridad

Condición de actividad

\section{CAPÍTULO 5}

\section{El juego problemático en México}

Participación en los juegos de azar

Motivaciones para el juego

Autopercepción de la conducta de juego

La adicción al juego

El juego problemático

CAPÍTULO 6

\section{El juego en línea}

Perfil sociológico de los jugadores en línea

¿Quiénes son los jugadores en línea?

Análisis de correspondencias

Motivaciones del juego por Internet

Análisis de correspondencias

¿A qué juegan por Internet?

¿Cuáles son los juegos más conocidos? 223

¿Cuáles son los juegos más jugados? 224

Perfil sociológico de los usuarios de los juegos por Internet 225

¿Quiénes los juegan? 225

La frecuencia del juego por Internet 226

¿Cuándo fue la última vez que compró o apostó tal juego? 226 
¿Con qué frecuencia se compra y juega?

Características de los juegos en línea 230

¿Con cuál juego considera que se puede ganar más dinero? 230

¿Cuál es el juego que más le gusta? 231

¿Cuáles juegos se juegan de manera presencial y en línea? 232

Modalidades del juego en línea 233

Tiempo destinado a jugar por Internet 233

¿Se juega durante más o menos tiempo? 233

En qué lugar se realiza el juego 234

Momentos predilectos para jugar 235

Dispositivo preferido para jugar 236

$\begin{array}{ll}\text { Cantidades jugadas } & 237\end{array}$

Estimación del dinero gastado y ganado apostando por Internet $\quad 237$

Estimación del balance entre lo ganado y lo perdido 238

Medios de pago 239

Problemas técnicos al jugar por Internet 241

Confianza en las casas de apuesta o casinos por Internet 243

Registro en las casas de apuestas por Internet 243

Conocimiento de la legalidad de las casas de apuesta por Internet 245

Confianza en las casas de apuesta por Internet 246

Juego problemático en línea 246

$\begin{array}{ll}\text { Jugar en exceso } & 248\end{array}$

Diagnósticos de juego problemático 249

Los no jugadores por Internet 251

Motivaciones para no jugar por Internet apostando dinero 251

Análisis de correspondencias 252

Otras características de los no jugadores en línea 253

Conclusiones 257

$\begin{array}{ll}\text { Conclusiones } & 259\end{array}$

$\begin{array}{ll}\text { Bibliografía } & 271\end{array}$ 
Anexos

Anexo 1. Perfil sociodemográfico 293

Anexo 2. Diseño muestral 305

Anexo 3. Confiabilidad de los ítems para juego problemático 313

Anexo 4. Metodología para la obtención del índice

de disponibilidad léxica 
Este libro forma parte del acervo de la Biblioteca Jurídica Virtual del Instituto de Investigaciones Jurídicas de la UNAM

\section{BIBLIOTECA}

\section{LOS MEXICANOS VISTOS POR SÍ MISMOS. LOS GRANDES TEMAS NACIONALES}

Enrique Graue Wiechers*

México enfrenta un panorama interno e internacional difícil y complejo. En muchos sentidos, asistimos a un cambio de época. Como consecuencia, hoy se hace más presente que nunca el compromiso constante que tiene la Universidad de la Nación con los problemas centrales que definen la vida política, social y cultural de nuestro país.

Para la Universidad, la responsabilidad de dar cuenta de los grandes retos que enfrentamos, señalarlos y proponer soluciones, implica recoger las voces de los demás en la búsqueda del bienestar público. La tarea exige una visión plural y diversa, necesaria para la asimilación de la complejidad y para la comprensión cabal de los problemas.

En momentos como los que atraviesa el país es necesario emprender una conversación acerca de los asuntos que nos importan como mexicanos y llevar a cabo una reflexión compartida que dé sostén a una comunidad política en tiempos inciertos. La mejor salvaguarda en una situación como ésta es la conservación y el acrecentamiento de una tradición de reflexión crítica en las instituciones, en las prácticas y en los proyectos de una sociedad.

Rector de la Universidad Nacional Autónoma de México. 
Este libro forma parte del acervo de la Biblioteca Jurídica Virtual del Instituto de Investigaciones Jurídicas de la UNAM

En la Biblioteca Los mexicanos vistos por sí mismos convergen investigaciones dirigidas a recoger la pluralidad de voces de los mexicanos, con miras a rescatar aquello que con frecuencia se pierde en las políticas públicas y en las teorías: el conocimiento del día a día y la experiencia del mundo de la gente común. La Biblioteca sumará, en cada uno de sus volúmenes, investigaciones rigurosas que registran las opiniones, actitudes y valoraciones de la población sobre las distintas aristas de los problemas nacionales.

La producción de conocimientos nuevos conlleva una división entre quienes tienen acceso a ellos y quienes no pueden obtenerlos. La Universidad está llamada a cerrar esta brecha. Al hacer públicos cada uno de sus volúmenes, instrumentos y bases de datos se espera que esta Biblioteca contribuya al registro de lo que somos y aspiramos como sociedad.

"Por mi Raza Hablará el Espíritu" 
Este libro forma parte del acervo de la Biblioteca Jurídica Virtual del Instituto de Investigaciones Jurídicas de la UNAM

\section{PREFACIO}

Pedro Salazar Ugarte*

Los libros que conforman la Biblioteca Los mexicanos vistos por sí mismos. Los grandes temas nacionales son el resultado de un esfuerzo académico colectivo imaginado y coordinado por la maestra Julia Isabel Flores y su equipo de trabajo en el Departamento de Investigación Aplicada y Opinión del Instituto de Investigaciones Jurídicas de la UNAM. Se trata de una iniciativa que pretende aportar insumos para una deliberación colectiva, seria y documentada sobre quiénes somos y qué pensamos los mexicanos del siglo XXI ante los grandes temas y problemas nacionales.

A partir de una serie de encuestas levantadas en el país, se invitó a reflexionar a investigadores y profesores de diversas disciplinas quienes, de manera individual o colectiva, dieron forma a cada volumen. El resultado son 28 libros en los que se entrelaza el rigor metodológico con el análisis experto para dar cuenta del pensamiento de los mexicanos en algunos de los temas más relevantes para su convivencia, en un momento crucial de la

\footnotetext{
Director del Instituto de Investigaciones Jurídicas de la UNAM.
} 
Este libro forma parte del acervo de la Biblioteca Jurídica Virtual del Instituto de Investigaciones Jurídicas de la UNAM

historia del país en el que los profundos procesos de transformación —-social, política y jurídica - interna se complejizan por los procesos de cambio global. De esta manera, la Biblioteca Los mexicanos vistos por sí mismos es, a la vez, un espejo y un proyector. Los textos reflejan nuestras ideas sobre cuestiones cruciales de la realidad nacional y, al mismo tiempo, nos obligan a mirar hacia el contexto más amplio en el que estamos insertos.

Vale la pena hacer el recuento de los temas elegidos: corrupción y cultura de la legalidad; cultura, lectura y deporte; derechos humanos, discriminación y grupos vulnerables; familia; salud; seguridad pública; movilidad y transporte; pobreza; migración; género; globalización; niños, adolescentes y jóvenes; condición de habitabilidad de la vivienda; envejecimiento; religión, secularización y laicidad; ciencia y tecnología; educación; economía y empleo; indígenas; justicia; sociedad de la información; medio ambiente; identidad y valores; federalismo; cultura política; cultura constitucional, y juegos de azar en México. Como puede verse, se trata de cuestiones de relevancia crucial para la vida cotidiana de las personas y que demandan una visión multidisciplinaria.

Ésta es otra de las virtudes de la colección. Los trabajos han sido realizados por expertos en diversas disciplinas y, por lo tanto, ofrecen un amplio fresco temático, pero con profundo rigor científico. Cada autor es experto en la materia que analiza y, además, escribió su colaboración después de conocer los avances del proyecto editorial en su conjunto. Por tanto, no se trata de textos aislados sino de un verdadero proyecto editorial imaginado y ejecutado con una visión global.

Espero que los lectores lo aprecien y disfruten tanto como lo hicimos quienes hemos tenido el honor de participar en su confección y desarrollo. En mi calidad de director del Instituto de Investigaciones Jurídicas agradezco al doctor Enrique Graue Wiechers, rector de la Universidad Nacional Autónoma de México, por el apoyo para la continuación de esta iniciativa, y felicito a la maestra Julia Isabel Flores y a su entusiasta equipo de trabajo por la llegada a buen puerto de esta empresa. 
Este libro forma parte del acervo de la Biblioteca Jurídica Virtual del Instituto de Investigaciones Jurídicas de la UNAM

\section{PRESENTACIÓN}

Julia Isabel Flores*

Los mexicanos vistos por sí mismos. Los grandes temas nacionales tiene como propósito ofrecer un panorama de los problemas del país y conocer su extensión y modalidades en la sociedad mexicana a partir de las percepciones de sus habitantes. Esta Biblioteca, que consta de 27 libros -28 con este volumen-, pretende dar cuenta de las transformaciones sociales en un contexto de globalización, de cambio cultural y político. El análisis de los temas permite obtener una visión integral de los cambios en la vida de hombres y mujeres y, de manera fundamental, de su percepción del México de principios del siglo XXI. Como podría decir Alfonso Reyes, el proyecto Los mexicanos vistos por sí mismos encierra a México en una nuez. ${ }^{\text {*t }}$

Con base en 27 encuestas nacionales de 1,200 casos cada una, aplicadas a personas de 15 años y más en sus propias viviendas, se recoge la diversidad de percepciones, opiniones, actitudes y valores de quienes vivimos en México: de los jóvenes y los adultos mayores, de los hombres y las mujeres,

* Investigadora del Instituto de Investigaciones Jurídicas de la UNAM.
Alfonso Reyes, México en una nuez y otras nueces (1931), México, FCE, 2000. 
Este libro forma parte del acervo de la Biblioteca Jurídica Virtual del Instituto de Investigaciones Jurídicas de la UNAM

de los habitantes de las grandes ciudades y el campo, en las diversas regiones del país. El diseño de los cuestionarios y la elaboración de los libros estuvo a cargo de distinguidos especialistas de la Universidad Nacional Autónoma de México en cada uno de los temas.

En los volúmenes que conforman esta colección se suman las voces, las inquietudes y los valores en las esferas que interesan a los mexicanos. En ellos se estudian los temas relativos a la población con base en las encuestas de familia, de niños, adolescentes y jóvenes; de procesos de envejecimiento; de género; de indígenas y de migración. Se abordan también los problemas y percepciones del bienestar y la economía en función de las encuestas de pobreza, y de economía y empleo. Se tratan cuestiones del mayor interés para la sociedad como la salud, la educación, la cultura, la lectura, el deporte y los juegos de azar. Se investigan, asimismo, la ciencia y la tecnología, al igual que la sociedad de la información, el medio ambiente y las condiciones de habitabilidad de la vivienda, la movilidad y el transporte.

En el campo de impartición y procuración de justicia se analizan datos de las encuestas de justicia, de derechos humanos, de seguridad pública y cultura constitucional, mientras que los estudios referentes a la organización política se sustentan en sendas encuestas relacionadas con el federalismo, corrupción y cultura de la legalidad, y con la cultura política. Finalmente, se da cuenta de las creencias, los valores y sus transformaciones a partir de las encuestas de religión, laicidad y secularización; de identidad nacional y valores, y de México frente a la globalización.

En esta Biblioteca se incorporan investigaciones sin antecedentes públicos en el país que llenan un vacío en la investigación social y permiten disponer de nuevos datos, tales como los que se derivan de las encuestas nacionales de religión, secularización y laicidad, la de indígenas, la de migración, la encuesta nacional de derechos humanos, la encuesta nacional de justicia, la de federalismo, la de sociedad de la información, la de movilidad y transporte, y la de los juegos de azar en México.

Producir análisis de alta calidad, basados en datos confiables, contribuye a conformar una visión de la sociedad mexicana en el tiempo; hace posible conocer en qué punto nos encontramos, así como medir el logro de los objetivos planteados en la política pública. Del mismo modo, permite registrar los aspectos que deben mejorarse y comparar los resultados con otros 
Este libro forma parte del acervo de la Biblioteca Jurídica Virtual del Instituto de Investigaciones Jurídicas de la UNAM

obtenidos en los ámbitos regional e internacional, a fin de llevar a cabo ejercicios de retrospección y prognosis.

Los volúmenes que conforman la Biblioteca no pretenden oponer la experiencia vivida a la abstracción teórica, sino enriquecer y poner en comunicación a ambas. El panorama resultante está lleno de contrastes: nos muestra los problemas, pero también recoge aspiraciones e indica posibles caminos. La Biblioteca nos ofrece un cuadro de claroscuros en el que las luces, las sombras y los colores se oponen y complementan mutuamente, de modo que, como en una pintura, toda sombra implica la presencia de la luz y el color, y en toda luz conviven el color y la sombra. Con la globalización asistimos a un proceso de rápidas transformaciones en los referentes de las conductas sociales y políticas, cuyo movimiento desplaza constantemente los límites de lo posible. El proyecto pretende recoger el pensamiento de la sociedad mexicana en un punto de inflexión y convertirlo en un ejercicio de pedagogía colectiva, en un momento crucial en el que la revaloración del pasado, el presente y el futuro ha de potenciar las fortalezas y los atributos del colectivo nacional, sobre las premisas de una sociedad libre y abierta.

Expreso en primer lugar mi agradecimiento al doctor Enrique Graue Wiechers, rector de nuestra Universidad, y al doctor Pedro Salazar, director del Instituto de Investigaciones Jurídicas, por su apoyo decidido en todo momento. A los investigadores de institutos y centros de investigación de la UNAM y a los jóvenes asistentes que colaboraron con ellos les agradezco su compromiso, dedicación y entusiasmo para crear esta Biblioteca. También quiero dejar constancia de mi profunda gratitud a los miembros del Departamento de Investigación Aplicada y Opinión del Instituto de Investigaciones Jurídicas, sin quienes no hubiera sido posible llevar a cabo esta empresa. 
Este libro forma parte del acervo de la Biblioteca Jurídica Virtual del Instituto de Investigaciones Jurídicas de la UNAM

\section{PRÓLOGO}

José Ignacio Cases

El juego de azar en la actualidad y en lo que se refiere a las democracias occidentales es considerado como una actividad lícita (frente a la tradicional prohibición que su práctica ha sufrido durante siglos) porque se contempla como un aspecto más de los muchos que constituyen el amplio contenido del derecho a la libertad civil. Esta libertad permite a los ciudadanos actuar sin cortapisas en cualquiera de las actividades que conforman la vida cotidiana y que no hayan sido directamente prohibidas por razones de seguridad, orden público o de salud.

No obstante, aun siendo lícita la actividad del juego de azar, los poderes públicos suelen establecer limitaciones precisamente para garantizar a los ciudadanos el ejercicio de su libertad civil de jugar sin resultar afectados por situaciones contrarias a su propia libertad. Esas limitaciones son semejantes a las que los conductores sufrimos con las normas de tráfico (direcciones prohibidas, limitaciones de velocidad, giros obligatorios, etcétera), que se 
Este libro forma parte del acervo de la Biblioteca Jurídica Virtual del Instituto de Investigaciones Jurídicas de la UNAM

establecen para garantizar la seguridad en el ejercicio de la libertad civil de desplazarse por medio de vehículos automóviles y que podemos gozar todos y cada uno de los ciudadanos.

Cuando en 2007, hace ya más de diez años, se constituyó la Fundación CODERE con el objetivo de profundizar en el estudio de los múltiples aspectos que concurren en el ejercicio de la libertad civil de participar en los juegos de azar como una forma más de ocio y entretenimiento, pero con seguridad, es decir, evitando todo aquello perjudicial a la salud y a los intereses personales de los jugadores, la Fundación entendió desde el primer momento que era preciso realizar ante todo una labor didáctica tan elemental y sencilla como la de dar a conocer la realidad y combatir los tópicos y lugares comunes que sobre esta materia existen entre la población de cualquier país.

Para actuar de modo positivo nada mejor que ayudar a la sociedad a que se conozca a sí misma. El aforismo latino Nosce te ipsum, que Pausanias transmitió inscrito en lengua griega en el pronaos del templo de Apolo en Delfos, es una invitación de gran contenido ético y una exigencia contundente que nos enfrenta a todos los seres humanos con la realidad que, en ocasiones, suele ser muy inquietante.

En 2010 la Fundación patrocinó el primer estudio sobre la percepción que los españoles tenían sobre el juego de azar y su práctica por la sociedad, que llevamos a cabo un grupo de profesores pertenecientes al Instituto de Política y Gobernanza (IPOLGOB) de la Universidad Carlos III de Madrid junto a otros valiosos colaboradores. El estudio tuvo una amplia repercusión porque dentro de lo que conocemos como "realidad" no están sólo los datos fríos y concretos, sino también la lectura y comprensión que de ellos hace la propia sociedad. La percepción es un elemento fundamental para establecer una política pública adecuada por los gobernantes porque refleja claramente la opinión pública. A través de las dos encuestas (juego presencial y juego en línea) logramos saber lo que la propia sociedad percibe de sus propios actos.

Estas encuestas se han repetido anualmente y, por tanto, este año verá la luz la novena, lo que permite extraer conclusiones y matizaciones muy ajustadas que pueden resistir con eficacia frente a las noticias alarmistas que tanto gustan a los medios de comunicación generalistas. Conocer 
Este libro forma parte del acervo de la Biblioteca Jurídica Virtual del Instituto de Investigaciones Jurídicas de la UNAM

científicamente la realidad, sin prejuicios ni fantasías, es lo que corresponde hacer al mundo académico y es la única ayuda eficaz para enfrentar las soluciones a los problemas que pueda presentar una práctica desordenada del juego, sea por inclinaciones personales, o bien, por políticas públicas erróneas.

La Fundación ha querido extender este tipo de estudios a los países en los que la empresa CODERE tiene presencia. En mayo de 2017 se publicó el estudio sobre la percepción referente a Italia realizado por la Fundación Bruno Visentini y la Libera Università Internazionale degli Studi Sociali (LUISS), una de las dos universidades privadas de mayor prestigio en Italia. En estos momentos se está elaborando el estudio correspondiente a 2018.

La posibilidad de colaborar con la Universidad Nacional Autónoma de México (UNAM) se presentó en 2009 tras firmar un convenio de colaboración entre el Instituto de Investigaciones Jurídicas (IIJ) y el IPOLGOB. Ello facilitó la celebración del seminario "Juegos de azar. Una visión multidisciplinaria", dirigido por Cecilia Mora-Donatto, y la posterior publicación de un libro con el mismo título en 2010.

La UNAM es un referente intelectual en el mundo y, por tanto, en el ámbito de los países de habla hispánica. Así lo ha reconocido España de forma solemne al otorgar el Premio Príncipe de Asturias de Comunicación y Humanidades de 2009 a esta Universidad.

La colaboración entre la Fundación y el IIJ se ha intensificado notablemente. En 2017 aparecieron los dos volúmenes del Diagnóstico del marco normativo y tributario de los juegos con apuestas, de Ezequiel González y Gabriela Ríos, y ahora, este enorme esfuerzo que el IIJ ha realizado para iluminar, desde una perspectiva estrictamente académica, un campo tan desconocido en México como el del juego de azar, se ve completado de forma espléndida por el libro que presentamos. Tengo la convicción que, como sus autores señalan, se abren nuevas perspectivas y ámbitos de reflexión sobre cuestiones que podrían ser abordadas en futuros trabajos, entre otras, el control del juego ilegal, el juego de los menores de edad o el abuso de Internet.

En este Prólogo deseo mostrar el agradecimiento de CODERE y de su Fundación tanto al director del IIJ, Pedro Salazar, como a la responsable del 
Este libro forma parte del acervo de la Biblioteca Jurídica Virtual del Instituto de Investigaciones Jurídicas de la UNAM

Departamento de Investigación Aplicada y Opinión, Julia Isabel Flores, y hacerlo extensivo a todo el elenco de investigadores y colaboradores que han participado en la realización del libro, al tiempo que formulo los más vivos votos para que esta tarea conjunta pueda continuarse con el patrocinio de nuevas publicaciones. 
Este libro forma parte del acervo de la Biblioteca Jurídica Virtual del Instituto de Investigaciones Jurídicas de la UNAM

\title{
INTRODUCCIÓN
}

\author{
Julia Isabel Flores \\ Rubén Hernández Cid \\ Azucena Rojas Parra \\ Patricia Noemí Vargas
}

Como la sota moza, Patria mía, en piso de metal, vives al día, de milagros, como la lotería

Ramón López Velarde, "La Suave Patria"

\section{DE LA SUERTE, EL JUEGO Y OTROS AZARES}

Cada cultura se entrega a la suerte de una manera singular y diversa (Semo, 2000: 139-163). Las fiestas y tradiciones populares, las ferias, las jugadas, los albures, las apuestas en general son parte de la vida de los mexicanos. El juego se acompaña de la suerte y ésta se entiende como destino en un volado donde se juega con la vida y, a veces, con la muerte.

Para comprender la presencia del azar en nuestra cultura debemos partir del análisis de las formas en que se manifiesta, que son, junto con el juego, y estrechamente vinculados a él, la suerte, los milagros y el talismán (Arizmendi, 2012). De allí el título que encabeza esta obra. 
Este libro forma parte del acervo de la Biblioteca Jurídica Virtual del Instituto de Investigaciones Jurídicas de la UNAM

El libro De la suerte, el juego y otros azares, volumen 28 de la Biblioteca Los mexicanos vistos por sí mismos: los grandes temas nacionales, se dedica a los juegos de azar. Construido sobre la interpretación y el análisis de la Encuesta Nacional de Percepciones Sociales sobre los Juegos de Azar en México, que se llevó a cabo en 2016 por primera vez, genera información pública sobre las percepciones, actitudes y valores, los hábitos y prácticas en torno a los juegos de azar, en la población de 18 años y más en las viviendas de la República Mexicana. ${ }^{1}$

La encuesta fue diseñada por especialistas del Instituto de Investigaciones Jurídicas de la UNAM para conocer los factores principales que inciden en las actitudes, opiniones y valores de la población y construir una línea base a nivel nacional para entender los puntos de vista y actitudes del público en general y de los usuarios de los juegos de azar presenciales y en línea, y levantada con el apoyo de la Fundación CODERE.

La investigación tuvo varios propósitos: por una parte, recoge las percepciones y las modalidades del juego como actividad social y se aproxima a los rasgos de los jugadores. En este sentido, se indagó sobre los usos del tiempo libre, se registraron las actitudes hacia los juegos de apuesta y sorteo, y los hábitos y las prácticas que los caracterizan. Se ocupa también de las nuevas modalidades del juego que se desarrollan con la irrupción de las modernas tecnologías, como el juego en línea. En segundo lugar, se orientó a la identificación de los patrones culturales, las opiniones y valores que enmarcan dicha actividad: la religión, las creencias y supersticiones, la satisfacción con la vida y las concepciones de la felicidad, el éxito y la vinculación de estos elementos con la predisposición al juego. Un tercer propósito de la investigación fue el de captar las tendencias hacia el juego problemático. Recoge, en fin, la diversidad y apertura de estilos de vida y de pensamiento que caracterizan a la sociedad mexicana de hoy.

En este libro se abordan los siguientes temas que se irán desgranando en cada uno de los capítulos: la azarosa historia de los juegos de azar en México; juego, religiones, creencias y prácticas tradicionales; el juego como

1 Entre los antecedentes de esta encuesta se tienen la Encuesta sobre juegos de azar de la Secretaría de Gobernación levantada en 2008, cuyos resultados no son públicos, y la Encuesta Juegos de Azar, de Consulta Mitofsky, encuesta telefónica nacional. Se realizaron 500 entrevistas vía telefónica del 17 al 18 de octubre de 2012. 
Este libro forma parte del acervo de la Biblioteca Jurídica Virtual del Instituto de Investigaciones Jurídicas de la UNAM

actividad social; los jugadores en México: una primera aproximación; el juego problemático en México, y el juego en línea. Los anexos metodológicos se incluyen al final.

Con la realización de la primera Encuesta Nacional de Percepciones Sociales sobre los Juegos de Azar en México el Instituto de Investigaciones Jurídicas brinda información y aportes para el análisis. Además de la utilidad académica de la encuesta se ofrecieron nuevos elementos a la consideración de quienes están interesados en conocer la importancia cultural, social, económica y para la salud de dichas prácticas y a quienes están formalmente investidos de atribuciones para tomar decisiones de políticas públicas. Sus resultados permiten dilucidar y valorar el sentido de las percepciones, las prácticas y su dirección. Por ello es importante que esta encuesta, apenas una primera aproximación, se transforme en un instrumento de aplicación periódica que permita valorar las diferentes facetas del diseño institucional y la dirección en la que nos movemos. Ello obliga a analizar con mayor profundidad el problema y continuar las mediciones existentes, incorporando nuevos temas.

Este libro es deudor de obras anteriores emprendidas por el Instituto con la visión de explorar y ofrecer soluciones a los problemas que impone la realidad mexicana: Juegos de azar. Una visión multidisciplinaria, coordinado por Cecilia Mora-Donatto en 2010, y Diagnóstico del marco normativo y tributario de los juegos con apuestas, de Gabriela Ríos Granados y Ezequiel González Matus en 2017. Igualmente, de la serie de libros Una aproximación a las percepciones sobre el comportamiento y las actitudes sociales respecto al juego y al juego on line en España (2010) y las encuestas anuales siguientes, resultado de la investigación emprendida en España que se ha realizado bajo los auspicios del Instituto de Políticas y Gobernanza de la Universidad Carlos III de Madrid bajo la coordinación de José Ignacio Cases.

Los autores queremos dejar constancia de nuestra gratitud a la Fundación CODERE, a José Ignacio Cases, Carlos Zamudio y Germán Gusano, que hicieron posible la realización de esta primera encuesta; a las autoridades del Instituto de Investigaciones Jurídicas y a los miembros de su Departamento de Investigación Aplicada y Opinión, sin quienes no hubiera sido posible llevar a cabo esta empresa. 
Este libro forma parte del acervo de la Biblioteca Jurídica Virtual del Instituto de Investigaciones Jurídicas de la UNAM

\section{METODOLOGÍA}

La metodología de investigación para la Encuesta Nacional de Percepciones de los Juegos de Azar en México implicó el uso de métodos de análisis cuantitativo que provienen de diversas disciplinas, tales como la estadística, la sociología y la psicología social. Asimismo, se recurrió a una combinación de diversas técnicas, como la encuesta probabilística en vivienda y la encuesta probabilística en línea con el objeto de recoger las percepciones y actitudes hacia los juegos de azar. Se buscó profundizar en las disposiciones (Bourdieu, 1977), preferencias, preocupaciones, valores y experiencias de la población, de acuerdo con las diversas características sociodemográficas y económicas.

La investigación permite conocer las diversas modalidades de los juegos de azar en el país — públicos y privados - y las motivaciones, entre otros factores, que llevan a la gente a participar en juegos de azar. Posibilita también establecer algunos rasgos de los jugadores en vivienda y de los usuarios de servicios de juegos en línea. 
Este libro forma parte del acervo de la Biblioteca Jurídica Virtual del Instituto de Investigaciones Jurídicas de la UNAM

El estudio tiene como objetivos:

- Proveer una línea base para medir la utilización de los juegos de azar en vivienda y en línea en el país, para que en un futuro puedan ser medidas las tendencias entre los usuarios.

- Proveer una línea base para medir las prácticas de juego problemático entre la población en vivienda y en línea, para que en un futuro puedan ser medidas las tendencias en la población.

Es importante construir un diagnóstico a nivel nacional para entender los puntos de vista y actitudes del público en general y de los usuarios presenciales y en línea. Esta información provee insumos para una planificación más efectiva y posibilita conocer elementos que pueden derivar en la calidad de servicio que se pretende ofrecer.

\section{DISEÑO DEL CUESTIONARIO}

Se diseñaron dos cuestionarios, uno para aplicar en vivienda y otro para aplicar en línea:

- Se diseñó un cuestionario general de opinión en vivienda para recoger el sentir individual, actitudes y valores de las personas sobre diversos temas relativos a los juegos de azar, con una sección diseñada para captar información acerca de las condiciones de vida de los hogares.

- Se diseñó un segundo cuestionario para aplicar en línea, dado que las nuevas tecnologías facilitan la práctica de juegos de azar sin tener que hacerlo de forma presencial.

Con propósitos de comparación se replicaron y adaptaron a la cultura mexicana algunas preguntas del estudio Percepción social sobre el juego de azar en España $2015^{1}$ y se incluyeron temas adicionales de interés para la sociedad mexicana.

1 Percepción social sobre el juego de azar en España 2015, Instituto de Política y Gobernanza, Universidad Carlos III de Madrid, 2013. 
Este libro forma parte del acervo de la Biblioteca Jurídica Virtual del Instituto de Investigaciones Jurídicas de la UNAM

\section{ENCUESTAS EN VIVIENDA Y EN LÍNEA}

El periodo de levantamiento de la encuesta nacional en vivienda fue del 23 al 29 de septiembre de 2016. Se encuestó a 1,200 personas de 18 años y más que habitan en viviendas distribuidas en todo el país. La encuesta está dirigida a recoger las valoraciones, percepciones, necesidades, conflictos y problemas de la población entrevistada en torno a su percepción sobre los juegos de azar.

Para la encuesta en línea la investigación comprendió la aplicación de un cuestionario para quienes practican los juegos de azar por este medio, que incluye también una sección dedicada a la captación de información sociodemográfica.

Gracias al apoyo de CODERE México, en el periodo comprendido entre el 3 y el 30 de noviembre de 2016 se lanzaron dichos cuestionarios a una base de 10,000 usuarios en línea y se obtuvieron 709 cuestionarios efectivos de personas que acostumbran jugar en línea, así como la respuesta de 1,224 personas que señalaron no ser jugadores en línea.

Debido al tipo de estudio y al origen de la muestra obtenida, debe puntualizarse que una encuesta en línea tiene como limitantes que el cuestionario sea de autollenado y que las personas que responden se autoseleccionen. Por lo anterior, no es posible determinar que los participantes sean representativos de los apostadores en línea en general y deben siempre tomarse con precaución estos resultados, pues contienen sesgos adicionales a los que regularmente conllevan las muestras aleatorias no representativas.

A pesar de estas limitantes, se procedió a levantar la encuesta en línea con el respaldo de que investigaciones realizadas en Inglaterra han indicado que utilizar encuestas en línea para este tipo de estudios es particularmente adecuado, ya que aseguran la privacidad de los jugadores cuando se desea estudiar sus actitudes frente a los juegos de azar (Griffiths et al., 2010: 84). Es así como se advierte que, aunque los resultados no son estadísticamente representativos de la población estudiada, constituyen un indicador de lo que parece ser una tendencia a nivel mundial y nacional.

En el Anexo 2 de este libro se expone en forma detallada la metodología de la investigación. 
Este libro forma parte del acervo de la Biblioteca Jurídica Virtual del Instituto de Investigaciones Jurídicas de la UNAM

\section{CAPÍTULO 1}

\section{LA AZAROSA HISTORIA DE LOS JUEGOS DE AZAR EN MÉXICO}

\section{INTRODUCCIÓN}

En este capítulo se lleva a cabo una reconstrucción histórica de los juegos de azar en México. A partir de la recopilación de datos de diferentes documentos, tanto científicos como de otro tipo de contenidos, la narración se ordena cronológicamente, agrupada en largos periodos significativos.

El juego nos interesa a todos porque "es más viejo que la cultura", diría Huizinga (2000: 11), y porque "la cultura humana brota del juego —como juego-y en él se desarrolla" (2000: 7-8). Aunque en cada cultura, tiempo y espacio se hace de manera particular. Así, para los modernos, el juego de azar se convierte en un sustituto de obtención de dinero sin trabajar, sin esforzarse pacientemente para obtener un ingreso. "De allí la seducción permanente de las loterías, de los casinos, de las quinielas en las carreras de caballos o en los partidos de futbol" (Caillois, 1986: 239). Eso resalta la diferencia entre Huizinga y Caillois; para este último, el tipo de juego de azar tiene un interés material y no solamente agonal, competitivo, si bien el juego de azar para Huizinga supone pertenecer "a la esfera de la fiesta o del 
Este libro forma parte del acervo de la Biblioteca Jurídica Virtual del Instituto de Investigaciones Jurídicas de la UNAM

culto, la esfera de lo sagrado" (2000: 22). En sociedades ociosas, sigue el autor, "es frecuente que los juegos de azar adquieran una importancia cultural inesperada, que también influye en el arte, en la ética, en la economía e incluso en el saber" (Caillois, 1986: 240).

Ambos, uno desde la filosofía y otro desde la sociología, coinciden en la paradoja del carácter lúdico del juego que orienta la evolución social.

\section{ANTECEDENTES}

Entre sociedades antiguas fueron populares los juegos de azar, en los cuales no sólo intervienen las habilidades del jugador sino la fortuna. "La fortuna se ponía a prueba entre los egipcios en distintos juegos de azar y de apuesta... En China, desde la Antigüedad, se prefieren los juegos de azar antes que los que implican esfuerzo físico" (Reyes, 1997: 18-19). En Grecia, "del lado del azar, aparecen los dados lanzados desde el cubilete, el pentagrama, el solitario, el tres en raya" (Reyes, 1997: 21). Entre los romanos, los juegos de azar "suscitaban en la capital del imperio tantas intenciones de cancelación como furores reiteradamente desplegados" (Reyes, 1997: 23).

Por parte de las culturas mesoamericanas, según Echeverría, Fuentes y Castillo (2011: 40), en el Códice Magliabecchi se dice que el patolli era un juego de azar que "incluía fuertes apuestas de productos como mantas, magueyales, cuentas de oro y piedras preciosas entre los jugadores y espectadores. Se llegaba incluso a apostar hasta la persona y los perdedores quedaban sometidos a la condición de esclavos hasta pagar la deuda". Según Morales (2000: 43), en las primeras "traducciones castellanas lo definen como un juego parecido a los dados", y "muy difundido entre los diferentes grupos sociales". En torno al juego había jugadores, apostadores y espectadores. No obstante la condena inquisidora de los conquistadores españoles, "la popularidad del patolli fue muy extendida, no sólo en el altiplano central, sino también en el sur y sureste de Mesoamérica" (Morales, 2000: 48). Por su parte, para los nahuas, tanto en "la fatalidad ritual como en el azar o en la incertidumbre, la tensión es el elemento motriz del juego" (Morales, 2000: 33). 
Este libro forma parte del acervo de la Biblioteca Jurídica Virtual del Instituto de Investigaciones Jurídicas de la UNAM

\section{EL AZAR EN LA COLONIA}

Las partidas de cartas llegaron a la Nueva España de la mano de los conquistadores, quienes eran asiduos, sobre todo los que se lanzaban a la aventura en la mar. "El mar se convirtió en un puente natural para el intercambio no sólo de mercancías e ideas, sino también de formas de manejar el ocio y la diversión, entre los cuales el juego de los naipes ocupó un lugar importante" (Chinchilla, 2000: 84). Con la llegada de los españoles a tierras mesoamericanas también llegó el juego.

Si bien la división estamentaria que caracterizó al periodo del virreinato en la Nueva España terminó por dividir étnica y culturalmente a la población, el juego "fue uno de los puentes que se tendieron entre los diversos grupos sociales, a través de los cuales se mezclaron tradiciones de origen indígena e hispano para conformar el mosaico cultural que hoy define a México" (Chinchilla, 2000: 56).

Isabel Grañén Porrúa narra que aquel grupo de conquistadores, encabezado por Hernán Cortés, acostumbraba jugar a los naipes en los momentos de ocio (1997: 369). Además, según los testimonios que existen, "Hernán Cortés era un gran aficionado a este juego y muy propenso a los dados" (Grañén, 1997: 369). Con la necesidad de jugar y ante la lejanía del viejo continente y del contacto con otros europeos, los conquistadores se vieron en la necesidad de crear sus propias barajas "con diversos materiales, ya fueran las pieles de los animales, las hojas o cortezas de los árboles, papeles de algodón o con cuero sacado de los parches de los tambores" (Sains, 1972: 562).

Con la influencia europea, principalmente el juego de naipes se comenzó a popularizar en el nuevo continente, ya que los soldados y los indígenas comenzaron a jugar, los primeros enseñaron a los segundos (Grañén, 1997: 370). Grañén trata de dar explicación al éxito que tuvo el juego en este lugar: la apuesta y el sentido mágico o adivinatorio. Ambos elementos que no se alejaban de la concepción de los indígenas del lugar (1997: 370). Entonces, no sólo los españoles dejaban a la suerte sus pertenencias, los indígenas también comenzaron a tomar cierta filia por los juegos de cartas e iniciaron a apostar. El papel que desempeñaron los juegos en el mestizaje fue relevante. Al respecto, Juan José Reyes menciona: 
Este libro forma parte del acervo de la Biblioteca Jurídica Virtual del Instituto de Investigaciones Jurídicas de la UNAM

Las cartas de la suerte serían también vías expeditas de la exposición de valores que habrían de ser compartidos por los colonizadores y los dueños originales de esta tierra... El mestizaje no se alejaría en ningún sentido de la reiterada búsqueda del azar. Incluso en su proceso de evolución hizo coincidir -en una carta correspondiente a un juego de 1583- una escena del juego del volador mexicano con la embestida de dos toros españoles. El juego había comenzado. ${ }^{1}$

Por su parte, Grañén narra la adaptación de las cartas de los naipes europeos al contexto del nuevo mundo; en este sentido, se elaboró una baraja "mexicana" que en sus cartas representaba a los emperadores Moctezuma Il y Cuauhtémoc, con lo que "el grabador logró captar el espíritu del lugar donde circularían las barajas" (1997: 379) y acercar el juego a los indígenas.

De hecho, cuenta Bernal Díaz del Castillo en sus crónicas que al estar preso en la ciudad de Tenochtitlan, "los españoles jugaban con él [Moctezuma II] a las barajas, y éste se entretenía con agrado" (Grañén, 1997: 369).

Como en todo tema con implicaciones sociales, el juego tuvo sus adeptos, pero también a personajes que veían en él una acción inmoral o pecaminosa. Por ejemplo, "se imprimieron libros sobre la moralidad del juego al establecer los límites entre la recreación de un pasatiempo o la necesidad de descanso y el peligro que corría la conciencia al desafiar a Dios" (Grañén, 1997: 370). Las opiniones acerca de que las mujeres jugaran y apostaran también eran negativas: "La práctica de juegos de suerte, como se les llamaba, provocaba escándalos públicos, y también privados, como el que suscitaba la exposición de «tantas doncellas» a perder su honor en las casas de juego" (Reyes, 1997: 42). Para el fraile e historiador Diego Durán, el mal era más grave, ya que para él "el juego no sólo era la pérdida de sus haciendas y vidas", sino "las almas, lo cual es mucho doler", ya que los viciosos se volvían "esclavos perpetuos", y esto orillaba a los jugadores a olvidar de cumplir con sus trabajos, por ello eran considerados como "gente infame y de mal vivir" (Grañén, 1997: 370). En este sentido, las Constituciones del arzobispado de la Nueva España prohibieron a los eclesiásticos "el juego de tablas, dados, naipes, primera, dobladilla, torillo, u otros entretenimientos",

1 Juan José Reyes (1997: 29). 
Este libro forma parte del acervo de la Biblioteca Jurídica Virtual del Instituto de Investigaciones Jurídicas de la UNAM

que eran calificados como "deshonestos"... Los religiosos debían emplear su tiempo en "(sic) sanctos y buenos ejercicios, y dar de sí buen ejemplo", porque los legos podían juzgarlos o notar actos de liviandad, y aclaran las Constituciones: "no vengan por ello, a ser menospreciados o tenidos en menos, de lo que su orden y (sic) abito requiere" (Grañén, 1997: 370).

Para el resto de la población, los juegos de azar eran perseguidos con penas severas cuando no eran públicos (Echeverría, Fuentes y Castillo, 2011: 42). Las opiniones de los eclesiásticos influyeron para que se crearan normas que prohibían los juegos de apuesta; al respecto, Grañén menciona que "la más antigua se dio para los juegos de naipes y dados que data del 1 de febrero de 1525" (1997: 371).

"Durante la colonia fueron popularísimos los juegos de envite, es decir, esa clase de juegos en donde ocurre una suerte de puja de postura, de apuestas para derrotar al contrario a partir de la confianza en la suerte propia" (Reyes, 1997: 34). En la Nueva España se fomentaba la celebración de festividades, no obstante la rigurosa normativa civil y eclesiástica con los juegos de pelota vasca, peleas de gallos, bolos, pero cuando se trataba de juegos de azar, la tolerancia "se convertía en franca prohibición por lo menos en la letra" (Chinchilla, 2000: 64).

Y las restricciones no tuvieron vigencia porque las costumbres se encontraban arraigadas (Grañén, 1997: 371). Lo único que acaso cambió fue migrar de lugares públicos a lugares privados para jugar. Pero la poca tolerancia provocó tomar medidas hacia los jugadores; por ejemplo, no realizarles préstamos (Grañén, 1997: 371).

Pronto la Corona se dio cuenta de la gran fuente de ingreso que representaba el juego, y al respecto: "Felipe II fue quien incorporó a la legislación indiana la reglamentación correspondiente al juego de naipes. Mediante estas leyes el rey permitió que el juego de naipes se convirtiera en un estanco, es decir, en un negocio exclusivamente administrado por la Corona" (Chinchilla, 2000: 84). Y los indígenas "no tardaron en aficionarse a los naipes y a cruzar apuestas" (Reyes, 1997: 29). Con lo anterior, desde el inicio del siglo XVI la Corona prohibió la producción de barajas en América; posteriormente, Felipe II, "el 13 de septiembre de 1552, mandó establecer un estanco encargado de la producción y distribución de las barajas en las Indias, tal como funcionaba en Europa, el cual debía proporcionar una renta estable a 
Este libro forma parte del acervo de la Biblioteca Jurídica Virtual del Instituto de Investigaciones Jurídicas de la UNAM

las cajas reales" (Grañén, 1997: 371), pero según Grañén: "la fabricación de los naipes continuó durante el virreinato". El bibliógrafo Joaquín García Icazbalceta afirma que "a fines del siglo XVI se fabricaban en México nueve mil docenas de naipes cada año, y que éstos se vendían a tres reales y eran más estimados que los traídos de España" (1997: 371).

"Muchos coinciden en calificar a los jugadores no sólo como aficionados, sino como adictos al juego de azar" (Chinchilla, 2000: 65). Y entre ellos había dos sectores de la población que eran los más afectados:

...los que no tenían nada y los que tenían mucho. Los primeros, los pobres, eran presa muchas veces de los estafadores, sobre todo en los llamados arrastraderos donde perdían no sólo dinero sino sus pocas pertenencias.. Los jugadores con fortuna adictos a las apuestas eran un grupo que preocupaba en especial a las autoridades y a sus parientes, ya que no sólo caían muchas veces en la ruina económica, sino que ponían en entredicho el honor de su estirpe (Chinchilla, 2000: 70).

Las apuestas incluían tanto los naipes y dados cuanto las peleas de gallos y los juegos de pelota, "hasta aquellos en los que aparentemente no había nada que apostar, como el palo encebado o los mismos toros" (Chinchilla, 2000: 71).

"En los garitos donde reinaban tahúres y fulleros (hacedores de la flor de la baraja), la tirada de dados fue también fuente de grandes pérdidas para muchos, y de ganancias casi siempre exclusivas de adiestrados tiradores" (Reyes, 1997: 35).

Las peleas de gallos eran muy socorridas, más en el ámbito rural que en el urbano. Éstas nacieron en épocas antiguas en Asia Meridional, India, China y Grecia; en Inglaterra durante los siglos XVII y posteriores.

Las peleas de gallos pertenecían claramente a la clase de juegos prohibidos, ya que, como se decía entonces, eran «una pura apuesta»... Pero en la Nueva España siempre se alzaron voces — sobre todo provenientes de la Iglesiaque veían con preocupación la proliferación de las peleas de gallos porque fomentaban los excesos de la bebida y la mala conducta (Chinchilla, 2000: 75). 
Este libro forma parte del acervo de la Biblioteca Jurídica Virtual del Instituto de Investigaciones Jurídicas de la UNAM

En 1727 se aprobó el juego de gallos en espacios públicos "a partir de la una de la tarde vigilado por los ministros de justicia y no se admitiría a «hijos de familia» ni a esclavos... las autoridades, contrariamente a lo dispuesto, jugaban a los gallos e incluso eran propietarios de gallos de apuesta" (Chinchilla, 2000: 76). "En las plazas públicas la gente llegó a arriesgar, en la Colonia, grandes cantidades en favor de "su gallo»" (Reyes, 1997: 35).

A diferencia de otros juegos como los naipes, en los que había espacios separados para jugar dependiendo del estrato social, a las peleas de gallos - que se realizaban casi a diario en plazas públicas de la Ciudad de México- "acudía una gran variedad de personas, aunque predominaban las clases populares" (Chinchilla, 2000: 76).

Las peleas de gallos subsistieron incluso hasta en la Independencia, donde los que guerreaban las practicaban "como forma de descanso y distracción" (Chinchilla, 2000: 76).

Por otro lado, el juego de pelota se promovió en el siglo XVIII por considerarlo un deporte que beneficiaba a la salud; empero, "su práctica podía ser saludable, pero distaba de ser inocente y honesta. En los partidos, a veces arreglados de antemano, se cruzaban fuertes apuestas en las que a menudo los apostadores perdían grandes sumas de dinero" (Chinchilla, 2000: 81). En principio, los comerciantes vascos eran los aficionados que llevaron la pelota vasca a la Nueva España, pero con el tiempo, otros sectores de la población no vasca se aficionaron, hasta que el cobro por entrada a los partidos evitó que se popularizara y practicara ese juego en espacios públicos, como "plazas y arrabales" (Chinchilla, 2000: 82).

Mención especial tiene el surgimiento de la lotería en la Nueva España, en el siglo XVIII, obedeciendo a un mandamiento del rey Carlos III de España en el cual ordenaba que se estableciera la lotería, por lo que en 1770 se instituyó la Real Lotería General de la Nueva España. A partir de entonces, el Estado la administró argumentando que sus ganancias serían para el sostenimiento de hospitales y albergues. Se ganaba bien con las apuestas a la lotería: "de una oferta de un millón de pesos a la que contribuirían, y por la que jugarían, cincuenta mil personas" (Reyes, 1997: 41). Al ver el monto a que ascendían los ingresos, ya no otorgaron los porcentajes ofrecidos: "Las ganancias iban en constante aumento; a los once años había ya rendimientos de 714,354 pesos. El virrey Martín Mayorga decretó que se cediera dos por ciento de ese fondo 
Este libro forma parte del acervo de la Biblioteca Jurídica Virtual del Instituto de Investigaciones Jurídicas de la UNAM

al hospicio de pobres, además el catorce por ciento que se deducía para el erario... Esa cantidad se consideró finalmente excesiva y se decidió entregar la suma de 12,000 pesos anuales para gastos del hospicio" (Chinchilla, 2000: 64). Otros también notaron las ganancias robustas, por lo que abrieron sus propias loterías, como la eclesiástica (Echeverría, Fuentes y Castillo, 2011: 43).

"El 1 de octubre se inició la venta de billetes de lotería en una casa de la calle de las Capuchinas y el primer sorteo se llevó a cabo el 13 de mayo de 1771 en el Salón de Cabildos del Ayuntamiento de la Ciudad de México con el premio mayor de 10 mil pesos". ${ }^{2}$ La diferencia entre la venta y el sorteo se debió a que no fue "suficiente el tiempo para que la colectoría general, situada en la ciudad de México, y las particulares, establecidas en Puebla, Oaxaca, Orizaba, Veracruz, Querétaro, Guanajuato, Celaya, Guadalajara, Valladolid (Morelia) y Durango, se allegaran los fondos necesarios para la premiación ofrecida" (Reyes, 1997: 44).

Al comienzo se vendía un billete completo, sin divisiones en cachitos, el cual costaba 20 pesos, pero pronto "los organizadores resintieron los efectos de su error: la lotería no podía ser un juego para ricos. Se decidió entonces bajar el precio a cuatro pesos y se instituyeron las fracciones" (Reyes, 1997: 41). Desde 1771 se aumentó el número de sorteos "de nueve anuales a doce. En 1775 los fondos aumentan de cuarenta a cincuenta mil pesos" (Reyes, 1997: 46).

También desde 1771 hubo "niños gritones", y las niñas empezaron a participar hasta 2001:

... los niños gritones han sido un ícono de transparencia en cada uno de los sorteos que realiza esta casa de asistencia pública, debido a que son ellos quienes se encargan de cantar los números de billete que son premiados en cada sorteo que organiza la lotería. Con objetivo de generar equidad, en 2001 se incorporaron las niñas (Canchola y Villa, 2017: s/p).

La lotería se mantendría como una fuente de ingreso importante para el virreinato y la Iglesia católica al menos hasta el inicio de la guerra de Independencia.

2 Véase "La real lotería", en wikimexico.com, http://www.wikimexico.com/articulo/la-real-loteria [fecha de consulta: 18 de octubre de 2017]. 
Este libro forma parte del acervo de la Biblioteca Jurídica Virtual del Instituto de Investigaciones Jurídicas de la UNAM

\section{LOS JUEGOS DE AZAR EN LA INDEPENDENCIA}

En el México independiente los gobiernos "continuarán la emisión de bandos, reglamentos y leyes que combaten a los juegos de azar, aunque por su insistencia manifestaban su escasa efectividad. Lo único que cambiará es la argumentación —ahora secular y republicana- que caracteriza a las leyes de prohibición" (Vázquez, 2000: 94-95). Y como desde el siglo XVIII, Vázquez señala que alrededor de los juegos de azar se continuaban reuniendo personas de diferentes clases sociales que, "aunque sea por un momento, viven una especie de igualdad republicana" (2000: 95).

Al estallido de la guerra de Independencia se suspendió el sorteo de la lotería. Pero en 1815 se ordenó que se realizaran loterías forzadas para la causa realista.

"Don Felipe María Calleja mandó en 1815 que se llevaran a cabo "dos loterías forzosas", una para la capital y la otra para el resto del virreinato, para con ellas hacerse de fondos con el noble fin de impulsar la batida que se daba a los insurgentes" (De Valle, 1997: 36). Éstas tuvieron "como primeras víctimas a los hombres que se empleaban en una caduca burocracia, obligados a «jugar» para contribuir al castigo y escarmiento de los revoltosos" (Reyes, 1997: 51).

Después de la independencia de México, la lotería siguió en manos del gobierno, ya con el nombre de Lotería del Estado, empero se fue desacreditando, por lo que "en 1843 el gobierno decidió ponerla en manos de la Academia de San Carlos, para que de las rifas obtuviera los recursos necesarios para su funcionamiento" (Vázquez, 2000: 113), y sucedió que de esa manera, al poco tiempo, se recuperó la credibilidad en los sorteos por parte del público. Mas para 1861 el presidente Juárez por decreto "quitó a la Academia de San Carlos la administración de la lotería gubernamental y ordenó la creación de la Lotería Nacional" (Vázquez, 2000: 114), orientada a "dar sustento (mediante el 25 por ciento de lo recaudado) a las escuelas de Bellas Artes y de Agricultura y a la Casa de la Cuna" (Reyes, 1997: 54).

En cuanto a los juegos de azar, de forma paralela, en el siglo XIX

... los liberales (como Prieto) condenaron al juego porque representaba una oposición al "trabajo honrado", el valor ético secular que conduciría a la so- 
Este libro forma parte del acervo de la Biblioteca Jurídica Virtual del Instituto de Investigaciones Jurídicas de la UNAM

ciedad al progreso. Sin embargo, los jugadores no hacían caso de las prohibiciones legales ni de las críticas de los moralistas y seguían organizando partidas en pulquerías y cafés (Vázquez, 2000: 98).

Y no sólo eran hombres los que jugaban y apostaban, también las mujeres:

A pesar de que la Iglesia condenaba el juego, las señoras solían invocar a Santa Lucía para que en el siguiente reparto saliera el dos de oros; apostaban al tres pidiendo fortuna a la Santísima Trinidad; rezaban a Santiago Matamoros para que saliera el caballo; o bien, asociaban la carta del rey con plegarias al Rey David (Vázquez, 2000: 99).

No obstante que su práctica fuera contraria a la reglamentación, los jugadores lo hacían como forma de entretenimiento a pesar de representar un peligro latente (Vázquez, 2000: 100). No así en el ámbito rural, donde en las ferias "se practicaba abiertamente el juego, como un lugar de excepción a las leyes que prohibían toda forma de diversión relacionada con el azar" (Vázquez, 2000: 104); también ahí convivían personas de variado origen social que se mezclaban en las distintas casetas de apuestas; entre ellos, los juegos más comunes eran naipes, dados, carcamán, lotería de cartones, albures con baraja (alburitos por las apuestas de más bajo monto), ruleta o imperial, o peleas de gallos. Como señaló el viajero inglés George F. Ruxton, "aquí acudían el hacendado con sus doradas onzas, el ranchero con sus pesos de plata y el lépero con sus tlacos de cobre. En un puesto de regular categoría, donde la apuesta más baja era en pesetas, se congregaba una mezcla de todas las clases sociales" (citado en Vázquez, 2000: 104). El gobierno sabía bien que la baraja era una modalidad más común para el juego y la apuesta, por lo que se adjudicaba la producción de ese material, obteniendo cuantiosas ganancias (Vázquez, 2000: 102).

Y cuando no había feria "los jugadores empedernidos se veían obligados a acudir a casas clandestinas, habitualmente ubicadas en los barrios aledaños a la capital" (Vázquez, 2000: 110). Algunas eran administradas por mujeres, donde, además de prostitución, había juegos de azar con apuestas. Éstas eran igualmente combatidas por el gobierno. Era obvio que la 
Este libro forma parte del acervo de la Biblioteca Jurídica Virtual del Instituto de Investigaciones Jurídicas de la UNAM

población era aficionada al juego, así como las clases pudientes, por lo que en 1853 Santa Anna, estando en su último año de gobierno, emitió un decreto que estipulaba las penas sobre quienes se consideraban vagos:

...todos los tahúres de profesión, así como aquellos que aun cuando tengan alguna renta y patrimonio, no tienen otro objeto que el de asistir a casas de juego o de prostitución, cafés, tabernas o parajes sospechosos. Las penas que imponía el decreto a los jugadores eran severas: aquellos que fueran aptos estarían destinados al servicio de las armas o de la marina; los que no, a casas de corrección, fábricas, talleres o haciendas de labor. También serían destinados a la colonización de zonas poco habitadas (Vázquez, 2000: 112).

En el Imperio de Maximiliano y la República Restaurada, entre 1864 y 1867, se prohibió el juego de azar y se promocionó el deporte, sobre todo desde las clases altas, en dos vertientes:

...la práctica del deporte como manera de mantenerse saludable y por otro lado, la asistencia a eventos deportivos como forma de entretenimiento. Sin embargo, las apuestas no tardaron en invadir este espacio, que hasta ese momento sólo había estado presente en el juego de pelota practicado desde la Colonia por los comerciantes vascos en el frontón de San Camilo. Pronto comenzarían las apuestas en espectáculos deportivos como el hipódromo y el box (Vázquez, 2000: 116).

"En 1869, los palenques habían sido una vez más prohibidos" (Semo, 2000: 140), por lo que los aficionados buscaron seguir con ellos y sus apuestas de manera clandestina, tal como se hizo en El Gallo de Oro, hacienda ubicada en Comitán, donde su dueño había "logrado comprar la condescendencia del jefe político y de las autoridades locales" (Semo, 2000: 140). A principios de siglo, historias como la de Comitán no abundaban. La prensa "científica" aprovechó la ocasión para reclamar medidas rigurosas contra los centros de vicio y apuestas en general; sus editorialistas prodigaban Ilamados "contra los gallos, las apuestas y los juegos de azar" (Semo, 2000: 146). Así, desaparecieron de a poco en la capital y solamente se llegaban a realizar en zonas rurales. "Había «gallos» en Xochimilco, Coyoacán y Tlal- 
Este libro forma parte del acervo de la Biblioteca Jurídica Virtual del Instituto de Investigaciones Jurídicas de la UNAM

pan... Fueron probablemente los afanes de modernización —más que el rigor liberal- los que desterraron las peleas de gallos en las principales urbes" (Semo, 2000: 146).

Para la década de los años setenta del siglo XIX, los liberales se opusieron al juego de azar y las apuestas por considerarlos contrarios a los principios positivistas de la ética del trabajo, del orden y el progreso. En el periodo de la presidencia de Sebastián Lerdo de Tejada, entre 1872-1876,

...volvieron otra vez numerosas «loteriítas» a invadir la ciudad. Desde las que había del Ferrocarril de Toluca a México, la de la Compañía Lancasteriana, la del Conservatorio, etcétera, existían 28 ○ 30 más... La citada del Ferrocarril y la Nacional se fusionaron, constituyendo así una sola en 1881 (De Valle, 1997: 37-38).

Las loteriítas "habían comenzado merced al trabajo de los curas de la iglesia de Santa Catalina, quienes reunían fondos para atender las necesidades de su templo y no las de los menesterosos" (Reyes, 1997: 48).

En la misma época, las ferias comenzaron a tomar relevancia y éstas eran generalmente aceptadas. Para Vázquez Mantecón, "las ferias constituían otro espacio, habitualmente rural, en el que se practicaba abiertamente el juego, como un lugar de excepción a las leyes que prohibían toda forma de diversión relacionada con el azar. Las ferias provincianas, importantes para el comercio regional, eran atractivas para los tahúres y vendedores ambulantes" (2000: 104). Fueron importantes en nuestro país desde la Colonia, pues eran lugares en donde el juego y lo popular se juntaban de una forma natural que desembocaba en una auténtica fiesta, fiesta de comida, juegos y, sobre todo, apuestas.

Antonio García Cubas cuenta sobre lo que sucedía en el siglo XIX en el pueblo de San Agustín de las Cuevas, ahora conocido como Tlalpan. Aquel lugar, que se levantaba como una pequeña población a las faldas del Ajusco, en los tres días de la "Pascua de Espíritu Santo" era "recorrida intensamente por toda clase de personas, que hacían camino a pie, a caballo o en burros, en elegantes carretas o en coches de alquiler, unos en buen estado y otros desvencijados" (García, 1997: 48-49). Los habitantes de la Ciudad de México y de poblados cercanos al pueblo de Tlalpan acudían al "lugar de las 
Este libro forma parte del acervo de la Biblioteca Jurídica Virtual del Instituto de Investigaciones Jurídicas de la UNAM

fiestas, que en aquella época podía tenerse por el Baden Baden o el Monte Carlo de México" (García, 1997: 49). Así, de día y de noche la actividad no se detenía; además de "cafeteros y neveros", en las calles se encontraban puestos donde se "jugaba a las cartas, a los dados, al reloj, al imperial [ruleta imperial] y a la lotería de cartones, sin faltar el ordinario carcamán ni el famoso juego de las tres cartitas" (García, 1997: 49). Como se puede imaginar, la feria de la Pascua de San Agustín de las Cuevas era una festividad donde se cruzaban apuestas y se ganaba o se perdía todo.

Otra feria importante en la historia de México es la feria de San Marcos, la cual desde 1848 y hasta nuestros días es un referente de diversión y apuesta. Se cuenta que desde sus primeros años, alrededor de 1880, en "la feria era común encontrar garitas alrededor de El Parián, donde había toda clase de juegos, a partir de 1879 se determinó que lo recaudado de la jugada se destinaría al Liceo de Niños, así como al Ayuntamiento para invertirlo en obra pública" (Feria de San Marcos, 2017). ${ }^{3}$

Más al sur, allá por el siglo XIX, en Yucatán y Campeche, los juegos de azar eran bien vistos por todas las personas, sin ningún tipo de distinción, lo cual, junto con la corrupción y complicidad de las autoridades yucatecas, hacía casi imposible su erradicación (Echeverría, Fuentes y Castillo, 2011: 46). En Campeche, continúan diciendo los autores, la lotería campechana se instituyó en 1895 y continúa vigente hasta hoy, aunque ya no en ferias públicas por no acatar la normatividad de pagar impuestos, pero la siguieron jugando en privado (Echeverría, Fuentes y Castillo, 2011: 46-47). La "campechana" en sus orígenes era clandestina, es "(la versión más remota del actual ráscale, es decir, una lotería de dividendos inmediatos)... y consistía en una lotería de gritones y cartones compuesta por 24 figuras" (González del Rivero, 2000: 178-179). de su espacio al juego, a los palenques y a los casinos. La feria se lleva a cabo desde 1848 en la ciudad de Aguascalientes, Aguascalientes. Véase la página oficial de la Feria de San Marcos, en: http://www.feriadesanmarcos.gob.mx/UI/Historia.aspx. 


\section{EL RÉGIMEN PORFIRISTA Y LA INFLUENCIA EXTRANJERA: DE LAS CARRERAS DE CABALLOS A LOS HIPÓDROMOS}

En el régimen de Porfirio Díaz, presidente de México en siete ocasiones distintas, ${ }^{4}$ la política la ejercía el general, según Beezley (1983: 266), mediante la persuasión, caracterizada por "un sentimiento popular, vago, pero profundo, basado en lo que algunos mexicanos pensaban del país y de su futuro", sobre todo en lo referente a sus diversiones, las que, siguiendo al autor, escogían sin ambigüedades ni una compulsión de supervivencia implícita, a diferencia de lo que representaba la política, la cual en esos tiempos era de estabilidad después de un periodo de guerra independentista.

La influencia extranjera en los juegos de azar se fortaleció hacia 1890, en que "varios grupos habían establecido en clubes y casinos sus centros de actividad" (Beezley, 1983: 267). La sensación de compartir los estilos extranjeros llevó a los mexicanos pudientes y de clase media a dejarse persuadir por las "maneras y diversiones de otras naciones avanzadas de occidente" (Beezley, 1983: 270), tal es el caso del impulso dado a las carreras de caballos.

Hay quienes aseguran que la primera actividad deportiva que se efectuó en tierras americanas, traída del viejo mundo, fueron carreras de caballos organizadas por los soldados de Hernán Cortés apenas a su arribo a tierras veracruzanas por el año de 1519. No obstante, la hípica en la Nueva España estaba prohibida para indios y mestizos, y es propiamente hasta que se logró la independencia que se puede decir que los mexicanos empezamos a montar y a realizar carreras, casi en cualquier calle y acompañadas de las apuestas.

Fue en 1840 cuando se "organizaron clubes para que hubiera carreras regularmente" (Beezley, 1983: 270), como el jockey club con sede en la Casa de los Azulejos y el Piñón Turf Exchange, en donde también colocaban apuestas, entre otras actividades, para las corridas que se desarrollaban en el Hipódromo de Peralvillo; este club Piñón pasó de ser un centro social a "una estación indispensable de lobby político y producción de modas y costumbres" (Semo, 2000: 150). O bien el Hipódromo suburbano de Indianilla, donde el equipo extranjero "permitía apostar al estilo parisino" (Beezley,

Del 24 de noviembre al 6 de diciembre de 1876; del 17 de febrero al 5 de mayo de 1877; del 5 de mayo de 1877 al 30 de noviembre de 1880, y luego entre 1884 y 1911. 
Este libro forma parte del acervo de la Biblioteca Jurídica Virtual del Instituto de Investigaciones Jurídicas de la UNAM

1983: 271-272), que daba al favorito con base en las apuestas realizadas: "una sola apuesta a un solo ganador, cuyos montos ascendían en función de las cantidades acumuladas" (Semo, 2000: 151); esta modalidad se debió al fracaso del sistema estadounidense, "en el que había una treintena de variantes distintas y que daba enorme libertad al apostador, aunque a la vez exigía conocimientos e información" (Semo, 2000: 151).

Las carreras de caballos al estilo inglés, o sea dentro de un hipódromo, ocurrieron a partir de 1857 en el rancho de Nápoles, aunque fue muy fugaz su existencia. En 1881 nace la Sociedad Mexicana de Carreras y sus integrantes conforman el aún hoy vigente Jockey Club Mexicano, uno de los más antiguos del continente. Su intención era edificar un recinto en el que se efectuaran carreras dentro de un óvalo. Es así como nace el llamado Hipódromo Mexicano, más conocido como el de Peralvillo, mismo que se inauguró el 22 de abril de 1882, y ya en estas instalaciones, donde se daban cita políticos, aristócratas y la población en general, se podían correr apuestas. Fue construido mediante encargo por Richard de Bergue, "quien al parecer tenía mucha experiencia en hipódromos de Francia, Inglaterra y Estados Unidos" (Vázquez, 2000: 117); a la celebración asistió la cúpula del gobierno, el cuerpo diplomático y la elite mexicana.

El éxito de éste motivó al coronel norteamericano R. C. Pate a edificar uno nuevo en el Peñón de los Baños y posteriormente otro por el rumbo de Indianilla, en la colonia de los Doctores, más cercano a los habitantes de la ciudad. Con motivo de los festejos de la Independencia se inauguró el recién edificado Hipódromo de la Condesa, que cerró a los pocos años debido al movimiento revolucionario que utilizó los caballos en la gesta militar.

También al Jockey Club perteneció parte de la crema y nata del gobierno porfiriano (la otra parte era asidua a las charreadas), según asevera Vázquez (2000). Ese Club contaba con un hipódromo en la Hacienda de la Condesa, que sirvió de modelo para otros en distintas entidades: "En las principales ciudades del país (Veracruz, Amatlán, León, Matamoros, Guadalajara, Chihuahua) las elites locales no tardaron en fundar sus respectivos jockey clubs" (Vázquez, 2000: 118), donde, entre otras cosas, también apostaban.

El de Indianilla, que se inauguró en 1895, "a la orilla del camino de La Piedad (actualmente Av. Cuauhtémoc), contaba con un costoso equipo para el cómputo de apuestas" (Vázquez, 2000: 118). Al respecto, el autor agrega 
Este libro forma parte del acervo de la Biblioteca Jurídica Virtual del Instituto de Investigaciones Jurídicas de la UNAM

que, desde sus comienzos, allá por 1870, mientras el azar "no intervenía en los caballos, las autoridades no encontraron ningún impedimento para que los espectadores corrieran apuestas" (Vázquez, 2000: 117).

"Los hipódromos se multiplicaron a lo largo del país. Veracruz, Guadalajara y Chihuahua ensayaron experimentos que no sólo se convirtieron en negocios ostensibles, sino que se reproducía la moda de tener sus propias réplicas del centro social del Piñón" (Semo, 2000: 150).

Ya desde la antigüedad bizantina, por ejemplo, los hipódromos eran espacios políticos y sociales, "espacios que representan monumentalidad y grandeza... símbolo de potestas imperial, donde el emperador es imagen y ley, presencia y poder" (Castro, 2010: 34). Aunque la simbología era para el pueblo, también lo era para los poderosos, en especial las facciones opositoras, no así para el emperador, quien era invitado en el hipódromo y no tenía autoridad en tal lugar físico y simbólico (Castro, 2010: 45). Lo mismo siguió sucediendo siglos después en una cultura tan diferente como la mexicana del porfiriato, ya que en los hipódromos o en los clubes que para efecto de las carreras de caballos se crearon, se reunían o coincidían políticos y aristócratas, nacionales y extranjeros, algunos por el riesgo de montar el caballo competidor y otros por el de apostar grandes sumas, indiferentes ante el resultado apostado y estoicos ante lo que les deparaba la fortuna (Beezley, 1983: 272); pero sobre todo para observar y tomar decisiones a posteriori, si fuese necesario; es decir, para hacer política.

Además de los hipódromos, las peleas de box se convirtieron en otro "espacio potencial para los apostadores hacia finales del siglo XIX" (Vázquez, 2000: 118); este deporte, promovido por extranjeros asentados en México, y aunque pasado el tiempo se llegó a institucionalizar, seguía fascinando a los apostadores, quienes, ante la prohibición de la apuesta, acudían a "lugares habitualmente condenados por una sociedad que de manera tácita los permitía" (Vázquez, 2000: 120), tales como cantinas, burdeles, garitos clandestinos, cafés que a medianoche hacían las veces de mesas de juego y apuestas, o casas particulares que abrían sus puertas para transformarse en casinos, donde los asistentes sobornaban a los policías para realizar sus actividades secretas (Vázquez, 2000: 121). No sin la reprobación de la clase dirigente liberal ni la opinión pública por parte de escritores como Manuel Acuña o Vicente Morales; de ahí devino una crítica moral a los 
Este libro forma parte del acervo de la Biblioteca Jurídica Virtual del Instituto de Investigaciones Jurídicas de la UNAM

jugadores y apostadores, que se convirtió en "patrimonio común de la sociedad" (Vázquez, 2000: 125).

\section{LOTERÍAS, JUEGOS DE AZAR, CASINOS E HIPÓDROMOS EN MÉXICO DESDE EL SIGLO XX}

\section{LA LOTERÍA NACIONAL EN EL SIGLO XX}

En el periodo revolucionario se dieron muchos cambios en las cúpulas del poder y del gobierno, producto de la guerra revolucionaria y de disputas entre facciones, mediadas por intereses públicos y privados —en otras palabras, el juego de la política-, que afectaron la vida nacional. Incluidos los juegos de azar y la parafernalia a su alrededor. Empezando por la Lotería Nacional, la cual se disputaban el gobierno federal y los gobiernos estatales para controlar los dineros de esa institución: "En plena revolución, el cierre temporal de la Lotería Nacional trae consigo un auge de las loterías regionales" (Semo, 2000: 159).

Francisco I. Madero, en los últimos meses de su presidencia en 1913, propuso la supresión de la Lotería, sin embargo el Congreso —disuadido por la Secretaría de Hacienda, que la defendió por ser una de las fuentes de ingresos públicos - no lo aprobó. Victoriano Huerta, en 1914, "siguiendo el esquema de concesiones que había operado durante el porfiriato, concedió a José Echegoyen un permiso por 20 años para explotar una lotería que quedaría bajo la vigilancia de la Secretaría de Gobernación" (Lorenzo, 2014: 176). Pero no duró ese tiempo.

En enero de 1915, el presidente Venustiano Carranza suprimió por decreto las operaciones de la Lotería, argumentando el detrimento moral de los intereses públicos y resaltando el valor del "trabajo, el ahorro y la moderación" (Lorenzo, 2014: 175). Aunque tal argumento bien pudo esconder una estrategia política para impedir que las facciones opositoras se hicieran de los dineros recaudados por la Lotería, en particular porque "podía servir para comprar armas y sostener una rebelión, sobre todo en los estados del norte, donde las loterías habían tenido una importante expansión después de la prohibición definitiva del juego en Estados Unidos en 1895" (Lorenzo, 
Este libro forma parte del acervo de la Biblioteca Jurídica Virtual del Instituto de Investigaciones Jurídicas de la UNAM

2014: 177). Sin embargo, como sucedió en tiempos pasados, y seguirá sucediendo después cuando fue prohibido el juego de azar, las loterías seguían operando de manera ilícita.

En contraste, fue también en 1915 que, en Yucatán, "la beneficencia pública estatal registró la cantidad de 34,300 pesos como ingreso de las utilidades de su lotería, que equivalía aproximadamente a la mitad de lo que la beneficencia de ese estado gastaba en la estancia de enfermos, cuya erogación era de 60,000 pesos. El 2 de abril de 1918 se publicó el Código Civil del estado que prohibió la venta de billetes de lotería" (Lorenzo, 2014: 181). En el mismo sentido, en 1916 Venustiano Carranza dispuso en Querétaro que se prohibieran los juegos de azar, y prevenía "a las autoridades locales que será castigado severamente quien infrinja esta disposición". En el caso de otorgamiento de permisos para el juego se imponía "pena corporal o pecuniaria según la importancia de las concesiones que otorguen" (Lorenzo, 2014: 180).

Así, a pesar de las prohibiciones de la lotería, en 1919 el gobernador interino de Nayarit aprobó la instalación de loterías en la entidad, concesionadas, pero bajo autorización gubernamental sólo cuando se destinaran a utilidad pública, instrucción o beneficencia; al año siguiente y practicando el ejemplo, en Querétaro el gobernador autorizó la concesión de la "organización de la compañía de sorteos de inmuebles, dinero u objetos varios" (Lorenzo, 2014: 186).

Por su parte, para 1920 el presidente interino Adolfo de la Huerta reanudó las operaciones para la lotería que Venustiano Carranza había prohibido cinco años antes, dando paso a una "renovada organización de la empresa del juego al servicio del Estado" (Lorenzo, 2014: 172). Pero la Lotería Nacional para la Beneficencia Pública, centralizada en el Distrito Federal, tuvo que competir con diversas loterías que se crearon también con fines benéficos, aunque con intereses particulares, por lo que fue restringida su circulación por instrucción gubernamental federal; sin embargo, los amparos contra esa medida no se hicieron esperar, y los interpusieron "las loterías de Toluca, de Tlaxcala, de Veracruz, la de la Cruz Blanca Neutral, la Internacional Mexicana, la de Michoacán, la de Zacatecas y el Sorteo Tampico" (Lorenzo, 2014: 190).

Para su puesta en marcha, "los premios de los primeros sorteos se garantizaron con una aportación de la Comisión Monetaria, que depositó 280,000 
Este libro forma parte del acervo de la Biblioteca Jurídica Virtual del Instituto de Investigaciones Jurídicas de la UNAM

pesos a cuenta de la lotería" nacional (Lorenzo, 2014: 187). Para cuidar sus capitales, invertidos y por ganar, también se prohibió la venta de loterías extranjeras. Además, en un periodo entre 1920 y 1928 se creó un consejo que administrara la lotería: "los empresarios del porfiriato se convirtieron en los consejeros de la Lotería Nacional de la posrevolución; ellos tenían el prestigio en el mundo del dinero y ellos conocían las «reglas del juego», luego este capital se transfirió a los altos funcionarios públicos que los sucedieron" (Lorenzo, 2014: 192).

Intereses privados empresariales del viejo régimen porfirista y los de los políticos revolucionarios se juntaron para jugar a la política. Y de la misma forma, cuidando sus intereses, el gobierno central dispuso en 1928 que la administración de la propia Beneficencia Pública y el manejo de sus bienes y caudales, incluyendo los de la Lotería Nacional, estarían a cargo de un consejo que se denominaría Junta Directiva de la Beneficencia Pública en el Distrito Federal, y para 1933 "el Estado posrevolucionario consiguió que la administración de las utilidades de la Lotería Nacional quedara a cargo del Departamento del Distrito Federal... como dependencia de la Secretaría de Hacienda" (Lorenzo, 2014: 173, 200).

En los años cuarenta, las ganancias de la Lotería Nacional para la Asistencia Pública se empleaban para el sostenimiento de la Secretaría de Salubridad y el Hipódromo de las Américas, "que funcionaba bajo control del gobierno y servía a los mismos fines" (Shelley, 2012: 37). "Los cuantiosos dividendos de la Lotería Nacional (45 millones de pesos tan sólo en 1943) se tradujeron en un nuevo interés por una industria dedicada al mercado de consumidores de billetes de la suerte" (González del Rivero, 2000: 179).

En los años cincuenta, de acuerdo con González de Rivero (2000: 179), los vendedores de billetes para la lotería formaban parte del imaginario colectivo en las sociedades urbanas que eran parte de la reiteración de un ritual al Ilamarlos los gritoncitos del sorteo semanal y, al mismo tiempo, de la certidumbre de la transparencia.

Desde los años setenta las loterías gubernamentales se diversificaron con los pronósticos deportivos y la lotería instantánea, ampliada a instituciones privadas como la Cruz Roja (Shelley, 2012: 37). En 1978, Pronósticos para la Asistencia Pública ya era un organismo descentralizado: "En 1997 contaba con más de seis mil expendios que daban trabajo a miles de familias a lo 
Este libro forma parte del acervo de la Biblioteca Jurídica Virtual del Instituto de Investigaciones Jurídicas de la UNAM

largo y ancho del país, cinco sorteos componían su oferta: Melate, Tris, Progol, Protouch y Prohit. El valor de sus ventas había alcanzado 1,623 millones de pesos y sus contribuciones al Estado y al deporte sumaban 428 millones de pesos" (González del Rivero, 2000: 180-181). Poco después, en 1992, la Lotería Nacional lanzó la lotería instantánea (también conocida como rascaditos), que fue un éxito desde el primer momento.

La primera iniciativa fue la de los pronósticos deportivos. La atracción del deporte era acompañada de las tentaciones de la suerte. Con ello no sólo se respondía al vasto sistema de quinielas clandestinas, sino que se desarrollaba una nueva forma de sorteo. El jugador debía emplear su conocimiento en la apuesta. Más aún, podía formar su propia apuesta (Echeverría, Fuentes y Castillo, 2011: 49).

\section{LOS CASINOS A INICIOS DEL SIGLO XX: DEL PORFIRIATO AL PRESIDENTE LÁZARO CÁRDENAS}

La cuestión de los casinos en México data de la época revolucionaria, principalmente en el norte del país. Mexicali, ciudad situada al norte de México, en la frontera con Estados Unidos, fue una de las primeras metrópolis en contar con casinos. Se tiene el dato de que "en 1910 existían casas de juego y, generalmente, quienes solicitaban la autorización para operar declaraban que practicarían el póquer y otros permitidos por el reglamento municipal" (Sánchez, 2013: 31). Pero es ya visto que los gobiernos, federal o municipales, dependían en gran medida de los ingresos por impuestos de los juegos de azar, por lo que la prohibición no se mantuvo mucho tiempo. En especial por el "recurrente abandono y falta de apoyo en que el gobierno federal tenía al Distrito Norte de Baja California", lo cual "obligaba a que los gobiernos de esta entidad dependieran para su sostenimiento, en buena medida, de los impuestos que generaban los lugares de diversión" (Sánchez, 2013: 31).

Cerca de ahí, en Chihuahua, cuando Francisco Villa fue gobernador de esa entidad, entre 1913 y 1914, emitió leyes para despenalizar los juegos de azar, "sobre todo en la zona fronteriza" (Semo, 2000: 160). En contraste, en 1913 Plutarco Elías Calles fue nombrado gobernador interino de Sonora, 
Este libro forma parte del acervo de la Biblioteca Jurídica Virtual del Instituto de Investigaciones Jurídicas de la UNAM

desde donde tomó la bandera de erradicar los antros de juego y alcohol. "Las campañas antialcohólicas de los ejércitos callistas iban acompañadas con la proscripción de tahúres y sitios de juego" (Semo, 2000: 160). Sin embargo, ante la prohibición del alcohol en el vecino país del norte, se abrieron oportunidades en México para operar casinos, como el Agua Caliente en Tijuana.

Es así que "durante los gobiernos del coronel Esteban Cantú Jiménez (1915-1920) y del general Abelardo L. Rodríguez (1923-1929) en el Distrito Norte de Baja California proliferaron los negocios de juegos de azar, apuestas y consumo de licor, así como uno que otro burdel" (Castro, 2013: 22), giros que tienen antecedentes en Mexicali desde su constitución en 1903. Castro (2013: 22) narra que

...cuando el coronel Esteban Cantú llega al poder del Distrito Norte de Baja California en diciembre de 1914 y se instala como gobernador del mismo, en la ciudad de Mexicali ya existían 40 sitios de diversión (Gómez, 2002: 43): música, mujeres, licor, juegos de azar y no poca droga (opio), permisos que se habían venido otorgando desde 1910... Quienes explotaban estos giros eran principalmente norteamericanos.

A diferencia de los asistentes al hipódromo, en los centros de apuestas de Mexicali el público eran "tahúres, jugadores, ladrones, dipsómanos, prostitutas y todo tipo de malandrines" (Castro, 2013: 22).

Por fortuna para unos y desgracia para otros, en "los años de gobierno de Cantú (1915-1920) la economía se sustentó en estos tipos de negocios, y con ingresos al erario muy importantes, los que sirvieron para que se realizara una amplia obra pública" (Castro, 2013: 27). Observación que también hicieron los gobiernos posteriores. Cuando terminó la administración de Cantú se tomaron medidas, "clausurando los centros de diversión que había autorizado y la cancelación de permisos para la inmigración de chinos. No tardaron mucho tiempo en reconocer que los impuestos que pagaban los casinos, bares, cantinas y otros lugares recreativos sostenían las finanzas del gobierno del Distrito (representaban el 51 por ciento de los ingresos) (Gómez, 2002)" (citado en Castro, 2013: 28). 
Este libro forma parte del acervo de la Biblioteca Jurídica Virtual del Instituto de Investigaciones Jurídicas de la UNAM

Posteriormente, en 1925 Abelardo L. Rodríguez, en Baja California, siendo gobernador "renunció al subsidio federal destinado a distintos ramos, dado que ya podía absorberlos con recursos propios; la realidad es que los ingresos que se tenían por impuestos de casinos, bares, y otros rubros similares eran muy altos" (Castro, 2013: 28), lo que dejaba ver que estas medidas no tuvieron gran éxito.

Con la promulgación de la Ley Volstead en los Estados Unidos en 1919, 5 que imponía la ley seca y prohibía los juegos de azar, se dieron oportunidades en México para abrir casinos, como el de Agua Caliente en Tijuana, creado en 1927, 6 que contaba con hipódromo, galgódromo y centros de juego, uno de cuyos socios era el presidente Abelardo L. Rodríguez, gran aficionado al juego. Los turistas estadounidenses visitaban Mexicali para hacer sus apuestas y disfrutar de otras diversiones que allí se crearon (por empresarios del país vecino y de China, para empezar).

Aunque no sólo los estadounidenses se asentaron en Mexicali, los chinos hicieron lo suyo: "A lo largo de medio siglo, los chinos fueron muy persistentes en su empeño de contar con diversos casinos y lo lograron. En 1957 y 1958, todavía había solicitudes para la apertura de casinos y lograban su objetivo" (Sánchez, 2013: 35).

La bonanza con los giros empresariales lícitos llegó a su fin en los años de la depresión económica en Estados Unidos a partir de 1929. Luego se agravó con la autorización de la venta de bebidas alcohólicas en aquel país en 1933, lo que provocó que los empresarios que invirtieron en casinos en Mexicali lo hicieran en su propio país.

Desde su ascensión a la Presidencia, el general Lázaro Cárdenas dejó clara su desaprobación de la existencia de casinos y lugares de apuesta en nuestro país. El 17 de junio de 1936 fue publicado en el Diario Oficial de la Federación el Reglamento de Juegos para el Distrito Federal y Territorios

La Ley Volstead, también conocida como "Ley Seca", del 18 de octubre de 1919, fue una prohibición al consumo de alcohol impulsada por el senador Andrew J. Volstead en los Estados Unidos de América. Dicha ley entró en vigor en todo el territorio estadounidense el 18 de octubre de 1920. Después de 13 años de hechos violentos, la conformación y consolidación de grupos criminales dedicados a traficar con alcohol y muertes por la mala calidad de las bebidas, en 1933 terminó la veda con la legalización del consumo de bebidas alcohólicas en este país.

6 Actualmente convertido en canódromo y operado por la empresa que mantuvo el nombre de Caliente. 
Este libro forma parte del acervo de la Biblioteca Jurídica Virtual del Instituto de Investigaciones Jurídicas de la UNAM

Federales, conformado de cuatro artículos, donde se declaraban legales y permitidas las "casas o lugares especiales en que se practicaran" (artículo 2o.) los juegos de "ajedrez, damas y otros semejantes; dominó, boliche, bolos, billar y pelota en todas sus formas y denominaciones, dados, póker y sus variedades, conquián, tute, brisca, ecarté, malilla, panguiandi, paco, tresillo y bridge; tiro al blanco, carreras de personas a pie, carreras de caballos, de perros, carreras de vehículos, peleas de gallos, luchas y boxeo" (artículo 10.). Además, con la publicación de este Reglamento quedaban disueltos los permisos otorgados con anterioridad, lo que provocó que todos los casinos y las casas de apuesta de la época fueran cerrados hasta obtener un nuevo permiso. Sin embargo, siete días después, el 24 de junio de 1936, el presidente Cárdenas modificó el primer artículo del Reglamento y dejó fuera de la lista de los juegos permitidos: dados, póker y sus variedades, conquián, tute, brisca, ecarté, malilla, panguiandi, paco, tresillo y bridge (artículo 10.). Con lo anterior, las medidas se volvieron aún más inflexibles y los casinos abiertos en la época quedaban sin posibilidad de seguir funcionando.

Se ordenó clausurar los casinos, entre ellos el Agua Caliente de Tijuana, El Tecolote de la capital, el Foreign Club de Naucalpan y el Casino de la Selva de Cuernavaca. El general Cárdenas cerró los casinos, pero, contradictoriamente, otorgó un permiso al italiano Bruno Pagliai para edificar un óvalo de carreras en la Ciudad de México cuya construcción se pudo iniciar hasta 1941, bajo el mandato del general Ávila Camacho, quien era un apasionado de la hípica.

El 6 de marzo de 1943 los hipódromos regresaron a la capital; se inauguró el que hoy es conocido como el Hipódromo de las Américas, cuya actividad se vio fortalecida con el cierre de los hipódromos en los Estados Unidos debido a la guerra, por lo que en la nueva pista corrían los mejores caballos de la nación vecina. Pagliai se vio en la necesidad de vender sus acciones, que fueron adquiridas por Deborah Rood Morrison. Bajo la administración de la señora Rood y su esposo, el doctor Milhe, evolucionó el mundo de la hípica y también el de las apuestas, integrándose la exacta, la trifecta y varias otras incluidas dentro de las llamadas "apuestas exóticas".?

7 En la terminología de las carreras de caballos, una trifecta es un tipo de apuesta combinada en la que el apostante debe acertar los caballos que finalizarán en primero, segundo y tercer lugar, en el orden exacto, dentro de una misma carrera. Por su parte, la exacta es también una apuesta 
Este libro forma parte del acervo de la Biblioteca Jurídica Virtual del Instituto de Investigaciones Jurídicas de la UNAM

El Hipódromo de las Américas, por su parte, continuó en funcionamiento hasta 1968, en que al concluir el permiso de operación del señor Milhe inició la concesión de una nueva empresa encabezada por Justo Fernández, denominada Hipódromo de las Américas, S. A. El empresario, al igual que antes Paglai, fue víctima de los altos costos de manutención del Hipódromo y además empezó a sufrir la aparición de los libros de apuestas (books) foráneas, que se quedaban con lo mejor de las apuestas; por ello, en los últimos días de agosto de 1996, la Secretaría de Gobernación tomó control y cerró las puertas del inmueble.

La autoridad decidió entonces realizar un concurso en el que participaron varias empresas interesadas en el manejo del Hipódromo; el ganador se desistió y la concesión le fue entregada al segundo lugar, OCESA. La empresa inició de inmediato los trabajos de reconstrucción del Hipódromo y la edificación del Centro de Convenciones y Exposiciones. El 20 de noviembre de 1999 se reiniciaron las carreras de caballos, suspendidas desde 1995. El permiso para operar el Hipódromo de las Américas incluyó también permisos para instalar y operar libros (books) foráneos, en los que se podían captar apuestas de carreras de caballos del Hipódromo de las Américas, de otros hipódromos, así como con el juego del bingo, esto con la intención de apoyar el financiamiento y los altos costos de mantenimiento del lugar, en donde actualmente se encuentran estabulados de fijo 1,400 caballos.

\section{EL REGRESO DE LOS CASINOS A NUESTRO PAÍS}

A pesar de la prohibición cardenista, las casas de juego y otros negocios reaparecieron en el sexenio avilacamachista y el país vivió en una ambigüedad legal por lo que a este tipo de juegos se refiere.

Después de la II Guerra Mundial, en billares, cantinas y cabarets se reservaban "apartados" donde los dados, el dominó y las cartas reagrupaban la posibilidad de jugar manos por pequeñas o por grandes cantidades. Eran convites de pocos y escogidos apostadores y no existía la "casa" sino tahúres individuales (González del Rivero, 2000: 175-176).

combinada en la que el apostador selecciona el primer y segundo lugar de dos caballos que deben cruzar la meta en el mismo orden seleccionado. 
Este libro forma parte del acervo de la Biblioteca Jurídica Virtual del Instituto de Investigaciones Jurídicas de la UNAM

En 1947 el presidente Miguel Alemán, a través de la Secretaría de Gobernación, dispuso la "autorización, reglamentación, control y vigilancia de los juegos, apuestas, rifas y sorteos" (Arteaga, 2013: s/p), expidiendo la Ley Federal de Juegos y Sorteos, la cual sigue vigente pero no rige sobre la Lotería, pues ésta tiene su propia ley. ${ }^{8}$ Sin embargo, en el artículo 4o. estableció que la Secretaría de Gobernación determinaría los requisitos y condiciones que todos los inmuebles dedicados a los juegos de azar deberían cumplir, aceptando de esta manera la reapertura de algunos mini casinos.

A raíz de esto, durante la década de los años cincuenta, juegos de apuesta y sorteo que hasta el momento eran poco conocidos, comenzaron a extenderse entre la sociedad. "El bridge, con sus complejas combinaciones y tácticas, suma nuevos adeptos. El backgammon se practicaba en torneos nacionales e internacionales en Acapulco y Cancún. El Monopoly pasó a ser parte del esparcimiento en familias de clase media" (Echeverría, Fuentes y Castillo, 2011: 48). En 1955 se entrega el primer permiso para juegos con apuestas en el país a la entidad Espectáculos Deportivos Frontón México, aunque no fue hasta finales del siglo XX cuando el otorgamiento de licencias se convirtió en una norma.

Por lo que respecta a la legalización de los casinos, permanecieron vetados por completo desde su prohibición durante el cardenismo; éstos habían estado vetados por completo, hasta que en 1967 se otorgó un permiso para la operación de un casino en Acapulco, que finalmente no se consolidó debido al desacuerdo y presión de la opinión pública. El siguiente intento por su legalización fue hasta 1994 a propuesta del entonces presidente de la República Carlos Salinas de Gortari, con la finalidad de obtener ingresos en puntos turísticos para combatir la crisis; no obstante, esta propuesta fue frenada por el titular de la Secretaría de Turismo, Jesús Silva Herzog, con el argumento de que "México aún no se encontraba preparado para la instalación de casinos en centros vacacionales" (LVIII Legislatura, 2003: 67).

8 Véase Diario Oficial de la Federación, Ley Orgánica de la Lotería para la Asistencia Pública, disponible en: http://dof.gob.mx/nota_detalle.php?codigo=4713878\&fecha=14/01/1985 [fecha de consulta: 18 de octubre de 2017].

9 Cabe señalar que en la Ley Federal de Juegos y Sorteos de 1947 no se mencionó explícitamente a los casinos, sino únicamente a los juegos de apuesta y sorteo en general, por lo que parecía que los primeros continuaban prohibidos desde 1938. 
Este libro forma parte del acervo de la Biblioteca Jurídica Virtual del Instituto de Investigaciones Jurídicas de la UNAM

Lo anterior abrió el camino para retomar el tema de los casinos en el Congreso, por lo que en 1995 la Cámara de Diputados sometió al acuerdo del Pleno realizar un foro de consulta para evaluar la instalación de casinos en México debido al interés que mostraban diferentes sectores de la sociedad. "El evento, como tal, representó todo un acontecimiento político, en virtud de que era el primero en el que se iba a abordar un tema que era tabú desde el punto de vista político-social y por lo delicado de sus implicaciones" (Cámara de Diputados, 1995) (citado en LVIII Legislatura, 2003: 68).

Después de haber retomado el tema de los casinos en México, y ante la necesidad de actualizar el marco normativo de 1947 para juegos y sorteos, así como legalizar la instalación de los casinos, en 1997 se estableció la Subcomisión de Casinos, que tuvo a su cargo supervisar y analizar el trabajo de los órganos reguladores del juego y los sorteos. El debate legislativo aún en nuestros días no llega a buen puerto, pues desde 1999 se han presentado diversas iniciativas de ley para su regulación, sin obtener una postura homogénea al respecto ni la publicación de una nueva ley. ${ }^{10}$

Pero otras normas regulatorias proliferaron en años posteriores; en 2004 se publica el Reglamento de la Ley de Juegos y Sorteos, con lo que se ponen en operación las primeras terminales electrónicas de juego. Con ello se permitió la expansión hacia otras modalidades de juego. Al amparo de este Reglamento, en mayo de 2005, se otorgaron diversos permisos para la instalación de salas de juego en el país, lo que vino a sumar a nuevos participantes. Poco a poco, los casinos en México pasaron de ser salas de bingo a lugares en los que se instalaron nuevos juegos como la ruleta, y otras modalidades de apuesta, así como el juego en línea.

Para 2005 había 185 locales de apuesta en el país; llegó a un máximo de 370 en 2013, y en los últimos años ha permanecido estable alrededor de 320. Hoy en día, prácticamente es posible apostar a distintos juegos de azar que se efectúen en cualquier parte del mundo a través de computadoras y dispositivos móviles.

10 En total han sido cinco las iniciativas legislativas: iniciativa de Ley Federal de Juegos con Apuestas, Sorteos y Casinos, del 3 de marzo de 1999; iniciativa de Ley Federal de Juegos con Apuestas y Sorteos, del 29 de agosto de 2003; iniciativa de Ley Federal de Juegos con Apuestas y Sorteos, del 29 de abril de 2004; iniciativa de Ley Federal de Juegos con Apuestas y Sorteos, y la Ley Federal de Juegos con Apuestas y Sorteos, del 27 de noviembre de 2014 (Tépach, 2010: 99-100). 
Este libro forma parte del acervo de la Biblioteca Jurídica Virtual del Instituto de Investigaciones Jurídicas de la UNAM

El 16 de enero de 2013 se presentó una solicitud al Pleno de la Comisión Permanente del Congreso de la Unión, por diputados del grupo parlamentario Movimiento Ciudadano, para indagar sobre los permisos otorgados a casinos en funcionamiento. A raíz de esto, el 15 de febrero de 2013 se creó una Comisión de Investigación Bicamaral. Lo anterior trajo como resultado, meses después, un proyecto de Ley que fue dictaminado y aprobado por la Cámara de Diputados el 27 de noviembre de 2014 y turnado días después a la Cámara de Senadores, pero a la fecha esta Cámara no lo ha dictaminado.

El incendio del casino Royale ocurrido en agosto de 2011 y la falta de una ley que norme con certeza la industria de los casinos han causado avances y retrocesos para contar con una industria moderna y competitiva que ofrezca a los jugadores mexicanos la variedad de los casinos de otras partes del mundo.

\section{EL SURGIMIENTO DE LOS JUEGOS DE APUESTA Y LOS SORTEOS EN LÍNEA}

Aunque en nuestro país hay "una gran variedad de juegos de azar tradicionales, como son la oca, la pirinola, serpientes y escaleras, el coyote, y la lotería, entre muchos más" (Van't Hooft, 2016: 297), además de las corridas de caballos, las peleas de gallos, el box, las ferias, estas modalidades de juego están siendo relegadas por la práctica de las apuestas en casinos, así como las apuestas en línea que se realizan a través de computadoras o teléfonos celulares.

En la década de los años setenta, con el boom tecnológico que provocó la aparición del Internet en 1969, en Estados Unidos, y con su posterior desarrollo, las prácticas y reglas de los juegos de azar comenzaron a cambiar los viejos mecanismos de juego con la creación en Europa del primer casino en línea en 1994.

En México, en sus inicios, la red de Internet se creó con fines exclusivamente académicos y universitarios en 1982; no obstante, la primera conexión de México como país se reconoció hasta 1989. ${ }^{11}$ Posteriormente, en

11 Los primeros accesos desde México a la red ARPAnet, el antecesor del Internet, se realizaron en 1982 en el Departamento de Computación del IIMAS (Instituto de Investigación en Matemáticas Aplicadas y Sistemas) de la UNAM. En 1988 se firmó un acuerdo entre la UNAM, el ITESM, la NSF y 
Este libro forma parte del acervo de la Biblioteca Jurídica Virtual del Instituto de Investigaciones Jurídicas de la UNAM

1992, se aprobó la creación del primer dominio comercial ".com.mx" de México.

A partir de la década de los años noventa hasta la fecha, el uso de Internet ha tenido un desarrollo importante. Según datos del INEGI (ENDUTIH: 2016), al segundo trimestre de 2016 el 59.5 por ciento de la población de seis años o más en México se declaró usuaria de Internet. Lo anterior se corresponde con el 47.0 por ciento de los hogares del país que tienen conexión a Internet. Según el mismo estudio, el 96.0 por ciento de los usuarios utiliza internet de uno a siete días por semana; agregando a los que lo utilizan una vez al mes, la cifra aumenta a 99.5 por ciento. Además, el 73.6 por ciento de la población utiliza celular, del cual el 76.0 por ciento cuenta con smartphone. ${ }^{12}$

A pesar del crecimiento que experimenta el país en este rubro, según cifras de la Organización para la Cooperación y el Desarrollo Económicos (OCDE, ICT Access and Usage by Households and Individuals, 2016), en 2016 el 47.02 por ciento de los hogares en México tuvo acceso a Internet, ocupando el último lugar de los países miembros con información sobre el tema, por debajo del 64.8 por ciento de los hogares en Costa Rica y muy por debajo de los países europeos, que tienen una mayor proporción de hogares con acceso a Internet —en Noruega y Luxemburgo representan alrededor del 97 por ciento, respectivamente-.

Es también en la década de los años noventa en que empieza a proliferar el juego en línea en el país. La regulación de los juegos de apuesta en línea se dio junto a la publicación del Reglamento de la Ley Federal de Juegos y Sorteos el 17 de septiembre de 2004. Al respecto, este Reglamento permite

la NASA, mediante el cual se establecerían dos enlaces desde México a Estados Unidos, uno en la UNAM, en su Campus Ciudad Universitaria, y el segundo en el ITESM, en su Campus Estado de México. En febrero de 1989 se llevó a cabo la conexión entre el Campus Monterrey del ITESM y la Escuela de Medicina de la Universidad de Texas en San Antonio por medio de una línea privada, utilizando la dirección 131.178.1.1 del equipo MicroVAX II con nombre dns.mty.itesm.mx, misma que fue reconocida por la NSFnet como la primera conexión de México como país. Véase Huesca (1998: 11).

12 Según las regiones del país, Baja California Sur, Sonora y Baja California son las entidades federativas que presentan mayor disponibilidad de Internet en los hogares: 75.5, 71.7 y 68.0 por ciento, respectivamente. En el otro extremo, Tlaxcala, Oaxaca y Chiapas presentan la menor disponibilidad, con proporciones de 28.4, 20.6 y 13.3 por ciento, respectivamente, en cada caso. A nivel nacional, la proporción se incrementó en 7.8 por ciento con respecto a 2015 (INEGI, ENDUTIH: 2016). 
Este libro forma parte del acervo de la Biblioteca Jurídica Virtual del Instituto de Investigaciones Jurídicas de la UNAM

que los establecimientos autorizados por la Secretaría de Gobernación puedan captar apuestas vía Internet, telefónica o electrónica. La norma es muy específica respecto al control interno que debe guardarse en las apuestas que se realicen en línea; por ejemplo, la ley exige que el control interno de cada establecimiento quede por escrito, aprobado por la Secretaría de Gobernación, y con el registro en una base de datos que incluya (artículo 85):

- El número de cuenta e identidad del apostador.

- La fecha, hora, número de la transacción, cantidad apostada y selección solicitada.

En cuanto a sorteos por Internet, el Reglamento sólo exige que al participante se le otorgue un número de folio y que la empresa responsable del sorteo dé la oportunidad al jugador de consultar e imprimir dicho comprobante de folio en cualquier momento (artículo 104). El Reglamento es omiso respecto a las páginas de Internet extranjeras que ofrecen apuestas y sorteos, y de aquellas que no constituyen un establecimiento jurídicamente formalizado. 
Este libro forma parte del acervo de la Biblioteca Jurídica Virtual del Instituto de Investigaciones Jurídicas de la UNAM

\section{CAPÍTULO 2}

\section{RELIGIONES, CREENCIAS Y PRÁCTICAS TRADICIONALES}

La idea de que las religiones perderían importancia y que finalmente iban a desaparecer creando un mundo particular — secularizado, desencantado-, postulada inicialmente por autores como Weber y Durkheim, fue, durante muchos años, el pilar de la teoría de la modernización y uno de los ejes del pensamiento moderno en el mundo occidental. No obstante, la globalización ha puesto de relieve que si bien las religiones pueden haber perdido importancia en algunos aspectos de la vida social e institucional, no por ello ha disminuido su relevancia para las personas.

El papel de la religión puede diferir en varias épocas para diversos individuos y en distintas culturas. La religión, al fusionar el ethos y la cosmovisión, aporta al juego de valores sociales "lo que, tal vez, necesitan más para ser coercitivos: la apariencia de objetividad. En los rituales sagrados y los mitos, los valores se presentan no como preferencias humanas subjetivas sino como condiciones impuestas para la vida, implícitas en un mundo con una estructura particular" (Geertz, 2003). Aquellos que privilegian el estudio de los avances de la secularización en la sociedad actual, la mayoría de las veces "descuidan atender los procesos adaptativos y de reconquista que ejercen las religiones sobre aquellas parcelas de la realidad, a las cuales parecía que las religiones no tendrían acceso" (Berger, 1977). 
Este libro forma parte del acervo de la Biblioteca Jurídica Virtual del Instituto de Investigaciones Jurídicas de la UNAM

La mayor parte de las iglesias históricas se han adaptado de distintos modos al proceso de secularización institucional. Con reservas y matices podría decirse que las creencias religiosas y los valores relacionados con ellas se han movido en la segunda mitad del siglo XX de la salvación personal a la ética social; de la preocupación con el orden sobrenatural a los problemas y sufrimientos actuales; de las actividades rituales y sacramentales a actividades de servicio social y un involucramiento en temas internos e internacionales. Personalmente se enfatizan más la devoción y el servicio que el ascetismo, sacrificio y deberes impersonales, y se ha reducido, en la mayor parte de los casos, la capacidad de intervención de lo divino en la vida cotidiana.

Peter Berger señala que estos procesos se dieron de manera más acentuada en el protestantismo, que "se despojó todo lo posible de los tres concomitantes más antiguos y poderosos de lo sagrado: el misterio, el milagro y la magia... (mientras que) el católico vive en un mundo en que lo sagrado llega a él a través de toda una variedad de canales: los sacramentos de la Iglesia, la intercesión de los santos, la recurrente erupción de lo sobrenatural en los milagros, etcétera" (Berger, 1977: 140).

Los procesos de globalización que caracterizan a la sociedad contemporánea han traído consigo la fragmentación de los valores y de los campos de su difusión e institucionalización. Instituciones sociales como la familia, la Iglesia, la escuela y el Estado, que habían jugado un papel central para la legitimación, tienden a ser desplazadas por los medios de comunicación masiva en sus distintas modalidades. Al dejar de ser las transmisoras y normadoras únicas, dichas instituciones entran a una situación de mercado, compiten con los medios y entre sí, mientras que se abre al individuo la posibilidad de elegir. Ello trae como consecuencia la relativización de los valores y la pluralidad de las creencias.

El pluralismo religioso, en vez de debilitar la influencia de la religión como se creía, parece, por el contrario, fortalecerla. Como señalan varios autores (Forni, 1986: 4-24; Frigerio, 1993: 14-30), en un ambiente de libertad de cultos, la diversidad de la competencia religiosa puede satisfacer las demandas de los más variados sectores sociales, y con frecuencia, este tipo de cultos, propios de la religiosidad popular, son paralelos e independientes de la Iglesia y del control clerical: 
Este libro forma parte del acervo de la Biblioteca Jurídica Virtual del Instituto de Investigaciones Jurídicas de la UNAM

El pueblo no sólo espera resultados mágicos, sino que concibe a la religión como una directa relación con la divinidad usando como mediadores imágenes, la virgen, santos o los muertos en vez de (o paralelamente con) una mediación de la Iglesia a través de la disciplina sacramental. El término "religiosidad popular" no debe hacernos creer, sin embargo, que este tipo de relación con lo sagrado está exclusivamente restringida a los sectores socio-económicos "bajos", su extensión en la sociedad excede en mucho a lo que este concepto pueda sugerir (Massolo, 1994).

Su éxito se debería a que expresan, fomentan y legitiman elementos de la religiosidad popular que no encontraban cabida en las religiones instituidas.

\section{LAS CREENCIAS RELIGIOSAS EN MÉXICO}

México es una sociedad de una gran diversidad y complejidad en materia religiosa. El hecho de que las generaciones más jóvenes sean hoy igual o incluso más religiosas que los grupos etarios de más edad es indicativo de una tendencia hacia una renovación de valores religiosos más que una reducción de esta dimensión. Pero el posible aumento de la religiosidad no sólo se explica por factores demográficos, sino principalmente por elementos valorativos y culturales.

Hoy en día, la población que se identifica a sí misma como católica sigue siendo mayoritaria; sin embargo, existe una tendencia al decrecimiento del porcentaje de católicos en el país. En 2010, los católicos representaban alrededor del 82.7 por ciento de la población del país (INEGI, 2010). En 2016, a la pregunta ¿Qué religión tiene usted? en la Encuesta Nacional de Percepciones Sociales de los Juegos de Azar en México, se identificó como católico el 71.8 por ciento de los entrevistados. A su vez, la población que se definió en el Censo de Población y Vivienda de 2010 como sin religión representaba alrededor del 4.7 por ciento de la población total, mientras que, en 2016, un 7.1 por ciento expresó no tener ninguna religión. El 16.7 por ciento dijo profesar otra religión (véase gráfica 2.1). 
Este libro forma parte del acervo de la Biblioteca Jurídica Virtual del Instituto de Investigaciones Jurídicas de la UNAM

GRÁFICA 2.1

¿A QUÉ RELIGIÓN, CREENCIA O CULTO PERTENECE USTED? (PORCENTAJES)

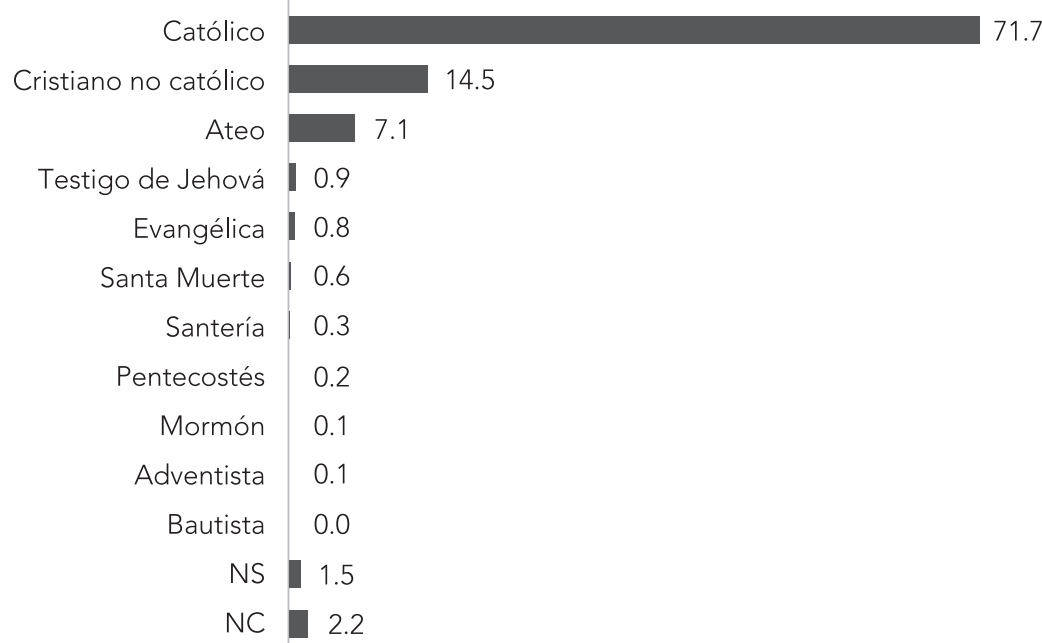

Fuente: Encuesta Nacional de Percepciones Sociales de los Juegos de Azar en México, México, UNAM, Instituto de Investigaciones Jurídicas, Departamento de Investigación Aplicada y Opinión, 2016

Del análisis sociodemográfico de la información se desprende que, en general, las mujeres son más religiosas que los varones. Igualmente se observan mayores porcentajes de jóvenes entre los 18 y los 25 años que declararon tener una religión. La identificación de estos jóvenes disminuye entre el grupo de Católicos, pero aumenta en denominaciones religiosas tradicionales y otras creencias como los Cristianos no católicos, Testigos de Jehová, la Santa Muerte y la Santería.

Los entrevistados que se identificaron como ateos son en su mayoría varones, entre los 55 y 64 años y con altos niveles de escolaridad.

\section{EL AZAR, LA SUERTE Y LOS MILAGROS}

Se tiene la creencia de que el azar es una fuerza difícil de concebir por aquellos que desdeñan la idea de fuerzas sobrenaturales y creadas. Tiene connotaciones negativas relacionadas con malograrse o salir mal una cosa. Se trata de un acontecimiento excepcional que llega al hombre en circunstan- 
Este libro forma parte del acervo de la Biblioteca Jurídica Virtual del Instituto de Investigaciones Jurídicas de la UNAM

cias poco definidas, no así inexplicables, todas relacionadas con la naturaleza o con fenómenos naturales. En contraste, la suerte es "una ventaja no ganada, es decir, algo afortunado para una persona sin ningún esfuerzo de su parte o que lo sucedido sea inesperado o contra lo normal o una influencia exterior" (Cohen 1972: 126). Lo azaroso es todo aquello que no es previsible, aquello que se escapa de las manos al determinismo. En este sentido, el milagro es un hecho excepcional que se sale del curso normal. Lo milagroso también lo es en cuanto inexplicable. La sobrenaturalidad del milagro lo sitúa fuera de los parámetros de lo creíble. El milagro es un hecho extraordinario aparecido en lugar de otro que debió producirse de manera natural; esto indica que se le considera como una desviación de las leyes de la naturaleza, las cuales deben estar sujetas al natural devenir de la vida. Este fenómeno está vinculado a creencias religiosas, "...es producto de la constancia, la fe y la entrega de quienes creen en él" (Cohen, 1972).

\section{PRÁCTICAS Y CREENCIAS TRADICIONALES}

Tratándose de un proceso tan dinámico como esquivo a los marcos institucionales — sobre todo en Occidente-, la religiosidad encarna enormes desafíos, incluso dentro de las ciencias que deben estudiarlo: cómo captar de la manera más fidedigna posible su enorme riqueza cuando ésta no se limita a las propuestas de las religiones tradicionales:

De cara al futuro, se impone la construcción de categorías capaces de dar cuenta de formas menos institucionales de religión y creencia. Tal vez el ingreso en el campo religioso ya no deba ser exclusivamente a través de lo institucional, porque hay otras maneras de vivencia y expresión religiosa inherentes al individuo (Dobbelaere, 1992).

Los usuarios de religiones populares están poco preocupados por el origen de sus creencias y prácticas, y sí, en cambio, por la eficacia de su versión de la religión: 
Este libro forma parte del acervo de la Biblioteca Jurídica Virtual del Instituto de Investigaciones Jurídicas de la UNAM

Ellos se apropian de símbolos y los aplican o los reinterpretan en situaciones particulares con el fin de ayudarse a sí mismos (a resolver sus situaciones financieras o a curarse da alguna enfermedad, etcétera). Los usuarios de la religión popular no tienen escrúpulos acerca de mezclar e incorporar elementos a fin de satisfacer sus necesidades, independientemente de que ellas sean espirituales o materiales (Rostas y Droogers, 1995).

Para saber qué tanto las creencias tradicionales están presentes entre los encuestados, se indagó sobre algunas de las creencias más comunes en la sociedad: ¿Cree usted... ? a) en la suerte, b) el destino, c) el infierno, d) el mal de ojo y e) los horóscopos. Fueron ocho de cada diez (80.9 por ciento) los que señalaron que sí creen o creen en parte en la suerte. Asimismo, fueron más de seis de cada diez los que indicaron que creen o creen en parte en el destino (69.7 por ciento) y en el infierno (65.0 por ciento), mientras que más de cuatro de cada diez sujetos seleccionados para el estudio dijeron que creen o lo hacen en parte en el mal de ojo (46.6 por ciento). Únicamente cerca de cuatro de cada diez (37.5 por ciento) señalaron que creen en los horóscopos (véase gráfica 2.2).

\section{GRÁFICA 2.2}

¿CREE USTED EN...?

(PORCENTAJES)

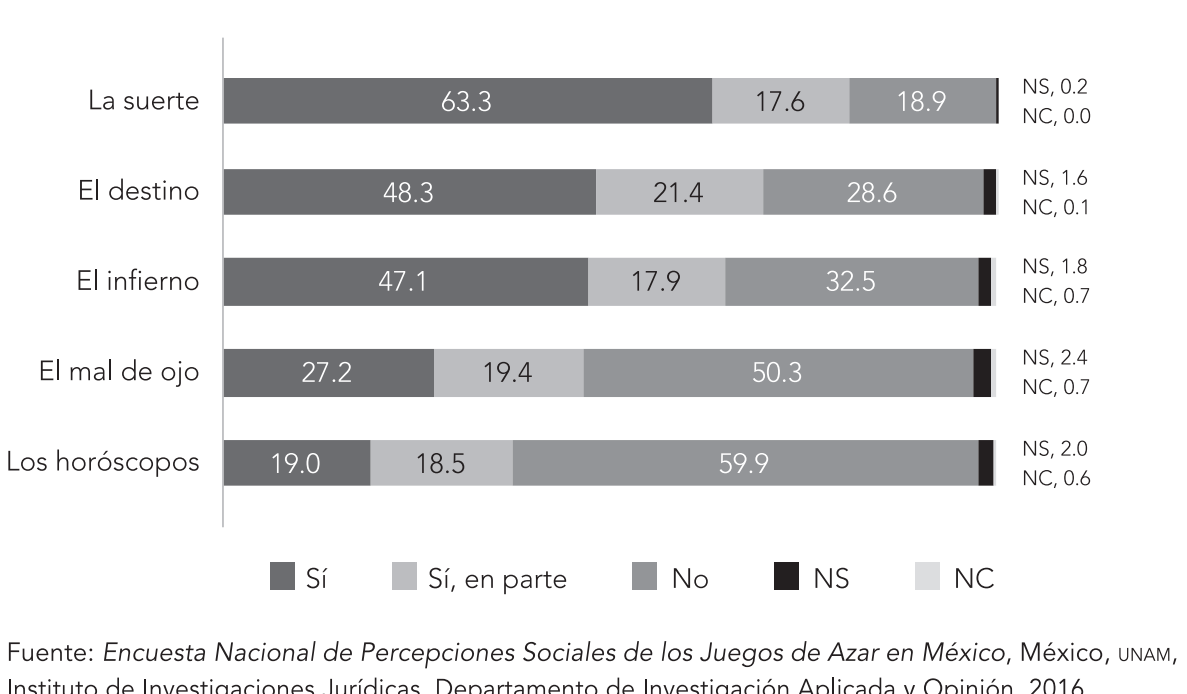

Instituto de Investigaciones Jurídicas, Departamento de Investigación Aplicada y Opinión, 2016. 
Este libro forma parte del acervo de la Biblioteca Jurídica Virtual del Instituto de Investigaciones Jurídicas de la UNAM

Por grupo de edad, los entrevistados que más creen en la suerte son los de 25 a 34 años, pero también los de 65 años o más. Se observa, igualmente, una menor creencia en la suerte conforme aumenta la escolaridad. Los católicos creen mucho más en la suerte que los ateos y aquellos de otras religiones. Las creencias en el destino, el infierno y el mal del ojo tienen en común un cierto perfil de los entrevistados: son las personas de la tercera edad y los católicos los que expresaron más frecuentemente que sí creen o creen en parte en dichas prácticas. También se observa una tendencia en la que los porcentajes de respuesta aumentan a medida que disminuyen los niveles de escolaridad.

Sobre los horóscopos se puede decir que no hay diferencias por edad, pero sí por escolaridad. Se observa una tendencia en donde el aumento de la escolaridad va de la mano con una mayor creencia en los horóscopos, aunque sin rebasar de manera importante la media nacional. Es decir, las personas con menor escolaridad creen menos en los horóscopos que la media nacional y, al mismo tiempo, el porcentaje de creencia va aumentando conforme aumenta la escolaridad hasta rebasar, ligeramente, la media nacional. Mientras tanto, de acuerdo con la religión, los encuestados que dijeron ser católicos creen en mayor medida en los horóscopos.

\section{LA CREENCIA EN LA SUERTE}

La creencia más extendida entre los entrevistados es la creencia en la suerte, seguida de la creencia en el destino. La creencia en la suerte es un elemento esencial de la condición humana y por lo tanto constituye un factor definitorio en la práctica de los juegos de azar. ${ }^{1}$

La suerte puede ser definida como

...el resultado positivo de un suceso poco probable... Hay diversos significados a los que se puede referir cuando se utiliza el término, que varían desde percibir a la suerte como una cuestión del azar, hasta aquellos que le atribu-

1 De acuerdo con la definición de la Real Academia Española, suerte es la circunstancia de ser, por mera casualidad, favorable o adverso a alguien o algo de lo que ocurre o sucede; se trata de una fuerza que determina el curso de los acontecimientos. 
Este libro forma parte del acervo de la Biblioteca Jurídica Virtual del Instituto de Investigaciones Jurídicas de la UNAM

yen explicaciones de fe o superstición, como la organización sobrenatural de los sucesos afortunados y desafortunados (Barlow, 2007). Así, una aproximación racionalista a la suerte incluye la aplicación de las leyes de la probabilidad y la elusión de creencias no científicas. El racionalista siente que la creencia en la suerte es el resultado de un razonamiento pobre o "pensamiento ilusorio".

Siguiendo a Scheu, la suerte es uno de los factores que definen la condición humana; dado su conocimiento limitado, los hombres deben tomar decisiones basándose en una información fragmentaria, por lo que la suerte resulta ser un útil instrumento de autoexculpación (Scheu, 1996: 61-70).

\section{LAS REPRESENTACIONES SOCIALES DE LA SUERTE EN MÉXICO}

En esta investigación uno de los puntos de interés fue conocer los significados que se atribuyen a la suerte. Se buscó profundizar en las disposiciones, preferencias, preocupaciones, valores y experiencias de la población, de acuerdo con las diversas características sociodemográficas y económicas. El análisis de las representaciones sociales permite recoger el pensamiento social y nos aproxima a la visión del mundo de las personas desde su posicionamiento social, tiempo y espacio. Las representaciones sociales son de manera simultánea "el producto y proceso de una actividad mental por la cual un individuo o un grupo reconstituye lo real con lo que está confrontado y le atribuye una significación específica" (Abric, 1994). En este sentido, las representaciones sociales permiten recoger otras construcciones verbales o cognoscitivas, como por ejemplo los estereotipos y prejuicios.

El término suerte se ha aplicado a la relación desconocida que supone que hay entre los sucesos; a la buena o mala fortuna del encadenamiento de los acontecimientos fortuitos y azarosos en general. Se ha señalado que la palabra suerte tiene múltiples connotaciones: el griego tukhé enfatiza el azar; en latín, fortuna ofrece una mezcla de casualidad (casus) y beneficio (positivo o negativo); en alemán, Glück no sólo significa suerte (fortuna), sino también felicidad (felicitas); en francés, chance (del latín cadere) alude a 
Este libro forma parte del acervo de la Biblioteca Jurídica Virtual del Instituto de Investigaciones Jurídicas de la UNAM

"cómo caen las cosas" (cómo caen los dados), y es un equivalente aproximado del inglés luck y del castellano suerte (Rescher, 1997: 18).

Con el objeto de indagar qué representaciones existen acerca de México y de los mexicanos y conocer el léxico disponible en relación con la palabra suerte, se solicitó a los entrevistados mencionar tres palabras que asociaran con ésta. Las 3,600 respuestas fueron ordenadas por su importancia, tomando en cuenta no sólo la frecuencia con que fueron seleccionadas, sino también la posición en que ocurrieron las menciones. Luego de ser procesadas estadísticamente se obtuvo para cada una de las palabras un índice de disponibilidad léxica que varía del 0 al 1.

Para obtener una idea del significado del índice consideremos lo siguiente: si una misma palabra fuera mencionada como primera opción de todos los encuestados, se obtendría un índice de 1; si fuera la segunda opción de todos los encuestados tendría un índice de 0.42; pero si fuera seleccionada por el 25 por ciento de los encuestados como primera opción y el 25 por ciento como segunda opción, tendría un índice de 0.36. En otras palabras, el índice otorga una mayor ponderación a las menciones en la primera posición que a las menciones en segunda o tercera posición (véase Anexo 5).

Para los entrevistados, los significados del término son altamente positivos. La suerte se asocia con el dinero y las ganancias, la fortuna, el juego y el trabajo. La felicidad, la alegría y el destino, el éxito y el azar. La familia y la esperanza. Entre las asociaciones aparecen también los amuletos, como los tréboles o las herraduras, y algunos juegos de azar, como la lotería.

La suerte se asocia principalmente con el dinero, la fortuna y las ganancias. Al contrario de las asociaciones para la palabra azar, que tienen una connotación negativa -el hecho de suceder algo no deseado con consecuencias negativas - para los entrevistados, la suerte es de signo positivo. Su asociación con los juegos de azar queda de relieve; en el habla cotidiana de México, la expresión "sacarse la lotería" es una expresión de buena fortuna que se aplica a todo tipo de situaciones. 
Este libro forma parte del acervo de la Biblioteca Jurídica Virtual del Instituto de Investigaciones Jurídicas de la UNAM www.juridicas.unam.mx

CUADRO 2.1

ÍNDICE DE DISPONIBILIDAD LÉXICA
DÍGAME, POR FAVOR, TRES PALABRAS QUE ASOCIE CON SUERTE

\begin{tabular}{|c|c|}
\hline PALABRA & ÍNDICE DE DISPONIBILIDAD LÉXICA \\
\hline dinero & 0.201899007 \\
\hline fortuna & 0.089004346 \\
\hline ganar & 0.085420366 \\
\hline trabajo & 0.044129703 \\
\hline juego & 0.034710100 \\
\hline felicidad & 0.033351129 \\
\hline bueno & 0.031376568 \\
\hline destino & 0.030974263 \\
\hline salud & 0.020934612 \\
\hline alegría & 0.019931957 \\
\hline bienestar & 0.019848474 \\
\hline encontrar algo & 0.019182173 \\
\hline éxito & 0.018793019 \\
\hline oportunidad & 0.017168093 \\
\hline azar & 0.016237994 \\
\hline trébol & 0.016167596 \\
\hline casualidad & 0.015112206 \\
\hline amor & 0.014294379 \\
\hline lotería & 0.013223483 \\
\hline riqueza & 0.012682538 \\
\hline familia & 0.011904229 \\
\hline ganancia & 0.011695324 \\
\hline lujo & 0.011543599 \\
\hline premio & 0.011321477 \\
\hline bendición & 0.010875141 \\
\hline afortunado & 0.010167164 \\
\hline herradura & 0.009153516 \\
\hline ganador & 0.009069967 \\
\hline esperanza & 0.008625788 \\
\hline abundancia & 0.008416949 \\
\hline
\end{tabular}


Este libro forma parte del acervo de la Biblioteca Jurídica Virtual del Instituto de Investigaciones Jurídicas de la UNAM

GRÁFICA 2.3

ÍNDICE DE DISPONIBILIDAD LÉXICA

DÍGAME, POR FAVOR, TRES PALABRAS QUE ASOCIE CON LA PALABRA SUERTE

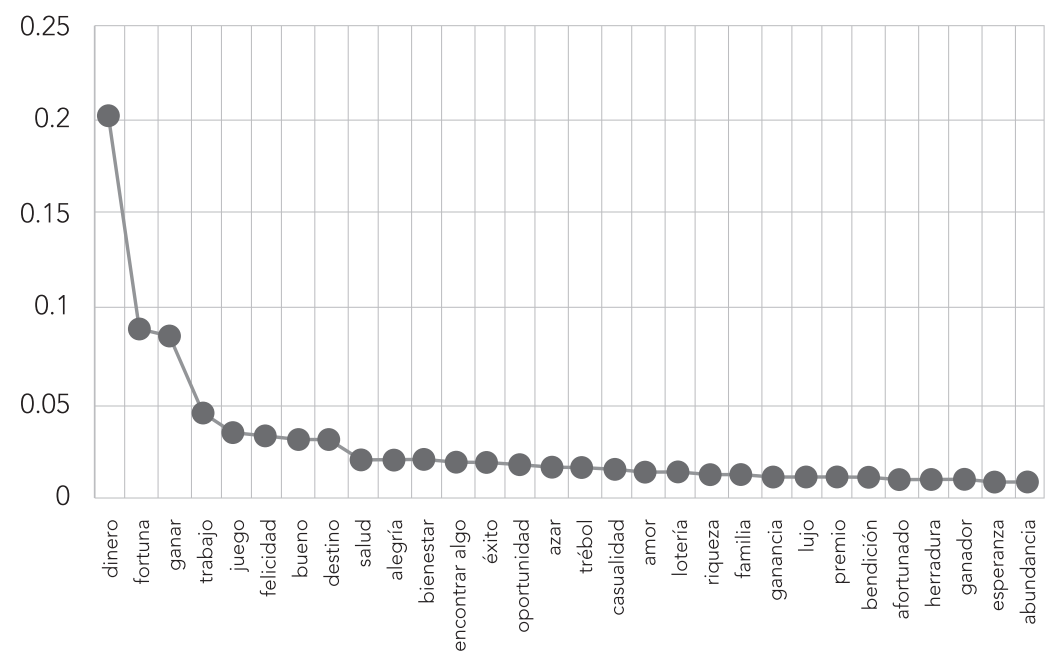

Fuente: Encuesta Nacional de Percepciones Sociales de los Juegos de Azar en México, México, UnAM, Instituto de Investigaciones Jurídicas, Departamento de Investigación Aplicada y Opinión, 2016.

\section{SUPERSTICIONES Y RITUALES}

Decía Malinowsky que

La magia se encuentra en cualquier lugar en donde los elementos del azar, el accidente y el juego emocional entre la esperanza y el miedo tienen un amplio rango. La magia no se encuentra cuando el fin es cierto, confiable y bajo el control de métodos racionales y procesos tecnológicos. Más aún, encontramos la magia donde el elemento de peligro es conspicuo (Malinowsky, 1965 [1931]: 139-140).

De acuerdo con Malinowsky, esta distinción también se aplica a las "formas totalmente modernas de emprendimiento" (Malinowsky, 1965 [1931]: 105). La superstición es aquella creencia que atribuye carácter mágico o sobrenatural 
Este libro forma parte del acervo de la Biblioteca Jurídica Virtual del Instituto de Investigaciones Jurídicas de la UNAM

a objetos y sucesos; ${ }^{2}$ se trata de explicaciones fundamentadas desde lo irracional para el entendimiento de fenómenos, procesos y sus relaciones.

Las supersticiones surgen del miedo ante cualquier incertidumbre o peligro, como las enfermedades o la muerte; ante ello, el hombre y su cultura se han encargado de desarrollar una serie de creencias y ritos a los que atribuyen poderes para alterar su destino o suerte, ya sea de manera positiva como negativa, realizando acciones que puedan atraer o ahuyentar ciertas situaciones dependiendo de la abundante tipología de supersticiones (Koszla-Szymanska, 2009). Centini (2003) señala que la superstición puede servir para descubrir en acciones simbólicas, sin significado aparente, el reflejo de las necesidades del ser humano, siempre temeroso ante las fuerzas de la naturaleza (Centini, 2003).

Se elaboró una pregunta para conocer la presencia de supersticiones entre los entrevistados y recoger la práctica de algunos rituales. De esta manera, al plantear la pregunta Todos tenemos algunas creencias, por ejemplo, ¿usted acostumbra evitar...? la mitad de los entrevistados evita o evita en parte pasar por debajo de una escalera, romper un espejo y derramar la sal. Aproximadamente, tres de cada diez entrevistados evitan cruzarse con un gato negro y el número 13. Es decir, las supersticiones menos difundidas son cruzarse con un gato negro y el número 13 (véase gráfica 2.4).

Entre quienes evitan pasar debajo de una escalera destacan con porcentajes mayores que la media nacional: las mujeres, aquellos de 65 años y más, y las personas sin escolaridad. En el mismo tenor, las tendencias se repiten en evitar el número trece. Los que dicen en porcentajes mayores evitar, o evitar en parte, son las mujeres, los que no tienen ninguna escolaridad, y los de 65 años y más.

2 El término "superstición" deriva de una raíz latina. Quienes hablaban el latín utilizaban la palabra superstitio para dar la impresión de que algo era demasiado bueno — por encima y más allá de lo regular-. En la literatura latina, el término superstitio puede estar cualificado por adjetivos (como turpis, inanis, insana), lo cual hace probable que esta superstitio no fuera vista como estúpida o innoble, ya que precisaba estos adjetivos para expresar esa noción. La mayor parte de las veces que Cicerón utiliza el término parece indicar que, por superstitio, entendía la credulidad opuesta a la búsqueda del conocimiento sólido. La actitud de la Iglesia Católica está mejor expresada en las palabras del Consejo Tridentino (1545-1563): superstitio es verae pietatis falsa imitatrix (un falso imitador de la verdadera piedad). Homero llama a las cosas "superstición" cuando son, o bien aborrecidas, o bien observadas con pasión o temor, pero que representan, en todos los casos, relaciones erradas con Dios. Véanse Menard (2015) y Steiner (2001). 
Este libro forma parte del acervo de la Biblioteca Jurídica Virtual del Instituto de Investigaciones Jurídicas de la UNAM

\section{GRÁFICA 2.4}

TODOS TENEMOS ALGUNAS CREENCIAS, POR EJEMPLO, ¿USTED ACOSTUMBRA EVITAR...? (PORCENTAJES)

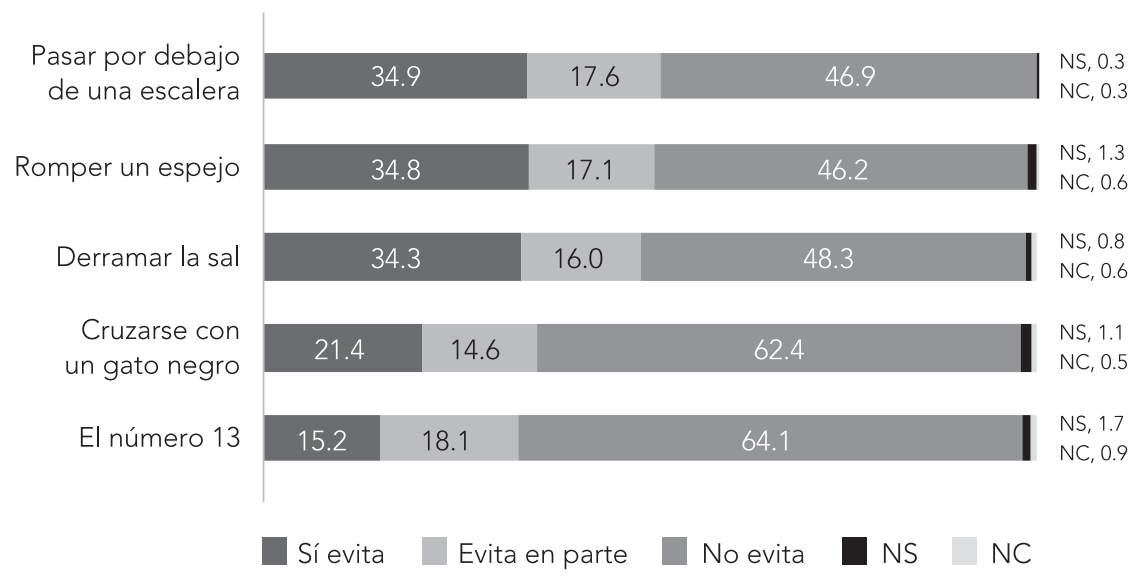

Fuente: Encuesta Nacional de Percepciones Sociales de los Juegos de Azar en México, México, UNAm, Instituto de Investigaciones Jurídicas, Departamento de Investigación Aplicada y Opinión, 2016.

Se observa una tendencia general en la que las mujeres, los mayores de 65 años y más, y aquellos sin ninguna escolaridad son quienes mencionaron en mayor medida la celebración de ciertas prácticas y rituales.

\section{LAS PROTECCIONES: TALISMANES, AMULETOS Y FETICHES}

Los amuletos, al menos en su origen, son vehículos de fuerzas místicas que proceden del mundo sobrenatural. El amuleto, en su estadio más elevado, es el "talismán". ${ }^{3}$ Todo objeto fetiche o talismán sustentado en lo pre-lógico o mágico es un símbolo de protección o fe, "una continua búsqueda del origen, de aquel modelo utópico e imaginario que bajo un sentido espiritual y ontológico de la vida permite la aseveración de la existencia de un dios o un ser creador y poderoso". Estos objetos inscritos en el devenir de acciones, pensamientos y sentimientos se matizan al poder de los sentidos

3 La palabra talismán es un término de origen incierto, que puede estar en la palabra hebrea tseiem, imagen. Se encuentra entre los árabes bajo la forma de tilasm y tillams (plural talásim, tilasmát y tilassamát). Véase Vázquez (1989: 171-196). 
Este libro forma parte del acervo de la Biblioteca Jurídica Virtual del Instituto de Investigaciones Jurídicas de la UNAM

en la intención, siempre bajo una promesa estética: "todo objeto elaborado en un tiempo remoto se carga de un valor fetichista y se vuelve susceptible de ser coleccionado" (Rojo Betancurt, 2009).

La magia de un fetiche es transmitida al objeto mediante el deseo proyectado del hombre; las reliquias religiosas, y en concreto las católicas, como ejemplo, aumentan su valor bajo la bendición del rito del agua bendita, sin importar el valor de dicho objeto si éste es de procedencia serial; son la creatividad y la fe las que lo reconfiguran y lo valorizan como talismán. Es posible aseverar que el contenido simbólico de dichos objetos los valorizan tanto en su valor apreciativo como monetario. Son pequeños tesoros, talismanes que acompañan y protegen.

A la pregunta ¿Tiene usted algún objeto que le dé buena suerte?, únicamente la cuarta parte dijo que sí, y siete de cada diez respondieron no tener dicho objeto. Menos de uno de cada diez indicó que antes tenía (véase gráfica 2.5).

\section{GRÁFICA 2.5}

¿TIENE USTED ALGÚN OBJETO QUE LE DÉ BUENA SUERTE?

(PORCENTAJES)

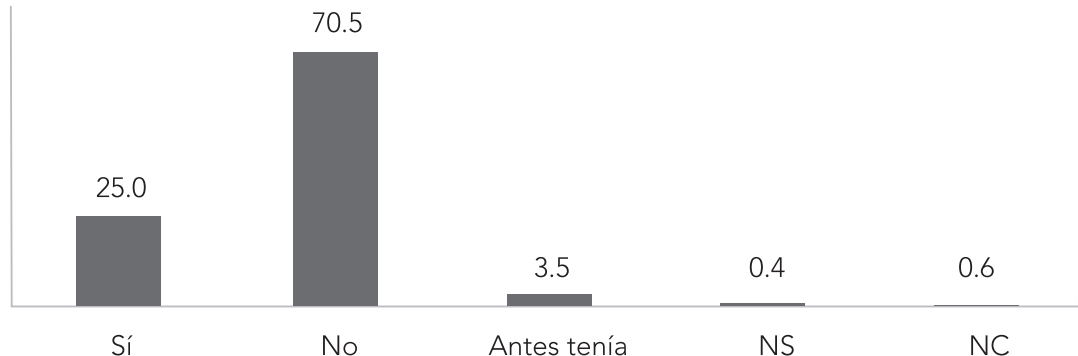

Fuente: Encuesta Nacional de Percepciones Sociales de los Juegos de Azar en México, México, UnAM, Instituto de Investigaciones Jurídicas, Departamento de Investigación Aplicada y Opinión, 2016.

La posesión de un amuleto para protección o buena suerte alcanza al 28.5 por ciento de los entrevistados, que manifestó que tiene o ha tenido un objeto de la buena suerte. Una amplia mayoría no posee un amuleto. Son las personas entrevistadas de 65 años y más las que tienen más frecuentemente objetos de buena suerte. Asimismo, señalan tener un objeto que les dé buena suerte quienes cuentan con niveles más bajos de escolaridad. Fi- 
Este libro forma parte del acervo de la Biblioteca Jurídica Virtual del Instituto de Investigaciones Jurídicas de la UNAM

nalmente, es importante destacar que según la religión no se observan diferencias importantes en la posesión de un objeto de buena suerte.

\section{LAS DENOMINACIONES RELIGIOSAS Y LA PRÁCTICA DE LOS JUEGOS DE AZAR EN MÉXICO}

Los juegos del azar, de lo probable, del dominio del futuro, siempre se instalan en una lógica que ambiciona crear un orden, una certeza. La historia de los juegos de azar está por ello vinculada también a la historia de la religión y las creencias, si bien, en general, las religiones han tenido una relación ambivalente con éstos (Ferentzy y Turner, 2013). F. N. David (1962), al estudiar la historia de la probabilidad, especula con el hecho de que el juego sea el primer invento de la sociedad humana (David, 1962). Señala Gadamer (1996) que

Lo primero que hemos de tener claro es que el juego es una función elemental de la vida humana, hasta el punto de que no se puede pensar en absoluto la cultura humana sin un componente lúdico. Pensadores como Huizinga, Guardini y otros han destacado hace mucho que la práctica del culto religioso entraña un elemento lúdico (Gadamer, 1996).

El juego de azar se entiende como una competencia en la que el participante lo hace no sólo con la finalidad de pasar el tiempo o distraerse, sino también como una forma de obtener ganancia de manera práctica y senciIla, aunque ilícita, pues es "cierto, en muchos jugadores, la idea de una ganancia adquirida sin trabajar, y que permitiría un rápido «cambio de clase» o la adquisición de objetos deseados, es más clara que la motivación que la explica" (Duvignaud 1982: 143).

Históricamente, la relación de los juegos de azar y las religiones se ha caracterizado por dos facetas que se asocian a elementos negativos: riesgos, peligro y como pecado e inmoralidad; el juego ha sido simultáneamente común y prohibido, y su presencia y distintas alternativas "son dictadas por los caprichos del gobierno y la sociedad" (McGurrin, 1992). La pertenencia a una religión y la práctica de los juegos de azar ha sido desde siempre una relación ambigua: mientras que por una parte las distintas iglesias los 
Este libro forma parte del acervo de la Biblioteca Jurídica Virtual del Instituto de Investigaciones Jurídicas de la UNAM

han condenado y prohibido, por la otra algunas los han permitido, e incluso participan de ellos.

Los elementos religiosos y el esparcimiento no constituyen en sí mismos espacios opuestos. De acuerdo con McGurrin, los usos y las prácticas de los juegos de azar en relación con la religión podrían vincularse con dos factores: "el aspecto de control social, donde algunas religiones o denominaciones religiosas pueden ser más estrictas con la asistencia a ciertos espacios". Así, por ejemplo, algunas religiones, particularmente las basadas en principios como el trabajo duro, la prosecución moralmente obligatoria de una vocación, la creencia de que Dios ayuda a quienes se ayudan, el mantenerse alejado de la atención del diablo y el absoluto rechazo de todo lo que se aparte de este modo ascético, en general, de vida, constituyen preceptos de la ética protestante, fundamentalmente de origen calvinista. Por otra parte, se ha señalado la oferta de actividades de la congregación religiosa a la que se pertenece (McGurrin, 1992).

De este modo, los católicos tenderían a participar en mayor medida en juegos de azar que las personas que tienen otras denominaciones religiosas, al igual que los ateos (véase cuadro 2.2).

\section{CUADRO 2.2}

\section{RELIGIONES Y PRÁCTICA DE JUEGO} (PORCENTAJES)

\begin{tabular}{l|c|c}
\hline & JUGÓ EN EL ÚLTIMO AÑO & NO JUEGA NINGÚN JUEGO \\
\hline Católico & 76.5 & 66.4 \\
\hline Cristiano no católico & 12.1 & 17.7 \\
\hline Ateo & 7.1 & 6.7 \\
\hline Testigo de Jehová & 0.6 & 1.3 \\
\hline Evangélica & 0.2 & 1.4 \\
\hline Santa Muerte & 0.6 & 0.8 \\
\hline Santería & 0.0 & 0.6 \\
\hline Pentecostés & 0.2 & 0.1 \\
\hline Mormón & 0.0 & 0.2 \\
\hline Bautista & 0.1 & 0.0 \\
\hline Adventista & 0.0 & 0.2 \\
\hline NS & 1.0 & 2.1 \\
\hline NC & 1.6 & 2.5 \\
\hline
\end{tabular}

Fuente: Encuesta Nacional de Percepciones Sociales de los Juegos de Azar en México, México, UNAM, Instituto de Investigaciones Jurídicas, Departamento de Investigación Aplicada y Opinión, 2016. 
Este libro forma parte del acervo de la Biblioteca Jurídica Virtual del Instituto de Investigaciones Jurídicas de la UNAM

\section{CREENCIAS TRADICIONALES Y PRÁCTICAS DE JUEGO}

Mientras más arraigadas están las creencias tradicionales y las supersticiones, crece la disposición a participar en los juegos de azar. Así, las personas que creen en la suerte dijeron en mayor medida haber jugado un juego de azar en el último año. En contraste, quienes no creen en la suerte señalaron con porcentajes más altos no jugar ningún juego (véase cuadro 2.3).

\section{CUADRO 2.3}

¿CREE USTED...?
(PORCENTAJES)

SUERTE?

\begin{tabular}{l|c|c|c}
\hline & MEDIA NACIONAL & JUEGA EN EL ÚLTIMO AÑO & NO JUEGA NINGÚN JUEGO \\
\hline Sí & 63.4 & 69.8 & 56.8 \\
\hline Sí, en parte & 17.6 & 16.9 & 18.7 \\
\hline No & 18.9 & 13.3 & 24.2 \\
\hline NS & 0.2 & 0.0 & 0.3 \\
\hline NC & 0.0 & 0.0 & 0.0
\end{tabular}

INFIERNO?

\begin{tabular}{l|c|c|c}
\hline & MEDIA NACIONAL & JUEGA EN EL ÚLTIMO AÑO & NO JUEGA NINGÚN JUEGO \\
\hline Sí & 47.1 & 45.1 & 49.7 \\
\hline Sí, en parte & 17.9 & 19.5 & 16.0 \\
\hline No & 32.5 & 32.8 & 31.7 \\
\hline NS & 1.8 & 2.2 & 1.5 \\
\hline NC & 0.7 & 0.4 & 1.1 \\
\hline
\end{tabular}

DESTINO?

\begin{tabular}{l|c|c|c}
\hline & MEDIA NACIONAL & JUEGA EN EL ÚLTIMO AÑO & NO JUEGA NINGÚN JUEGO \\
\hline Sí & 48.3 & 48.9 & 47.4 \\
\hline Sí, en parte & 21.4 & 25.4 & 17.7 \\
\hline No & 28.6 & 23.9 & 33.3 \\
\hline NS & 1.6 & 1.7 & 1.6 \\
\hline NC & 0.1 & 0.1 & 0.0 \\
\hline
\end{tabular}

HORÓSCOPOS?

\begin{tabular}{l|c|c|c}
\hline & MEDIA NACIONAL & JUEGA EN EL ÚLTIMO AÑO & NO JUEGA NINGÚN JUEGO \\
\hline Sí & 19.0 & 22.0 & 16.5 \\
\hline Sí, en parte & 18.5 & 21.7 & 15.1 \\
\hline No & 59.9 & 54.3 & 65.4 \\
\hline NS & 2.0 & 1.9 & 2.0 \\
\hline NC & 0.6 & 0.1 & 1.1 \\
\hline
\end{tabular}


Este libro forma parte del acervo de la Biblioteca Jurídica Virtual del Instituto de Investigaciones Jurídicas de la UNAM

(CONTINUACIÓN)

MAL DE OJO?

\begin{tabular}{l|c|c|c}
\hline & MEDIA NACIONAL & JUEGA EN EL ÚLTIMO AÑO & NO JUEGA NINGÚN JUEGO \\
\hline Sí & 27.2 & 28.0 & 25.6 \\
\hline Sí, en parte & 19.4 & 22.3 & 17.1 \\
\hline No & 50.3 & 46.6 & 54.1 \\
\hline NS & 2.4 & 2.6 & 2.4 \\
\hline NC & 0.6 & 0.5 & 0.8 \\
\hline
\end{tabular}

Fuente: Encuesta Nacional de Percepciones Sociales de los Juegos de Azar en México, México, UNAM, Instituto de Investigaciones Jurídicas, Departamento de Investigación Aplicada y Opinión, 2016.

De la misma manera, quienes creen en el destino muestran una mayor tendencia a participar en este tipo de juegos que las personas que no creen en él. La creencia en el infierno parecería en principio inhibir a los individuos de participar en juegos de azar; no obstante, dicha tendencia no está fuertemente marcada, dado que a pesar de creer en el infierno o creer en él sólo en parte, un porcentaje sustantivo de los entrevistados participó en juegos de azar.

Si bien la creencia en los horóscopos y el mal de ojo está menos presente en la población, la creencia en ellos se relaciona con la práctica de juego.

En contraste, la práctica de rituales y supersticiones está presente por igual entre las poblaciones que dijeron practicar juegos de azar y entre quienes no los practican, como se observa en el siguiente cuadro (véase cuadro 2.4).

CUADRO 2.4

SUPERSTICIONES, RITUALES Y PRÁCTICAS DE JUEGO (PORCENTAJES)

\begin{tabular}{l|c|c|c}
\hline \multicolumn{4}{c}{ ¿USTED ACOSTUMBRA EVITAR PASAR POR DEBAJO DE UNA ESCALERA? } \\
\hline & MEDIA NACIONAL & JUEGA EN EL ÚLTIMO AÑO & NO JUEGA NINGÚN JUEGO \\
\hline Sí evita & 34.9 & 35.3 & 39.9 \\
\hline Sí evita, en parte & 17.6 & 18.8 & 12.4 \\
\hline No evita & 46.9 & 45.4 & 47.7 \\
\hline NS & 0.3 & 0.0 & 0.0 \\
\hline NC & 0.3 & 0.4 & 0.0 \\
\hline
\end{tabular}


Este libro forma parte del acervo de la Biblioteca Jurídica Virtual del Instituto de Investigaciones Jurídicas de la UNAM

(CONTINUACIÓN)

¿USTED ACOSTUMBRA EVITAR CRUZARSE CON UN GATO NEGRO?

\begin{tabular}{l|c|c|c}
\hline & MEDIA NACIONAL & JUEGA EN EL ÚLTIMO AÑO & NO JUEGA NINGÚN JUEGO \\
\hline Sí evita & 21.4 & 22.2 & 21.1 \\
\hline Sí evita, en parte & 14.6 & 15.1 & 14.0 \\
\hline No evita & 62.5 & 60.9 & 63.6 \\
\hline NS & 1.1 & 1.3 & 1.0 \\
\hline NC & 0.5 & 0.6 & 0.4 \\
\hline
\end{tabular}

¿USTED ACOSTUMBRA EVITAR DERRAMAR LA SAL?

\begin{tabular}{l|c|c|c}
\hline & MEDIA NACIONAL & JUEGA EN EL ÚLTIMO AÑO & NO JUEGA NINGÚN JUEGO \\
\hline Sí evita & 34.3 & 33.9 & 34.5 \\
\hline Sí evita, en parte & 16.0 & 17.9 & 14.7 \\
\hline No evita & 48.3 & 46.7 & 49.3 \\
\hline NS & 0.8 & 0.7 & 1.0 \\
\hline NC & 0.6 & 0.8 & 0.5 \\
\hline
\end{tabular}

¿USTED ACOSTUMBRA EVITAR ROMPER UN ESPEJO?

\begin{tabular}{l|c|c|c}
\hline & MEDIA NACIONAL & JUEGA EN EL ÚLTIMO AÑO & NO JUEGA NINGÚN JUEGO \\
\hline Sí evita & 34.8 & 36.9 & 32.6 \\
\hline Sí evita, en parte & 17.1 & 17.5 & 17.2 \\
\hline No evita & 46.2 & 43.8 & 48.1 \\
\hline NS & 1.3 & 1.2 & 1.5 \\
\hline NC & 0.6 & 0.7 & 0.5 \\
\hline
\end{tabular}

¿USTED ACOSTUMBRA EVITAR EL NÚMERO 13?

\begin{tabular}{l|c|c|c}
\hline & MEDIA NACIONAL & JUEGA EN EL ÚLTIMO AÑO & NO JUEGA NINGÚN JUEGO \\
\hline Sí evita & 15.2 & 16.5 & 13.7 \\
\hline Sí evita, en parte & 18.1 & 19.0 & 17.5 \\
\hline No evita & 64.1 & 62.3 & 65.5 \\
\hline NS & 1.7 & 1.5 & 2.2 \\
\hline NC & 0.9 & 0.8 & 1.1 \\
\hline
\end{tabular}

Fuente: Encuesta Nacional de Percepciones Sociales de los Juegos de Azar en México, México, UNAM, Instituto de Investigaciones Jurídicas, Departamento de Investigación Aplicada y Opinión, 2016.

Por lo que respecta a la utilización de amuletos, menos difundida entre la población entrevistada, se advierte su fuerte presencia en la población que practica algún juego de azar, como se muestra en el siguiente cuadro (véase cuadro 2.5). 
Este libro forma parte del acervo de la Biblioteca Jurídica Virtual del Instituto de Investigaciones Jurídicas de la UNAM www.juridicas.unam.mx

CUADRO 2.5

¿TIENE USTED ALGÚN OBJETO QUE LE DÉ BUENA SUERTE? (PORCENTAJES)

\begin{tabular}{l|c|c|c}
\hline & MEDIA NACIONAL & $\begin{array}{c}\text { JUEGA EN EL ÚLTIMO } \\
\text { AÑO }\end{array}$ & $\begin{array}{c}\text { NO JUEGA NINGÚN } \\
\text { JUEGO }\end{array}$ \\
\hline Sí & 25 & 27.8 & 22.7 \\
\hline No & 70.5 & 68.0 & 72.2 \\
\hline Antes tenía & 3.5 & 3.6 & 3.5 \\
\hline NS & 0.4 & 0 & 0.9 \\
\hline NC & 0.6 & 0.6 & 0.7 \\
\hline
\end{tabular}

Fuente: Encuesta Nacional de Percepciones Sociales de los Juegos de Azar en México, México, UNAM, Instituto de Investigaciones Jurídicas, Departamento de Investigación Aplicada y Opinión, 2016.

Finalmente, con el propósito de conocer la extensión de las supersticiones y rituales entre los mexicanos entrevistados, se construyó un índice segmentando a la población en grupos de acuerdo con la intensidad de su superstición: alta, media alta, media baja y baja. ${ }^{4}$ Los resultados se presentan en la gráfica 2.6. tas ¿Cree usted en...? La suerte, el infierno, el destino, los horóscopos y el mal de ojo, se asignaron ponderaciones a cada una de las opciones de respuesta de la siguiente forma: a la opción sí se le dio una puntuación de 2, a la opción sí, en parte, se le puntuó con 1, y finalmente se les asignó un cero a quienes respondieron negativamente a la pregunta. De igual forma, se buscaron puntuaciones para las preguntas ¿Tiene usted algún objeto que le dé buena suerte? y ¿Usted acostumbra evitar...? Pasar por debajo de una escalera, cruzarse con un gato negro, derramar la sal, romper un espejo y el número trece, las cuales obtuvieron una ponderación menor: a la opción sí evita se le dio una puntuación de 1, la opción sí evita, en parte se puntuó con 0.5, mientras que la opción no evita tuvo una puntuación de cero. Para cada caso, se creó una nueva variable formada por la suma de las puntuaciones de las respuestas para las preguntas descritas anteriormente. Finalmente, se utilizó el método de clusterización o conglomerados de k-medias para formar cuatro grupos, que identifican el nivel de superstición al que pertenecen los entrevistados. 
Este libro forma parte del acervo de la Biblioteca Jurídica Virtual del Instituto de Investigaciones Jurídicas de la UNAM

GRÁFICA 2.6

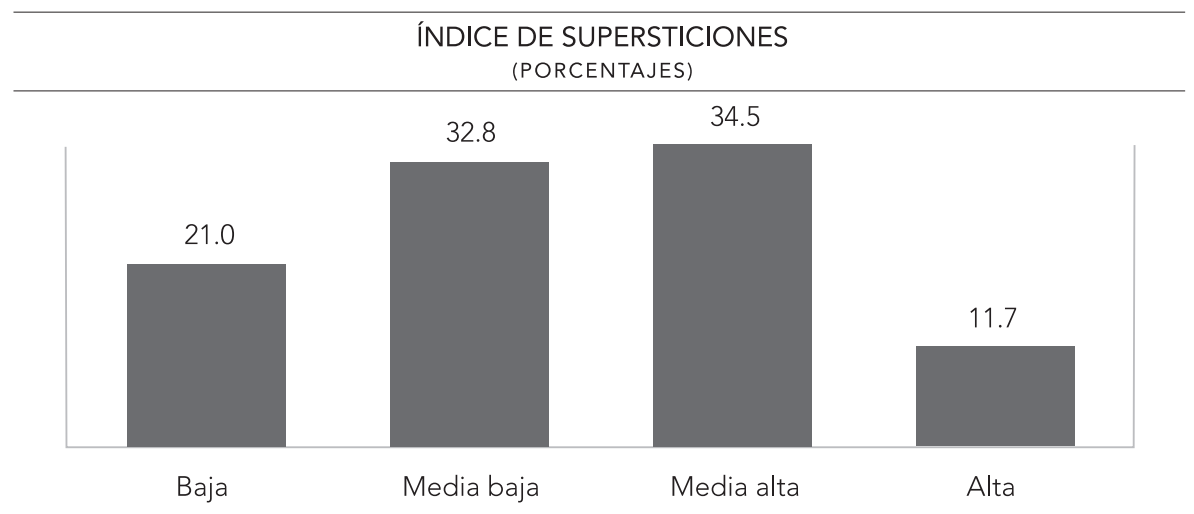

Fuente: Encuesta Nacional de Percepciones Sociales de los Juegos de Azar en México, México, UnAM, Instituto de Investigaciones Jurídicas, Departamento de Investigación Aplicada y Opinión, 2016.

De los resultados del índice se desprende que si bien las supersticiones y creencias tradicionales están extendidas en la sociedad mexicana, no se sitúan en los extremos. Más de la mitad de la población (53.8 por ciento) se ubica, en todo caso, en los niveles bajo y medio-bajo.

\section{EL BIENESTAR SUBJETIVO Y EL AZAR}

Mucho se ha especulado sobre la relación entre el bienestar subjetivo y la práctica de los juegos de azar. Se ha convertido en un lugar común — principalmente desde algunas visiones- señalar que quienes juegan lo hacen por un vacío existencial: la insatisfacción con su vida o la infelicidad. Con el propósito de indagar sobre esta relación, se decidió incluir en la encuesta varias preguntas sobre el bienestar subjetivo.

El bienestar subjetivo es uno de los cuatro dominios que engloba la calidad de vida y refleja la evaluación dinámica que efectúa una persona en relación con los otros tres dominios (competencias de comportamiento, condiciones objetivas del entorno y percepción de la calidad de vida) (Liberalesso, 2002). Así, el bienestar subjetivo es el nombre que se otorga a la manera en que la gente evalúa su vida. Las personas pueden evaluar sus vidas con un juicio global —como la satisfacción con la vida o sentimientos de plenitud-, evaluar determinados aspectos de sus vidas (trabajo, matri- 
Este libro forma parte del acervo de la Biblioteca Jurídica Virtual del Instituto de Investigaciones Jurídicas de la UNAM

monio) o sus sentimientos actuales acerca de lo que les sucede, esto es, sentir emociones placenteras que surgen de las evaluaciones positivas de la experiencia propia y bajos niveles de sentimientos no placenteros que emanan de evaluaciones negativas de nuestras experiencias (Veenhoven, 1991). ${ }^{5}$

El núcleo central del concepto consiste en que es la propia persona quien efectúa la evaluación de su vida, no alguien ajeno: ¿qué tan bien va mi vida de acuerdo con los estándares que yo mismo elijo utilizar? Se reconocen dos componentes del bienestar subjetivo: el emocional, conocido hoy como felicidad, y el cual implica el predominio coyuntural de afectos positivos sobre afectos negativos (Lucas, Diener y Suh, 1996), y el cognitivo o satisfacción vital. En general, el bienestar subjetivo incluye el análisis de varias condiciones: ¿qué tan satisfechas están las personas con su vida en general?, ¿qué tan felices son? y ¿cómo se sienten acerca de las oportunidades que tienen para participar, en general, en su vida social?

Para conocer la satisfacción de los entrevistados con su vida, a la pregunta: Pensando en su vida, ¿qué tan satisfecho o insatisfecho está con la vida que ha llevado hasta hoy?, tres cuartas partes de los encuestados indicaron estar muy satisfechos o satisfechos con la vida que han Ilevado hasta ahora (74 por ciento); cerca de dos de cada diez señalaron no estar ni satisfechos ni insatisfechos, y menos de uno dijo sentirse insatisfecho o muy insatisfecho (véase gráfica 2.7).

Igualmente, se realizaron tablas cruzadas de acuerdo con la pregunta y una variable que se generó a partir de quienes jugaron durante el último año y los que no jugaron.

Entre los más satisfechos con su vida destacan los participantes en el estudio que tienen 65 años y más, y los de una religión diferente a la católica. También, entre los grupos más escolarizados es mayor el nivel de satisfacción con la vida. Como se observa, la práctica del juego no incide significativamente en la satisfacción que tienen con la vida que han llevado hasta la actualidad las personas entrevistadas.

5 Existen dos posiciones en la literatura con respecto a los conceptos de felicidad y satisfacción con la vida; mientras que para algunos las mediciones de satisfacción con la vida y felicidad pueden utilizarse de forma intercambiable (Veenhoven, 1991, 2008; Frey, 2008; Frey y Stutzer, 2002), para otros autores existen diferencias significativas entre ambos conceptos, tanto de carácter teórico (Lane, 2000) como en el análisis de los datos (Gundelach y Kreiner, 2004), particularmente en el análisis de subgrupos. 
Este libro forma parte del acervo de la Biblioteca Jurídica Virtual del Instituto de Investigaciones Jurídicas de la UNAM www.juridicas.unam.mx

GRÁFICA 2.7

PENSANDO EN SU VIDA, ¿QUÉ TAN SATISFECHO O INSATISFECHO

ESTÁ CON LA VIDA QUE HA LLEVADO HASTA HOY?

(PORCENTAJES)

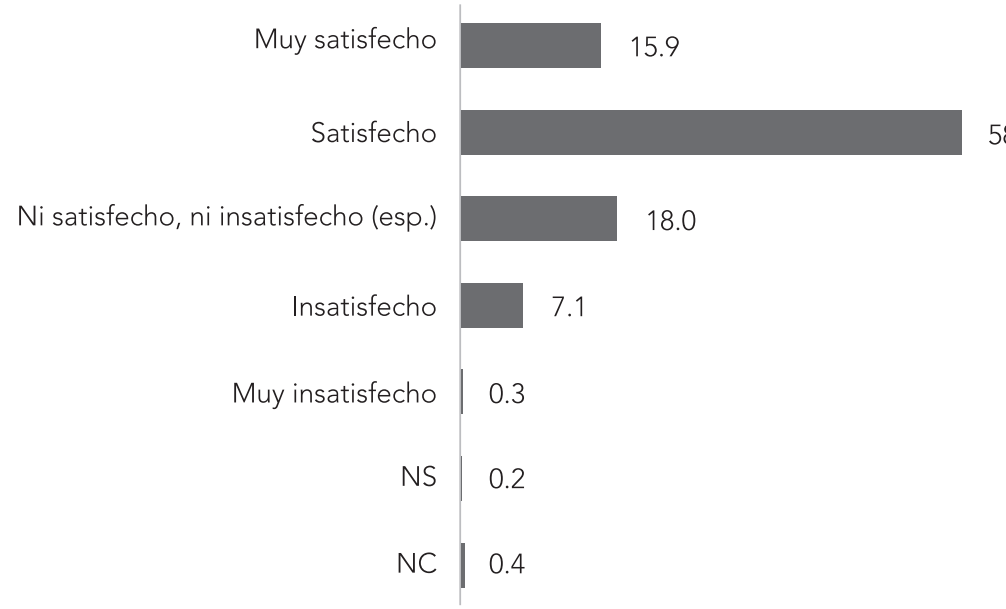

58.1

Fuente: Encuesta Nacional de Percepciones Sociales de los Juegos de Azar en México, México, UNAM, Instituto de Investigaciones Jurídicas, Departamento de Investigación Aplicada y Opinión, 2016.

Los resultados de esta pregunta, de acuerdo con la práctica de algún juego de azar, se muestran en el cuadro 2.6.

CUADRO 2.6

PENSANDO EN SU VIDA, ¿QUÉ TAN SATISFECHO O INSATISFECHO
ESTÁ CON LA VIDA QUE HA LLEVADO HASTA HOY? (PORCENTAJES)

\begin{tabular}{l|c|c|c}
\hline & MEDIA NACIONAL & $\begin{array}{c}\text { JUEGA EN EL ÚLTIMO } \\
\text { AÑO }\end{array}$ & $\begin{array}{c}\text { NO JUEGA NINGÚN } \\
\text { JUEGO }\end{array}$ \\
\hline Muy satisfecho & 15.9 & 14.8 & 16.8 \\
\hline Satisfecho & 58.1 & 60.7 & 55.4 \\
\hline $\begin{array}{l}\text { Ni satisfecho, } \\
\text { ni insatisfecho }\end{array}$ & 18.0 & 16.8 & 19.3 \\
\hline Insatisfecho & 7.1 & 7.0 & 7.6 \\
\hline Muy insatisfecho & 0.3 & 0.3 & 0.1 \\
\hline NS & 0.2 & 0.3 & 0.2 \\
\hline NC & 0.4 & 0.1 & 0.6 \\
\hline
\end{tabular}

Fuente: Encuesta Nacional de Percepciones Sociales de los Juegos de Azar en México, México, UNAM, Instituto de Investigaciones Jurídicas, Departamento de Investigación Aplicada y Opinión, 2016. 
Este libro forma parte del acervo de la Biblioteca Jurídica Virtual del Instituto de Investigaciones Jurídicas de la UNAM

Al respecto, se encontró que tanto los jugadores (75.5 por ciento) como quienes no practican juegos de azar (72.2 por ciento) se encuentran muy satisfechos o satisfechos de la misma manera con la vida que han llevado hasta hoy. De allí se desprendería una reflexión relativa a que la satisfacción con la vida no es un elemento relevante para que las personas practiquen juegos de azar.

\section{CONTROL SOBRE LA VIDA, LOCUS DE CONTROL Y PERCEPCIÓN DEL FUTURO}

Es difícil la detección de los factores objetivos sobre situaciones como el estrés o la falta de equilibrio, pero es medible la apropiación personal del individuo a través de indicadores como la percepción del control sobre los propios recursos para responder a los estímulos o necesidades. La falta de control puede conducir a la desmoralización, el agotamiento y la pérdida de motivación.

La psicología explica que el locus de control es un recurso de afrontamiento en los acontecimientos de la vida. Velasco Matus et al. (2015) señalan que las personas llevan a cabo procesos de atribución sobre lo que les sucede cotidianamente, de tal manera que pueden definir si tienen algún control sobre las cosas o no. Autores clásicos como Rotter (1966) y La Rosa (1986) definen este concepto como la creencia que tiene cada uno respecto a quién o qué factores controlan los sucesos de su vida; es decir, las personas desarrollan la creencia de que se puede tener cierto control sobre lo que les sucede, en caso de no poder, la creencia radica en la posibilidad de atribuir esas causas a factores ajenos, es decir, locus de control interno y locus de control externo. Por su parte, Velasco Matus et al. (2015: 46) señalan que "la utilidad del LC (locus de control) radica en la posibilidad de entender las diferentes formas en las que las personas explican sus éxitos o fracasos, ya sea a partir de su desempeño personal en tareas y actividades específicas, habilidades sociales, suerte, destino, azar, etcétera".

Al respecto, en la encuesta se incluyó una pregunta para conocer qué tanto control sienten tener los entrevistados en diferentes ámbitos de su vida. Al realizar la pregunta, en una escala del 0 al 10, donde 0 es nada y 10 
Este libro forma parte del acervo de la Biblioteca Jurídica Virtual del Instituto de Investigaciones Jurídicas de la UNAM

es mucho, ¿qué tanto cree que puede decidir su futuro? Se llevó a cabo una agrupación por conglomerados para establecer del 0 al 3 un nivel bajo, del 4 al 7 un nivel medio y del 8 al 10 un nivel alto.

De esta manera, menos de uno de cada diez entrevistados se situó en un nivel bajo; mientras que más de tres de cada diez se colocaron en un nivel medio. Fueron cerca de seis de cada diez los que señalaron que pueden decidir sobre su futuro en un alto nivel (véase gráfica 2.8).

GRÁFICA 2.8

ALGUNAS PERSONAS PIENSAN QUE PUEDEN DECIDIR Y ELEGIR LIBREMENTE SU FUTURO; EN CAMBIO, OTRAS PERSONAS PIENSAN QUE NO TIENEN INFLUENCIA SOBRE SU FUTURO. EN UNA ESCALA DE 0 A 10, EN DONDE 0 ES NADA Y 10 ES MUCHO, ¿QUÉ TANTO CREE USTED QUE PUEDE DECIDIR SU FUTURO? (PORCENTAJES)

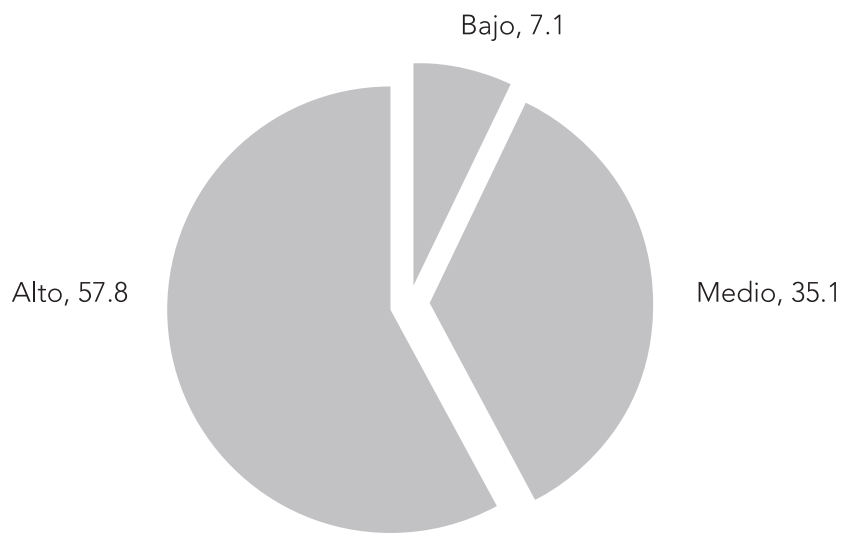

Fuente: Encuesta Nacional de Percepciones Sociales de los Juegos de Azar en México, México, UNAM, Instituto de Investigaciones Jurídicas, Departamento de Investigación Aplicada y Opinión, 2016.

Del análisis de la sección sociodemográfica destaca que son los más jóvenes, de 18 a 24 años, los que sienten que tienen un control alto sobre su futuro, mientras que los que presentan porcentajes por debajo de la media son los entrevistados de 65 años y más. Siguiendo con el control alto sobre su futuro, fueron los de escolaridad preparatoria los que se agrupan más frecuentemente en dicha categoría. 
Este libro forma parte del acervo de la Biblioteca Jurídica Virtual del Instituto de Investigaciones Jurídicas de la UNAM www.juridicas.unam.mx

GRÁFICA 2.9

¿QUÉ TANTO CREE USTED QUE PUEDE DECIDIR SU FUTURO? (PROMEDIOS)

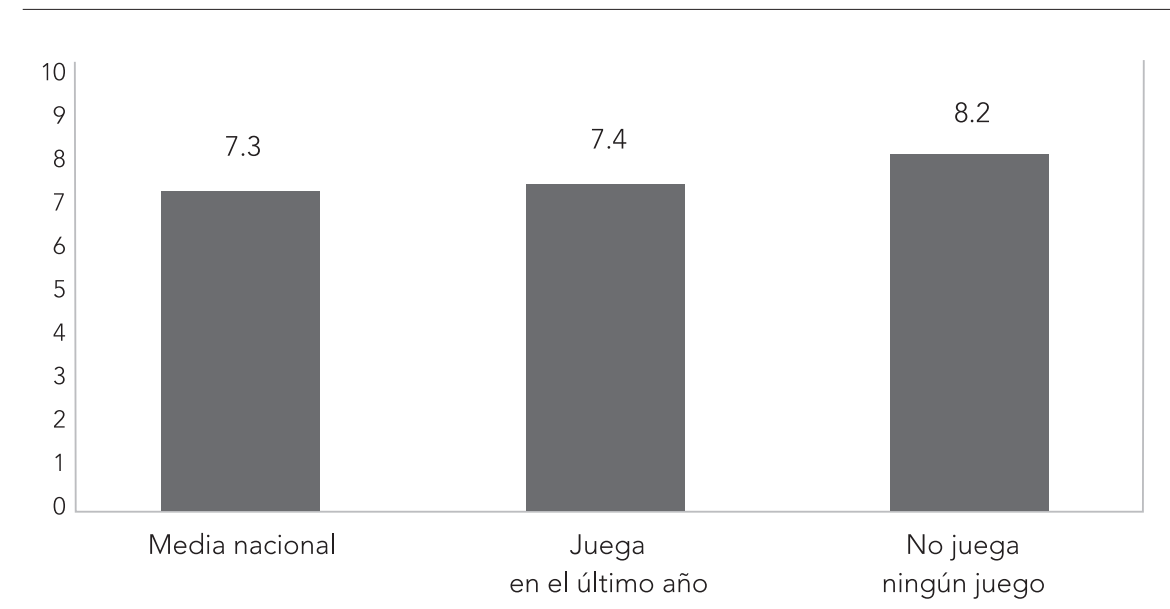

Fuente: Encuesta Nacional de Percepciones Sociales de los Juegos de Azar en México, México, UNAM, Instituto de Investigaciones Jurídicas, Departamento de Investigación Aplicada y Opinión, 2016.

Sobresale, como se observa en la gráfica anterior, que las personas que no juegan ningún juego señalaron en mayor medida que pueden decidir sobre su futuro, en contraste con la media nacional y entre quienes han jugado alguna vez en el último año.

Posteriormente se preguntó: Según su experiencia, para tener una buena posición en el trabajo, ¿qué cree que sea más importante, el esfuerzo de cada persona o los contactos que tenga? 
Este libro forma parte del acervo de la Biblioteca Jurídica Virtual del Instituto de Investigaciones Jurídicas de la UNAM www.juridicas.unam.mx

GRÁFICA 2.10

SEGÚN SU EXPERIENCIA, PARA TENER UNA BUENA POSICIÓN EN EL TRABAJO, ¿QUÉ CREE QUE SEA MÁS IMPORTANTE, EL ESFUERZO DE CADA PERSONA O LOS CONTACTOS QUE TENGA?

(PORCENTAJES)

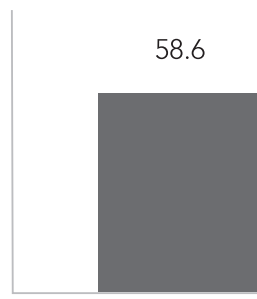

El esfuerzo de cada persona

25.8

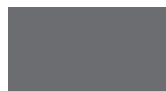

Los contactos
14.3

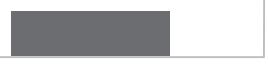

Su suerte

que tenga

Fuente: Encuesta Nacional de Percepciones Sociales de los Juegos de Azar en México, México, unam, Instituto de Investigaciones Jurídicas, Departamento de Investigación Aplicada y Opinión, 2016.

Como se observa, seis de cada diez personas consideran que una buena posición en el trabajo depende del esfuerzo de cada persona, mientras que una cuarta parte indicó que eran más importantes los contactos con los que se cuenta.

\section{CUADRO 2.7}

EN ORDEN DE IMPORTANCIA, SEGÚN SU EXPERIENCIA, PARA TENER UNA BUENA POSICIÓN EN EL TRABAJO, ¿QUÉ CREE QUE SEA MÁS IMPORTANTE? (PORCENTAJES)

\begin{tabular}{l|c|c|c}
\hline & $\begin{array}{c}\text { MEDIA } \\
\text { NACIONAL }\end{array}$ & JUEGA EN EL ÚLTIMO AÑO & $\begin{array}{c}\text { NO JUEGA NINGÚN } \\
\text { JUEGO }\end{array}$ \\
\hline $\begin{array}{l}\text { El esfuerzo de } \\
\text { cada persona }\end{array}$ & 58.0 & 54.6 & 62.0 \\
\hline $\begin{array}{l}\text { Los contactos } \\
\text { que tenga }\end{array}$ & 25.9 & 30.1 & 21.6 \\
\hline Su suerte & 14.4 & 14.9 & 13.7 \\
\hline NS & 0.5 & 0.1 & 0.8 \\
\hline NC & 1.2 & 0.3 & 1.9 \\
\hline
\end{tabular}

Fuente: Encuesta Nacional de Percepciones Sociales de los Juegos de Azar en México, México, UNAM, Instituto de Investigaciones Jurídicas, Departamento de Investigación Aplicada y Opinión, 2016. 
Este libro forma parte del acervo de la Biblioteca Jurídica Virtual del Instituto de Investigaciones Jurídicas de la UNAM

Entre quienes han jugado en el último año, consideraron que son más relevantes los contactos que se tengan (30.1 por ciento) por sobre la media nacional y casi diez puntos porcentuales más que quienes no juegan ningún juego (21.6 por ciento).

\section{PERCEPCIÓN E IMAGEN DEL FUTURO: SUEÑOS Y DESEOS}

Fantaseamos, imaginamos, esperamos y deseamos porque proyectamos en el futuro la posibilidad de gozar de una experiencia de satisfacción cuyas huellas retenemos en nuestra memoria. Los sueños y deseos de las personas llevan a la posibilidad de crear, a la constancia permanente de que nada está agotado, a la construcción de un horizonte de futuro.

Los deseos de cambio se inscriben en las representaciones que se hace la gente de su realidad respectiva en determinado momento. Descansan sobre una apreciación de cómo funciona la vida social; evaluación que se encuentra condicionada por los hábitos mentales, las experiencias acumuladas del pasado y las imágenes acerca de "lo posible" en el futuro. "Las aspiraciones son... complejos productos culturales, elaborados en la sociabilidad cotidiana" (Lechner, 2002).

¿En torno a qué giran los sueños y deseos de los mexicanos? A la pregunta Imagine que en las próximas semanas usted tuviera la oportunidad de realizar alguno de sus sueños, ¿cuál sueño realizaría?, tres de cada diez indicaron que la obtención de bienes, mientras que dos de cada diez encuestados dijeron que viajar y poco más de uno de cada diez indicó que tener un negocio o trabajo. Menos de uno de cada diez se refirió a cuestiones como el progreso personal, abundancia económica, progreso familiar o social, entre otros (véase gráfica 2.11). 
Este libro forma parte del acervo de la Biblioteca Jurídica Virtual del Instituto de Investigaciones Jurídicas de la UNAM

GRÁFICA 2.11

IMAGINE QUE EN LAS PRÓXIMAS SEMANAS USTED TUVIERA LA OPORTUNIDAD

DE REALIZAR ALGUNO DE SUS SUEÑOS, ¿CUÁL SUEÑO REALIZARÍA?

(PORCENTAJES)

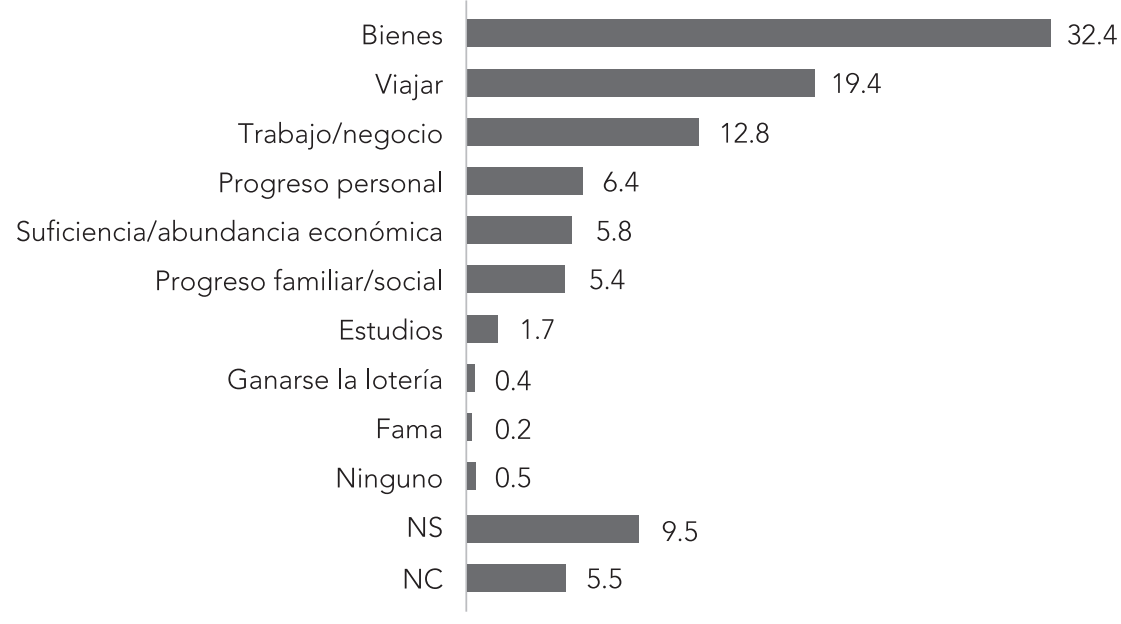

Fuente: Encuesta Nacional de Percepciones Sociales de los Juegos de Azar en México, México, UnAM, Instituto de Investigaciones Jurídicas, Departamento de Investigación Aplicada y Opinión, 2016.

Del análisis sociodemográfico se encontró que entre los encuestados que se inclinaron principalmente por la obtención de bienes destacaron los más jóvenes, de 18 a 24 años, los de nivel escolar de secundaria y los que perciben un ingreso individual menor a un salario mínimo. Por su parte, los que más ambicionan viajar son en mayor medida los adultos de 55 a 64 años y quienes tienen un nivel escolar de bachillerato y licenciatura. Respondieron tener un trabajo o un negocio quienes tienen de 25 a 34 años, un nivel escolar de preparatoria o bachillerato, así como aquellos que perciben más de dos y hasta cuatro salarios mínimos.

Por su parte, destaca que quienes han jugado en el último año indicaron en mayor medida — con respecto a los no jugadores y a la media nacional_ que realizarían el sueño de tener bienes, de viajar, así como de tener un trabajo o negocio. 
Este libro forma parte del acervo de la Biblioteca Jurídica Virtual del Instituto de Investigaciones Jurídicas de la UNAM

\section{CUADRO 2.8}

IMAGINE QUE EN LAS PRÓXIMAS SEMANAS USTED TUVIERA LA OPORTUNIDAD DE REALIZAR ALGUNO DE SUS SUEÑOS, ¿CUÁL SUEÑO REALIZARÍA? (PORCENTAJES)

\begin{tabular}{l|c|c|c}
\hline & $\begin{array}{c}\text { MEDIA } \\
\text { NACIONAL }\end{array}$ & $\begin{array}{c}\text { JUEGA EN EL ÚLTIMO } \\
\text { AÑO }\end{array}$ & $\begin{array}{c}\text { NO JUEGA NINGÚN } \\
\text { JUEGO }\end{array}$ \\
\hline Viajar & 19.4 & 23.4 & 16.3 \\
\hline Progreso personal & 6.4 & 5.2 & 7.1 \\
\hline $\begin{array}{l}\text { Progreso familiar/ } \\
\text { social }\end{array}$ & 5.4 & 5.2 & 5.7 \\
\hline Trabajo/negocio & 12.8 & 13.9 & 11.1 \\
\hline Bienes & 32.5 & 33.4 & 31.5 \\
\hline Estudios & 1.7 & 1.5 & 0.3 \\
\hline Fama & 0.2 & & 6.1 \\
\hline Suficiencia/ & & 5.3 & 0.1 \\
abundancia & 5.8 & 0.7 & 1.0 \\
\hline económica & 0.4 & & 11.5 \\
\hline Ganarse la lotería & 0.4 & 7.4 & 7.4 \\
\hline Ninguno & 9.6 & 4.0 & 0.9 \\
\hline NS & 5.4 & & 0.9 \\
\hline
\end{tabular}

Fuente: Encuesta Nacional de Percepciones Sociales de los Juegos de Azar en México, México, UNAM، Instituto de Investigaciones Jurídicas, Departamento de Investigación Aplicada y Opinión, 2016.

Como se señaló anteriormente, la satisfacción con la vida se relaciona con la posibilidad de cumplir con las aspiraciones y proyectos deseados. Con la finalidad de saber el nivel de confianza que tienen los encuestados de poder realizar sus proyectos a futuro, se les planteó la pregunta ¿Qué tan confiado o desconfiado se siente de que en el futuro va a poder realizar sus proyectos más anhelados?, a lo que seis de cada diez (60.9 por ciento) dijeron que se sienten confiados o muy confiados en que en el futuro van a poder realizar sus proyectos más anhelados, mientras que más de uno de cada diez (14.7 por ciento) señaló que se siente desconfiado o muy desconfiado al respecto; por su parte, son más de dos de cada diez (22.4 por ciento) los que no se sienten ni confiados ni desconfiados (véase gráfica 2.12). 
Este libro forma parte del acervo de la Biblioteca Jurídica Virtual del Instituto de Investigaciones Jurídicas de la UNAM

GRÁFICA 2.12

¿QUÉ TAN CONFIADO O DESCONFIADO SE SIENTE QUE EN EL FUTURO

VA A PODER REALIZAR SUS PROYECTOS MÁS ANHELADOS?

(PORCENTAJES)

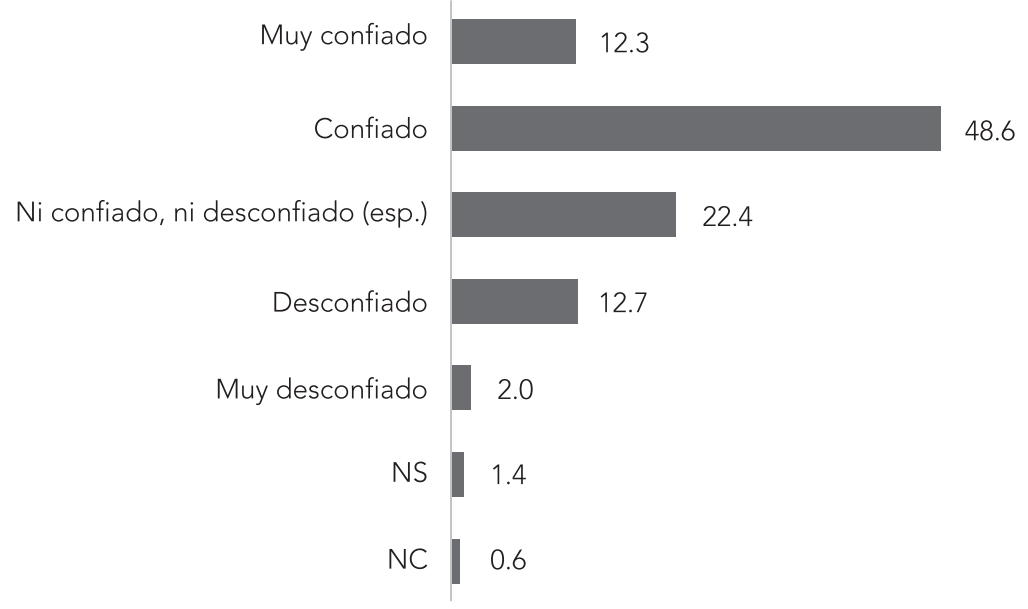

Fuente: Encuesta Nacional de Percepciones Sociales de los Juegos de Azar en México, México, UNAM, Instituto de Investigaciones Jurídicas, Departamento de Investigación Aplicada y Opinión, 2016.

Quienes se sienten más confiados de poder cumplir sus sueños son los jóvenes de 25 a 34 años; de igual forma, conforme aumenta el nivel de escolaridad se incrementa la confianza en la realización de dichos proyectos. Asimismo, destacan aquellos que tienen un ingreso individual menor a un salario mínimo. Entre quienes juegan y entre quienes no, no se observa diferencia significativa en el nivel de confianza y desconfianza en realizar sus proyectos más anhelados.

Igualmente, es posible observar que, en promedio, la mayor parte de los entrevistados tiene confianza en que en el futuro va a poder realizar sus sueños más anhelados (60.9 por ciento). No obstante, sobresalen ligeramente quienes han jugado en el último año, pues señalaron más frecuentemente que se sienten muy confiados o confiados (63.6 por ciento) al respecto que aquellos que no son jugadores (58.6 por ciento). 
Este libro forma parte del acervo de la Biblioteca Jurídica Virtual del Instituto de Investigaciones Jurídicas de la UNAM

CUADRO 2.9

\begin{tabular}{|c|c|c|c|}
\hline \multicolumn{4}{|c|}{$\begin{array}{c}\text { ¿QUÉ TAN CONFIADO O DESCONFIADO SE SIENTE QUE EN EL FUTURO } \\
\text { VA A PODER REALIZAR SUS PROYECTOS MÁS ANHELADOS? } \\
\text { (PORCENTAJES) }\end{array}$} \\
\hline & $\begin{array}{c}\text { MEDIA } \\
\text { NACIONAL }\end{array}$ & $\begin{array}{c}\text { JUEGA EN EL ÚLTIMO } \\
\text { AÑO }\end{array}$ & $\begin{array}{c}\text { NO JUEGA NINGÚN } \\
\text { JUEGO }\end{array}$ \\
\hline Muy confiado & 12.2 & 13.6 & 11.7 \\
\hline Confiado & 48.7 & 50.0 & 46.9 \\
\hline $\begin{array}{l}\text { Ni confiado, ni } \\
\text { desconfiado }\end{array}$ & 22.4 & 22.2 & 22.4 \\
\hline Desconfiado & 12.7 & 12.0 & 13.0 \\
\hline Muy desconfiado & 2.0 & 1.0 & 3.0 \\
\hline NS & 1.5 & 1.1 & 2.0 \\
\hline NC & 0.5 & 0.1 & 1.0 \\
\hline
\end{tabular}

Fuente: Encuesta Nacional de Percepciones Sociales de los Juegos de Azar en México, México, UNAM, Instituto de Investigaciones Jurídicas, Departamento de Investigación Aplicada y Opinión, 2016.

No obstante la seguridad y el optimismo de la mitad de los entrevistados con respecto a la posibilidad de cumplir los proyectos más anhelados, la población ve al futuro en un marco de incertidumbre. Ello representa la imposibilidad de planeación y de previsión.

Para conocer la percepción que tenían los encuestados sobre el futuro se incluyó la pregunta ¿Qué tan de acuerdo o en desacuerdo está usted con la siguiente afirmación? El futuro es tan incierto que es mejor vivir cada día como si fuera el último. Fueron siete de cada diez encuestados (71.7 por ciento) los que estuvieron muy de acuerdo y de acuerdo con que el futuro es incierto. En contraste, fue menos de uno (7.0 por ciento) el que estuvo en desacuerdo o muy en desacuerdo con que el futuro es tan incierto que es mejor vivir cada día como si fuera el último. En el mismo sentido, fueron dos de cada diez los que no estuvieron ni de acuerdo ni en desacuerdo con la frase (véase gráfica 2.13). 
Este libro forma parte del acervo de la Biblioteca Jurídica Virtual del Instituto de Investigaciones Jurídicas de la UNAM

GRÁFICA 2.13

¿QUÉ TAN DE ACUERDO O EN DESACUERDO ESTÁ USTED CON LA SIGUIENTE AFIRMACIÓN? EL FUTURO ES TAN INCIERTO QUE ES MEJOR VIVIR CADA DÍA COMO SI FUERA EL ÚLTIMO

(PORCENTAJES)

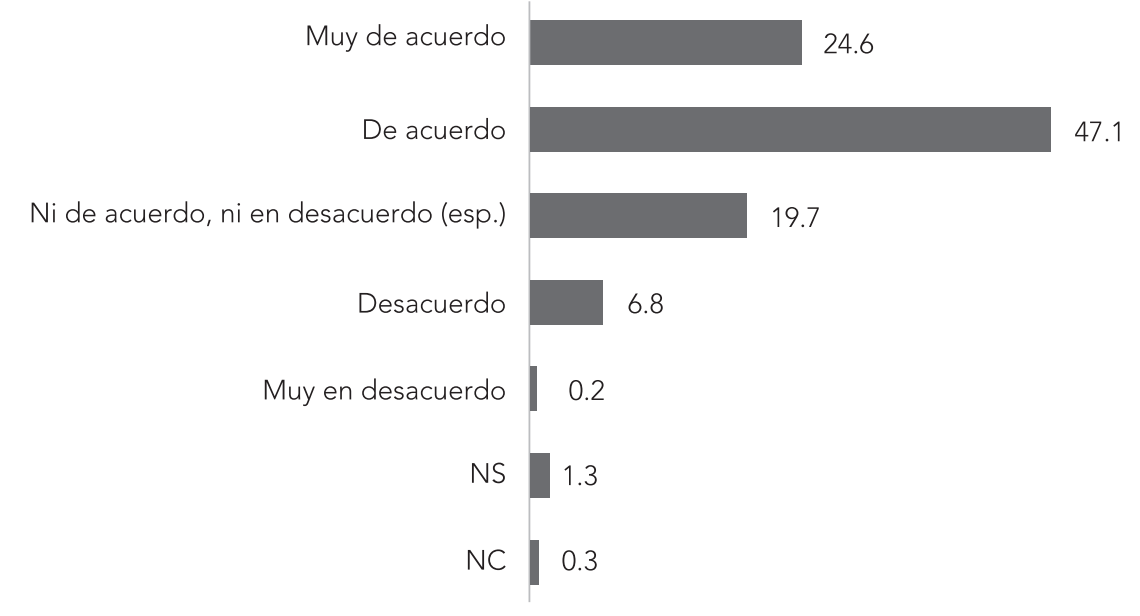

Fuente: Encuesta Nacional de Percepciones Sociales de los Juegos de Azar en México, México, UnAm, Instituto de Investigaciones Jurídicas, Departamento de Investigación Aplicada y Opinión, 2016.

Del análisis sociodemográfico se desprende que quienes estuvieron de acuerdo en mayor medida con la frase El futuro es tan incierto fueron las personas de 65 años y más, aquellos que tienen un nivel escolar de primaria, así como los que tienen los niveles más altos de escolaridad (licenciatura o posgrado), y también quienes perciben un ingreso individual de más de dos a tres salarios mínimos. No existen diferencias significativas entre quienes han jugado en el último año (74.7 por ciento) en contraste con la media nacional (71.7 por ciento); casi por igual consideran estar de acuerdo o muy de acuerdo en que el futuro es tan incierto que es mejor vivir cada día como si fuera el último. 
Este libro forma parte del acervo de la Biblioteca Jurídica Virtual del Instituto de Investigaciones Jurídicas de la UNAM

CUADRO 2.10

¿QUÉ TAN DE ACUERDO O EN DESACUERDO ESTÁ USTED CON LA SIGUIENTE AFIRMACIÓN? EL FUTURO ES TAN INCIERTO QUE ES MEJOR VIVIR CADA DÍA COMO SI FUERA EL ÚLTIMO (PORCENTAJES)

\begin{tabular}{l|c|c|c}
\hline & MEDIA NACIONAL & $\begin{array}{c}\text { JUEGA EN EL ÚLTIMO } \\
\text { AÑO }\end{array}$ & $\begin{array}{c}\text { NO JUEGA NINGÚN } \\
\text { JUEGO }\end{array}$ \\
\hline Muy de acuerdo & 24.6 & 24.8 & 24.9 \\
\hline De acuerdo & 47.1 & 49.9 & 43.8 \\
\hline $\begin{array}{l}\text { Ni de acuerdo, ni } \\
\text { en desacuerdo }\end{array}$ & 19.7 & 18.3 & 20.6 \\
\hline Desacuerdo & 6.8 & 4.8 & 8.9 \\
\hline Muy en desacuerdo & 0.2 & 0.2 & 0.2 \\
\hline NS & 1.3 & 1.8 & 1.0 \\
\hline NC & 0.3 & 0.2 & 0.6 \\
\hline
\end{tabular}

Fuente: Encuesta Nacional de Percepciones Sociales de los Juegos de Azar en México, México, UNAM, Instituto de Investigaciones Jurídicas, Departamento de Investigación Aplicada y Opinión, 2016.

De acuerdo con los cruces, son los jugadores quienes se encuentran más de acuerdo con que el futuro es incierto (74.7 por ciento), pues el acuerdo por parte de los no jugadores (68.7 por ciento) fue ligeramente menor (véase cuadro 2.10).

\section{EL SIGNIFICADO DEL ÉXITO}

La idea del éxito es muy elusiva, ya que existen tantas vivencias y concepciones del éxito como personas, pero ser exitoso, sentirse como tal o no, es algo con lo que se convive diariamente en los diversos ámbitos de la vida: la escuela, el trabajo, la pareja, la familia. Existen muchas clases de éxitos. Hay un éxito cotidiano, un éxito futuro, experiencias personales que se relacionan con sentirse más o menos plenos con ellas, de cumplimiento, en las que se cumple con algo o con alguien.

La idea del éxito está cultural, social e históricamente construida, y combina estos elementos con otros de carácter individual e íntimo, mediados 
Este libro forma parte del acervo de la Biblioteca Jurídica Virtual del Instituto de Investigaciones Jurídicas de la UNAM

también por el género y la edad. Si bien las discusiones sobre el éxito se inician en el campo de la psicología, hoy son el foco de disciplinas tan diversas como los estudios de mercadotecnia o el budismo Zen. No obstante, es un tema que ha sido poco tratado en estudios sociales, culturales o políticos.

Con el propósito de indagar los significados diversos del éxito en la vida de los entrevistados se planteó una pregunta abierta: ¿Para usted qué significa tener éxito en su vida? Los resultados conjugan los aspectos personales de superación y de cumplimiento de objetivos con aspectos económicos y materiales. En la percepción y vivencias del éxito entran en juego elementos como el dinero, los bienes materiales, el trabajo, los afectos y la persona.

Asimismo, para conocer las principales condiciones que los entrevistados consideraban más importantes para tener éxito, se preguntó: De las siguientes condiciones, ¿cuál considera que es más importante para tener éxito en la vida?, a lo que cuatro de cada diez respondieron que trabajar duro, mientras que un cuarto de los encuestados indicó que tener una buena educación, y poco más de uno de cada diez dijo que tener buenas conexiones y contactos. Menos de 10 por ciento indicó que para tener éxito en la vida era importante contar con una familia unida, nacer en una familia con dinero y tener buena suerte (véase gráfica 2.14).

Entre los entrevistados que mencionaron en primer lugar la opción trabajar duro destacan: los mayores de 65 años y más, los de mayor escolaridad y los de otra religión. Entre quienes eligieron en primer lugar tener una buena educación se encuentran principalmente las mujeres y los jóvenes entre los 18 y 34 años, quienes cuentan con altos niveles de escolaridad y en el noreste y occidente del país.

Ahora bien, para la opción tener buenas conexiones y contactos en primer lugar, destacan los más jóvenes, de 18 a 24 años, y los de 45 a 54 años de edad, así como quienes tienen más altos niveles de escolaridad y habitan en el centro del país. Consideran a la suerte como factor para tener éxito principalmente los varones, los entrevistados entre los 25 y 34 años de edad y quienes viven en el norte del país. Para la opción la suerte como primera mención se observa una tendencia en la que conforme aumenta la escolaridad, disminuye el porcentaje de respuesta de quienes se inclinan por dicha opción. 
Este libro forma parte del acervo de la Biblioteca Jurídica Virtual del Instituto de Investigaciones Jurídicas de la UNAM

GRÁFICA 2.14

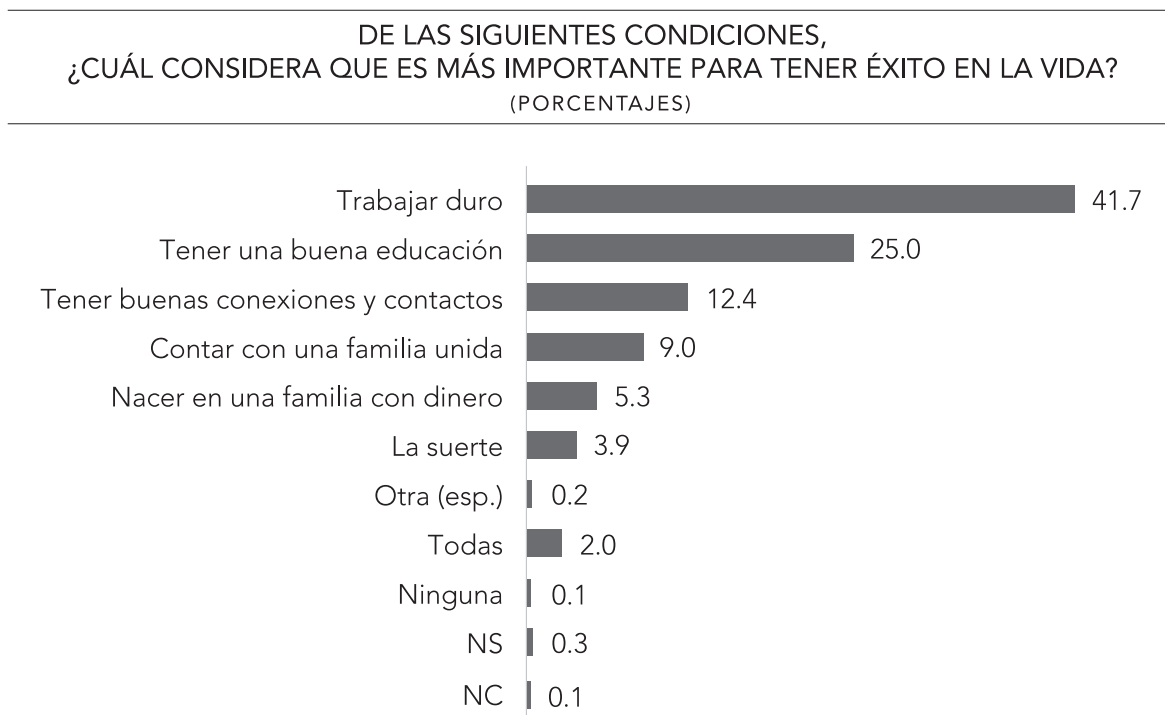

Fuente: Encuesta Nacional de Percepciones Sociales de los Juegos de Azar en México, México, UNAM, Instituto de Investigaciones Jurídicas, Departamento de Investigación Aplicada y Opinión, 2016.

Nacer en una familia con dinero fue la opción mencionada en mayor medida por las personas de 45 a 54 años y los de 64 años y más, quienes no tienen ninguna escolaridad, los entrevistados con bajos niveles de ingreso individual y familiar, y los que habitan en el occidente y el sureste del país. Finalmente, mencionaron en primer lugar contar con una familia unida principalmente las mujeres, las personas entre los 45 y 64 años de edad, sin escolaridad o con escolaridad de primaria, con los menores niveles de ingreso individual y quienes tienen los niveles más altos de ingreso familiar, así como en las regiones noreste, noroeste y sureste del país.

Al efectuar un cruce entre los resultados de la pregunta relativa a los factores para tener éxito en la vida de acuerdo con la práctica de algún juego de azar, encontramos que quienes han jugado en el último año se ubican por debajo de la media nacional y de quienes no han practicado ningún juego por lo que respecta a considerar al trabajo duro como el principal factor para tener éxito en la vida. Igualmente, quienes han jugado en el último año se ubican por debajo del promedio nacional y de los no jugadores 
Este libro forma parte del acervo de la Biblioteca Jurídica Virtual del Instituto de Investigaciones Jurídicas de la UNAM

en lo relativo a tener una buena educación o contar con una familia unida como recursos que conducen al éxito (véase cuadro 2.11).

\section{CUADRO 2.11}

DE LAS SIGUIENTES CONDICIONES,
¿CUÁL CONSIDERA QUE ES MÁS IMPORTANTE PARA TENER ÉXITO EN LA VIDA? (PORCENTAJES)

\begin{tabular}{l|c|c|c}
\hline & $\begin{array}{c}\text { MEDIA } \\
\text { NACIONAL }\end{array}$ & $\begin{array}{c}\text { JUEGA EN EL ÚLTIMO } \\
\text { AÑO }\end{array}$ & $\begin{array}{c}\text { NO JUEGA NINGÚN } \\
\text { JUEGO }\end{array}$ \\
\hline Trabajar duro & 41.7 & 38.4 & 44.7 \\
\hline $\begin{array}{l}\text { Tener una buena } \\
\text { educación }\end{array}$ & 25.0 & 24.4 & 25.6 \\
\hline $\begin{array}{l}\text { Tener buenas } \\
\text { conexiones y } \\
\text { contactos }\end{array}$ & 12.4 & 16.2 & 8.8 \\
\hline $\begin{array}{l}\text { Contar con una } \\
\text { familia unida }\end{array}$ & 9.0 & 7.6 & 10.3 \\
\hline $\begin{array}{l}\text { Nacer en una familia } \\
\text { con dinero }\end{array}$ & 5.3 & 5.0 & 5.5 \\
\hline La suerte & 3.9 & 5.7 & 2.2 \\
\hline Otra & 0.2 & 0.0 & 0.5 \\
\hline Todas & 2.0 & 2.0 & 2.0 \\
\hline Ninguna & 0.1 & 0.3 & 0.0 \\
\hline NS & 0.3 & 0.3 & 0.2 \\
\hline NC & 0.1 & 0.0 & 0.1 \\
\hline
\end{tabular}

Fuente: Encuesta Nacional de Percepciones Sociales de los Juegos de Azar en México, México, UNAM, Instituto de Investigaciones Jurídicas, Departamento de Investigación Aplicada y Opinión, 2016.

En contraste, la respuesta tener buenas conexiones y contactos obtuvo entre los jugadores porcentajes más elevados que la media nacional y prácticamente dobla los porcentajes obtenidos para los no jugadores. Igualmente, son los jugadores quienes consideran en mayor medida a la suerte como elemento que conduce al éxito. Para la opción nacer en una familia con dinero los jugadores se ubican en la media nacional. 
Este libro forma parte del acervo de la Biblioteca Jurídica Virtual del Instituto de Investigaciones Jurídicas de la UNAM

\section{AISLAMIENTO SOCIAL Y EMOCIONAL}

Cuando Emile Durkheim definió la naturaleza de los hechos sociales en Las reglas del método sociológico habló de "modos de actuar, de pensar y de sentir, exteriores al individuo, y que están dotados de un poder de coerción en virtud del cual se imponen a él" (Durkheim, 1980). Al mismo tiempo, afirmó de forma explícita que "no somos solamente seres racionales, somos también criaturas emocionales", señalando que las acciones morales de las personas están fundamentalmente enraizadas en sus "lazos emocionales con grupos sociales particulares" (Durkheim, 2002).

Max Weber también estaba convencido de que la sociología tenía que enfocar necesariamente a las emociones para poder entender los motivos de lo que denominaba la acción social, una acción social con sentido. Al definir esta acción, la interpretación del sentido sugiere que una estrategia metodológica podría ser lo que denominó "la empatía emocional", ya que la "precisión emocional o apreciativa se obtiene cuando a través de la participación empática se puede obtener adecuadamente el contexto emocional en el cual una acción tuvo lugar" (Weber, 1998).

Con una larga tradición en el pensamiento filosófico y en otras disciplinas, se pone de relieve la importancia de la dimensión emocional en el estudio y la comprensión de los fenómenos políticos y sociales, las características de la adhesión del individuo a su comunidad y de los sentimientos de pertenencia o distanciamiento, individuales y colectivos, que moldean las relaciones político-sociales. Hoy, la teoría defiende la existencia de dos tipos de sentido o significado que, aunque convergentes, también son distintos: el formal y el afectivo. Los dos son necesarios para que la vida social sea posible:

...el significado entendido en términos del ordenamiento de las referencias puede ser relacionado con ambos, la inteligibilidad y el involucramiento. El significado formal explica las relaciones dentro de un todo, haciendo así algo inteligible, mientras que lo que podría ser llamado significado afectivo se relaciona con el involucramiento que una persona tiene con un objeto o evento, esto es, qué tanto le importa (Barbelet, 2002). 
Este libro forma parte del acervo de la Biblioteca Jurídica Virtual del Instituto de Investigaciones Jurídicas de la UNAM

El sociólogo Thomas Scheff estableció que los valores son creencias con carga emocional, y señala que las emociones son una fuerza poderosa en la estructura y el cambio de las sociedades (Scheff, 1990). Esta propuesta conduce a pensar que el significado de los objetos, cosas, eventos y personas no es una propiedad intrínseca de tales objetos, cosas, eventos y personas, sino de las relaciones que se establecen con ellos, hasta llegar a los sentimientos como la reflexión cognitiva de las emociones y a la vinculación de las emociones con las actitudes, los valores, las decisiones y la acción. ${ }^{6}$

En esta encuesta se indaga sobre los sentimientos, porque se pone de relieve el lugar que ocupan los afectos en la sociabilidad que, a través de la percepción, otorgan sentido a la actividad individual e incluso a la acción colectiva en su conjunto.?

Durante la última década, los esfuerzos por analizar la soledad se han incrementado considerablemente. Ha sido y continúa siendo un tema difícil de conceptualizar y medir, a pesar de que se han desarrollado escalas y modelos desde la década de los años setenta. La soledad se ha definido como aislamiento emocional. Generalmente se concibe como formada por dos elementos principales: el aislamiento social y el aislamiento emocional (Weiss, 1973). Para intentar una aproximación inicial a este campo, se indagó sobre el entorno social y emocional de los encuestados con la pregunta: Ahora, pensando en sus relaciones personales, por favor dígame qué tanto se siente... cercano a otras personas; parte de un grupo de amigos; que le hace falta compañía. Fueron prácticamente ocho de cada diez entrevistados (79.3 por ciento) los que se sienten mucho o algo cercanos a otras personas, mientras que más de cinco de cada diez (56.3 por ciento) se sienten parte de un grupo de amigos, y casi siete de cada diez (66.5 por ciento) dijeron sentir poco o nada que les hace falta compañía (véase cuadro 2.12).

El neurobiólogo portugués Antonio Damasio estableció la distinción entre los términos: emociones y sentimientos. Las emociones son cambios en el estado del cuerpo, controlado por el sistema cerebral, que responden a estímulos relevantes, pertinentes o emocionalmente competentes, provocadores de la emoción. Los sentimientos se entienden como la conciencia de la experiencia de esos cambios, como la percepción, idea o pensamiento de un estado particular del cuerpo. Los sentimientos traducen el estado de vida en lenguaje de la mente. Son pensamientos específicos, no cualesquiera, que representan el cuerpo en un proceso reactivo. El paso de la emoción al sentimiento es inmediato y de ahí su empleo como sinónimos (Damasio, 2014). 
Este libro forma parte del acervo de la Biblioteca Jurídica Virtual del Instituto de Investigaciones Jurídicas de la UNAM www.juridicas.unam.mx

CUADRO 2.12

\section{AHORA, PENSANDO EN SUS RELACIONES PERSONALES, POR FAVOR DÍGAME QUÉ TANTO SE SIENTE...} (PORCENTAJES)

\begin{tabular}{l|c|c|c|c|c|c}
\hline & MUCHO & ALGO & POCO & NADA & NS & NC \\
\hline $\begin{array}{l}\text { Cercano a otras } \\
\text { personas }\end{array}$ & 40.3 & 39.0 & 13.1 & 5.2 & 0.4 & 2.0 \\
\hline $\begin{array}{l}\text { Parte de un grupo } \\
\text { de amigos }\end{array}$ & 22.5 & 33.8 & 22.9 & 16.1 & 1.4 & 3.3 \\
\hline $\begin{array}{l}\text { Que le hace falta } \\
\text { compañía }\end{array}$ & 8.8 & 20.1 & 32.5 & 34.0 & 1.3 & 3.3 \\
\hline
\end{tabular}

Fuente: Encuesta Nacional de Percepciones Sociales de los Juegos de Azar en México, México, UNAM, Instituto de Investigaciones Jurídicas, Departamento de Investigación Aplicada y Opinión, 2016.

Del análisis sociodemográfico destaca que quienes más se sienten cercanos a otras personas son aquellos que tienen el nivel de estudios más alto, así como los que perciben más de cuatro a cinco salarios mínimos. Los que más se sienten parte de un grupo de amigos son los más jóvenes y los que tienen el nivel más alto de estudios. Asimismo, entre los que menos sienten que les hace falta compañía son quienes tienen el nivel más alto de escolaridad y aquellos que perciben más de seis a siete salarios mínimos.

Al cruzar esta batería de preguntas con la práctica de un juego de azar se encuentra que quienes han practicado un juego de azar también se sienten más cercanos a otras personas (véase cuadro 2.13).

CUADRO 2.13

\begin{tabular}{l|c|c|c}
\hline \multicolumn{5}{c}{ ¿QUÉ TANTO SE SIENTE...? CERCANO A OTRAS PERSONAS } \\
(PORCENTAJES)
\end{tabular}

Fuente: Encuesta Nacional de Percepciones Sociales de los Juegos de Azar en México, México, UNAM, Instituto de Investigaciones Jurídicas, Departamento de Investigación Aplicada y Opinión, 2016. 
Este libro forma parte del acervo de la Biblioteca Jurídica Virtual del Instituto de Investigaciones Jurídicas de la UNAM

Con respecto a sentirse mucho o algo cercanos a otras personas, lo señalaron con porcentajes similares a la media nacional (79.3 por ciento); no obstante, fueron los jugadores quienes dijeron más frecuentemente sentirse así (81.6 por ciento), frente al 76.6 por ciento de los no jugadores que dio la misma respuesta.

La pregunta diseñada para recoger el sentimiento de aislamiento emocional muestra que menos de tres de cada diez personas dijeron sentir que les hace falta compañía. Se observa al respecto que, al contrario de lo que generalmente se piensa, los entrevistados que sienten que les hace falta compañía tienden a jugar en menor medida (véase cuadro 2.14).

\section{CUADRO 2.14}

¿QUÉ TANTO SE SIENTE...? QUE LE HACE FALTA COMPAÑÍA (PORCENTAJES)

\begin{tabular}{l|c|c|c}
\hline & $\begin{array}{c}\text { MEDIA } \\
\text { NACIONAL }\end{array}$ & $\begin{array}{c}\text { JUEGA EN EL ÚLTIMO } \\
\text { AÑO }\end{array}$ & $\begin{array}{c}\text { NO JUEGA NINGÚN } \\
\text { JUEGO }\end{array}$ \\
\hline Mucho & 8.8 & 7.9 & 10.0 \\
\hline Algo & 20.1 & 19.1 & 21.7 \\
\hline Poco & 32.5 & 37.5 & 27.9 \\
\hline Nada & 34.1 & 32.3 & 34.7 \\
\hline NS & 1.3 & 0.8 & 1.3 \\
\hline NC & 3.2 & 2.4 & 4.4 \\
\hline
\end{tabular}

Fuente: Encuesta Nacional de Percepciones Sociales de los Juegos de Azar en México, México, UNAM, Instituto de Investigaciones Jurídicas, Departamento de Investigación Aplicada y Opinión, 2016.

Fueron los no jugadores quienes dijeron más frecuentemente que sienten mucho o algo que les hace falta compañía (31.7 por ciento), frente al 27.0 por ciento de los jugadores y el 28.9 por ciento de la media nacional.

Los mexicanos entrevistados son gregarios: más de la mitad dijo sentirse parte de un grupo de amigos. Como es posible observar, las personas que se sienten parte de un grupo de amigos también tienden a practicar juegos de azar. 
Este libro forma parte del acervo de la Biblioteca Jurídica Virtual del Instituto de Investigaciones Jurídicas de la UNAM

CUADRO 2.15

¿QUÉ TANTO SE SIENTE...? PARTE DE UN GRUPO DE AMIGOS (PORCENTAJES)

\begin{tabular}{l|c|c|c}
\hline & MEDIA NACIONAL & JUEGA EN EL ÚLTIMO AÑO & NO JUEGA NINGÚN JUEGO \\
\hline Mucho & 22.5 & 24.5 & 20.9 \\
\hline Algo & 33.9 & 35.3 & 30.9 \\
\hline Poco & 22.9 & 23.1 & 24.4 \\
\hline Nada & 16.1 & 13.1 & 18.3 \\
\hline NS & 1.4 & 1.5 & 1.4 \\
\hline NC & 3.2 & 2.5 & 4.1 \\
\hline
\end{tabular}

Fuente: Encuesta Nacional de Percepciones Sociales de los Juegos de Azar en México, México, UNAM, Instituto de Investigaciones Jurídicas, Departamento de Investigación Aplicada y Opinión, 2016.

Finalmente, fueron los jugadores quienes indicaron en mayor medida que se sienten parte de un grupo de amigos (59.8 por ciento), frente a la media nacional (56.4 por ciento) y frente al 51.8 por ciento, de quienes no practican ningún juego.

\section{CONCLUSIONES}

La lectura en conjunto de los datos aquí presentados permite observar tres facetas de los mexicanos entrevistados en relación con las prácticas de juegos de azar:

En primer lugar, pone de relieve la importancia de la religión y las creencias y prácticas tradicionales en la vida de las personas y el aumento de la religiosidad en los jóvenes, particularmente en diversas denominaciones religiosas no católicas.

En segundo lugar, la información analizada pone en entredicho lugares comunes en las percepciones más generalizadas sobre la práctica de los juegos de azar. Las motivaciones de los jugadores que practican juegos de azar no son el aislamiento o la soledad —se juega en compañía, con los amigos o familiares - o la insatisfacción con la vida.

En tercer lugar, el trabajo constituye un elemento básico en la vida y los valores de los mexicanos. Si bien la creencia en la suerte está muy extendida, el trabajo duro se considera la condición esencial para tener éxito, para enfrentar el futuro y cumplir los sueños. Incluso entre las asociaciones para la 
Este libro forma parte del acervo de la Biblioteca Jurídica Virtual del Instituto de Investigaciones Jurídicas de la UNAM

palabra suerte aparece el trabajo. Trabajo y suerte no constituyen elementos separados.

\section{LAS CREENCIAS RELIGIOSAS EN MÉXICO}

México es una sociedad de una gran diversidad y complejidad en materia religiosa. El hecho de que las generaciones más jóvenes sean hoy igual o incluso más religiosas que los grupos etarios de más edad es indicativo de una tendencia hacia una renovación de valores religiosos más que una reducción de esta dimensión. Pero el posible aumento de la religiosidad no sólo se explica por factores demográficos, sino principalmente por elementos valorativos y culturales. Hoy en día, la población que se identifica a sí misma como católica sigue siendo mayoritaria; sin embargo, existe una tendencia al decrecimiento del porcentaje de católicos en el país:

- Los católicos y los ateos tenderían a participar en mayor medida en juegos de azar que los miembros de otras denominaciones religiosas.

\section{CREENCIAS Y PRÁCTICAS TRADICIONALES}

La suerte se asocia principalmente con el dinero, la fortuna y las ganancias, pero también con el trabajo. Al contrario de las asociaciones para la palabra azar, que tienen una connotación negativa —el hecho que suceda algo no deseado con consecuencias negativas-, para los entrevistados la suerte es de signo positivo. Su asociación con los juegos de azar queda de relieve; en el habla cotidiana de México "sacarse la lotería" es una expresión de buena fortuna que se aplica a todo tipo de situaciones:

- Mientras más arraigadas están las creencias tradicionales y las supersticiones, crece la disposición a participar en los juegos de azar. Así, las personas que creen en la suerte dijeron en mayor medida haber jugado un juego de azar en el último año. En contraste, quienes no creen en la suerte señalaron con porcentajes más altos no jugar ningún juego.

- La mayoría de los entrevistados cree en la suerte (80.9 por ciento). Asimismo, fueron más de seis de cada diez los que indicaron que 
Este libro forma parte del acervo de la Biblioteca Jurídica Virtual del Instituto de Investigaciones Jurídicas de la UNAM

creen o creen en parte en el destino (69.7 por ciento) y en el infierno (65.0 por ciento), mientras que más de cuatro de cada diez sujetos seleccionados para el estudio dijeron que creen o lo hacen en parte en el mal de ojo (46.6 por ciento). Únicamente cerca de cuatro de cada diez (37.5 por ciento) señalaron que creen en los horóscopos.

De los resultados del índice de superstición se desprende que si bien las supersticiones y creencias tradicionales están extendidas en la sociedad mexicana, no se sitúan en los extremos. Más de la mitad de la población (53.8 por ciento) se ubica en todo caso en los niveles bajo y medio-bajo. Y se manifiestan por igual entre las poblaciones que dijeron practicar juegos de azar y entre quienes no los practican:

- La mitad de los seleccionados para el estudio señaló que evita o evita en parte pasar por debajo de una escalera (52.5 por ciento), así como romper un espejo (51.9 por ciento) y derramar la sal (50.3 por ciento). Se observa una tendencia general en las mujeres, los mayores de 65 años y más, y aquellos sin ninguna escolaridad, que son quienes mencionaron en mayor medida la celebración de ciertas prácticas y rituales.

- Por lo que respecta a la utilización de amuletos, menos difundida entre la población entrevistada, se advierte su fuerte presencia en la población de quienes practican algún juego de azar. Únicamente la cuarta parte de los encuestados dijo contar con un amuleto, mientras que siete de cada diez respondieron no tener dicho objeto.

\section{BIENESTAR SUBJETIVO}

Mucho se ha especulado sobre la relación entre el bienestar subjetivo y la práctica de los juegos de azar. Se ha convertido en un lugar común —principalmente desde algunas visiones - señalar que quienes juegan lo hacen por un vacío existencial: la insatisfacción con su vida o la infelicidad. Los resultados muestran que:

- La satisfacción con la vida no es un elemento relevante para que las personas practiquen juegos de azar. La gran mayoría de los entrevista- 
Este libro forma parte del acervo de la Biblioteca Jurídica Virtual del Instituto de Investigaciones Jurídicas de la UNAM

dos dijo estar satisfecho con su vida, por igual entre quienes practican juegos de azar y entre quienes no practican ningún juego.

- Las personas que no juegan ningún juego señalaron en mayor medida que pueden decidir sobre su futuro, en contraste con la media nacional y con quienes han jugado alguna vez en el último año.

- Seis de cada diez personas consideran que una buena posición en el trabajo depende del esfuerzo de cada persona, mientras que una cuarta parte indicó que son más importantes los contactos con los que se cuenta. Quienes han jugado en el último año consideraron que son más relevantes los contactos que se tengan (30.1 por ciento) sobre la media nacional y casi un diez por ciento más que quienes no juegan ningún juego (21.6 por ciento).

- Quienes han jugado en el último año indicaron en mayor medida — con respecto a los no jugadores y a la media nacional- que realizarían el sueño de tener bienes, de viajar, así como de tener un trabajo o negocio.

- Fueron siete de cada diez encuestados (71.7 por ciento) los que estuvieron muy de acuerdo y de acuerdo con que el futuro es tan incierto que es mejor vivir cada día como si fuera el último.

- Se considera que lo más importante para tener éxito en la vida es trabajar duro (cuatro de cada diez), mientras que un cuarto de los encuestados indicó que tener una buena educación, y poco más de uno de cada diez dijo que tener buenas conexiones y contactos. Menos del 10 por ciento indicó que para tener éxito en la vida era importante contar con una familia unida, nacer en una familia con dinero y tener buena suerte.

- Fueron ocho de cada diez entrevistados (79.3 por ciento) los que se sienten mucho o algo cercanos a otras personas, mientras que más de cinco de cada diez (56.3 por ciento) se sienten parte de un grupo de amigos, y casi siete de cada diez (66.5 por ciento) dijeron sentir poco o nada que les hace falta compañía. La pregunta diseñada para recoger el sentimiento de aislamiento emocional muestra que menos de tres de cada diez personas dijeron sentir que les hace falta compañía. Se observa al respecto que, al contrario de lo que generalmente se piensa, los entrevistados que sienten que les hace falta compañía tienden a jugar en menor medida. 
Este libro forma parte del acervo de la Biblioteca Jurídica Virtual del Instituto de Investigaciones Jurídicas de la UNAM

\section{CAPÍTULO 3}

\section{EL JUEGO COMO ACTIVIDAD SOCIAL}

\section{INTRODUCCIÓN}

Después de la revisión histórica, así como de las creencias y de los elementos subjetivos de los juegos de azar en el país, en este capítulo se presenta el análisis de los resultados de la primera Encuesta Nacional de Percepciones Sociales de los Juegos de Azar en México relativos al juego como actividad social, su contexto nacional y personal, así como las prácticas, actitudes, experiencias de participación y representaciones más recurridas.

El juego, a lo largo de la historia de la humanidad, ha sido una actividad articuladora de comunidades, especialmente en lo referente a prácticas, hábitos y formas de construir imaginarios y futuro. Durante la infancia es parte fundamental del desarrollo psicosocial y motriz, al representar microcosmos de estructuras y afirmación del entorno. Por su parte, el azar frecuentemente es acompañado de un halo velado, vinculado a creencias, poderes, inercias, dogmas, destino, designios, sujetos y un sinnúmero de factores alejados irracionalmente de la probabilidad.

Aunque algunos juegos de azar se desarrollan en solitario, éstos siempre se encuentran insertos en contextos comunitarios locales, nacionales e in- 
Este libro forma parte del acervo de la Biblioteca Jurídica Virtual del Instituto de Investigaciones Jurídicas de la UNAM

cluso internacionales, a través de distintos agentes de socialización que dotan de sentido a la incertidumbre, al riesgo, al ganar o perder. Por su parte, los juegos de azar se pueden desarrollar tanto entre amigos y compañeros en espacios privados como en lugares públicos: palenques, casinos, hipódromos, sitios de Internet, etcétera. Si bien los juegos de azar son frecuentemente relacionados con numerosos estigmas, como el riesgo del juego problemático o el lavado de dinero, igualmente refuerzan espacios de convivencia entre pares.

A continuación se presentan los resultados de la encuesta con respecto a la evaluación de la situación económica y política del país, la valoración personal de su presente y futuro económico, el uso del tiempo libre, los hábitos de participar en apuestas, rifas y sorteos, así como las actitudes y experiencias de participación en juegos de azar. Finalmente, se analizan las prácticas y representaciones vinculadas a los casinos, espacios siempre polémicos por su cuestionado impacto social, psicológico y económico, tanto en ciudades y países donde han sido regulados y permitidos, como en aquellos donde han sido prohibidos. En suma, se analizan las variables que permiten entender los juegos de azar en su contexto económico, político y social, con sus prácticas, imaginarios y principales representaciones recreadas por la sociedad mexicana en 2016.

\section{EVALUACIÓN ECONÓMICA Y POLÍTICA DEL PAÍS}

La evaluación económica y política del país es el punto de partida de la encuesta, pues además de rastrear las valoraciones de estas temáticas, también permite conocer la posible influencia de la situación económica y política en la confianza y la intensidad para participar en juegos de azar. En este sentido, el vínculo entre los juegos de azar y la situación económica y política del país permite trazar lazos entre la valoración del entorno y el grado de certidumbre a participar en juegos que involucran dinero, y las condiciones para cumplir lo establecido entre las partes.

De acuerdo con los resultados de la encuesta, ocho de cada diez personas entrevistadas (80.6 por ciento) señalaron que la situación económica del 
Este libro forma parte del acervo de la Biblioteca Jurídica Virtual del Instituto de Investigaciones Jurídicas de la UNAM

país está igual de mal o peor en relación con el año anterior (véase gráfica 3.1). Es importante mencionar que esta percepción es cercana a la realidad que en las últimas décadas se ha vivido en México en torno a la profunda desigualdad, al estancamiento y al magro crecimiento reflejado por los indicadores macroeconómicos, cuya tendencia se mantuvo en 2015 y 2016 (OCDE, 2017a; INEGI, 2017b). ${ }^{1}$

\section{GRÁFICA 3.1}

COMPARADA CON LA SITUACIÓN ECONÓMICA QUE TENÍA EL PAÍS HACE UN AÑO, ¿CÓMO DIRÍA USTED QUE ES LA SITUACIÓN ECONÓMICA ACTUAL DEL PAÍS: MEJOR O PEOR?

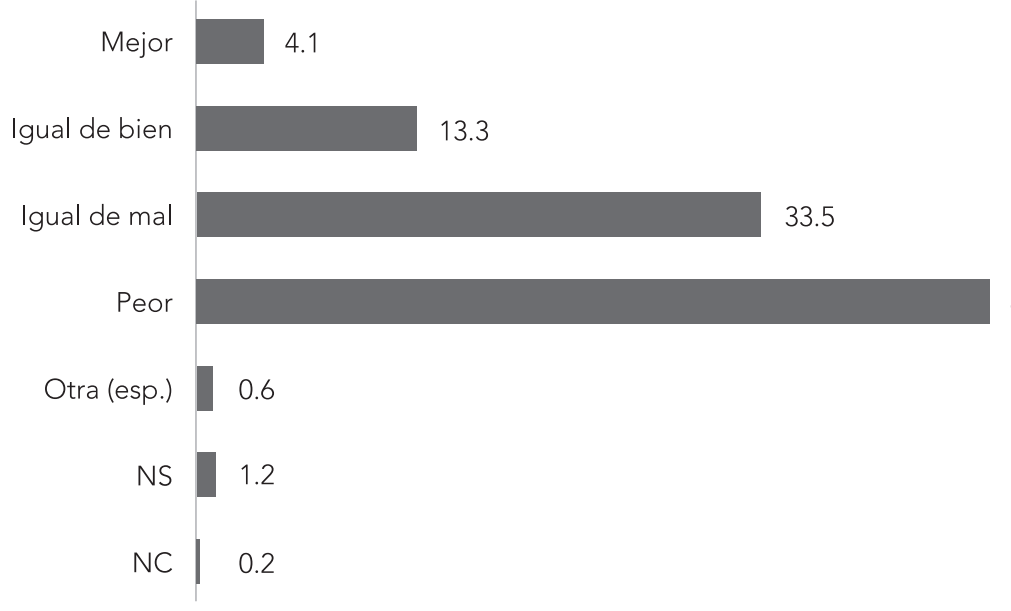

47.1

Fuente: Encuesta Nacional de Percepciones Sociales de los Juegos de Azar en México, México, UNAM, Instituto de Investigaciones Jurídicas, Departamento de Investigación Aplicada y Opinión, 2016.

Las características sociodemográficas permiten observar que los varones son quienes tienen una opinión menos optimista sobre la situación económica del país en 2016, comparada con la del año anterior. Las personas que se encuentran en el grupo de edad de 55 a 64 años y aquellas que únicamente tienen educación primaria también muestran una percepción negativa acerca de la situación económica del país.

1 El crecimiento anual del producto interno bruto en 2015 fue de 2.6 por ciento y en 2016 de 2.3 por ciento respecto al año anterior (INEGI, 2017b). 
Este libro forma parte del acervo de la Biblioteca Jurídica Virtual del Instituto de Investigaciones Jurídicas de la UNAM

Al parecer, la percepción de la situación económica del país no representa un obstáculo para la práctica del juego, dado que de las personas entrevistadas que dijeron que han jugado al menos un juego en el último año, poco menos de ocho de cada diez (77.8 por ciento) consideraron que la situación económica actual del país está igual de mal o peor que la del año pasado, proporción que se encuentra por debajo de la media nacional (80.6 por ciento); mientras que las personas que dijeron que no han jugado en el último año y que consideraron que la situación económica del país está igual de mal o peor representan más de ocho de cada diez (83.2 por ciento) (véase cuadro 3.1).

CUADRO 3.1

¿CÓMO DIRÍA USTED QUE ES LA SITUACIÓN ECONÓMICA ACTUAL DEL PAÍS: MEJOR O PEOR?

(PORCENTAJES)

\begin{tabular}{l|c|c|c}
\hline & $\begin{array}{c}\text { MEDIA } \\
\text { NACIONAL }\end{array}$ & $\begin{array}{c}\text { JUEGA EN EL ÚLTIMO } \\
\text { AÑO }\end{array}$ & $\begin{array}{c}\text { NO JUEGA NINGÚN } \\
\text { JUEGO }\end{array}$ \\
\hline Mejor & 4.1 & 4.1 & 4.1 \\
\hline Igual de bien & 13.3 & 15.7 & 11.0 \\
\hline Igual de mal & 33.5 & 36.0 & 31.1 \\
\hline Peor & 47.1 & 41.9 & 52.1 \\
\hline Otra & 0.6 & 0.4 & 0.7 \\
\hline NS & 1.2 & 1.9 & 0.6 \\
\hline NC & 0.2 & 0.0 & 0.4 \\
\hline
\end{tabular}

Fuente: Encuesta Nacional de Percepciones Sociales de los Juegos de Azar en México, México, UNAM, Instituto de Investigaciones Jurídicas, Departamento de Investigación Aplicada y Opinión, 2016.

En general, las personas tienen pocas expectativas de que en el futuro la situación económica del país mejore, pues si bien es cierto que una cuarta parte de la población entrevistada (24.7 por ciento) dijo que la situación económica del país mejorará o seguirá igual de bien, alrededor de dos terceras partes (65.0 por ciento) señalaron que seguirá igual de mal o que empeorará para el próximo año (véase gráfica 3.2). En este sentido, se observa que las personas de 55 a 64 años y las que tienen educación secundaria son las menos optimistas, pues son quienes en mayor medida dijeron que la si- 
Este libro forma parte del acervo de la Biblioteca Jurídica Virtual del Instituto de Investigaciones Jurídicas de la UNAM

tuación económica del país seguirá igual de mal o empeorará. Por su parte, las personas con ingresos más altos son quienes consideraron que en el futuro la situación económica del país mejorará o seguirá igual de bien.

GRÁFICA 3.2

\section{¿CREE USTED QUE EN EL PRÓXIMO AÑO \\ LA SITUACIÓN ECONÓMICA DEL PAÍS VA A MEJORAR O VA A EMPEORAR?}

(PORCENTAJES)

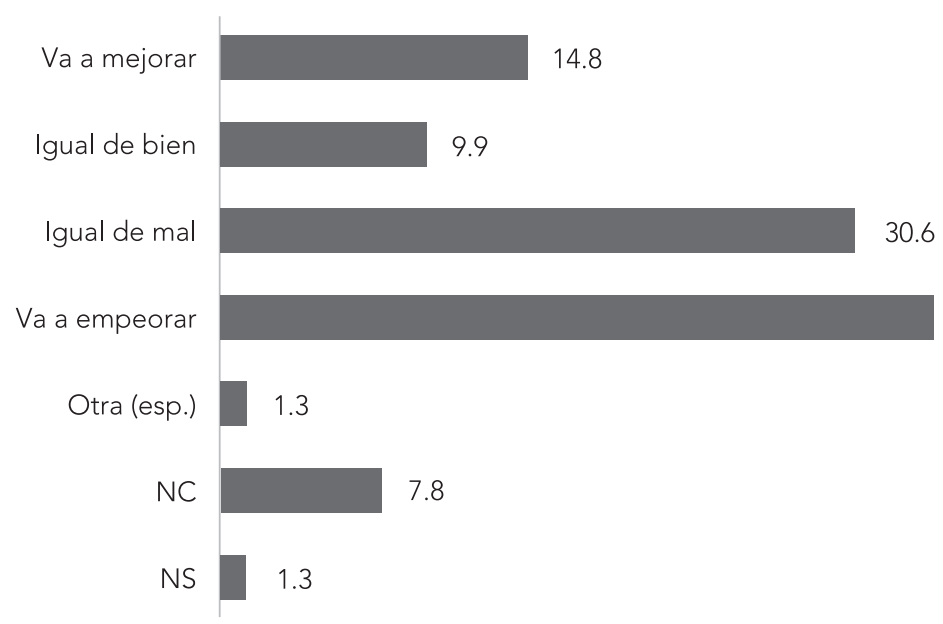

34.3

Fuente: Encuesta Nacional de Percepciones Sociales de los Juegos de Azar en México, México, UnAM, Instituto de Investigaciones Jurídicas, Departamento de Investigación Aplicada y Opinión, 2016.

Asimismo, las personas que han jugado algún juego en el último año se encuentran entre las más optimistas, ya que cerca de tres de cada diez (28.1 por ciento) consideraron que la situación económica del país mejorará o estará igual de bien en el futuro, proporción que se encuentra por encima de la media nacional (24.8 por ciento) y de la proporción de no jugadores, pues estos últimos representan dos de cada diez (21.7 por ciento) (véase cuadro 3.2). 
Este libro forma parte del acervo de la Biblioteca Jurídica Virtual del Instituto de Investigaciones Jurídicas de la UNAM

CUADRO 3.2

\begin{tabular}{l|c|c|c}
\hline \multicolumn{4}{c}{$\begin{array}{c}\text { ¿CREE USTED QUE EN EL PRÓXIMO AÑO LA SITUACIÓN ECONÓMICA } \\
\text { DEL PAÍS VA A MEJORAR O VA A EMPEORAR? } \\
\text { (PORCENTAJES) }\end{array}$} \\
\hline & $\begin{array}{c}\text { MEDIA } \\
\text { NACIONAL }\end{array}$ & $\begin{array}{c}\text { JUEGA EN EL ÚLTIMO } \\
\text { AÑO }\end{array}$ & $\begin{array}{c}\text { NO JUEGA NINGÚN } \\
\text { JUEGO }\end{array}$ \\
\hline Va a mejorar & 14.8 & 16.8 & 13.1 \\
\hline Igual de bien & 9.9 & 11.3 & 8.6 \\
\hline Igual de mal & 30.6 & 31.8 & 29.5 \\
\hline Va a empeorar & 34.3 & 30.6 & 37.8 \\
\hline Otra & 1.3 & 1.0 & 1.6 \\
\hline NC & 7.7 & 7.4 & 7.9 \\
\hline NS & 1.2 & 1.0 & 1.4 \\
\hline
\end{tabular}

Fuente: Encuesta Nacional de Percepciones Sociales de los Juegos de Azar en México, México, UNAM, Instituto de Investigaciones Jurídicas, Departamento de Investigación Aplicada y Opinión, 2016.

La situación política del país también es un asunto complicado para las personas entrevistadas. Los resultados obtenidos permiten observar que poco más de cuatro de cada diez entrevistados (42.9 por ciento) percibieron como preocupante la situación política del país, y una cuarta parte (25.2 por ciento) dijo que es peligrosa. Únicamente uno de cada diez (11.7 por ciento) señaló que la situación política del país es tranquila, y menos de uno de cada diez (8.6 por ciento) dijo que es prometedora y con oportunidades (véase gráfica 3.3). Un mayor porcentaje de varones, de jóvenes de 18 a 24 años y de personas con un nivel de escolaridad de preparatoria o bachillerato percibieron que la situación política del país es preocupante; mientras que los adultos de 45 a 54 años también dijeron con mayor frecuencia que es peligrosa. 
Este libro forma parte del acervo de la Biblioteca Jurídica Virtual del Instituto de Investigaciones Jurídicas de la UNAM

GRÁFICA 3.3

DE LAS SIGUIENTES PALABRAS, ¿CON CUÁL ESTÁ USTED MÁS DE ACUERDO

PARA DESCRIBIR LA SITUACIÓN POLITICA DEL PAÍS?

(PORCENTAJES)

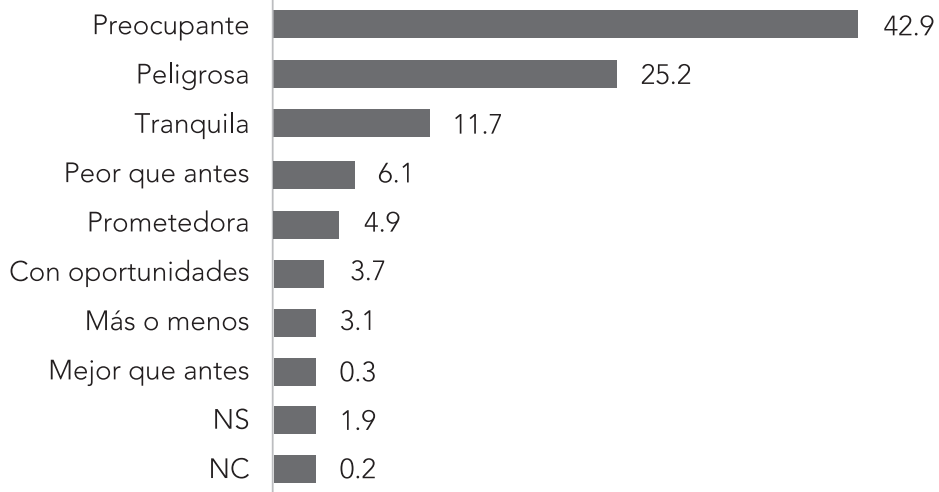

Fuente: Encuesta Nacional de Percepciones Sociales de los Juegos de Azar en México, México, unam, Instituto de Investigaciones Jurídicas, Departamento de Investigación Aplicada y Opinión, 2016.

Por otro lado, la proporción de personas que en el último año han jugado algún juego y que consideraron que la situación del país es preocupante (44.8 por ciento) se encuentra por encima de la media nacional; en tanto que el porcentaje de las personas jugadoras que dijeron que la situación política del país es tranquila (12.6 por ciento) y prometedora y con oportunidades (9.7 por ciento) es ligeramente mayor que la media nacional (véase cuadro 3.3).

Las expectativas que las personas tienen sobre la situación política del país no son tan alentadoras, ya que poco más de seis de cada diez entrevistados (64.4 por ciento) dijeron que para el siguiente año la situación política del país seguirá igual de mal o empeorará (véase gráfica 3.4). Las personas del sexo masculino, los jóvenes de 18 a 24 años, los adultos de 55 a 64 años y las personas con secundaria y con preparatoria o bachillerato son quienes con mayor frecuencia expresaron su pesimismo sobre la futura situación política en el país. 
Este libro forma parte del acervo de la Biblioteca Jurídica Virtual del Instituto de Investigaciones Jurídicas de la UNAM www.juridicas.unam.mx

CUADRO 3.3

\section{DE LAS SIGUIENTES PALABRAS, ¿CON CUÁL ESTÁ USTED MÁS DE ACUERDO PARA DESCRIBIR LA SITUACIÓN POLÍTICA DEL PAÍS?} (PORCENTAJES)

\begin{tabular}{l|c|c|c}
\hline & $\begin{array}{c}\text { MEDIA } \\
\text { NACIONAL }\end{array}$ & $\begin{array}{c}\text { JUEGA EN EL ÚLTIMO } \\
\text { AÑO }\end{array}$ & $\begin{array}{c}\text { NO JUEGA NINGÚN } \\
\text { JUEGO }\end{array}$ \\
\hline Preocupante & 42.9 & 44.8 & 41.1 \\
\hline Peligrosa & 25.2 & 23.3 & 27.0 \\
\hline Tranquila & 11.7 & 12.6 & 10.9 \\
\hline Peor que antes & 6.1 & 4.7 & 7.3 \\
\hline Prometedora & 4.9 & 5.5 & 4.4 \\
\hline Con oportunidades & 3.7 & 4.2 & 3.3 \\
\hline Más o menos & 3.1 & 2.7 & 3.4 \\
\hline Mejor que antes & 0.3 & 0.2 & 0.4 \\
\hline NS & 1.9 & 2.0 & 1.8 \\
\hline NC & 0.2 & 0.0 & 0.3 \\
\hline
\end{tabular}

Fuente: Encuesta Nacional de Percepciones Sociales de los Juegos de Azar en México, México, UNAM, Instituto de Investigaciones Jurídicas, Departamento de Investigación Aplicada y Opinión, 2016.

\section{GRÁFICA 3.4}

¿Y CREE USTED QUE EN EL PRÓXIMO AÑO LA SITUACIÓN POLÍTICA DEL PAÍS VA A MEJORAR O VA A EMPEORAR?

(PORCENTAJES)

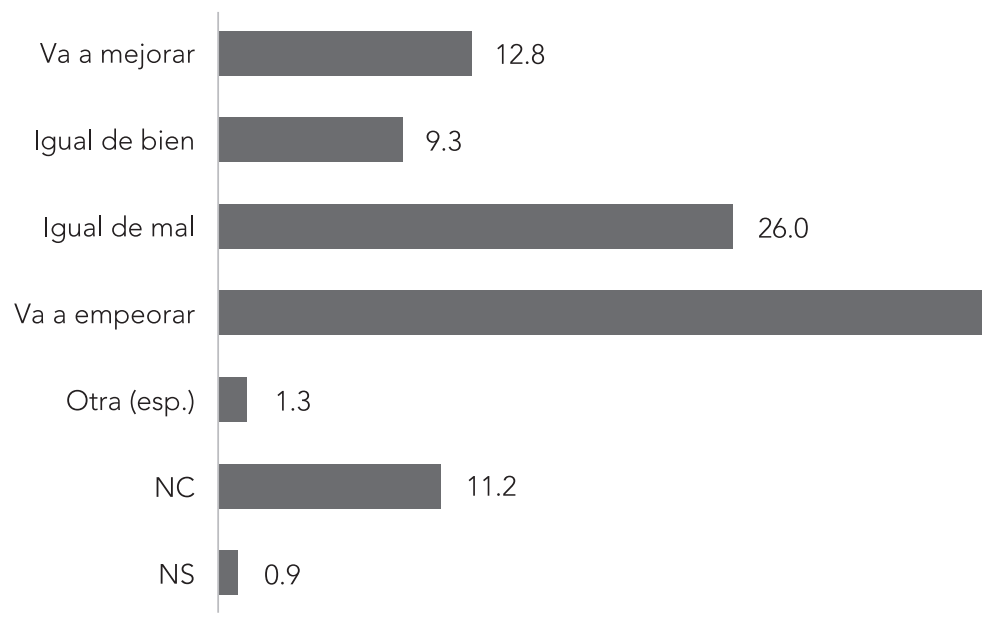

Fuente: Encuesta Nacional de Percepciones Sociales de los Juegos de Azar en México, México, UnAm, Instituto de Investigaciones Jurídicas, Departamento de Investigación Aplicada y Opinión, 2016. 
Este libro forma parte del acervo de la Biblioteca Jurídica Virtual del Instituto de Investigaciones Jurídicas de la UNAM

Las personas que en el último año han jugado algún juego son ligeramente más optimistas, pues casi una cuarta parte de la población jugadora (24.5 por ciento) dijo que la situación política del país en el futuro mejorará o seguirá igual de bien. Esta proporción se encuentra dos puntos porcentuales por encima de la media nacional (22.2 por ciento); mientras que las personas que en el último año no han jugado algún juego y que son más optimistas en relación con la situación política del país, únicamente representan dos de cada diez (19.9 por ciento) (véase cuadro 3.4).

CUADRO 3.4

¿Y CREE USTED QUE EN EL PRÓXIMO AÑO LA SITUACIÓN POLÍTICA DEL PAÍS VA A MEJORAR O VA A EMPEORAR? (PORCENTAJES)

\begin{tabular}{l|c|c|c}
\hline & MEDIA NACIONAL & JUEGA EN EL ÚLTIMO AÑO & NO JUEGA NINGÚN JUEGO \\
\hline Va a mejorar & 12.8 & 13.9 & 11.8 \\
\hline Igual de bien & 9.3 & 10.6 & 8.1 \\
\hline Igual de mal & 26.0 & 27.3 & 24.9 \\
\hline Va a empeorar & 38.4 & 35.8 & 40.8 \\
\hline Otra & 1.3 & 0.4 & 2.1 \\
\hline NC & 11.2 & 11.5 & 11.0 \\
\hline NS & 0.9 & 0.5 & 1.3 \\
\hline
\end{tabular}

Fuente: Encuesta Nacional de Percepciones Sociales de los Juegos de Azar en México, México, UNAM, Instituto de Investigaciones Jurídicas, Departamento de Investigación Aplicada y Opinión, 2016.

\section{EVALUACIÓN DE LA SITUACIÓN ECONÓMICA FAMILIAR Y PERSONAL}

En concordancia con la percepción sobre la situación económica del país, los resultados sobre la situación económica personal también son poco optimistas. Alrededor de dos terceras partes de la población entrevistada (66.2 por ciento) dijeron que su situación económica actual está igual de mal o peor en relación con el año pasado (véase gráfica 3.5). Las personas de 55 a 64 años y las que tienen educación primaria mencionaron con mayor frecuencia que su situación económica está igual de mal o peor que hace un año; mientras que las personas con más altos ingresos familiares en mayor medida dijeron que están mejor o igual de bien. 
Este libro forma parte del acervo de la Biblioteca Jurídica Virtual del Instituto de Investigaciones Jurídicas de la UNAM www.juridicas.unam.mx

GRÁFICA 3.5

COMPARADA CON LA SITUACIÓN ECONÓMICA QUE TENÍA USTED HACE UN AÑO, ¿CÓMO DIRÍA QUE ES SU SITUACIÓN ECONÓMICA ACTUAL: MEJOR O PEOR? (PORCENTAJES)

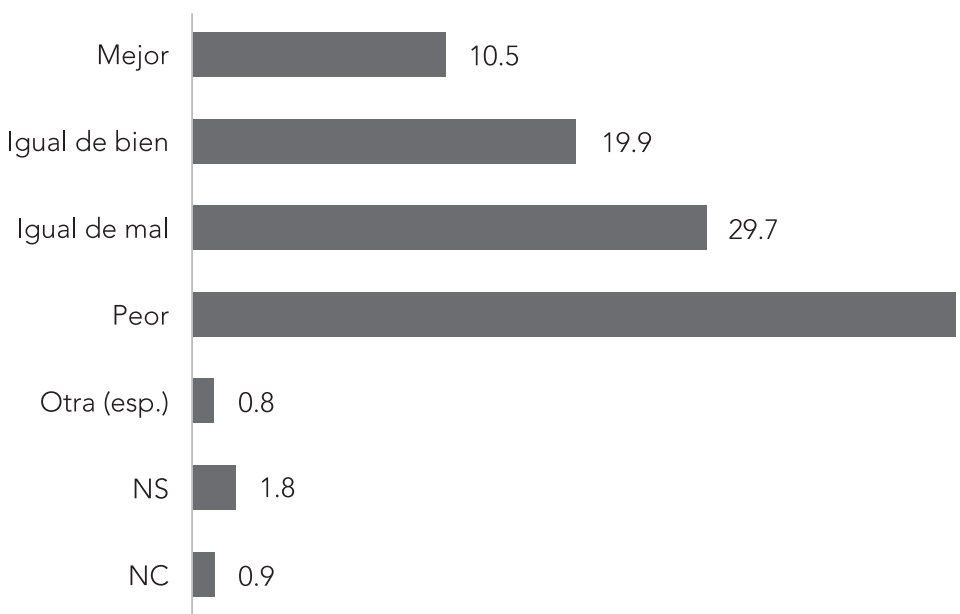

36.4

Fuente: Encuesta Nacional de Percepciones Sociales de los Juegos de Azar en México, México, UnAM, Instituto de Investigaciones Jurídicas, Departamento de Investigación Aplicada y Opinión, 2016.

Las personas que en el último año han jugado algún juego son más optimistas que la media nacional. Una tercera parte de la población jugadora (33.9 por ciento) dijo que está económicamente mejor o igual de bien comparado con el año anterior, mientras que a nivel nacional esta proporción representa tres de cada diez (30.4 por ciento). Las personas no jugadoras son menos optimistas, ya que menos de tres de cada diez (27.2 por ciento) señalaron que su situación económica está mejor o igual de bien con respecto al año pasado (véase cuadro 3.5). 
Este libro forma parte del acervo de la Biblioteca Jurídica Virtual del Instituto de Investigaciones Jurídicas de la UNAM

\section{CUADRO 3.5}

COMPARADA CON LA SITUACIÓN ECONÓMICA QUE TENÍA USTED HACE UN AÑO, ¿CÓMO DIRÍA QUE ES SU SITUACIÓN ECONÓMICA ACTUAL: MEJOR O PEOR? (PORCENTAJES)

\begin{tabular}{l|c|c|c}
\hline & $\begin{array}{c}\text { MEDIA } \\
\text { NACIONAL }\end{array}$ & $\begin{array}{c}\text { JUEGA EN EL ÚLTIMO } \\
\text { AÑO }\end{array}$ & $\begin{array}{c}\text { NO JUEGA NINGÚN } \\
\text { JUEGO }\end{array}$ \\
\hline Mejor & 10.5 & 11.9 & 9.2 \\
\hline Igual de bien & 19.9 & 21.9 & 18.0 \\
\hline Igual de mal & 29.7 & 29.6 & 29.9 \\
\hline Peor & 36.4 & 34.2 & 38.6 \\
\hline Otra & 0.8 & 0.8 & 0.8 \\
\hline NS & 1.8 & 1.0 & 2.5 \\
\hline NC & 0.9 & 0.6 & 1.1 \\
\hline
\end{tabular}

Fuente: Encuesta Nacional de Percepciones Sociales de los Juegos de Azar en México, México, UNAM, Instituto de Investigaciones Jurídicas, Departamento de Investigación Aplicada y Opinión, 2016.

Las expectativas de mejoramiento de la situación económica personal son igualmente menos optimistas, ya que más de cuatro de cada diez entrevistados (47.1 por ciento) dijeron que su situación económica seguirá igual de mal o empeorará para el próximo año; sin embargo, casi cuatro de cada diez (38.8 por ciento) consideraron que económicamente mejorarán o seguirán igual de bien (véase gráfica 3.6). Las personas menos optimistas en relación con su situación económica futura son aquellas que se encuentran en el grupo de edad de 35 a 44 años y las que tienen educación secundaria. Por su parte, las personas que dijeron que económicamente mejorarán o seguirán igual de bien son aquellas mayores de 65 años, las que tienen un nivel de educación de licenciatura o posgrado y las que perciben un ingreso familiar más alto.

Las personas que en el último año han jugado al menos un juego son más optimistas sobre las expectativas de su situación económica para el siguiente año, ya que cuatro de cada diez jugadores (41.4 por ciento) dijeron que económicamente mejorarán o seguirán igual de bien. Esta proporción se encuentra dos puntos porcentuales por encima de la media nacional (38.8 por ciento), en tanto que las personas no jugadoras son las menos optimistas (véase cuadro 3.6). 
Este libro forma parte del acervo de la Biblioteca Jurídica Virtual del Instituto de Investigaciones Jurídicas de la UNAM www.juridicas.unam.mx

GRÁFICA 3.6

\section{EN GENERAL, ¿CREE USTED QUE EN EL PRÓXIMO AÑO \\ SU SITUACIÓN ECONÓMICA VA A MEJORAR O VA A EMPEORAR? \\ (PORCENTAJES)}

\begin{abstract}
Va a mejorar
Igual de bien

Igual de mal
\end{abstract}

Va a empeorar

Otra (esp.)

NS

NC

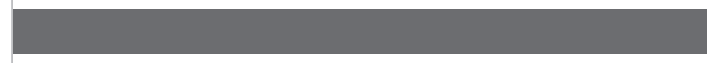

25.7

13.1

12.4

Fuente: Encuesta Nacional de Percepciones Sociales de los Juegos de Azar en México, México, UnAM, Instituto de Investigaciones Jurídicas, Departamento de Investigación Aplicada y Opinión, 2016.

\section{CUADRO 3.6}

\begin{tabular}{|c|c|c|c|}
\hline \multicolumn{4}{|c|}{$\begin{array}{l}\text { ¿CREE USTED QUE EN EL PRÓXIMO AÑO SU SITUACIÓN ECONÓMICA } \\
\text { VA A MEJORAR O VA A EMPEORAR? } \\
\text { (PORCENTAJES) }\end{array}$} \\
\hline & MEDIA NACIONAL & JUEGA EN EL ÚLTIMO AÑO & $\begin{array}{c}\text { NO JUEGA NINGÚN } \\
\text { JUEGO }\end{array}$ \\
\hline Va a mejorar & 25.7 & 26.3 & 25.1 \\
\hline Igual de bien & 13.1 & 15.2 & 11.2 \\
\hline Igual de mal & 18.8 & 18.8 & 18.9 \\
\hline Va a empeorar & 28.2 & 27.9 & 28.5 \\
\hline Otra & 0.5 & 0.1 & 0.9 \\
\hline NS & 12.4 & 10.9 & 13.8 \\
\hline NC & 1.2 & 0.9 & 1.6 \\
\hline
\end{tabular}

Fuente: Encuesta Nacional de Percepciones Sociales de los Juegos de Azar en México, México, UNAM, Instituto de Investigaciones Jurídicas, Departamento de Investigación Aplicada y Opinión, 2016. 
Este libro forma parte del acervo de la Biblioteca Jurídica Virtual del Instituto de Investigaciones Jurídicas de la UNAM

\section{APORTE ECONÓMICO AL HOGAR Y TRANSPARENCIA DE LAS FINANZAS}

Por otro lado, se observa que, en general, la mayoría de los entrevistados sí aporta al menos una parte de lo que gana para la manutención de su hogar. De manera particular, poco más de una tercera parte de los entrevistados (35.5 por ciento) mencionó que aporta la mayor parte de lo que gana; casi dos de cada diez (18.9 por ciento) señalaron que aportan todo lo que ganan, y poco más de uno de cada diez (12.0 por ciento) aporta únicamente la mitad de lo que gana. Sin embargo, poco más de uno de cada diez entrevistados (14.7 por ciento) mencionó que no aporta para la manutención del hogar (véase gráfica 3.7).

De acuerdo con las características sociodemográficas, la edad está relacionada con el aporte económico para el hogar, ya que un mayor porcentaje de personas en edad productiva, en los grupos de edad que se encuentran en el rango de 25 a 54 años, aporta la mayor parte de lo que gana, mientras que un porcentaje ligeramente mayor de los más jóvenes (en el grupo de 18 a 24 años) no aporta para el hogar. Por su parte, los hombres son quienes suelen aportar la mayor parte de lo que ganan y todo lo que ganan, así como también las personas con nivel licenciatura o posgrado, las que están en unión libre o casadas y las que sí trabajaron en la semana de referencia.

Con respecto a la condición de jugador, un mayor porcentaje de las personas que en el último año jugaron algún juego mencionó que aporta la mayor parte de lo que gana para la manutención del hogar (42.1 por ciento). Esta proporción se encuentra seis puntos porcentuales por encima de la media nacional (35.5 por ciento); mientras que los no jugadores con mayor frecuencia también mencionaron que no aportan para la manutención de su hogar (véase cuadro 3.7). 
Este libro forma parte del acervo de la Biblioteca Jurídica Virtual del Instituto de Investigaciones Jurídicas de la UNAM www.juridicas.unam.mx

DE LO QUE USTED GANA, ¿CUÁNTO APORTA PARA LA MANUTENCIÓN DE SU HOGAR?
(PORCENTAJES)

La mayor parte de lo que gana

Todo lo que gana

No aporta

La mitad de lo que gana

No gana

Menos de la mitad

Una parte muy pequeña
NS | 0.8
NC $\quad 1.0$

35.4

18.9

14.7

12.0

7.9

6.5

2.8

Fuente: Encuesta Nacional de Percepciones Sociales de los Juegos de Azar en México, México, UnAm, Instituto de Investigaciones Jurídicas, Departamento de Investigación Aplicada y Opinión, 2016.

\section{CUADRO 3.7}

DE LO QUE USTED GANA, ¿CUÁNTO APORTA PARA LA MANUTENCIÓN DE SU HOGAR? (PORCENTAJES)

\begin{tabular}{l|c|c|c}
\hline & MEDIA NACIONAL & JUEGA EN EL ÚLTIMO AÑO & NO JUEGA NINGÚN JUEGO \\
\hline $\begin{array}{l}\text { La mayor parte de } \\
\text { lo que gana }\end{array}$ & 35.5 & 42.1 & 29.4 \\
\hline Todo lo que gana & 18.9 & 19.3 & 18.5 \\
\hline No aporta & 14.7 & 8.8 & 20.1 \\
\hline $\begin{array}{l}\text { La mitad de lo que } \\
\text { gana }\end{array}$ & 12.0 & 12.8 & 11.2 \\
\hline No gana & 7.9 & 6.0 & 9.6 \\
\hline Menos de la mitad & 6.5 & 7.6 & 5.4 \\
\hline $\begin{array}{l}\text { Una parte muy } \\
\text { pequeña }\end{array}$ & 2.8 & 2.0 & 3.5 \\
\hline NS & 0.8 & 1.0 & 0.6 \\
\hline NC & 1.1 & 0.4 & 1.7 \\
\hline
\end{tabular}

Fuente: Encuesta Nacional de Percepciones Sociales de los Juegos de Azar en México, México, UNAM, Instituto de Investigaciones Jurídicas, Departamento de Investigación Aplicada y Opinión, 2016. 
Este libro forma parte del acervo de la Biblioteca Jurídica Virtual del Instituto de Investigaciones Jurídicas de la UNAM

En términos generales, las personas entrevistadas mantienen cierta comunicación con sus familiares cercanos cuando se trata de dinero guardado. No obstante, esta comunicación depende del tipo de parentesco que se tiene con la persona, pues se observa que la mayoría de los entrevistados (59.9 por ciento) dijo que si tiene dinero guardado sí o a veces se lo dice a su pareja o esposo(a); más de cuatro de cada diez (45.1 por ciento) sí o a veces se lo dicen a sus padres; casi una tercera parte (32.5 por ciento) se lo dice a sus hijos(as), y poco más de una cuarta parte (27.7 por ciento) se lo dice a sus hermanos(as) (véase gráfica 3.8).

La edad de los entrevistados muestra comportamientos distintos con respecto a este tema, ya que las personas en edad adulta (en las edades de 35 años y más) con mayor frecuencia manifestaron que sí o a veces le dicen a su pareja o esposo(a) o a los hijos(as) cuando tienen dinero guardado; mientras que los más jóvenes (en el grupo de 18 a 24 años) con mayor frecuencia sí o a veces les dicen a sus padres o a sus hermanos(as).

\section{GRÁFICA 3.8}

¿SI USTED TIENE UN DINERO GUARDADO, SE LO DICE...?

(PORCENTAJES)

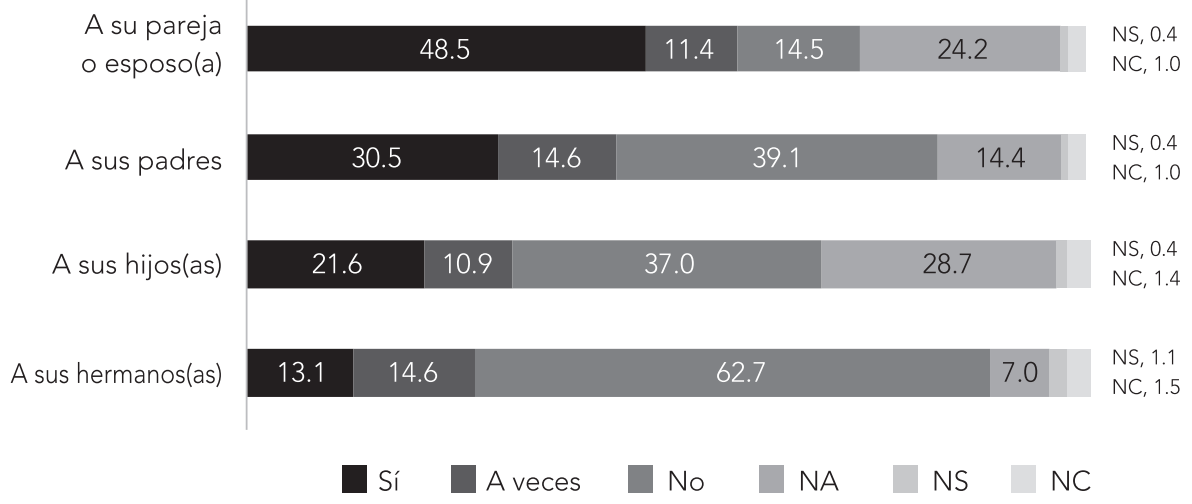

Fuente: Encuesta Nacional de Percepciones Sociales de los Juegos de Azar en México, México, UNAM, Instituto de Investigaciones Jurídicas, Departamento de Investigación Aplicada y Opinión, 2016.

Al respecto, la condición de jugador muestra pocas diferencias. Una de cada seis personas (60.0 por ciento) que se declararon jugadores de algún 
Este libro forma parte del acervo de la Biblioteca Jurídica Virtual del Instituto de Investigaciones Jurídicas de la UNAM

juego en el último año mencionó que sí o a veces le dice a su pareja o esposo(a) cuando tiene dinero guardado. Esta proporción es similar al promedio nacional. Asimismo, el porcentaje de jugadores que señaló que sí o a veces le dice a sus hermanos(as) si tiene dinero guardado (27.9 por ciento) es semejante al promedio nacional (véase cuadro 3.8).

Por otro lado, casi la mitad de las personas que jugaron al menos un juego en el último año señaló que si tiene dinero guardado sí o a veces se lo dice a sus padres. Es decir que la proporción de jugadores se encuentra cuatro puntos porcentuales por encima del promedio nacional. Mientras que poco menos de una tercera parte de los jugadores mencionó que cuando tiene dinero guardado sí o a veces se lo dice a sus hijos(as), siendo casi dos puntos porcentuales menor que el promedio nacional (véase cuadro 3.8).

\section{CUADRO 3.8}

¿SI USTED TIENE UN DINERO GUARDADO, SE LO DICE A...? JUGÓ AL MENOS UN JUEGO EN EL ÚLTIMO AÑO (PORCENTAJES)

\begin{tabular}{l|c|c|c|c}
\hline & SU PAREJA O ESPOSO(A) & SUS PADRES & SUS HERMANOS & SUS HIJOS \\
\hline Sí & 46.3 & 31.2 & 10.7 & 17.7 \\
\hline A veces & 13.7 & 18.2 & 17.2 & 13.1 \\
\hline No & 14.3 & 38.8 & 62.4 & 39.5 \\
\hline NA & 24.7 & 10.8 & 6.8 & 28.2 \\
\hline NS & 0.0 & 0.2 & 0.8 & 0.0 \\
\hline NC & 1.0 & 0.8 & 2.1 & 1.5 \\
\hline
\end{tabular}

Fuente: Encuesta Nacional de Percepciones Sociales de los Juegos de Azar en México, México, UNAM, Instituto de Investigaciones Jurídicas, Departamento de Investigación Aplicada y Opinión, 2016.

Sin embargo, se observa que los entrevistados están menos enterados acerca de cuánto ganan sus familiares más cercanos. La mitad de las personas (50.8 por ciento) dijo que sí y sí, en parte sabe cuánto gana su pareja o esposo(a); poco menos de una tercera parte de las personas (31.0 por ciento) mencionó que sí y sí, en parte sabe cuánto ganan sus padres; dos de cada diez (21.7 por ciento) dijeron que saben cuánto ganan sus hermanos(as), mientras que sólo una sexta parte de los entrevistados (17.5 por ciento) señaló que sí y sí, en parte sabe cuánto ganan sus hijos(as) (véase gráfica 3.9). 
Este libro forma parte del acervo de la Biblioteca Jurídica Virtual del Instituto de Investigaciones Jurídicas de la UNAM

GRÁFICA 3.9

$$
\begin{aligned}
& \text { ¿SABE USTED O NO CUÁNTO GANA SU...? } \\
& \text { (PORCENTAJES) }
\end{aligned}
$$

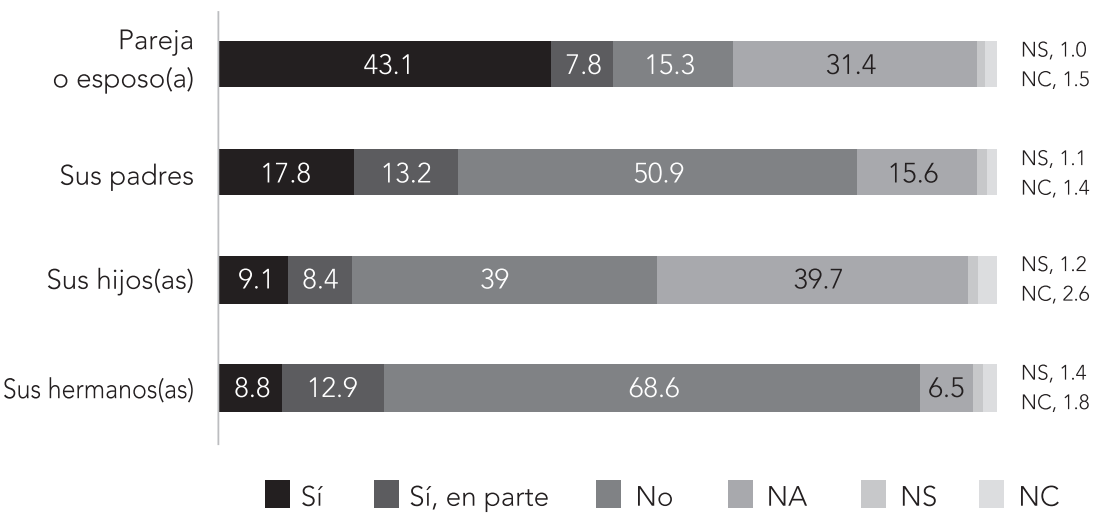

Fuente: Encuesta Nacional de Percepciones Sociales de los Juegos de Azar en México, México, unam, Instituto de Investigaciones Jurídicas, Departamento de Investigación Aplicada y Opinión, 2016.

Con respecto a las características sociodemográficas, se muestra que, a diferencia de los varones, un mayor porcentaje de mujeres contestó que síy sí, en parte sabe cuánto gana su pareja o esposo. Mientras que la edad marca una tendencia más o menos evidente en cuanto al conocimiento de lo que ganan los familiares más cercanos, ya que las personas de 35 a 44 años y de 55 a 64 años son las que con mayor frecuencia mencionaron que sí y sí, en parte saben cuánto gana su pareja o esposo(a); en tanto que los más jóvenes, en el grupo de 18 a 24 años, con mayor frecuencia saben cuánto ganan sus padres; los del grupo de 25 a 34 años saben cuánto ganan sus hermanos(as), y las personas en los rangos de edad de 45 años y más saben cuánto ganan sus hijos(as).

Las personas que han jugado al menos un juego en el último año con mayor frecuencia dijeron que sí saben cuánto ganan sus familiares más cercanos. En este sentido, la mitad de los jugadores señalaron que sí y sí, en parte saben cuánto gana su pareja o esposo(a) (51.1 por ciento), aunque este porcentaje es cercano a la media nacional (50.8 por ciento). Poco más de una tercera parte (34.1 por ciento) de las personas jugadoras mencionó que sí y sí, en parte sabe cuánto ganan sus padres, esto es tres puntos por- 
Este libro forma parte del acervo de la Biblioteca Jurídica Virtual del Instituto de Investigaciones Jurídicas de la UNAM

centuales por encima del promedio a nivel nacional (31.0 por ciento) (véase cuadro 3.9).

Por su parte, una cuarta parte de los jugadores dijo que sí y sí, en parte sabe cuánto ganan sus hermanos(as). Esta proporción es mayor en dos puntos porcentuales con respecto al promedio nacional. Mientras que casi dos de cada diez (18.7 por ciento) jugadores señalaron que sí y sí, en parte saben cuánto ganan sus hijos, lo cual es ligeramente mayor que el promedio nacional (17.5 por ciento) (véase cuadro 3.9).

\section{CUADRO 3.9}

\section{¿SABE USTED O NO CUÁNTO GANA...? JUGÓ AL MENOS UN JUEGO EN EL ÚLTIMO AÑO}

(PORCENTAJES)

\begin{tabular}{l|c|c|c|c}
\hline & $\begin{array}{c}\text { SU PAREJA } \\
\text { O ESPOSO(A) }\end{array}$ & SUS PADRES & SUS HERMANOS & SUS HIJOS \\
\hline Sí & 42.8 & 18.4 & 9.1 & 8.9 \\
\hline Sí, en parte & 8.3 & 15.7 & 15.0 & 9.8 \\
\hline No & 13.7 & 50.4 & 63.6 & 39.2 \\
\hline NA & 33.5 & 12.1 & 8.6 & 39.0 \\
\hline NS & 0.6 & 1.3 & 1.6 & 1.3 \\
\hline NC & 1.1 & 2.0 & 2.1 & 1.8 \\
\hline
\end{tabular}

Fuente: Encuesta Nacional de Percepciones Sociales de los Juegos de Azar en México, México, UNAM, Instituto de Investigaciones Jurídicas, Departamento de Investigación Aplicada y Opinión, 2016.

Las respuestas registradas con anterioridad ponen de manifiesto un fenómeno que en estudios de opinión pública es llamado con frecuencia deseabilidad social (social desirability). La deseabilidad social es la tendencia de los individuos a presentarse de una manera favorable al brindar una respuesta "políticamente correcta" a una interrogante. ${ }^{2}$

2 El sesgo de deseabilidad social es un sesgo de carácter cognitivo, un patrón general o tendencias a pensar de alguna manera específica, en el que la gente que responde a las interrogantes o cuestionamientos lo hace en forma que le permita destacar su lado más favorable hacia los demás (Converse, 1964; Phillips y Clancy, 1972; Zaller, 1992). 
Este libro forma parte del acervo de la Biblioteca Jurídica Virtual del Instituto de Investigaciones Jurídicas de la UNAM

\section{MENTALIDAD ECONÓMICA}

En los años setenta, Ronald Inglehart (1977) se preguntó si el desarrollo económico cambiaba las preocupaciones de las personas, es decir, si las sociedades que habían dejado atrás la escasez habían cambiado sus valores. La hipótesis era sencilla, una vez que se aseguran las necesidades más elementales (valores materialistas) se permiten nuevas preocupaciones relacionadas con la autonomía del individuo, la libre expresión de la personalidad de cada quien y el medio ambiente. Aunque la problematización inicial de Inglehart sigue vigente, existen revisiones modernas (véase Nový et al., 2017) que profundizan las investigaciones iniciales.

Así, entre las personas con valores materialistas, además de los valores de sobrevivencia, es posible encontrar combinaciones que incluyen valores individualistas propios de una mentalidad más orientada a los negocios y la competitividad; mientras que entre quienes poseen valores posmaterialistas se podrían encontrar en algunos casos valores presididos por la afectividad y orientados a lo colectivo.

Para rastrear los valores materialistas en la primera Encuesta Nacional de Percepciones Sociales sobre los Juegos de Azar, a los entrevistados se les presentó una situación hipotética: Si usted tuviera dinero ahorrado para la fiesta de quince años de una hija suya, pero se le presentara un buen negocio, usted: ¿haría la fiesta o invertiría en el negocio? Cerca de la mitad de los entrevistados respondió que invertiría en el negocio, mientras que la tercera parte dijo que haría la fiesta. Poco más de uno de cada diez señaló como respuesta que depende (véase gráfica 3.10).

Los hombres, las personas que tienen de 25 a 34 años, los que tienen un nivel escolar de preparatoria o bachillerato y aquellos que perciben un ingreso individual de 6 a 7 salarios mínimos son quienes dijeron más frecuentemente que invertirían en el negocio. Por su parte, las mujeres, las personas de 55 a 64 años, los que tienen un nivel de escolaridad de primaria y los que se declararon católicos con mayor frecuencia mencionaron que harían la fiesta. 
Este libro forma parte del acervo de la Biblioteca Jurídica Virtual del Instituto de Investigaciones Jurídicas de la UNAM www.juridicas.unam.mx

GRÁFICA 3.10

SI USTED TUVIERA DINERO AHORRADO PARA LA FIESTA

DE QUINCE AÑOS DE UNA HIJA SUYA, PERO SE LE PRESENTARA UN BUEN NEGOCIO, USTED: ¿HARÍA LA FIESTA O INVERTIRÍA EN EL NEGOCIO?

(PORCENTAJES)

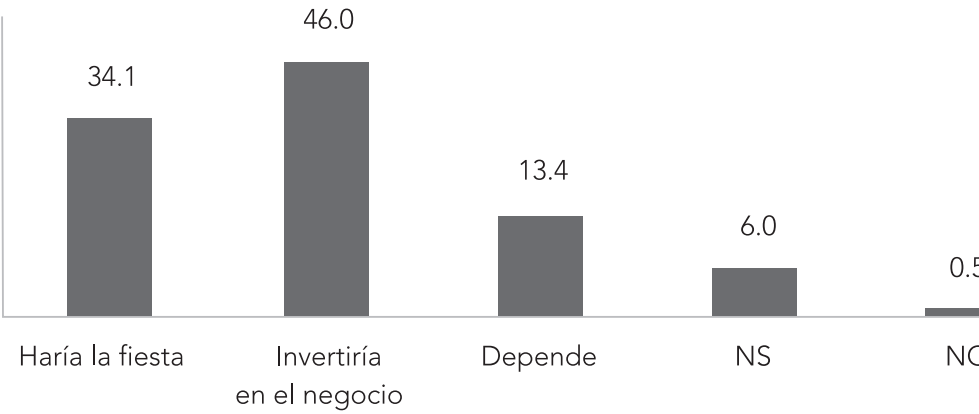

Fuente: Encuesta Nacional de Percepciones Sociales de los Juegos de Azar en México, México, UNAM, Instituto de Investigaciones Jurídicas, Departamento de Investigación Aplicada y Opinión, 2016.

CUADRO 3.10

\begin{tabular}{|c|c|c|c|}
\hline \multicolumn{4}{|c|}{$\begin{array}{l}\text { SI USTED TUVIERA DINERO AHORRADO PARA LA FIESTA DE QUINCE AÑOS } \\
\text { DE UNA HIJA SUYA, PERO SE LE PRESENTARA UN BUEN NEGOCIO, USTED: } \\
\text { ¿HARÍA LA FIESTA O INVERTIRÍA EN EL NEGOCIO? SEGÚN PRÁCTICAS DE JUEGO } \\
\text { (PORCENTAJES) }\end{array}$} \\
\hline & MEDIA NACIONAL & JUEGA EN EL ÚLTIMO AÑO & NO JUEGA NINGÚN JUEGO \\
\hline Haría la fiesta & 34.1 & 35.9 & 32.7 \\
\hline $\begin{array}{l}\text { Invertiría } \\
\text { en el negocio }\end{array}$ & 46 & 45.9 & 45.7 \\
\hline Depende & 13.4 & 14.7 & 12.3 \\
\hline NS & 6 & 3 & 9.1 \\
\hline NC & 0.5 & 0.5 & 0.2 \\
\hline
\end{tabular}

Fuente: Encuesta Nacional de Percepciones Sociales de los Juegos de Azar en México, México, UNAM, Instituto de Investigaciones Jurídicas, Departamento de Investigación Aplicada y Opinión, 2016.

La condición de jugador permite observar que poco más de cuatro de cada diez personas (45.9 por ciento) que en el último año han jugado al menos un juego dijeron que si tuvieran dinero ahorrado para la fiesta de quince años de una hija invertirían en el negocio si se les presentara la oportunidad, proporción cercana a la media nacional (46.0 por ciento); sin embargo, más de una tercera parte de los jugadores (35.9 por ciento) señaló que aunque se 
Este libro forma parte del acervo de la Biblioteca Jurídica Virtual del Instituto de Investigaciones Jurídicas de la UNAM

le presentara la oportunidad de invertir en un buen negocio, le haría la fiesta de quince años a su hija. Esta proporción es mayor en tres puntos porcentuales con respecto al porcentaje de no jugadores que mencionaron que harían la fiesta (32.4 por ciento) (véase cuadro 3.10). Siguiendo a Inglehart, se pueden clasificar como preponderantes los valores materialistas entre los encuestados, sobre todo en los jóvenes y, en cierta medida, entre los jugadores.

\section{USO DEL TIEMPO LIBRE}

A lo largo de la historia de las civilizaciones se ha contado con un sinnúmero de prácticas e interpretaciones sobre el tiempo libre, con algunos puntos en común. En la antigua Grecia únicamente las elites tenían la posibilidad de tiempo para contemplar los valores más elevados, mientras que los esclavos estaban para trabajar. Por su parte, los romanos enlazaban el trabajo y el tiempo libre, siendo este último necesario para el descanso y para alimentar el espíritu, aunque también diferenciaban entre las actividades destinadas para la nobleza y las propias de la plebe romana; basta recordar la frase "al pueblo pan y circo" (panem et circenses, véase Huizinga, 2000).

En la actualidad, el tiempo libre no sólo se ha convertido en una necesidad, sino también en una industria de entretenimiento. Si bien explícitamente no se hacen diferencias en el uso del tiempo libre, visiblemente las sociedades pos-industriales cuentan con más tiempo libre, pero también con preferencias, estereotipos y usos distintos del mismo.

De todos los países miembros de la OCDE, México es el que más horas trabaja al año: 2,255 horas totales en promedio por persona durante 2016 (OCDE, 2017b). Esto es casi dos horas más por día que el promedio de todos los países de la OCDE. Si a esto se suma que, en nuestro país, más de la mitad cuenta con trabajos sin prestaciones; que en la práctica es poco frecuente que se paguen horas extras, y que muchas personas cuentan con dos o más actividades remuneradas para cubrir sus necesidades básicas, el panorama del tiempo libre es sin duda desalentador.

Como se observa en la gráfica 3.11, los países pos-industriales tienen más horas para dedicar a sus actividades fuera del trabajo, mientras que para los trabajadores mexicanos este tiempo es particularmente limitado. 
Este libro forma parte del acervo de la Biblioteca Jurídica Virtual del Instituto de Investigaciones Jurídicas de la UNAM www.juridicas.unam.mx

\section{GRÁFICA 3.11}

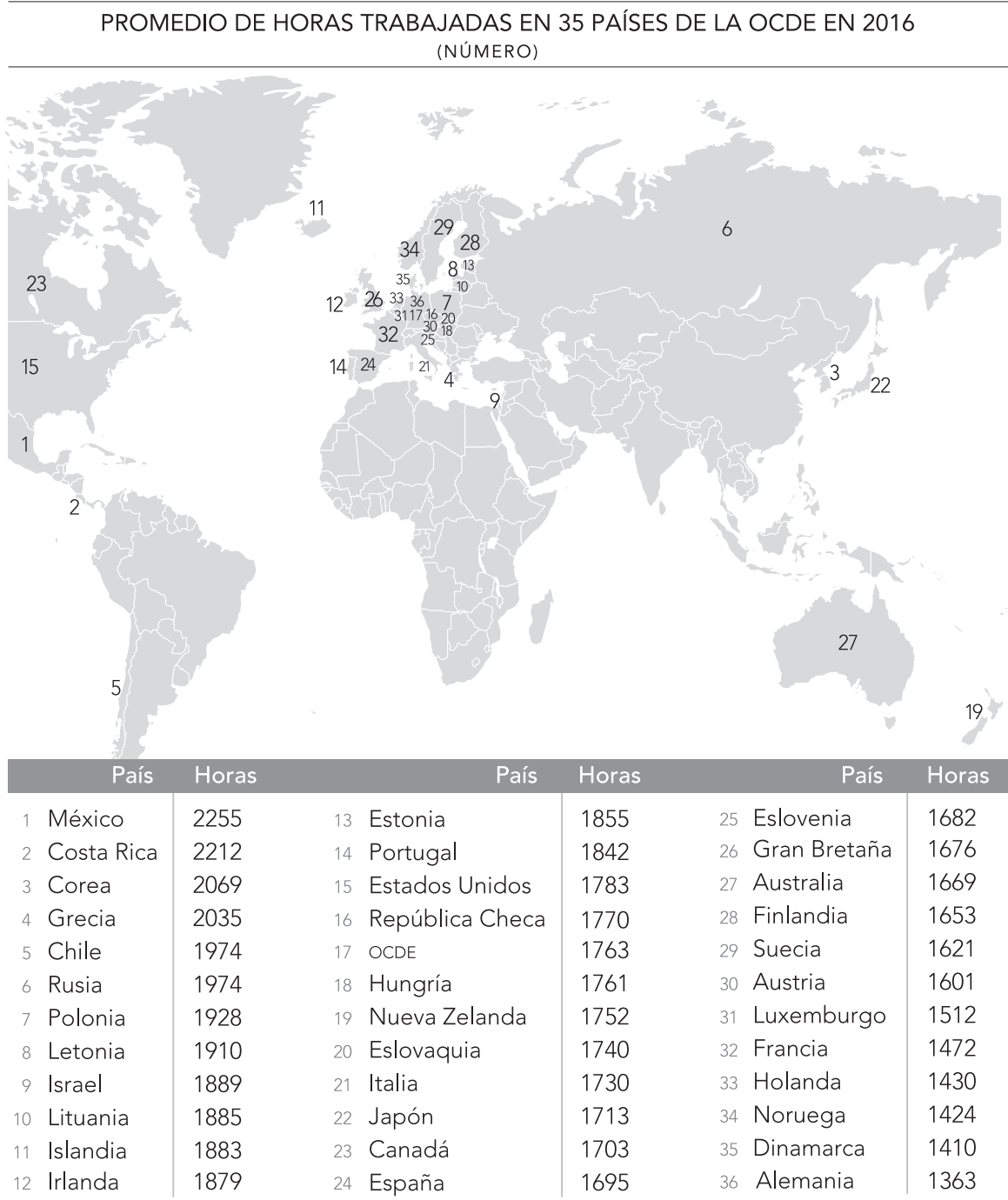

Fuente: OCDE, 2017b.

Al respecto, es importante señalar que para los pobres el tiempo libre no significa ocio, sino que es tiempo que se dedica a actividades que puedan incrementar el ingreso de las familias. Según la Encuesta Nacional sobre Uso del Tiempo del INEGI (2014), los miembros de 12 años y más en el hogar destinan 12.8 horas en promedio a la semana para actividades de esparcimiento, cultura y convivencia, mientras que los hombres destinan en prome- 
Este libro forma parte del acervo de la Biblioteca Jurídica Virtual del Instituto de Investigaciones Jurídicas de la UNAM

dio 14.0 horas semanales para estas actividades y las mujeres 11.8 horas en promedio. Esto pone de relieve no sólo la escasa cantidad de horas dedicadas a este tipo de actividades, sino también una desigualdad de género.

Una menor cantidad de tiempo libre tiene consecuencias sobre las distintas áreas de la actividad humana. En primer lugar se advierte un impacto económico, pues se reducen las horas para hacer uso de bienes y servicios, culturales, deportivos y de entretenimiento; tiene también un impacto psicológico, pues el tiempo libre es fundamental para el desarrollo personal, desahogo de estrés y disminución de la ansiedad; de manera muy importante tiene consecuencias también sobre los ambientes familiar y social, pues impacta en la cohesión familiar y del tejido social de las comunidades.

La primera Encuesta Nacional de Percepciones Sociales de los Juegos de Azar en México preguntó acerca de este tema. En este sentido, en la gráfica 3.12 se observa que cerca de una tercera parte de las personas entrevistadas (32.3 por ciento) mencionó que cuenta con 20 horas o menos de tiempo libre a la semana; mientras que alrededor de tres de cada diez (29.1 por ciento) dijeron que cuentan con más de 20 y hasta 48 horas, pero cabe señalar que quienes indicaron este número de horas probablemente descansan en sus trabajos los fines de semana.

Las principales actividades que las personas entrevistadas prefieren hacer en su tiempo libre son actividades de esparcimiento y diversión, así como convivir con amigos y familiares. Como se puede observar en la gráfica 3.13, las actividades que menos prefieren son quehaceres y actividades del hogar, así como actividades religiosas y filantrópicas. De acuerdo con las características demográficas, los hombres, las personas en los grupos de edad dentro del rango de 25 a 54 años y los que no tienen escolaridad prefieren convivir con los amigos y familiares; por su parte, las mujeres, los jóvenes de 18 a 24 años y las personas mayores de 65 años, con mayor frecuencia mencionaron que prefieren actividades de esparcimiento y diversión. Actualmente, contar con una mayor cantidad de tiempo libre por elección, más allá de los bienes que las personas podrían poseer, es un distintivo de estatus entre algunos sectores. 
Este libro forma parte del acervo de la Biblioteca Jurídica Virtual del Instituto de Investigaciones Jurídicas de la UNAM www.juridicas.unam.mx

GRÁFICA 3.12

¿CON CUÁNTO TIEMPO LIBRE CUENTA APROXIMADAMENTE A LA SEMANA PARA HACER LAS COSAS QUE MÁS LE GUSTAN?

(PORCENTAJES)

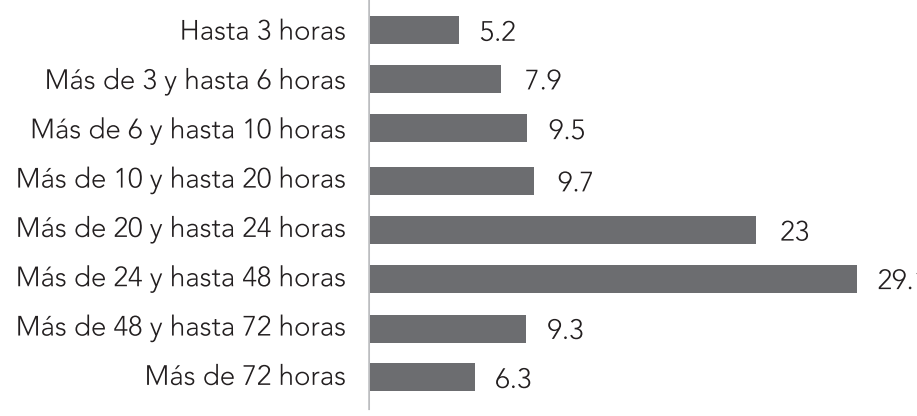

Fuente: Encuesta Nacional de Percepciones Sociales de los Juegos de Azar en México, México, unam, Instituto de Investigaciones Jurídicas, Departamento de Investigación Aplicada y Opinión, 2016.

GRÁFICA 3.13

POR FAVOR, DÍGAME TRES ACTIVIDADES QUE PREFIERE HACER EN SU TIEMPO LIBRE (RESPUESTA MÚLTIPLE, NO SUMA 100\%)

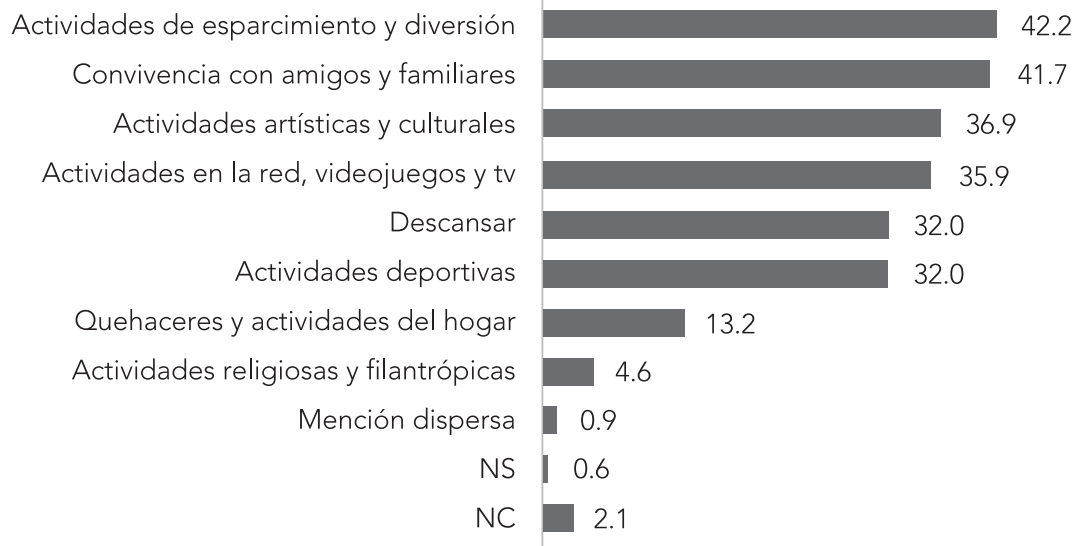

Fuente: Encuesta Nacional de Percepciones Sociales de los Juegos de Azar en México, México, UnAm, Instituto de Investigaciones Jurídicas, Departamento de Investigación Aplicada y Opinión, 2016.

La condición de jugador muestra algunas diferencias en las actividades que las personas realizan en su tiempo libre. Si bien es cierto que un porcentaje similar de jugadores (41.4 por ciento) y no jugadores (41.9 por ciento) 
Este libro forma parte del acervo de la Biblioteca Jurídica Virtual del Instituto de Investigaciones Jurídicas de la UNAM

prefieren convivir con amigos y familiares, también los jugadores, en contraste con los no jugadores, con mayor frecuencia mencionaron que prefieren realizar actividades de esparcimiento y diversión, actividades artísticas y culturales, actividades deportivas, actividades en la red, videojuegos y tv y descansar (véase cuadro 3.11).

CUADRO 3.11

POR FAVOR, DÍGAME TRES ACTIVIDADES QUE PREFIERE

HACER EN SU TIEMPO LIBRE

(RESPUESTA MÚLTIPLE, NO SUMA 100\%)

\begin{tabular}{l|c|c}
\hline & $\begin{array}{c}\text { JUEGA EN EL ÚLTIMO } \\
\text { AÑO }\end{array}$ & $\begin{array}{c}\text { NO JUEGA NINGÚN } \\
\text { JUEGO }\end{array}$ \\
\hline Actividades de esparcimiento y diversión & 43.9 & 40.7 \\
\hline Convivencia con amigos y familiares & 41.4 & 41.9 \\
\hline Actividades artísticas y culturales & 40.0 & 34.1 \\
\hline Actividades deportivas & 39.0 & 25.3 \\
\hline Actividades en la red, videojuegos y tv & 37.7 & 34.3 \\
\hline Descansar & 33.0 & 31.0 \\
\hline Quehaceres y actividades del hogar & 12.7 & 13.7 \\
\hline Actividades religiosas y filantrópicas & 3.6 & 5.5 \\
\hline Otro & 0.4 & 1.5 \\
\hline NS & 0.3 & 0.8 \\
\hline NC & 0.3 & 3.7 \\
\hline
\end{tabular}

Fuente: Encuesta Nacional de Percepciones Sociales de los Juegos de Azar en México, México, UNAM, Instituto de Investigaciones Jurídicas, Departamento de Investigación Aplicada y Opinión, 2016.

\section{APUESTAS Y JUEGOS DE AZAR}

En la primera Encuesta Nacional de Percepciones Sociales de los Juegos de Azar en México se les preguntó a las personas si acostumbran apostar. Al respecto, dos de cada diez entrevistados (20.9 por ciento) indicaron que sí acostumbran apostar y cerca de ocho de cada diez (78.4 por ciento) señalaron no hacerlo (véase gráfica 3.14). Las personas del sexo masculino son quienes con mayor frecuencia dijeron que sí acostumbran apostar, así como también las personas con un nivel de escolaridad de licenciatura o posgra- 
Este libro forma parte del acervo de la Biblioteca Jurídica Virtual del Instituto de Investigaciones Jurídicas de la UNAM

do y aquellos que perciben más de 8 a 10 salarios mínimos de ingreso familiar (véase cuadro 3.12).

\section{GRÁFICA 3.14}

\section{Y DÍGAME, ¿USTED ACOSTUMBRA APOSTAR?}

(PORCENTAJES)
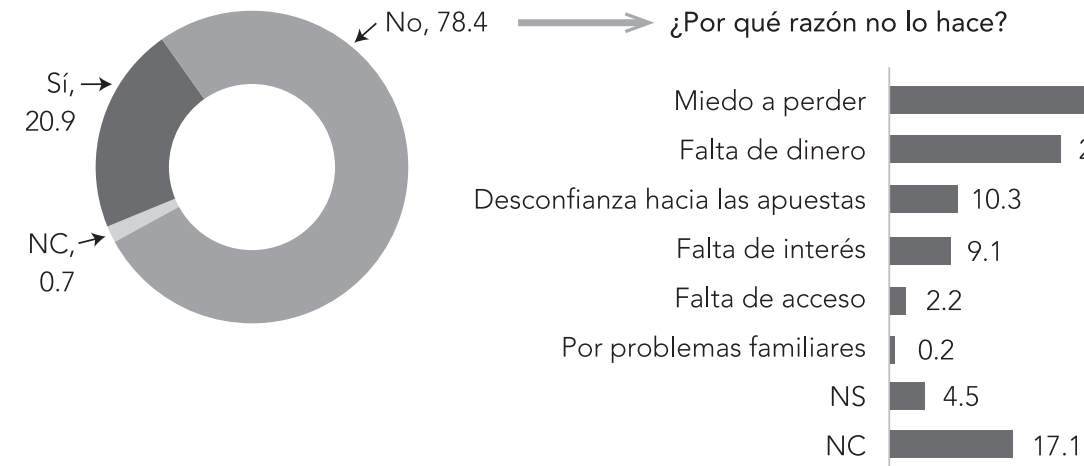

Fuente: Encuesta Nacional de Percepciones Sociales de los Juegos de Azar en México, México, UNAM, Instituto de Investigaciones Jurídicas, Departamento de Investigación Aplicada y Opinión, 2016.

De las personas entrevistadas que dijeron que no acostumbran apostar, tres de cada diez (30.3 por ciento) no apuestan por miedo a perder, poco más de una cuarta parte (26.3 por ciento) no lo hace por falta de dinero y uno de cada diez (10.3 por ciento) por desconfianza en las apuestas (véase gráfica 3.14). Los hombres, las personas de 55 a 65 años y los que tienen un nivel de educación de licenciatura o posgrado con mayor frecuencia señalaron que no acostumbran apostar por miedo a perder.

En este mismo sentido, a los entrevistados se les preguntó si acostumbran participar en rifas o sorteos, a lo que poco más de tres cuartas partes (76.2 por ciento) respondieron que no acostumbran participar en rifas y sorteos, mientras que dos de cada diez (23.2 por ciento) dijeron que sí lo hacen (véase gráfica 3.15). Las personas del sexo masculino, las de 35 a 44 años, las de 45 a 54 años y las que tienen nivel de educación de licenciatura o posgrado con mayor frecuencia mencionaron que sí acostumbran participar en rifas y sorteos. 
Este libro forma parte del acervo de la Biblioteca Jurídica Virtual del Instituto de Investigaciones Jurídicas de la UNAM

CUADRO 3.12

\section{Y DÍGAME, ¿USTED ACOSTUMBRA APOSTAR?}

(PORCENTAJES)

\begin{tabular}{|c|c|c|c|c|}
\hline & & Sí & No & NC \\
\hline & TOTAL NACIONAL & 20.9 & 78.3 & 0.7 \\
\hline Sovo & Hombre & 31.7 & 68.0 & 0.4 \\
\hline שטגסת & Mujer & 11.4 & 87.5 & 1.1 \\
\hline & De 18 a 24 años & 23.0 & 75.4 & 1.6 \\
\hline & De 25 a 34 años & 16.7 & 82.2 & 1.2 \\
\hline Fdod & De 35 a 44 años & 22.6 & 76.9 & 0.5 \\
\hline Lidate & De 45 a 54 años & 24.0 & 75.7 & 0.3 \\
\hline & De 55 a 64 años & 22.7 & 77.3 & \\
\hline & 65 años y más & 16.5 & 83.5 & \\
\hline & Ninguno & 6.3 & 93.7 & \\
\hline & Primaria & 20.2 & 79.8 & \\
\hline Escolaridad & Secundaria & 18.5 & 81.2 & 0.3 \\
\hline & Preparatoria o bachillerato & 24.5 & 74.7 & 0.8 \\
\hline & Licenciatura o posgrado & 32.8 & 62.0 & 5.2 \\
\hline & Unión libre/casado & 20.5 & 79.1 & 0.4 \\
\hline Estado civil & Separado/divorciado/viudo & 18.9 & 80.1 & 1.0 \\
\hline & Soltero & 23.3 & 75.0 & 1.7 \\
\hline Condición & Sí trabajó & 28.6 & 70.5 & 0.8 \\
\hline de actividad & No trabajó & 10.2 & 89.2 & 0.6 \\
\hline & No percibe ingreso & 8.3 & 91.7 & \\
\hline Ingreso & $\begin{array}{l}\text { De } \$ 1 \text { a } \$ 4,382 \\
\text { (hasta } 2 \text { SM) }\end{array}$ & 24.3 & 75.7 & \\
\hline individual & De $\$ 4,383$ a $\$ 8,765$ (más de 2 hasta 4 SM) & 31.6 & 66.9 & 1.5 \\
\hline & $\begin{array}{l}\text { Más de } \$ 8,765 \\
\text { (más de } 4 \text { SM) }\end{array}$ & 39.8 & 59.2 & 1.0 \\
\hline & Menos de $\$ 4,382$ (hasta 2 SM) & 13.2 & 85.2 & 1.5 \\
\hline & De $\$ 4,383$ a $\$ 8,765$ (más de 2 hasta 4 SM) & 22.4 & 75.9 & 1.7 \\
\hline familiar & De $\$ 8,766$ a $\$ 13,147$ (más de 4 hasta 6 SM) & 25.9 & 74.1 & \\
\hline & $\begin{array}{l}\text { Más de } \$ 13,147 \\
\text { (más de } 6 \text { SM) }\end{array}$ & 39.9 & 59.1 & 1.0 \\
\hline & Católico & 22.2 & 77.5 & 0.3 \\
\hline Religión & Ateo & 21.8 & 78.2 & \\
\hline & Otra & 15.8 & 81.7 & 2.5 \\
\hline
\end{tabular}


Este libro forma parte del acervo de la Biblioteca Jurídica Virtual del Instituto de Investigaciones Jurídicas de la UNAM www.juridicas.unam.mx

(CONTINUACIÓN)

\begin{tabular}{l|l|l|l|c}
\hline \multirow{7}{*}{ Región } & Noroeste & 25.5 & 72.4 & 2.1 \\
\cline { 2 - 5 } & Noreste & 23.6 & 76.4 & \\
\cline { 2 - 5 } & Occidente & 20.3 & 79.7 & \\
\cline { 2 - 5 } & Centro & 20.6 & 79.4 & \\
\cline { 2 - 5 } & Sureste & 17.4 & 80.4 & 2.2 \\
\hline
\end{tabular}

Fuente: Encuesta Nacional de Percepciones Sociales de los Juegos de Azar en México, México, UNAM, Instituto de Investigaciones Jurídicas, Departamento de Investigación Aplicada y Opinión, 2016.

GRÁFICA 3.15

¿ACOSTUMBRA PARTICIPAR EN RIFAS O SORTEOS?

(PORCENTAJES)

No, $76.2 \longrightarrow$

Fuente: Encuesta Nacional de Percepciones Sociales de los Juegos de Azar en México, México, UNAM, Instituto de Investigaciones Jurídicas, Departamento de Investigación Aplicada y Opinión, 2016.

Por otro lado, la gran mayoría de las personas entrevistadas dijo que no está registrada en alguna página de apuestas por Internet, en tanto que únicamente el 0.8 por ciento señaló que sí está registrado (véase gráfica 3.16). Si bien la proporción de personas que tiene acceso a páginas de apuestas por Internet es mínimo, es importante destacar que tienen un perfil definido, ya que son personas adultas jóvenes en el grupo de edad de 25 a 34 años, las que tienen licenciatura o posgrado y las que obtienen un ingreso individual más alto. 
Este libro forma parte del acervo de la Biblioteca Jurídica Virtual del Instituto de Investigaciones Jurídicas de la UNAM

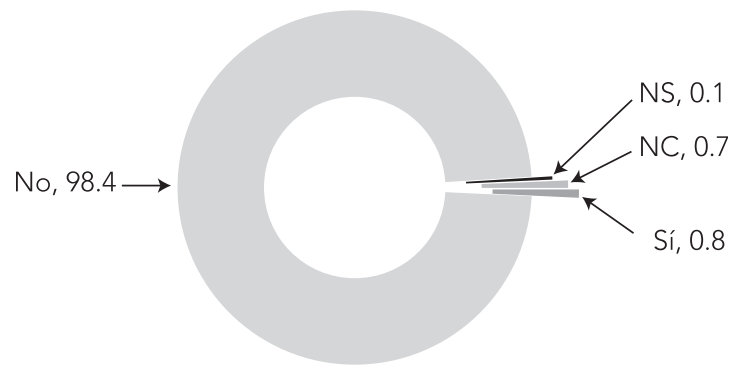

Fuente: Encuesta Nacional de Percepciones Sociales de los Juegos de Azar en México, México, unam, Instituto de Investigaciones Jurídicas, Departamento de Investigación Aplicada y Opinión, 2016.

En cuanto al conocimiento que los encuestados tienen de los juegos y sorteos, la Lotería Nacional, Zodiaco y El Gordo fueron los más mencionados, ya que cerca de nueve de cada diez entrevistados los reconocieron; por su parte, fueron cerca de ocho de cada diez los que respondieron conocer el Melate, mientras que siete de cada diez mencionaron conocer la Lotería mexicana. Asimismo, más de seis de cada diez indicaron conocer las rifas y tómbolas, las máquinas tragamonedas, los juegos tradicionales, los juegos de cartas fuera de casinos, otros sorteos (raspar), las apuestas en carreras de caballos, perros, automóviles, futbol, gallos, frontón y quinielas. Por otro lado, fueron más de cinco de cada diez los entrevistados que señalaron conocer el jaripeo, el rodeo, los casinos y los telejuegos. Finalmente, fueron poco más de cuatro de cada diez los que contestaron que conocen el bingo y los juegos por Internet (véase cuadro 3.13).

Los encuestados que en mayor medida afirmaron conocer la Lotería Nacional fueron los mayores de 55 años. Además, se observa una tendencia donde a mayor escolaridad, mayor es el conocimiento de este sorteo. En el caso de Melate (sorteos en papel, elegir números) también se encontró la misma tendencia relacionada con la escolaridad. 
Este libro forma parte del acervo de la Biblioteca Jurídica Virtual del Instituto de Investigaciones Jurídicas de la UNAM www.juridicas.unam.mx

CUADRO 3.13

\begin{tabular}{|c|c|c|c|}
\hline \multicolumn{4}{|c|}{$\begin{array}{c}\text { ¿USTED CONOCE O NO CONOCE...? } \\
\text { (PORCENTAJES) }\end{array}$} \\
\hline & Sí & No & NC \\
\hline Lotería Nacional, Zodiaco, El Gordo (comprar boleto) & 87.3 & 12.6 & 0.1 \\
\hline Melate (sorteos en papel, elegir números) & 79.8 & 20.2 & 0.0 \\
\hline Lotería mexicana & 70.6 & 29.4 & 0.0 \\
\hline Rifa, tómbola & 68.1 & 31.9 & 0.0 \\
\hline Máquinas tragamonedas (de peso o de cinco pesos) & 66.4 & 33.6 & 0.0 \\
\hline $\begin{array}{l}\text { Juegos tradicionales (rayuela, dados, cubilete, volado, } \\
\text { dominó) }\end{array}$ & 65.8 & 34.2 & 0.0 \\
\hline $\begin{array}{l}\text { Juegos de cartas fuera de casinos, como en casas, } \\
\text { bares, etcétera (baraja española, póker, dados) }\end{array}$ & 65.5 & 34.5 & 0.0 \\
\hline Otros sorteos (raspar) & 64.9 & 35.1 & 0.0 \\
\hline $\begin{array}{l}\text { Apuestas en carreras de caballos, perros, automóviles, } \\
\text { futbol, gallos, frontón, etcétera }\end{array}$ & 64.7 & 35.3 & 0.0 \\
\hline Quinielas (deportes) & 63.5 & 36.5 & 0.0 \\
\hline Jaripeo o rodeo (montar toros y lazar ganado) & 59.2 & 40.8 & 0.0 \\
\hline Ir al casino & 57.7 & 42.3 & 0.0 \\
\hline $\begin{array}{l}\text { Concursos de preguntas y respuestas o rompecabezas } \\
\text { por televisión en los que se envía un mensaje de texto } \\
\text { o se llama por teléfono (telejuegos) }\end{array}$ & 53.7 & 46.3 & 0.0 \\
\hline Bingo & 45.3 & 54.7 & 0.0 \\
\hline Juegos por Internet (póker, loterías, etcétera) & 41 & 59 & 0.0 \\
\hline
\end{tabular}

Fuente: Encuesta Nacional de Percepciones Sociales de los Juegos de Azar en México, México, UNAM, Instituto de Investigaciones Jurídicas, Departamento de Investigación Aplicada y Opinión, 2016.

Posteriormente, para recoger prácticas y experiencia en distintos juegos y sorteos, a los encuestados se les preguntó sobre su participación o la compra de un boleto. ${ }^{3}$ En este sentido, en el cuadro 3.14 se observa que los juegos y sorteos donde las personas entrevistadas en mayor medida señalaron haber participado son: rifas/tómbolas, boletos de lotería y juegos de cartas. Un mayor porcentaje de mujeres dijo que ha participado en rifas o tómbolas. Por otra parte, los hombres con más frecuencia afirmaron que han comprado boletos de lotería, al igual que las personas que cuentan con licenciatura o posgrado y quienes trabajan.

3 Los porcentajes aquí presentados corresponden a todas las personas que dijeron haber jugado alguna vez un juego de azar, sin mediar ningún otro criterio. 
Este libro forma parte del acervo de la Biblioteca Jurídica Virtual del Instituto de Investigaciones Jurídicas de la UNAM

Los juegos y sorteos menos recurridos por las personas entrevistadas fueron los telejuegos y apuestas por Internet, aunque frente a la creciente penetración de los servicios de Internet a lo largo del país y el gradual incremento de la confianza en los servicios y compras en línea, las apuestas por Internet tienen un importante potencial de crecimiento en el futuro.

CUADRO 3.14

¿USTED HA PARTICIPADO O COMPRADO UN BOLETO?

(PORCENTAJES)

\begin{tabular}{l|c|c}
\hline & Sí & No \\
\hline Rifa, tómbola & 20.5 & 79.5 \\
\hline Lotería Nacional, Zodiaco, El Gordo (comprar boleto) & 17.7 & 82.3 \\
\hline $\begin{array}{l}\text { Juegos de cartas fuera de casinos, como en casas, bares, etcétera (baraja } \\
\text { española, póker, dados) }\end{array}$ & 17.7 & 82.3 \\
\hline Ir al casino & 16.4 & 83.6 \\
\hline Máquinas tragamonedas (de peso o de cinco pesos) & 16.3 & 83.7 \\
\hline Lotería mexicana & 15.7 & 84.3 \\
\hline Juegos tradicionales (rayuela, dados, cubilete, volado, dominó) & 15.7 & 84.3 \\
\hline Otros sorteos (raspar) & 14.2 & 85.8 \\
\hline Melate (sorteos en papel, elegir números) & 14.0 & 86.0 \\
\hline Quinielas (deportes) & 13.5 & 86.5 \\
\hline $\begin{array}{l}\text { Apuestas en carreras de caballos, perros, automóviles, futbol, gallos, } \\
\text { frontón, etcétera }\end{array}$ & 10.8 & 89.2 \\
\hline Bingo & 7.1 & 92.9 \\
\hline Jaripeo o rodeo (montar toros y lazar ganado) & 2.3 & 97.7 \\
\hline Juegos por Internet (póker, loterías, etcétera) & 2.0 & 98.0 \\
\hline $\begin{array}{l}\text { Concursos de preguntas y respuestas o rompecabezas por televisión en } \\
\text { los que se envía un mensaje de texto o se llama por teléfono (telejuegos) }\end{array}$ & 1.6 & 98.4 \\
\hline
\end{tabular}

Fuente: Encuesta Nacional de Percepciones Sociales de los Juegos de Azar en México, México, UNAM, Instituto de Investigaciones Jurídicas, Departamento de Investigación Aplicada y Opinión, 2016.

\section{ACTITUDES HACIA LOS JUEGOS DE APUESTAS}

Con el objetivo de recoger distintas actitudes hacia los juegos de apuestas, en la encuesta se incluyó una serie de frases que permite analizar las creencias que tienen los mexicanos hacia este tipo de actividad. En este sentido, 
Este libro forma parte del acervo de la Biblioteca Jurídica Virtual del Instituto de Investigaciones Jurídicas de la UNAM

en el cuadro 3.15 se observa que más de la mitad de las personas entrevistadas (57.6 por ciento) está de acuerdo o muy de acuerdo con la frase: En los juegos de apuesta la casa nunca pierde. Asimismo, casi cuatro de cada diez entrevistados están de acuerdo o muy de acuerdo con las frases: Si se le apuesta siempre al mismo número hay más probabilidad de que salga premiado (39.5 por ciento) y Hay jugadores que saben cuándo retirarse (39.4 por ciento); mientras que más de tres de cada diez están de acuerdo o muy de acuerdo con las frases: Para poder ganar en las máquinas tragamonedas sólo se necesita encontrarle el truco (36.2 por ciento), Los juegos de apuesta son para la gente ociosa (35.7 por ciento) y Los juegos de apuesta son una forma sana de diversión (32.3 por ciento).

Por su parte, una mayor proporción de personas estuvo en desacuerdo y muy en desacuerdo con las siguientes frases: Apostar es un pecado (54.6 por ciento) y Los juegos de apuesta son sólo para los ricos (41.4 por ciento). Con respecto a la última frase, si bien no es determinante, más adelante se observa que son los grupos con ingresos más altos quienes con mayor frecuencia participan en los juegos de azar.

\section{CUADRO 3.15}

\begin{tabular}{|c|c|c|c|c|c|c|c|}
\hline \multicolumn{8}{|c|}{$\begin{array}{c}\text { ¿QUÉ TAN DE ACUERDO O EN DESACUERDO } \\
\text { ESTÁ CON LAS SIGUIENTES FRASES? } \\
\text { (PORCENTAJES) }\end{array}$} \\
\hline & $\begin{array}{l}\text { MUY DE } \\
\text { ACUERDO }\end{array}$ & $\begin{array}{c}\text { DE } \\
\text { ACUERDO }\end{array}$ & $\begin{array}{l}\text { NIDE } \\
\text { ACUERDO, } \\
\text { NI EN } \\
\text { DESACUERDO }\end{array}$ & $\begin{array}{c}\text { EN } \\
\text { DESACUERDO }\end{array}$ & $\begin{array}{c}\text { MUY EN } \\
\text { DESACUERDO }\end{array}$ & NS & NC \\
\hline $\begin{array}{l}\text { En los juegos de apuesta } \\
\text { la casa nunca pierde }\end{array}$ & 22.6 & 35.0 & 17.3 & 10.8 & 3.4 & 9.9 & 1.0 \\
\hline $\begin{array}{l}\text { Si se le apuesta siempre } \\
\text { al mismo número hay } \\
\text { más probabilidad que } \\
\text { salga premiado }\end{array}$ & 8.8 & 30.7 & 18.3 & 21.7 & 3.3 & 17.0 & 0.2 \\
\hline $\begin{array}{l}\text { Hay jugadores que } \\
\text { saben cuándo retirarse }\end{array}$ & 10.7 & 28.7 & 20.4 & 18.1 & 6.3 & 14.7 & 1.1 \\
\hline $\begin{array}{l}\text { Para poder ganar en las } \\
\text { máquinas tragamonedas } \\
\text { sólo se necesita } \\
\text { encontrarle el truco }\end{array}$ & 10.1 & 26.1 & 21.8 & 12.8 & 4.1 & 23.6 & 1.5 \\
\hline $\begin{array}{l}\text { Los juegos de apuesta } \\
\text { son para la gente ociosa }\end{array}$ & 9.6 & 26.1 & 24.4 & 25.4 & 6.1 & 7.5 & 0.9 \\
\hline
\end{tabular}


Este libro forma parte del acervo de la Biblioteca Jurídica Virtual del Instituto de Investigaciones Jurídicas de la UNAM

\begin{tabular}{l|c|c|c|c|c|c|c}
\hline \multicolumn{2}{c}{ (CONTINUACIÓN) } \\
\hline $\begin{array}{l}\text { Los juegos de apuesta } \\
\text { son una forma sana de } \\
\text { diversión }\end{array}$ & 5.1 & 27.2 & 28.9 & 22.6 & 8.7 & 6.9 & 0.6 \\
\hline $\begin{array}{l}\text { Los juegos de apuesta } \\
\text { son sólo para los ricos } \\
\text { (para gente que tiene } \\
\text { mucho dinero) }\end{array}$ & 10.0 & 21.7 & 21.2 & 31.3 & 10.1 & 5.1 & 0.6 \\
\hline Apostar es un pecado & 5.1 & 14.3 & 18.4 & 40.4 & 14.2 & 6.7 & 0.9 \\
\hline
\end{tabular}

Fuente: Encuesta Nacional de Percepciones Sociales de los Juegos de Azar en México, México, UNAM, Instituto de Investigaciones Jurídicas, Departamento de Investigación Aplicada y Opinión, 2016.

En suma, estos resultados permiten observar que en México no existe una tendencia estigmatizadora de los juegos de apuesta como un problema o un vicio vinculado a personas inactivas o problemáticas, aunque tampoco es considerada una actividad virtuosa.

\section{PERCEPCIÓN DE LA LEGALIDAD DE LOS JUEGOS DE AZAR Y APUESTAS}

El contexto actual en el que se presentan los juegos con apuestas permite su crecimiento y diversificación, lo que posibilita que cualquier persona pueda acceder y participar en ellos. La regulación jurídica de los juegos de azar y las apuestas brinda a quienes participan en ellos certidumbre respecto a sus ganancias y a practicar una actividad legal.

Sobre la regulación del tema, el Estado mexicano cuenta con tres instrumentos legales que orientan y regulan a los sujetos que intervienen en los juegos con apuestas. El primero de ellos es la Constitución Política de los Estados Unidos Mexicanos, en su artículo 76, fracción X, mediante la cual se faculta al Congreso de la Unión (Poder Legislativo) para legislar en materia de juegos con apuestas y sorteos. El segundo instrumento legal es la Ley Federal de Juegos y Sorteos, vigente desde 1947 sin que haya tenido alguna reforma o adición. El tercer instrumento legal es el Reglamento de la Ley Federal de Juegos y Sorteos, vigente desde 2004.

En este contexto, pareció importante explorar sobre el tema, porque a pesar de que existe una regulación jurídica en la materia, la Ley Federal de Juegos y Sorteos tiene alrededor de 70 años de vigencia y su Reglamento, 
Este libro forma parte del acervo de la Biblioteca Jurídica Virtual del Instituto de Investigaciones Jurídicas de la UNAM

aunque reciente, se encarga de regular actividades que no son mencionadas en la Ley; los casinos son el ejemplo más importante en este sentido. Por tal razón, se planteó la siguiente pregunta general: ¿qué nivel de conocimiento tienen los mexicanos en relación con la regulación jurídica de los juegos de azar y las apuestas? Para comenzar, se planteó la pregunta: Por lo que usted sabe, ¿los juegos de apuesta y sorteo están o no están regulados por la ley? Al respecto, poco más de la mitad sostuvo que sí se encuentran regulados en las normas jurídicas; en contraste, más de dos de cada diez respondieron que no, mientras poco más de dos de cada diez dijeron no saber (véase gráfica 3.17).

GRÁFICA 3.17

\author{
POR LO QUE USTED SABE, ¿LOS JUEGOS DE APUESTA \\ Y SORTEO ESTÁN O NO ESTÁN REGULADOS POR LA LEY? \\ (PORCENTAJES)
}

\title{
Sí, 53.4
}

No, 21.0 NS, $24.0 \quad$ NC, 1.6

Fuente: Encuesta Nacional de Percepciones Sociales de los Juegos de Azar en México, México, unam, Instituto de Investigaciones Jurídicas, Departamento de Investigación Aplicada y Opinión, 2016.

A partir de los datos sociodemográficos, los que respondieron en mayor medida que sí estaban regulados por la ley fueron los hombres, los de 35 a 44 años, los que perciben más de cuatro salarios mínimos individuales, los habitantes del noreste del país, y a partir de la escolaridad de los encuestados se halló una tendencia donde entre mayor escolaridad tenía la persona, mayor era también el porcentaje de esta respuesta. En contraste, quienes respondieron que los juegos de apuesta y sorteos no están regulados por la ley fueron, por encima de la media, las personas de 45 a 54 años, sin escolaridad, quienes perciben de 0 a 2 salarios mínimos familiares al mes y los habitantes del centro y occidente de nuestro país.

Al efectuar un cruce de esta pregunta de acuerdo con la práctica de juego, se observan diferencias significativas en relación con el conocimiento de la regulación legal de los juegos de apuesta y sorteos. Los jugadores en mayor medida respondieron que los juegos están regulados por la ley (63.9 por ciento), en comparación con la media nacional (53.4 por ciento) y los no jugadores (véase cuadro 3.16). De aquí se desprende la hipótesis de que a 
Este libro forma parte del acervo de la Biblioteca Jurídica Virtual del Instituto de Investigaciones Jurídicas de la UNAM

mayor participación en juegos de azar, crece el conocimiento de la situación legal de los mismos.

\section{CUADRO 3.16}

POR LO QUE USTED SABE, ¿LOS JUEGOS DE APUESTA Y SORTEO ESTÁN O NO ESTÁN REGULADOS POR LA LEY? (PORCENTAJES)

\begin{tabular}{l|c|c|c}
\hline & MEDIA NACIONAL & JUEGA EN EL ÚLTIMO AÑO & NO JUEGA NINGÚN JUEGO \\
\hline Sí & 53.4 & 63.9 & 43.6 \\
\hline No & 21.0 & 17.7 & 24.0 \\
\hline NS & 24.0 & 17.9 & 29.7 \\
\hline NC & 1.6 & 0.4 & 2.7 \\
\hline
\end{tabular}

Fuente: Encuesta Nacional de Percepciones Sociales de los Juegos de Azar en México, México, UNAM, Instituto de Investigaciones Jurídicas, Departamento de Investigación Aplicada y Opinión, 2016.

Para completar la información y verificar el nivel de conocimiento del tema, al 53.6 por ciento de los entrevistados que señalaron que los juegos de azar sí están regulados por la ley se les preguntó ¿quién los regula? Un poco más de la mitad (53.1 por ciento) mencionó que están a cargo las autoridades federales (gobierno federal, Secretaría de Gobernación); no obstante, hay un gran desconocimiento sobre la regulación de los juegos de azar: casi cuatro de cada diez entrevistados dijeron no saber o mencionaron a otras autoridades (véase gráfica 3.18).

Cabe señalar que en la Ley Federal de Juegos y Sorteos se encuentra la regulación sobre los juegos con apuestas en México; en ella se disponen de manera específica las directrices y principios por los que debe regirse dicha actividad, además se establece el marco de prohibición y permisión de los juegos con apuestas. Asimismo, en esta Ley se plasma el marco de actuación de la autoridad responsable de vigilar y operar dichas actividades, en este caso el Ejecutivo Federal a través de la Secretaría de Gobernación. El Reglamento de la Ley Federal de Juegos y Sorteos establece, de manera específica, los requisitos y obligaciones que deben cumplir los sujetos que participen en los juegos con apuestas, con el fin de que la autoridad pueda otorgar la autorización para estas actividades, además de que sean sujetas a un control, vigilancia e inspección. 
Este libro forma parte del acervo de la Biblioteca Jurídica Virtual del Instituto de Investigaciones Jurídicas de la UNAM

GRÁFICA 3.18

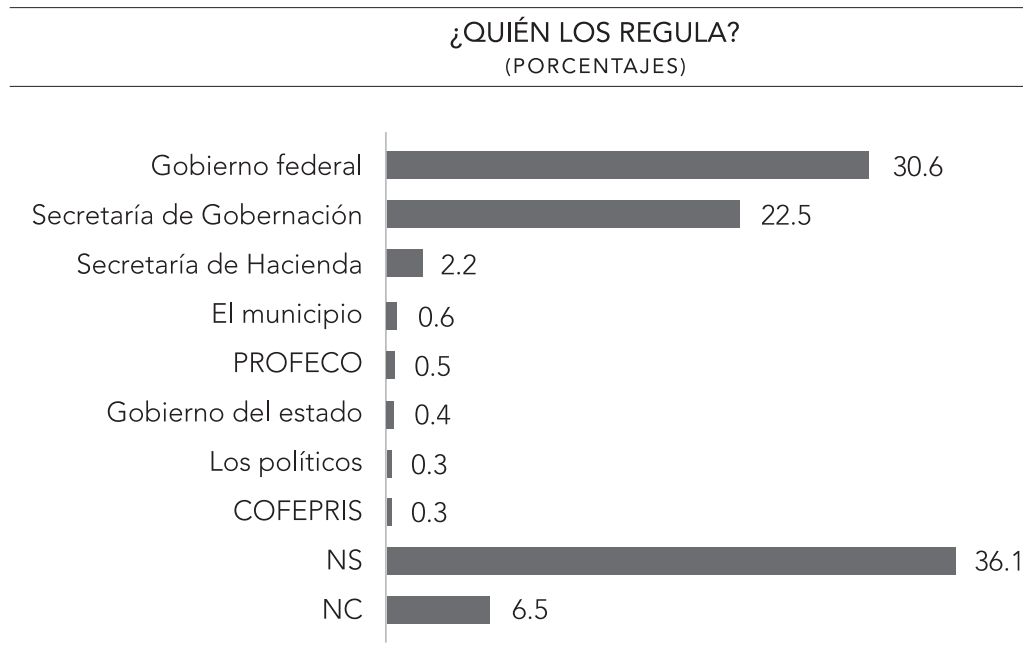

Fuente: Encuesta Nacional de Percepciones Sociales de los Juegos de Azar en México, México, unam, Instituto de Investigaciones Jurídicas, Departamento de Investigación Aplicada y Opinión, 2016.

Al cruzar la información relativa al conocimiento de las autoridades que regulan los juegos de azar con la práctica de juego, se observa que no existen diferencias significativas entre quienes han practicado algún juego de azar en el último año y quienes no lo han hecho. Sin embargo, las personas encuestadas que no juegan demuestran un menor nivel de información que las que sí lo hacen (véase cuadro 3.17).

En el mismo sentido, se preguntó a los encuestados sobre su percepción acerca de la legalidad o ilegalidad de los casinos en nuestro país. Sobre este tema, cabe señalar que la legalidad y permisión en la operación de los casinos se encuentra establecida tanto en la Ley Federal de Juegos y Sorteos como en su Reglamento. En este último se define a los casinos como "establecimientos", ya que pueden ser lugares abiertos o cerrados en los que se llevan a cabo juegos con apuestas y sorteos, y que cuentan con un permiso vigente otorgado por la Secretaría de Gobernación, siempre y cuando cumplan con los requisitos establecidos en el título segundo del Reglamento en mención. 
Este libro forma parte del acervo de la Biblioteca Jurídica Virtual del Instituto de Investigaciones Jurídicas de la UNAM

CUADRO 3.17

\begin{tabular}{l|c|c|c}
\hline \multicolumn{4}{c}{$\begin{array}{c}\text { ¿QUIÉN LOS REGULA? } \\
\text { (PORCENTAJES) }\end{array}$} \\
\hline & $\begin{array}{c}\text { MEDIA } \\
\text { NACIONAL }\end{array}$ & $\begin{array}{c}\text { JUEGA EN EL ÚLTIMO } \\
\text { AÑO }\end{array}$ & $\begin{array}{c}\text { NO JUEGA NINGÚN } \\
\text { JUEGO }\end{array}$ \\
\hline Gobierno federal & 30.6 & 31.6 & 29.4 \\
\hline $\begin{array}{l}\text { Secretaría de } \\
\text { Gobernación }\end{array}$ & 22.5 & 23.2 & 21.5 \\
\hline $\begin{array}{l}\text { Secretaría de } \\
\text { Hacienda }\end{array}$ & 2.2 & 2.2 & 2.2 \\
\hline El municipio & 0.6 & 0.6 & 0.7 \\
\hline PROFECO & 0.5 & 0.7 & 0.3 \\
\hline Gobierno del estado & 0.4 & 0.7 & 0.0 \\
\hline Los políticos & 0.3 & 0.2 & 0.4 \\
\hline COFEPRIS & 0.3 & 0.5 & 0.0 \\
\hline NS & 36.1 & 33.7 & 39.3 \\
\hline NC & 6.5 & 6.7 & 6.1 \\
\hline
\end{tabular}

Fuente: Encuesta Nacional de Percepciones Sociales de los Juegos de Azar en México, México, UNAM, Instituto de Investigaciones Jurídicas, Departamento de Investigación Aplicada y Opinión, 2016.

Los casinos, además de cumplir con los requisitos para obtener un permiso, deben procurar que en sus instalaciones se prohíba el acceso o permanencia en las áreas de juegos con apuestas: a las personas que sean menores de edad, excepto cuando en compañía de un adulto ingresen a espectáculos en vivo; a los menores de edad que pretendan participar en el cruce de apuestas; a las personas que se encuentren en posesión o bajo la influencia de sustancias psicotrópicas o prohibidas, o en estado de ebriedad; a las personas que porten armas de cualquier tipo; a las personas que sean miembros de instituciones policiales o militares uniformados en servicio, salvo cuando sea necesario para el cumplimiento de sus funciones públicas; a las personas que con su conducta alteren la tranquilidad o el orden en el establecimiento; a las personas que sean o hayan sido sorprendidas haciendo trampa, y a quienes no cumplan con el reglamento interno del establecimiento, previamente aprobado por la Secretaría. ${ }^{4}$ 
Este libro forma parte del acervo de la Biblioteca Jurídica Virtual del Instituto de Investigaciones Jurídicas de la UNAM

De las respuestas otorgadas por los entrevistados se desprendió que casi seis de cada diez dijeron que los casinos sí son legales, mientras que tres de cada diez no supieron responder a la pregunta, y sólo uno de cada diez los consideró ilegales. Puede decirse que aunque la percepción de la legalidad de los casinos es mayor en comparación con la percepción licita de los juegos de apuesta y sorteo, aún sigue existiendo un desconocimiento importante acerca de su permisión, ya que si se suman los porcentajes obtenidos en las respuestas no son legales y no sabe, el resultado es el 40.1 por ciento del total de los encuestados (véase gráfica 3.19).

\section{GRÁFICA 3.19}

Y, ¿LOS CASINOS SON O NO SON LEGALES EN MÉXICO?

(PORCENTAJES)

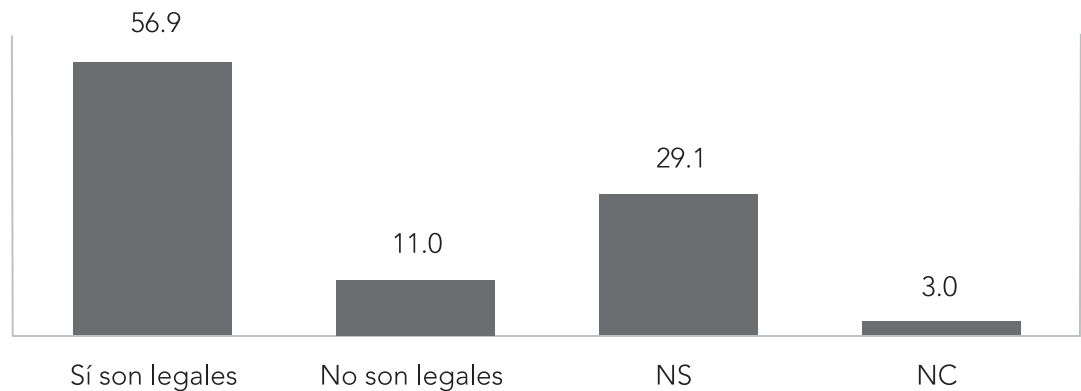

Fuente: Encuesta Nacional de Percepciones Sociales de los Juegos de Azar en México, México, UnAm, Instituto de Investigaciones Jurídicas, Departamento de Investigación Aplicada y Opinión, 2016.

Expresaron que los casinos sí son legales en México en mayor medida los hombres, quienes tienen de 18 a 24 años y de 35 a 44 años. Asimismo, existe una tendencia en función de la educación y el ingreso individual, pues conforme aumentan el nivel escolar y el ingreso de los entrevistados, aumenta el conocimiento sobre la legalidad de los casinos. Por otra parte, las personas que viven en el noreste del país tienen un conocimiento mayor sobre el tema.

En cuanto al cruce de las respuestas de los encuestados que jugaron y no jugaron en el último año, se encontraron diferencias reveladoras. Por ejemplo, de aquellos que respondieron que sí son legales los casinos en México, los que sí juegan representan el 71.2 por ciento, lo cual se encuentra por encima del promedio nacional (56.9 por ciento) y de los no jugadores (43.6 
Este libro forma parte del acervo de la Biblioteca Jurídica Virtual del Instituto de Investigaciones Jurídicas de la UNAM

por ciento). En cambio, los que respondieron en una proporción más elevada no saber si los casinos son o no legales en México fueron los no jugadores (37.1 por ciento) (véase cuadro 3.18).

\section{CUADRO 3.18}

\begin{tabular}{l|c|c|c}
\hline \multicolumn{3}{c}{ Y, ¿LOS CASINOS SON O NO SON LEGALES EN MÉXICO? } \\
(PORCENTAJES)
\end{tabular}

Fuente: Encuesta Nacional de Percepciones Sociales de los Juegos de Azar en México, México, UNAM, Instituto de Investigaciones Jurídicas, Departamento de Investigación Aplicada y Opinión, 2016.

Es clara la relación entre aquellos que juegan y la percepción de que los casinos son legales; a la inversa, los no jugadores en mayor medida no supieron qué responder a dicha pregunta.

Con miras a la creación de una legislación más actualizada, a partir de las discusiones que se han dado en torno a la regulación de los casinos y los juegos de apuesta en México, y tomando en cuenta las omisiones de la ley en el tema, diversos organismos y actores han planteado sugerencias dirigidas sobre todo a prevenir el juego problemático. Para conocer la opinión de los entrevistados al respecto, se planteó una batería de preguntas con el siguiente cuestionamiento general: en caso de crearse una nueva ley, iusted estaría de acuerdo o en desacuerdo con las siguientes medidas?

En respuesta, siete de cada diez entrevistados (76 por ciento) estuvieron muy de acuerdo y de acuerdo con la medida de establecer como edad mínima los 21 años para el acceso a sitios de apuesta. Más de cinco de cada diez de los individuos (56.4 por ciento) se mostraron muy de acuerdo y de acuerdo con que se limite la cantidad de dinero que una persona puede gastar a la semana en los sitios de apuesta. Cinco de cada diez de los entrevistados (50.7 por ciento) respondieron estar muy de acuerdo y de acuerdo con que se prohíba entrar a los sitios de apuesta a las personas que juegan mucho. Asimismo, la mitad de los entrevistados (50.1 por ciento) manifestó 
Este libro forma parte del acervo de la Biblioteca Jurídica Virtual del Instituto de Investigaciones Jurídicas de la UNAM www.juridicas.unam.mx

estar muy de acuerdo y de acuerdo con que no se pongan cajeros automáticos en los sitios donde se hacen apuestas. Y poco más de cuatro de cada diez de los entrevistados (43.2 por ciento) se inclinaron hacia el muy de acuerdo y de acuerdo con que se prohíban las máquinas tragamonedas en las tienditas (véase cuadro 3.19).

CUADRO 3.19

EN CASO DE CREARSE UNA NUEVA LEY, ¿USTED ESTÁ DE ACUERDO O EN DESACUERDO CON LAS SIGUIENTES MEDIDAS? (PORCENTAJES)

\begin{tabular}{l|c|c|c|c|c|c|c}
\hline & $\begin{array}{c}\text { MUY DE } \\
\text { ACUERDO }\end{array}$ & $\begin{array}{c}\text { DE } \\
\text { ACUERDO }\end{array}$ & $\begin{array}{c}\text { NI DE } \\
\text { ACUERDO, } \\
\text { NI EN } \\
\text { DESACUERDO }\end{array}$ & $\begin{array}{c}\text { EN } \\
\text { DESACUERDO }\end{array}$ & $\begin{array}{c}\text { MUY EN } \\
\text { DESACUERDO }\end{array}$ & NS & NC \\
\hline $\begin{array}{l}\text { Que la edad mínima para } \\
\text { el acceso a sitios de } \\
\text { apuesta sea de 21 años }\end{array}$ & 31.9 & 44.1 & 12.8 & 4.6 & 2.3 & 3.7 & 0.6 \\
\hline $\begin{array}{l}\text { Que los sitios de apuesta } \\
\text { limiten la cantidad de } \\
\begin{array}{l}\text { dinero que una persona } \\
\text { puede gastar a la semana }\end{array}\end{array}$ & 17.7 & 38.7 & 19.6 & 11.0 & 3.8 & 7.8 & 1.4 \\
\hline $\begin{array}{l}\text { Que a las personas que } \\
\text { juegan mucho se les } \\
\text { prohíba entrar a los sitios } \\
\text { de apuesta }\end{array}$ & 18.0 & 32.7 & 19.0 & 18.1 & 3.3 & 7.8 & 1.1 \\
\hline $\begin{array}{l}\text { Que no se pongan } \\
\text { cajeros automáticos en } \\
\text { los sitios de apuesta }\end{array}$ & 16.4 & 33.7 & 22.6 & 13.9 & 4.6 & 7.4 & 1.4 \\
\hline $\begin{array}{l}\text { Que se prohiban las } \\
\text { máquinas tragamonedas } \\
\text { (de 1 o 5 pesos) en las } \\
\text { tienditas }\end{array}$ & 14.9 & 28.3 & 24.1 & 15.8 & 8.0 & 7.7 & 1.2 \\
\hline
\end{tabular}

Fuente: Encuesta Nacional de Percepciones Sociales de los Juegos de Azar en México, México, UNAM, Instituto de Investigaciones Jurídicas, Departamento de Investigación Aplicada y Opinión, 2016.

Por lo tanto, la medida que tuvo mayor aceptación, con más de dos terceras partes de los entrevistados, fue el aumento de la edad mínima para acceder a los sitios de apuesta. En contraste, es interesante que la medida de prohibir las máquinas tragamonedas en las tienditas haya sido la menos popular, con una mención de poco más de cuatro de cada diez de los entrevistados, sobre todo al tomar en cuenta que estas máquinas de hecho están prohibidas por el artículo 12 del Reglamento de la Ley Federal de Juegos y Sorteos. 
Este libro forma parte del acervo de la Biblioteca Jurídica Virtual del Instituto de Investigaciones Jurídicas de la UNAM www.juridicas.unam.mx

CUADRO 3.20

\section{EN CASO DE CREARSE UNA NUEVA LEY, ¿USTED ESTÁ DE ACUERDO O EN DESACUERDO CON LAS SIGUIENTES MEDIDAS?}

(PORCENTAJES)

\begin{tabular}{l|c|c|c}
\hline \multicolumn{4}{c}{ QUE LA EDAD MÍNIMA PARA EL ACCESO A SITIOS DE APUESTA SEA DE 21 AÑOS } \\
\hline & MEDIA NACIONAL & $\begin{array}{c}\text { JUEGA EN EL } \\
\text { ÚLTIMO AÑO }\end{array}$ & $\begin{array}{c}\text { NO JUEGA NINGÚN } \\
\text { JUEGO }\end{array}$ \\
\hline Muy de acuerdo & 31.9 & 31.8 & 32.1 \\
\hline De acuerdo & 44.1 & 49.8 & 38.8 \\
\hline $\begin{array}{l}\text { Ni de acuerdo, ni en } \\
\text { desacuerdo }\end{array}$ & 12.8 & 10.6 & 14.8 \\
\hline En desacuerdo & 4.6 & 3.9 & 5.2 \\
\hline Muy en desacuerdo & 2.3 & 2.3 & 2.4 \\
\hline NS & 3.7 & 1.6 & 5.6 \\
\hline NC & 0.6 & 0.0 & 1.1 \\
\hline
\end{tabular}

QUE LOS SITIOS DE APUESTA LIMITEN LA CANTIDAD DE DINERO QUE UNA PERSONA PUEDE GASTAR A LA SEMANA

\begin{tabular}{l|c|c|c}
\hline & MEDIA NACIONAL & $\begin{array}{c}\text { JUEGA EN EL } \\
\text { ÚLTIMO AÑO }\end{array}$ & $\begin{array}{c}\text { NO JUEGA NINGÚN } \\
\text { JUEGO }\end{array}$ \\
\hline Muy de acuerdo & 17.7 & 16.7 & 18.7 \\
\hline De acuerdo & 38.7 & 44.3 & 33.5 \\
\hline $\begin{array}{l}\text { Ni de acuerdo, ni en } \\
\text { desacuerdo }\end{array}$ & 19.6 & 20.2 & 19.0 \\
\hline En desacuerdo & 11.0 & 11.4 & 10.6 \\
\hline Muy en desacuerdo & 3.8 & 4.6 & 3.1 \\
\hline NS & 7.8 & 2.6 & 12.7 \\
\hline NC & 1.3 & 0.2 & 2.4 \\
\hline
\end{tabular}

QUE SE PROHÍBAN LAS MÁQUINAS TRAGAMONEDAS (DE 1 O 5 PESOS) EN LAS TIENDITAS

\begin{tabular}{l|c|c|c}
\hline & MEDIA NACIONAL & $\begin{array}{c}\text { JUEGA EN EL } \\
\text { ÚLTIMO AÑO }\end{array}$ & $\begin{array}{c}\text { NO JUEGA NINGÚN } \\
\text { JUEGO }\end{array}$ \\
\hline Muy de acuerdo & 14.9 & 11.2 & 18.5 \\
\hline De acuerdo & 28.3 & 30.7 & 26.1 \\
\hline $\begin{array}{l}\text { Ni de acuerdo, ni en } \\
\text { desacuerdo }\end{array}$ & 24.1 & 24.6 & 23.6 \\
\hline En desacuerdo & 15.8 & 18.0 & 13.7 \\
\hline Muy en desacuerdo & 8.0 & 12.5 & 3.8 \\
\hline NS & 7.7 & 2.8 & 12.4 \\
\hline NC & 1.1 & 0.3 & 1.9 \\
\hline
\end{tabular}

Fuente: Encuesta Nacional de Percepciones Sociales de los Juegos de Azar en México, México, UNAM, Instituto de Investigaciones Jurídicas, Departamento de Investigación Aplicada y Opinión, 2016. 
Este libro forma parte del acervo de la Biblioteca Jurídica Virtual del Instituto de Investigaciones Jurídicas de la UNAM

Al analizar las respuestas de los entrevistados entre lo dicho por los jugadores y los no jugadores se hallaron diferencias importantes. Así, quienes contestaron estar de acuerdo con que la edad mínima para tener acceso a sitios de apuesta sea de 21 años fueron en mayor medida los jugadores (49.8 por ciento), si se contrasta con la respuesta promedio nacional (44.1 por ciento) y con los que dijeron no haber jugado en el último año (38.8 por ciento). Algo similar sucedió con la propuesta: que los sitios de apuesta limiten la cantidad de dinero que una persona puede gastar a la semana, pues los que sí juegan estuvieron de acuerdo en mayor medida (44.3 por ciento) por sobre la media nacional (38.7 por ciento) y el porcentaje de los que no juegan (33.5 por ciento). En cuanto a la propuesta de prohibir las máquinas tragamonedas en las tienditas sucedió lo contrario, ya que aquellos que dijeron no haber jugado en el último año respondieron en mayor medida que estaban muy de acuerdo (18.5 por ciento), frente a la media nacional (14.9 por ciento) y a los que sí juegan (11.2 por ciento), que respondieron lo mismo (véase cuadro 3.20).

Aunado a la pregunta anterior, se les cuestionó a los entrevistados lo siguiente: y si se aprobaran estas medidas en nuestro país, ¿usted tendría más confianza o menos confianza para participar en los juegos de apuesta y sorteo?

Un tercio de los entrevistados indicó que tendría la misma confianza para participar en juegos de apuesta y sorteo en caso de que se aprobaran las medidas antes mencionadas. Resalta que un poco más de dos de cada diez manifestaran que tendrían más confianza (véase gráfica 3.20).

Entre los que señalaron por encima del promedio que tendrían la misma confianza, destacan las personas que habitan en el centro del país. Asimismo, las personas que manifestaron que tendrían más confianza fueron las de 18 a 24 años y de 35 a 44 años, las que obtienen un ingreso individual de dos a tres salarios mínimos mensuales, quienes cuentan con licenciatura o posgrado y las que radican en el occidente del país. 
Este libro forma parte del acervo de la Biblioteca Jurídica Virtual del Instituto de Investigaciones Jurídicas de la UNAM www.juridicas.unam.mx

\section{GRÁFICA 3.20}
Y SI SE APROBARAN ESTAS MEDIDAS EN NUESTRO PAÍS, ¿USTED TENDRÍA MÁS CONFIANZA O MENOS CONFIANZA PARA PARTICIPAR EN LOS JUEGOS DE APUESTA Y SORTEOS? (PORCENTAJES)

Tendría la misma confianza

Tendría más confianza

Depende (esp.)

Tendría menos confianza

NS

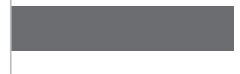

NC

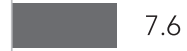

33.8

23.2

16.2

Fuente: Encuesta Nacional de Percepciones Sociales de los Juegos de Azar en México, México, Unam, Instituto de Investigaciones Jurídicas, Departamento de Investigación Aplicada y Opinión, 2016.

\section{CUADRO 3.21}

Y SI SE APROBARAN ESTAS MEDIDAS EN NUESTRO PAÍS, ¿USTED TENDRÍA MÁS CONFIANZA O MENOS CONFIANZA PARA PARTICIPAR EN LOS JUEGOS DE APUESTA Y SORTEOS? (PORCENTAJES)

\begin{tabular}{l|c|c|c}
\hline & MEDIA NACIONAL & $\begin{array}{c}\text { JUEGA EN EL ÚLTIMO } \\
\text { AÑO }\end{array}$ & $\begin{array}{c}\text { NO JUEGA NINGÚN } \\
\text { JUEGO }\end{array}$ \\
\hline $\begin{array}{l}\text { Tendría la misma } \\
\text { confianza }\end{array}$ & 33.8 & 39.3 & 28.6 \\
\hline Tendría más confianza & 23.2 & 33.9 & 13.3 \\
\hline Depende & 10.2 & 6.6 & 13.6 \\
\hline $\begin{array}{l}\text { Tendría menos } \\
\text { confianza }\end{array}$ & 9.0 & 7.6 & 10.3 \\
\hline NS & 16.2 & 10.3 & 21.7 \\
\hline NC & 7.6 & 2.3 & 12.5 \\
\hline
\end{tabular}

Fuente: Encuesta Nacional de Percepciones Sociales de los Juegos de Azar en México, México, UNAM, Instituto de Investigaciones Jurídicas, Departamento de Investigación Aplicada y Opinión, 2016. 
Este libro forma parte del acervo de la Biblioteca Jurídica Virtual del Instituto de Investigaciones Jurídicas de la UNAM

En el cruce de información de los jugadores y no jugadores se encontró una diferencia muy alta entre el porcentaje de jugadores encuestados que dijeron que tendrían más confianza si estas medidas fueran aprobadas en nuestro país (33.9 por ciento), la media nacional (23.2 por ciento) y los no jugadores (13.3 por ciento) (véase cuadro 3.21).

En general, el marco regulatorio, tanto administrativo como tributario, resulta esencial para lograr una correcta vigilancia de los juegos con apuestas y los establecimientos dedicados a esta actividad, además de las reglas claras acerca de las autorizaciones y condiciones generales para ponerlos en funcionamiento.

El marco de percepción sobre la legalidad de los juegos con apuestas y sorteos ofrece una serie de conclusiones y recomendaciones que pueden ser de gran utilidad para los actores vinculados con el tema de los juegos con apuestas, para los legisladores y las autoridades competentes en la regulación de esta forma de diversión.

\section{IMAGINARIOS Y ASOCIACIONES DE LOS CASINOS}

El estudio de las representaciones sociales permite recoger el pensamiento social y nos aproxima a la visión del mundo de las personas desde su posicionamiento social, tiempo y espacio (Echeverria et al., 2017: 5-30). Con el objetivo de recoger las principales asociaciones de los entrevistados con la palabra casino, se preguntó: ¿Podría decirme por favor las tres primeras palabras que le vienen a la mente cuando escucha la palabra "casino"? (véase cuadro 3.22).

En el análisis de las menciones brindadas por los entrevistados, las principales asociaciones dibujan a los casinos como espacios sujetos a la contingencia, donde los resultados son inciertos: dinero, juego y apuesta, pero también implican diversión. Las pérdidas y ganancias dependen de la suerte: se obtienen en primer lugar ganancias (asociación positiva), pero con la misma intensidad aparecen las pérdidas (signo negativo). Como consecuencia de dichas actividades se derivan problemas que se vinculan a los asistentes a los casinos, tales como vicios. 
Este libro forma parte del acervo de la Biblioteca Jurídica Virtual del Instituto de Investigaciones Jurídicas de la UNAM www.juridicas.unam.mx

CUADRO 3.22

\begin{tabular}{|c|c|}
\hline \multicolumn{2}{|c|}{$\begin{array}{c}\text { PODRÍA DECIRME POR FAVOR LAS TRES PRIMERAS PALABRAS QUE LE VIENEN } \\
\text { A LA MENTE CUANDO ESCUCHA LA PALABRA "CASINO" }\end{array}$} \\
\hline PALABRA & ÍNDICE DE DISPONIBILIDAD LÉXICA \\
\hline Dinero & 0.243462493 \\
\hline Juego & 0.239508592 \\
\hline Apuesta & 0.236441743 \\
\hline Diversión & 0.059617913 \\
\hline Vicio & 0.039938693 \\
\hline Perder & 0.037159588 \\
\hline Suerte & 0.036227265 \\
\hline Ganar & 0.015182671 \\
\hline Deuda & 0.011015938 \\
\hline Perdición & 0.010431028 \\
\hline Robo & 0.009931891 \\
\hline Máquina & 0.009558111 \\
\hline Alcohol & 0.00858627 \\
\hline Corrupción & 0.007612206 \\
\hline Droga & 0.007445108 \\
\hline Amigo & 0.007196552 \\
\hline Ambición & 0.007042737 \\
\hline Fraude & 0.006820614 \\
\hline Ruleta & 0.00655675 \\
\hline Pérdida de tiempo & 0.006264362 \\
\hline Lujo & 0.006251145 \\
\hline Casa & 0.006180746 \\
\hline Malo & 0.006180746 \\
\hline Gastar & 0.00607083 \\
\hline Mujer & 0.00586199 \\
\hline Gente & 0.005681675 \\
\hline Estafa & 0.005514577 \\
\hline Fortuna & 0.00547277 \\
\hline Problema & 0.005459619 \\
\hline Fiesta & 0.005430962 \\
\hline
\end{tabular}

Fuente: Encuesta Nacional de Percepciones Sociales de los Juegos de Azar en México, México, UNAM, Instituto de Investigaciones Jurídicas, Departamento de Investigación Aplicada y Opinión, 2016. 
Este libro forma parte del acervo de la Biblioteca Jurídica Virtual del Instituto de Investigaciones Jurídicas de la UNAM

Aparece también una segunda esfera de asociaciones con menor peso, que se caracteriza por la preponderancia de menciones de signo negativo relacionadas con las actividades que allí se desarrollan: así, los casinos son contemplados como propicios para actividades como el robo, fraude, estafa, drogas y corrupción.

Las respuestas resaltan la diversidad de imaginarios que reflejan, en primer lugar, los estereotipos existentes sobre los casinos, que incluyen tanto valoraciones negativas como valoraciones positivas.

\section{GRÁFICA 3.21}

ÍNDICE DE DISPONIBILIDAD LÉXICA

DÍGAME, POR FAVOR, TRES PALABRAS QUE ASOCIE CON LA PALABRA "CASINO"

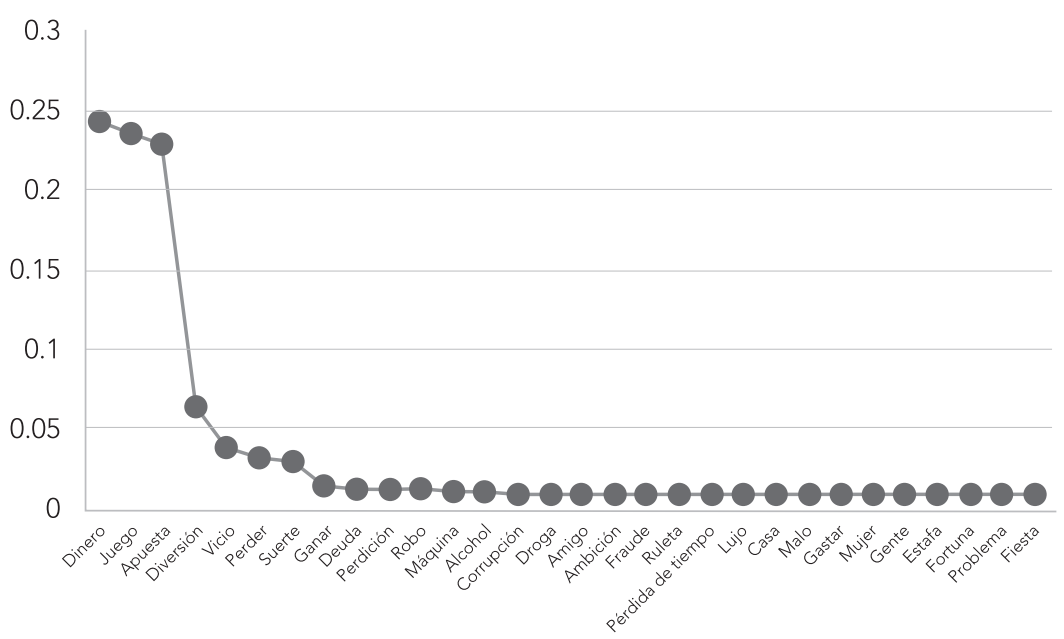

Fuente: Encuesta Nacional de Percepciones Sociales de los Juegos de Azar en México, México, UnAm, Instituto de Investigaciones Jurídicas, Departamento de Investigación Aplicada y Opinión, 2016.

De acuerdo con Korn y Shaffer (1999) (citados por Echeverria et al., 2017: 8), el consumo de juegos de azar puede tener consecuencias negativas como la adicción, pero también positivas como la generación de integración social, el entretenimiento o recreación y la reducción de ansiedad y estrés. El casino se considera un espacio abierto al que se puede acudir a cualquier hora. El casino es un espacio social de recreación. Pero los casinos no sólo representan un espacio de convivencia, sino también de pertenencia y status. "Hoy, los casinos ofrecen a sus consumidores el trascender la 
Este libro forma parte del acervo de la Biblioteca Jurídica Virtual del Instituto de Investigaciones Jurídicas de la UNAM

rutina de la cotidianidad; el placer inmediato, la esperanza de recompensa, estados paratélicos, la posibilidad de tomar riesgos poco amenazantes y fugaces, la evasión y el desahogo, ocupan un lugar prioritario" (Echeverria et al., 2017: 19).

\section{POLÍTICOS, EMPRESARIOS Y NARCOTRAFICANTES}

En el imaginario de los casinos están presentes las figuras de los políticos, los empresarios y los narcotraficantes, que en la opinión de la mayoría de los entrevistados se relacionan con las actividades de los casinos. A la pregunta elaborada para conocer la opinión de los entrevistados sobre el tema, la gran mayoría afirmó que existen vínculos entre estos personajes y los juegos de apuestas y sorteos, particularmente se percibe la presencia de los políticos y los empresarios (véase gráfica 3.22).

\section{GRÁFICA 3.22}

¿Y USTED CREE QUE ... TENGAN VÍNCULOS O NO CON LOS JUEGOS DE APUESTAS Y SORTEOS?

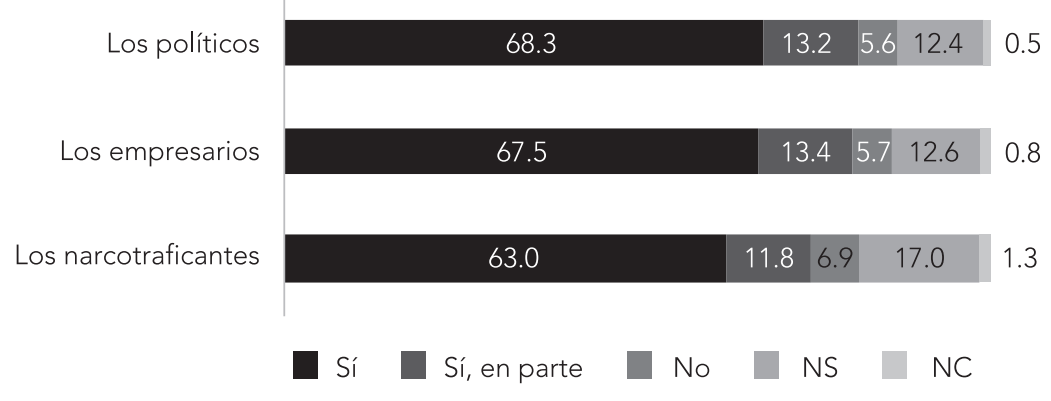

Fuente: Encuesta Nacional de Percepciones Sociales de los Juegos de Azar en México, México, unam, Instituto de Investigaciones Jurídicas, Departamento de Investigación Aplicada y Opinión, 2016.

Poco más de ocho de cada diez de los encuestados (81.5 por ciento) expresaron que creen que los políticos sí tienen o sí tienen en parte vínculos con los juegos de apuestas y sorteos. Asimismo, un porcentaje similar (81 por ciento) manifestó que cree que los empresarios sí tienen o tienen en 
Este libro forma parte del acervo de la Biblioteca Jurídica Virtual del Instituto de Investigaciones Jurídicas de la UNAM

parte esa clase de vínculos. En ambos casos, entre las personas que así lo piensan (sin considerar a los que lo piensan en parte) destacan las personas con preparatoria, licenciatura o posgrado.

En cambio, poco más de siete de cada diez de los encuestados (74.8 por ciento) señalaron que creen que los narcotraficantes tienen o tienen en parte esa clase de vínculos. No se observan particularidades ni tendencias en función del nivel escolar o del estado civil. En todos los casos (vínculos de los políticos, empresarios y narcotraficantes con los juegos de apuestas y sorteos) se observa que los hombres encuestados tienden a manifestar esa opinión en mayor medida que las mujeres.

CUADRO 3.23

\section{¿USTED CREE QUE ... TENGAN VÍNCULOS O NO CON LOS JUEGOS DE APUESTAS Y SORTEOS? JUGÓ AL MENOS UN JUEGO EN EL ÚLTIMO AÑO} (PORCENTAJES)

\begin{tabular}{l|c|c|c}
\hline & LOS POLÍTICOS & LOS EMPRESARIOS & LOS NARCOTRAFICANTES \\
\hline Sí & 71.5 & 67.6 & 61.7 \\
\hline Sí, en parte & 14.5 & 16.7 & 14.1 \\
\hline No & 5.5 & 6.3 & 8.8 \\
\hline NS & 8.3 & 8.8 & 14.6 \\
\hline NC & 0.3 & 0.6 & 0.8 \\
\hline
\end{tabular}

Fuente: Encuesta Nacional de Percepciones Sociales de los Juegos de Azar en México, México, UNAM, Instituto de Investigaciones Jurídicas, Departamento de Investigación Aplicada y Opinión, 2016.

La presencia de estos personajes en el imaginario de la población se vincula con la historia de los juegos de azar en el país. Durante el siglo XIX y más acentuadamente en el siglo XX, políticos y empresarios han sido una presencia constante no sólo en la instalación y manejo de casinos, sino en general en todos los juegos de azar. Desde el siglo XIX los casinos y los hipódromos se han vinculado con los políticos, los ricos y los empresarios al establecerse como centros de reunión y de diversión de las clases pudientes. Durante los siglos XX y XXI el establecimiento de casinos en el país se ha relacionado notoriamente con los políticos $y$, particularmente, en las últimas décadas, con los narcotraficantes. 
Este libro forma parte del acervo de la Biblioteca Jurídica Virtual del Instituto de Investigaciones Jurídicas de la UNAM

\section{ASISTENCIA A CASINOS}

La asistencia a los casinos es baja en el país. Menos de dos de cada diez entrevistados han asistido alguna vez a un casino. Ello se podría explicar en función de varios factores: las costumbres relativas a las diversiones y juegos de la población, al ingreso promedio de la mayoría, pero también, más recientemente, a la aparición de los juegos en línea.

A la pregunta ¿Alguna vez ha asistido usted a un casino?, el 16.4 por ciento de las personas entrevistadas señaló que alguna vez ha acudido a estos espacios, en contraste con 83.6 por ciento que indicó que no ha asistido (véase gráfica 3.23).

\section{GRÁFICA 3.23}

¿ALGUNA VEZ HA ASISTIDO USTED A UN CASINO?

(PORCENTAJES)

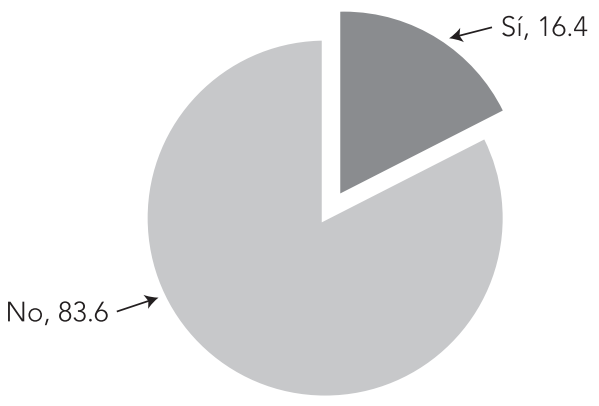

Fuente: Encuesta Nacional de Percepciones Sociales de los Juegos de Azar en México, México, unam, Instituto de Investigaciones Jurídicas, Departamento de Investigación Aplicada y Opinión, 2016.

Como se puede observar en el cuadro 3.24, las personas que alguna vez han asistido a un casino son principalmente hombres, personas de entre 35 y 54 años de edad, personas con alta escolaridad, las que trabajan, así como aquellas con mayor nivel de ingreso individual y familiar, y las que residen en el sur-sureste del país. 
Este libro forma parte del acervo de la Biblioteca Jurídica Virtual del Instituto de Investigaciones Jurídicas de la UNAM www.juridicas.unam.mx

CUADRO 3.24

\begin{tabular}{|c|c|c|c|}
\hline \multicolumn{4}{|c|}{$\begin{array}{c}\text { ¿USTED HA ASISTIDO A UN CASINO? } \\
\text { (PORCENTAJES) }\end{array}$} \\
\hline & & sí & NO \\
\hline \multicolumn{2}{|r|}{ TOTAL NACIONAL } & 16.4 & 83.6 \\
\hline \multirow{2}{*}{ Sexo } & Hombre & 21.0 & 79.0 \\
\hline & Mujer & 12.0 & 88.0 \\
\hline \multirow{6}{*}{ Edad } & De 18 a 24 años & 12.4 & 87.6 \\
\hline & De 25 a 34 años & 14.0 & 86.0 \\
\hline & De 35 a 44 años & 19.5 & 80.5 \\
\hline & De 45 a 54 años & 24.5 & 75.5 \\
\hline & De 55 a 64 años & 13.2 & 86.8 \\
\hline & 65 años y más & 11.7 & 88.3 \\
\hline \multirow{5}{*}{ Escolaridad } & Ninguno & 3.4 & 96.6 \\
\hline & Primaria & 8.3 & 91.7 \\
\hline & Secundaria & 9.9 & 90.1 \\
\hline & Preparatoria o bachillerato & 18.5 & 81.5 \\
\hline & Licenciatura o posgrado & 47.6 & 52.4 \\
\hline \multirow{3}{*}{ Estado civil } & Unión libre/casado & 16.4 & 83.6 \\
\hline & Separado/divorciado/viudo & 15.5 & 84.5 \\
\hline & Soltero & 16.6 & 83.4 \\
\hline \multirow{2}{*}{$\begin{array}{l}\text { Condición de } \\
\text { actividad }\end{array}$} & Sí trabajó & 21.7 & 78.3 \\
\hline & No trabajó & 8.1 & 91.9 \\
\hline \multirow{4}{*}{$\begin{array}{l}\text { Ingreso } \\
\text { individual }\end{array}$} & No percibe ingreso & 8.0 & 92.0 \\
\hline & De $\$ 1$ a $\$ 4,382$ (hasta 2 SM) & 8.1 & 91.9 \\
\hline & De $\$ 4,383$ a $\$ 8,765$ (más de 2 hasta 4 SM) & 20.6 & 79.4 \\
\hline & Más de $\$ 8,765$ (más de 4 SM) & 42.7 & 57.3 \\
\hline \multirow{4}{*}{ Ingreso familiar } & Menos de $\$ 4,382$ (hasta 2 SM) & 4.8 & 95.2 \\
\hline & De $\$ 4,383$ a $\$ 8,765$ (más de 2 hasta 4 SM) & 9.7 & 90.3 \\
\hline & De $\$ 8,766$ a $\$ 13,147$ (más de 4 hasta 6 SM) & 22.8 & 77.2 \\
\hline & Más de $\$ 13,147$ (más de 6 SM) & 28.8 & 71.2 \\
\hline \multirow{3}{*}{ Religión } & Católico & 16.6 & 83.4 \\
\hline & Ateo & 16.6 & 83.4 \\
\hline & Otra & 14.8 & 85.2 \\
\hline \multirow{5}{*}{ Región } & Noroeste & 17.9 & 82.1 \\
\hline & Noreste & 17.9 & 82.1 \\
\hline & Occidente & 18.5 & 81.5 \\
\hline & Centro & 9.9 & 90.1 \\
\hline & Sureste & 21.4 & 78.6 \\
\hline
\end{tabular}

Fuente: Encuesta Nacional de Percepciones Sociales de los Juegos de Azar en México, México, UNAM, Instituto de Investigaciones Jurídicas, Departamento de Investigación Aplicada y Opinión, 2016. 
Este libro forma parte del acervo de la Biblioteca Jurídica Virtual del Instituto de Investigaciones Jurídicas de la UNAM

\section{ASISTENCIA A CASINOS DURANTE EL ÚLTIMO AÑO}

Asistió a un casino durante el último año el 17.5\% de los entrevistados, mientras que $82.5 \%$ no lo hizo (véase gráfica 3.24).

\section{GRÁFICA 3.24}

¿ASISTIÓ A UN CASINO DURANTE EL ÚLTIMO AÑO?

(PORCENTAJES)

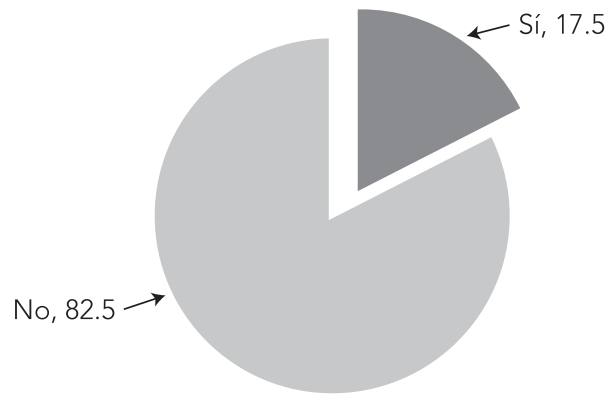

Fuente: Encuesta Nacional de Percepciones Sociales de los Juegos de Azar en México, México, UNAM, Instituto de Investigaciones Jurídicas, Departamento de Investigación Aplicada y Opinión, 2016.

Las personas que dijeron haber asistido a un casino durante el último año son en su mayoría varones, entre los 45 y 54 años, con estudios de licenciatura o posgrado. Igualmente, las personas solteras, quienes trabajaron, los entrevistados con mayores niveles de ingreso individual y familiar, así como los que habitan en el sureste del país, el noreste y el noroeste (véase cuadro 3.25).

Del análisis sociodemográfico del cruce anterior se desprende información importante que pone en cuestión varios de los tópicos relativos a las personas que asisten a los casinos: en primer lugar, no se trata de adultos mayores, dado que la mayoría de quienes asisten (casi tres de cada diez) tienen entre 45 y 54 años, y dos de cada diez tienen de 35 a 44 años y de 55 a 64 años. Igualmente, asisten más hombres que mujeres, y el 4.8 por ciento son personas que se dedican a los quehaceres del hogar (véase cuadro 3.26). 
Este libro forma parte del acervo de la Biblioteca Jurídica Virtual del Instituto de Investigaciones Jurídicas de la UNAM www.juridicas.unam.mx

\section{CUADRO 3.25}

\section{¿ASISTIÓ A UN CASINO DURANTE EL ÚLTIMO AÑO? DISTRIBUCIÓN SOCIODEMOGRÁFICA} (PORCENTAJES)

\begin{tabular}{|c|c|c|c|}
\hline & & sí & NO \\
\hline \multicolumn{2}{|r|}{ TOTAL NACIONAL } & 17.5 & 82.5 \\
\hline \multirow{2}{*}{ Sexo } & Hombre & 18.3 & 81.7 \\
\hline & Mujer & 16.4 & 83.6 \\
\hline \multirow{6}{*}{ Edad } & De 18 a 24 años & 17.1 & 82.9 \\
\hline & De 25 a 34 años & 12.4 & 87.6 \\
\hline & De 35 a 44 años & 19.2 & 80.8 \\
\hline & De 45 a 54 años & 29.2 & 70.8 \\
\hline & De 55 a 64 años & 18.1 & 81.9 \\
\hline & 65 años y más & 7.6 & 92.4 \\
\hline \multirow{5}{*}{ Escolaridad } & Ninguno & 1.9 & 98.1 \\
\hline & Primaria & 4.4 & 95.6 \\
\hline & Secundaria & 11.0 & 89.0 \\
\hline & Preparatoria o bachillerato & 20.1 & 79.9 \\
\hline & Licenciatura o posgrado & 49.1 & 50.9 \\
\hline \multirow{3}{*}{ Estado civil } & Unión libre/casado & 16.7 & 83.3 \\
\hline & Separado/divorciado/viudo & 16.8 & 83.2 \\
\hline & Soltero & 20.2 & 79.8 \\
\hline \multirow{2}{*}{$\begin{array}{l}\text { Condición de } \\
\text { actividad }\end{array}$} & Sí trabajó & 20.0 & 80.0 \\
\hline & No trabajó & 10.9 & 89.1 \\
\hline \multirow{4}{*}{$\begin{array}{l}\text { Ingreso } \\
\text { individual }\end{array}$} & No percibe ingreso & 10.8 & 89.2 \\
\hline & De $\$ 1$ a $\$ 4,382$ (hasta 2 SM) & 6.9 & 93.1 \\
\hline & De $\$ 4,383$ a $\$ 8,765$ (más de 2 hasta 4 SM) & 17.3 & 82.7 \\
\hline & Más de $\$ 8,765$ (más de 4 SM) & 38.1 & 61.9 \\
\hline \multirow{4}{*}{$\begin{array}{l}\text { Ingreso } \\
\text { familiar }\end{array}$} & Menos de $\$ 4,382$ (hasta 2 SM) & 5.2 & 94.8 \\
\hline & De $\$ 4,383$ a $\$ 8,765$ (más de 2 hasta 4 SM) & 8.4 & 91.6 \\
\hline & De $\$ 8,766$ a $\$ 13,147$ (más de 4 hasta 6 SM) & 23.3 & 76.7 \\
\hline & Más de $\$ 13,147$ (más de 6 SM) & 35.6 & 64.4 \\
\hline \multirow{3}{*}{ Religión } & Católico & 16.2 & 83.8 \\
\hline & Ateo & 19.6 & 80.4 \\
\hline & Otra & 20.6 & 79.4 \\
\hline \multirow{5}{*}{ Región } & Noroeste & 24.6 & 75.4 \\
\hline & Noreste & 26.7 & 73.3 \\
\hline & Occidente & 16.5 & 83.5 \\
\hline & Centro & 8.3 & 91.7 \\
\hline & Sureste & 26.9 & 73.1 \\
\hline
\end{tabular}

Fuente: Encuesta Nacional de Percepciones Sociales de los Juegos de Azar en México, México, UNAM, Instituto de Investigaciones Jurídicas, Departamento de Investigación Aplicada y Opinión, 2016. 
Este libro forma parte del acervo de la Biblioteca Jurídica Virtual del Instituto de Investigaciones Jurídicas de la UNAM

CUADRO 3.26

\section{ASISTENCIA A CASINOS DURANTE EL ÚLTIMO AÑO DE ACUERDO CON LA CONDICIÓN DE ACTIVIDAD. JUGÓ EN UN CASINO DURANTE EL ÚLTIMO AÑO}

(PORCENTAJES)

\begin{tabular}{|c|c|c|c|}
\hline & MEDIA NACIONAL & $\begin{array}{l}\text { JUEGA EN EL ÚLTIMO } \\
\text { AÑO }\end{array}$ & $\begin{array}{l}\text { NO JUEGA NINGÚN } \\
\text { JUEGO }\end{array}$ \\
\hline $\begin{array}{l}\text { Trabajó para obtener } \\
\text { ingresos }\end{array}$ & 70.5 & 81.1 & 68.2 \\
\hline $\begin{array}{l}\text { Trabajó sin pago ayudando } \\
\text { en el negocio/actividad que } \\
\text { desempeña un familiar }\end{array}$ & 0.5 & 0.0 & 0.6 \\
\hline $\begin{array}{l}\text { No trabajó, pero sí tiene } \\
\text { trabajo }\end{array}$ & 0.3 & 1.3 & 0.1 \\
\hline Buscó trabajo & 1.8 & 0.0 & 2.2 \\
\hline $\begin{array}{l}\text { Está en espera de que le } \\
\text { resuelvan una solicitud de un } \\
\text { trabajo al que acudió }\end{array}$ & 0.5 & 1.9 & 0.2 \\
\hline Es estudiante & 6.8 & 6.7 & 6.8 \\
\hline $\begin{array}{l}\text { Se dedica a los quehaceres } \\
\text { de su hogar }\end{array}$ & 14.6 & 4.8 & 16.7 \\
\hline $\begin{array}{l}\text { Es jubilado(a) o } \\
\text { pensionado(a) }\end{array}$ & 4.0 & 3.1 & 4.2 \\
\hline $\begin{array}{l}\text { Está incapacitado(a) } \\
\text { permanentemente para } \\
\text { trabajar }\end{array}$ & 0.5 & 0.0 & 0.6 \\
\hline NS & 0.2 & 1.2 & 0.0 \\
\hline $\mathrm{NC}$ & 0.3 & 0.0 & 0.3 \\
\hline
\end{tabular}

Fuente: Encuesta Nacional de Percepciones Sociales de los Juegos de Azar en México, México, UNAM, Instituto de Investigaciones Jurídicas, Departamento de Investigación Aplicada y Opinión, 2016.

Las personas que no tienen una ocupación remunerada no asisten a los casinos. Los porcentajes de asistencia a los casinos se incrementan entre los encuestados que cuentan con una ocupación remunerada.

\section{FORMAS DE PAGO EN LOS CASINOS}

Respecto a las formas de pago en los casinos, tres cuartas partes de los asistentes a los casinos mencionaron que su forma de pago es en efectivo. Dos de cada diez señalaron que utilizan tarjeta de crédito o débito (véase gráfica 3.25). 
Este libro forma parte del acervo de la Biblioteca Jurídica Virtual del Instituto de Investigaciones Jurídicas de la UNAM

GENERALMENTE, ¿CUÁL ES SU FORMA DE PAGO EN EL CASINO?

(PORCENTAJES)

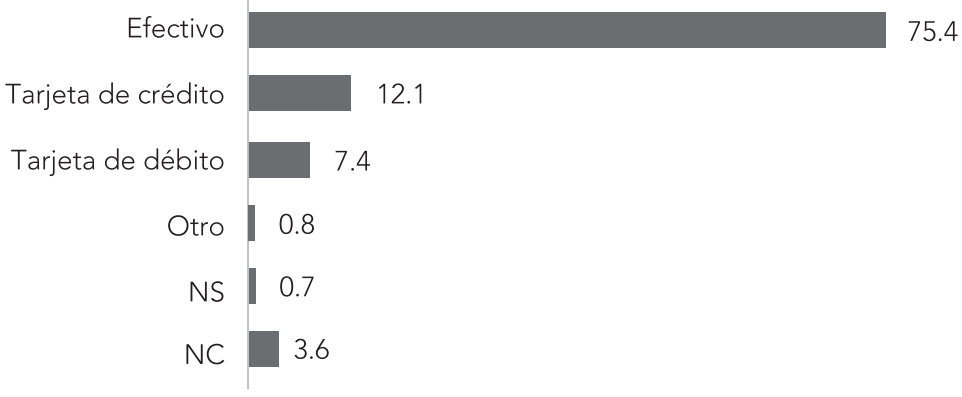

Fuente: Encuesta Nacional de Percepciones Sociales de los Juegos de Azar en México, México, UNAM, Instituto de Investigaciones Jurídicas, Departamento de Investigación Aplicada y Opinión, 2016.

La utilización de medios de pago electrónico, sin lugar a duda, será la tendencia creciente en los próximos años ante el aumento del uso de medios digitales para realizar transacciones monetarias. Lo cual, al mismo tiempo, puede tener como consecuencia que en un futuro se incremente el número de jugadores y la intensidad del juego, pues se ha comprobado en diversos estudios de economía conductual que el pago electrónico, especialmente con tarjetas de crédito, tiene como resultado que las transacciones sean menos razonadas por los consumidores.

Las investigaciones realizadas al respecto muestran que cuando las personas utilizan tarjetas de crédito como medio de pago, tienden a comprar productos de manera impulsiva. Lo anterior se deriva, aparentemente, de que para la generalidad de las personas el medio de pago en efectivo provoca una sensación de mayor sacrificio al desprenderse físicamente de recursos que de manera tangible perciben que poseen. Por el contrario, la adquisición a través de una tarjeta de crédito (e incluso de débito) genera la percepción de un pago a futuro, lo que propicia una conducta de mayor indulgencia (Thomas et al., 2011; Reith, Gerda y The Scottish Centre for Social Research, 2006).

Por último, en una evaluación de los casinos a los que acostumbran asistir las personas entrevistadas, la gran mayoría evaluó positivamente estos 
Este libro forma parte del acervo de la Biblioteca Jurídica Virtual del Instituto de Investigaciones Jurídicas de la UNAM

espacios de juegos de azar, con un promedio de 8.7 en la escala de 0 a 10; nueve de cada diez asistentes al casino evaluaron como muy buena o buena la calidad del servicio de las casas de apuestas; igualmente, entre quienes mencionaron haber asistido alguna vez a un casino, prácticamente la totalidad (96.6 por ciento) declaró no haber tenido algún problema o inconveniente dentro del casino (véase gráfica 3.26).

\section{GRÁFICA 3.26}

¿HA TENIDO ALGÚN PROBLEMA O INCONVENIENTE DENTRO DEL CASINO?

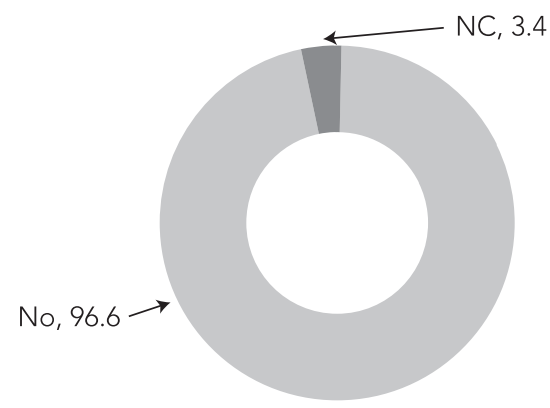

Fuente: Encuesta Nacional de Percepciones Sociales de los Juegos de Azar en México, México, UNAM, Instituto de Investigaciones Jurídicas, Departamento de Investigación Aplicada y Opinión, 2016.

\section{CONCLUSIONES}

Si bien los juegos de azar son frecuentemente relacionados con numerosos estigmas, como el riesgo del juego problemático o el lavado de dinero, igualmente refuerzan espacios de convivencia entre pares.

\section{SITUACIÓN DEL PAÍS}

- Los entrevistados son pesimistas sobre la situación del país. Es importante mencionar que esta percepción ha sido constante en los últimos años. No obstante, al parecer la percepción de la situación económica del país no representa un obstáculo para la práctica del juego, dado que de las personas entrevistadas que dijeron que han 
Este libro forma parte del acervo de la Biblioteca Jurídica Virtual del Instituto de Investigaciones Jurídicas de la UNAM

jugado al menos un juego en el último año, poco menos de ocho de cada diez (77.8 por ciento) consideraron que la situación económica actual del país está igual de mal o peor que la del año pasado, proporción que se encuentra por debajo de la media nacional (80.6 por ciento); mientras que las personas que dijeron que no han jugado en el último año y que consideraron que la situación económica del país está igual de mal o peor representan más de ocho de cada diez (83.2 por ciento).

- Asimismo, las personas que han jugado algún juego en el último año se encuentran entre las más optimistas, ya que cerca de tres de cada diez (28.1 por ciento) consideraron que la situación económica del país mejorará o estará igual de bien en el futuro, proporción que se encuentra por encima de la media nacional ( 24.8 por ciento) y de la proporción de no jugadores, pues estos últimos representan dos de cada diez (21.7 por ciento).

- En concordancia con la percepción sobre la situación económica del país, los resultados sobre la situación económica personal también son poco optimistas. Alrededor de dos terceras partes de la población entrevistada (66.2 por ciento) dijeron que su situación económica actual está igual de mal o peor en relación con el año pasado.

\section{TIEMPO LIBRE}

Dentro de este capítulo resultó capital el estudio del tiempo libre. Este tiempo libre ha dado lugar a la creación de una industria de entretenimiento que compite constantemente para atraer la atención de los potenciales clientes. Si bien explícitamente no se hacen diferencias en el uso del tiempo libre, nuestras sociedades cuentan con más tiempo libre, pero en el mismo uso y disfrute del tiempo libre se reproducen las contradicciones de la sociedad en su conjunto:

- Como ya se mencionó, de todos los países miembros de la OCDE, México es el que más horas trabaja al año; sin embargo, resulta paradójico que más de la mitad de la población ocupada vive en la informalidad. 
Este libro forma parte del acervo de la Biblioteca Jurídica Virtual del Instituto de Investigaciones Jurídicas de la UNAM

- Dentro de las posibilidades de uso del tiempo libre, se exploró el juego de azar como una actividad que es ubicua en todas las sociedades humanas. Amén de los hallazgos ya detallados durante el capítulo, es vital subrayar que en México no existe una tendencia generalizada a estigmatizar los juegos de apuesta como algo propio de tahúres. Esto no quiere decir que los juegos sean percibidos como una actividad virtuosa. Simplemente las opiniones son neutrales.

\section{IMAGINARIOS DE LOS CASINOS}

En el análisis de las menciones brindadas por los entrevistados, las principales asociaciones dibujan a los casinos como espacios sujetos a la contingencia, donde los resultados son inciertos: dinero, juego y apuesta, pero también implican diversión. Las pérdidas y ganancias dependen de la suerte: se obtienen en primer lugar ganancias (asociación positiva), pero con la misma intensidad aparecen las pérdidas (asociaciones negativas).

\section{LEGALIDAD Y REGULACIÓN DE LOS CASINOS}

- El amplio nivel de desconocimiento que existe entre los entrevistados sobre si los juegos son o no regulados, es testimonio de lo ajeno que resultan para la vida cotidiana de las personas (la hipótesis se apuntala con el hallazgo de que a mayor participación en juegos de azar, crece el conocimiento de la situación legal de los mismos). El análisis de las respuestas brindadas durante esta sección da cuenta de la variedad de representaciones que se tienen del azar, el juego, las apuestas y los casinos. Los debates sobre el marco regulatorio de los juegos de azar en México pasan necesariamente por la percepción que tienen los ciudadanos sobre las implicaciones de esta actividad y cuáles son los riesgos que les son atribuidos en los imaginarios.

\section{ASISTENCIA A LOS CASINOS}

Del análisis sociodemográfico se desprende información importante que pone en cuestión varios de los tópicos relativos a las personas que asisten a 
Este libro forma parte del acervo de la Biblioteca Jurídica Virtual del Instituto de Investigaciones Jurídicas de la UNAM

los casinos: en primer lugar, no se trata de adultos mayores, dado que la mayoría de quienes asisten (casi tres de cada diez) tienen entre 45 y 54 años, y dos de cada diez tienen de 35 a 44 años y de 55 a 64 años. Igualmente, asisten más hombres que mujeres, y el 4.8 por ciento son personas que se dedican a los quehaceres del hogar. 
Este libro forma parte del acervo de la Biblioteca Jurídica Virtual del Instituto de Investigaciones Jurídicas de la UNAM

\section{CAPÍTULO 4}

\section{LOS JUGADORES EN MÉXICO. UNA PRIMERA APROXIMACIÓN}

\section{ALGUNOS RASGOS SOCIALES DE LOS JUGADORES EN MÉXICO}

En este capítulo se pretende delinear algunos rasgos sociales de los jugadores en México. En primer lugar, se resumen las principales características de los practicantes de juegos de azar en México, y después se estudian los juegos, las razones que tienen para jugar, la participación múltiple en éstos, la frecuencia de la práctica lúdica y la apuesta en el contexto del juego de azar.

\section{¿QUIÉNES JUEGAN?}

Al abordar la definición de las personas que práctican algún juego de azar, es necesario dar cuenta de la diversidad que conforma ese conjunto que se identifica como "los jugadores". La ubicuidad de los juegos de azar en cualquier sociedad hace imposible efectuar generalizaciones sobre un grupo tan amplio y heterogéneo de personas. 
Este libro forma parte del acervo de la Biblioteca Jurídica Virtual del Instituto de Investigaciones Jurídicas de la UNAM

¿Quiénes son los que juegan? Al respecto, se puede destacar que son los hombres quienes juegan más en comparación con las mujeres, y que los que más consumen juegos de azar son las personas en los grupos de edad más jóvenes. También que conforme aumentan la escolaridad o el ingreso individual aumenta la participación en los juegos de azar, y que la condición de actividad es una variable que distingue de manera importante el ser o no jugador.

Esto puede crear una imagen estereotipada en la que se pierde de vista la variedad de razones, tipos de juego y frecuencias, que en realidad son sumamente diversos; así, por ejemplo, no es lo mismo ser hombre, joven y apostar en un hipódromo, que ser hombre, joven y jugar rayuela. Los juegos comparten el azar, pero no los recursos y los dispositivos necesarios para jugarlos; así, mientras que para el primero se necesita un lugar específico, caballos y jockeys, para el segundo sólo se requieren una pared y una moneda.

\section{¿A QUÉ SE JUEGA?}

En la primera Encuesta Nacional de Percepciones Sociales de los Juegos de Azar en México se indagó acerca de cada uno de los quince juegos de azar incluidos en el cuestionario. Con ello se obtuvo una multiplicidad de combinaciones de juegos y perfiles de entrevistados.

Para identificar el tipo de juego se seleccionó el juego más reciente, es decir, a cada persona que dijo haber jugado al menos un juego de azar durante el último año (jugador). Se presenta aquí el cuadro que relaciona a detalle el tipo de juego con los juegos contenidos en el cuestionario de este estudio (véase cuadro 4.1).

En México, el primer factor de diferenciación entre los jugadores es el tipo de juego. Así, los juegos más practicados en el último año por los entrevistados son aquellos que se pueden jugar en casa o con amigos, como la lotería tradicional mexicana, los juegos de cartas y algunos juegos tradicionales como rayuela, dados, cubilete o volado. ${ }^{1}$

1 Volado: lanzar una moneda al aire para decidir un resultado al azar: "cara o cruz". Diccionario del Español Usual en México (1996), México, El Colegio de México, dirigido por Luis Fernando Lara. 
Este libro forma parte del acervo de la Biblioteca Jurídica Virtual del Instituto de Investigaciones Jurídicas de la UNAM

\section{CUADRO 4.1}

\section{CLASIFICACIÓN DE LOS TIPOS DE JUEGO} (PORCENTAJES)

\begin{tabular}{|c|c|}
\hline \multirow{3}{*}{ Lotería Nacional y Pronósticos } & $\begin{array}{l}\text { Lotería Nacional, Zodiaco, El Gordo (comprar } \\
\text { boleto) }\end{array}$ \\
\hline & Melate (sorteos en papel, elegir números) \\
\hline & Otros sorteos (raspar) \\
\hline \multirow{5}{*}{$\begin{array}{l}\text { Lotería tradicional mexicana, juegos } \\
\text { de cartas y juegos tradicionales }\end{array}$} & Lotería mexicana \\
\hline & $\begin{array}{l}\text { Juegos tradicionales (rayuela, dados, cubilete, } \\
\text { volado, dominó) }\end{array}$ \\
\hline & $\begin{array}{l}\text { Juegos de cartas fuera de casinos, como en casas, } \\
\text { bares, etcétera (baraja española, póker, dados) }\end{array}$ \\
\hline & $\begin{array}{l}\text { Máquinas tragamonedas (de peso o de cinco } \\
\text { pesos) }\end{array}$ \\
\hline & Rifa, tómbola \\
\hline Telejuegos & $\begin{array}{l}\text { Concursos de preguntas y respuestas o } \\
\text { rompecabezas por televisión en los que se envía } \\
\text { un mensaje de texto o se llama por teléfono } \\
\text { (telejuegos) }\end{array}$ \\
\hline Quinielas & Quinielas (deportes) \\
\hline \multirow{2}{*}{$\begin{array}{l}\text { Apuestas en carreras de cualquier tipo, } \\
\text { jaripeo y rodeo }\end{array}$} & $\begin{array}{l}\text { Apuestas en carreras de caballos, perros, } \\
\text { automóviles, futbol, gallos, frontón, etcétera }\end{array}$ \\
\hline & Jaripeo o rodeo (montar toros y lazar ganado) \\
\hline \multirow{2}{*}{ Salas de juego } & Ir al casino \\
\hline & Bingo \\
\hline Apuestas por Internet & Juegos por Internet (póker, loterías, etcétera) \\
\hline
\end{tabular}

Fuente: Encuesta Nacional de Percepciones Sociales de los Juegos de Azar en México, México, UNAM, Instituto de Investigaciones Jurídicas, Departamento de Investigación Aplicada y Opinión, 2016.

El segundo tipo de juegos más difundido es aquel que implica comprar un boleto, como la Lotería Nacional o los Pronósticos, seguido por las máquinas tragamonedas de uno o cinco pesos, que se hicieron famosas en la última década por proliferar en las tiendas, mercados y farmacias del país (véase cuadro 4.2). 
Este libro forma parte del acervo de la Biblioteca Jurídica Virtual del Instituto de Investigaciones Jurídicas de la UNAM

\section{CUADRO 4.2}

\begin{tabular}{l|c}
\hline \multicolumn{2}{c}{ PORCENTAJE DE PARTICIPACIÓN SEGÚN EL JUEGO MÁS RECIENTE } \\
(PORCENTAJES) \\
\hline \multicolumn{2}{c}{ JUEGO RECIENTE } \\
\hline Lotería tradicional mexicana, juegos de cartas y juegos tradicionales & 40.6 \\
\hline Lotería Nacional y Pronósticos & 27.8 \\
\hline Máquinas tragamonedas de a peso o cinco pesos & 11.9 \\
\hline Salas de juego & 8.2 \\
\hline Quinielas & 5.5 \\
\hline Apuestas en carreras de cualquier tipo, jaripeo y rodeo & 5.3 \\
\hline Telejuegos & 0.4 \\
\hline Apuestas por Internet & 0.3 \\
\hline
\end{tabular}

Fuente: Encuesta Nacional de Percepciones Sociales de los Juegos de Azar en México, México, UNAM, Instituto de Investigaciones Jurídicas, Departamento de Investigación Aplicada y Opinión, 2016.

En tercer lugar se encuentran los juegos que se celebran en las salas de juego, como casinos o salas de bingo. En los últimos lugares aparecen las quinielas, las apuestas en carreras de caballos, galgos, coches, así como el jaripeo y rodeo. Finalmente aparecen los telejuegos y las apuestas por Internet.

Si además de los porcentajes de participación se observa cómo varían las prácticas según el sexo, la edad, la escolaridad y la religión con los principales tipos de juegos, surgen algunos hallazgos notables.

\section{PARTICIPACIÓN EN JUEGOS TRADICIONALES}

En lo que respecta a juegos como la lotería tradicional mexicana, los juegos de cartas y otros juegos tradicionales, los que participan de manera más frecuente son las mujeres y las personas de mayor edad. Además, se observan dos tendencias: conforme aumenta la escolaridad y el ingreso familiar, disminuye la participación en los juegos tradicionales.

Las prácticas de juegos de azar como la lotería tradicional mexicana, los juegos de cartas y otros juegos tradicionales están más extendidas entre las personas de menor escolaridad y menor ingreso (véase cuadro 4.3). 
Este libro forma parte del acervo de la Biblioteca Jurídica Virtual del Instituto de Investigaciones Jurídicas de la UNAM

CUADRO 4.3

PORCENTAJES DE JUGADORES SEGÚN TIPO DE JUEGO: LOTERÍA TRADICIONAL MEXICANA, JUEGOS DE CARTAS Y JUEGOS TRADICIONALES (PORCENTAJES)

\begin{tabular}{|c|c|c|}
\hline \multicolumn{2}{|r|}{ Total nacional } & 40.6 \\
\hline \multirow{2}{*}{ Sexo } & Hombre & 33.6 \\
\hline & Mujer & 50.7 \\
\hline \multirow{6}{*}{ Edad } & De 18 a 24 años & 39.5 \\
\hline & De 25 a 34 años & 36.1 \\
\hline & De 35 a 44 años & 44.4 \\
\hline & De 45 a 54 años & 25.5 \\
\hline & De 55 a 64 años & 50.4 \\
\hline & 65 años y más & 68.7 \\
\hline \multirow{5}{*}{ Escolaridad } & Ninguno & 65.5 \\
\hline & Primaria & 56.4 \\
\hline & Secundaria & 42.0 \\
\hline & Preparatoria o bachillerato & 36.9 \\
\hline & Licenciatura o posgrado & 23.2 \\
\hline \multirow{4}{*}{ Ingreso individual } & No percibe ingreso & 53.5 \\
\hline & De $\$ 1$ a $\$ 4,382$ (hasta 2 SM) & 45.1 \\
\hline & De $\$ 4,383$ a $\$ 8,765$ (más de 2 y hasta 4 SM) & 32.0 \\
\hline & Más de $\$ 8,765$ (más de 4 SM) & 38.2 \\
\hline \multirow{4}{*}{ Ingreso familiar } & Menos de $\$ 4,382$ (hasta 2 SM) & 60.9 \\
\hline & De $\$ 4,383$ a $\$ 8,765$ (más de 2 y hasta 4 SM) & 46.5 \\
\hline & De $\$ 8,766$ a $\$ 13,147$ (más de 4 y hasta 6 SM) & 38.3 \\
\hline & Más de $\$ 13,147$ (más de 6 SM) & 30.0 \\
\hline
\end{tabular}

Fuente: Encuesta Nacional de Percepciones Sociales de los Juegos de Azar en México, México, UNAM, Instituto de Investigaciones Jurídicas, Departamento de Investigación Aplicada y Opinión, 2016.

\section{LOTERÍA NACIONAL Y PRONÓSTICOS}

Entre los entrevistados que jugaron Lotería Nacional y Pronósticos, los que más destacan, en términos porcentuales, fueron aquellos con estudios de licenciatura o posgrado, los de mayor ingreso familiar (más de seis salarios mínimos) y los ateos (véase cuadro 4.4). 
Este libro forma parte del acervo de la Biblioteca Jurídica Virtual del Instituto de Investigaciones Jurídicas de la UNAM

CUADRO 4.4

PORCENTAJES DE JUGADORES SEGÚN TIPO DE JUEGO: LOTERÍA NACIONAL Y PRONÓSTICOS (PORCENTAJES)

\begin{tabular}{l|l|c}
\hline \multicolumn{1}{|c|}{ TOTAL NACIONAL } & 27.8 \\
\hline \multirow{4}{*}{ Sexo } & Hombre & 29.8 \\
\cline { 2 - 3 } & Mujer & 25.0 \\
\hline \multirow{5}{*}{ Edad } & De 18 a 24 años & 14.6 \\
\cline { 2 - 3 } & De 25 a 34 años & 30.2 \\
\cline { 2 - 3 } & De 35 a 44 años & 29.2 \\
\cline { 2 - 3 } & De 45 a 54 años & 39.2 \\
\cline { 2 - 3 } & De 55 a 64 años & 33.6 \\
\cline { 2 - 3 } & 65 años y más & 19.3 \\
\hline \multirow{5}{*}{ Ingreso familiar } & Ninguno & 29.4 \\
\cline { 2 - 3 } & Primaria & 27.0 \\
\cline { 2 - 3 } & Secundaria & 22.5 \\
\cline { 2 - 3 } & Preparatoria o bachillerato & 30.5 \\
\cline { 2 - 3 } & Licenciatura o posgrado & 37.8 \\
\cline { 2 - 3 } & Menos de \$4,382 (hasta 2 SM) $\$ 4,383$ a \$8,765 (más de 2 y hasta 4 SM) & 14.5 \\
\cline { 2 - 3 } & De \$8,766 a \$13,147 (más de 4 y hasta 6 SM) & 25.4 \\
\cline { 2 - 3 } & Más de \$13,147 (más de 6 SM) & 33.4 \\
\hline & & 36.5 \\
\hline
\end{tabular}

Fuente: Encuesta Nacional de Percepciones Sociales de los Juegos de Azar en México, México, UNAM, Instituto de Investigaciones Jurídicas, Departamento de Investigación Aplicada y Opinión, 2016.

El resto de tipos de juegos obtienen porcentajes de participación muy pequeños para poder hacer análisis más profundos; sin embargo, hay algunas hipótesis que se podrían desprender de los datos. A continuación se presenta un breve análisis sobre los entrevistados que participaron en salas de juego en México.

\section{SALAS DE JUEGO}

Entre los entrevistados cuya práctica de juego más reciente tuvo lugar en una sala de juego, es decir, asistieron a un casino o a una sala de bingo, destacan por su porcentaje de participación frente a la media nacional los hombres, las personas de 45 a 54 años, aquellos con licenciatura o posgrado y las personas con mayor ingreso familiar (véase cuadro 4.5). 
Este libro forma parte del acervo de la Biblioteca Jurídica Virtual del Instituto de Investigaciones Jurídicas de la UNAM

\section{CUADRO 4.5}

\begin{tabular}{|c|c|c|}
\hline \multicolumn{3}{|c|}{$\begin{array}{l}\text { PORCENTAJES DE JUGADORES SEGÚN TIPO DE JUEGO: SALA DE JUEGO } \\
\text { (PORCENTAJES) }\end{array}$} \\
\hline \multicolumn{2}{|r|}{ TOTAL NACIONAL } & 8.2 \\
\hline \multirow{2}{*}{ Sexo } & Hombre & 7.4 \\
\hline & Mujer & 9.4 \\
\hline \multirow{6}{*}{ Edad } & De 18 a 24 años & 11.9 \\
\hline & De 25 a 34 años & 7.4 \\
\hline & De 35 a 44 años & 5.9 \\
\hline & De 45 a 54 años & 13.1 \\
\hline & De 55 a 64 años & 5.3 \\
\hline & 65 años y más & 3.0 \\
\hline \multirow{5}{*}{ Escolaridad } & Ninguno & \\
\hline & Primaria & 1.3 \\
\hline & Secundaria & 5.2 \\
\hline & Preparatoria o bachillerato & 9.1 \\
\hline & Licenciatura o posgrado & 25.0 \\
\hline \multirow{4}{*}{ Ingreso familiar } & Menos de $\$ 4,382$ (hasta 2 SM) & \\
\hline & $\begin{array}{l}\text { De } \$ 4,383 \text { a } \$ 8,765 \\
\text { (más de } 2 \text { y hasta } 4 \text { SM) }\end{array}$ & 4.8 \\
\hline & $\begin{array}{l}\text { De } \$ 8,766 \text { a } \$ 13,147 \\
\text { (más de } 4 \text { y hasta } 6 \text { SM) }\end{array}$ & 8.9 \\
\hline & Más de $\$ 13,147$ (más de 6 SM) & 13.7 \\
\hline
\end{tabular}

Fuente: Encuesta Nacional de Percepciones Sociales de los Juegos de Azar en México, México, UNAM, Instituto de Investigaciones Jurídicas, Departamento de Investigación Aplicada y Opinión, 2016.

\section{¿QUIÉNES PARTICIPAN EN MÚLTIPLES JUEGOS?}

Hasta ahora se ha analizado el tipo de juego más reciente en el que participaron los jugadores entrevistados; no obstante, se quiere dejar constancia del número de juegos diferentes en los que se involucra cada jugador. El 35.8 por ciento de los jugadores participó en un juego único; el 28.5 participó en dos juegos; el 16.5 en tres juegos; el 13.0 por ciento en cuatro o cinco juegos y sólo el 6.1 por ciento en seis o más juegos (véase cuadro 4.6). 
Este libro forma parte del acervo de la Biblioteca Jurídica Virtual del Instituto de Investigaciones Jurídicas de la UNAM

\section{CUADRO 4.6}

PORCENTAJES DE JUGADORES SEGÚN TIPO DE JUEGO: SALA DE JUEGO (PORCENTAJES)

\begin{tabular}{l|c}
\hline \multicolumn{2}{c}{ PARTICIPACIÓN EN MÚLTIPLES JUEGOS DE AZAR } \\
\hline Un juego & 35.8 \\
\hline Dos juegos & 28.5 \\
\hline Tres juegos & 16.5 \\
\hline Cuatro o cinco juegos & 13.0 \\
\hline Más de cinco juegos & 6.1 \\
\hline
\end{tabular}

Fuente: Encuesta Nacional de Percepciones Sociales de los Juegos de Azar en México, México, UNAM, Instituto de Investigaciones Jurídicas, Departamento de Investigación Aplicada y Opinión, 2016.

La interpretación de este dato debe tener en cuenta que los porcentajes aquí presentados sólo hacen un recuento del número de juegos que se combinan por jugador; por tanto, no se debe concluir que la práctica de un mayor número de juegos significa más frecuencia o intensidad de juego.

Como se señaló anteriormente, cualquier intento de perfilar a los jugadores en México necesita tomar en cuenta la diversidad y complejidad que implica el juego. El fenómeno del juego está entrelazado con la cultura en la que se desarrolla. Cada contexto social tiene sus propios juegos, les atribuye distintos significados y restricciones.

\section{FRECUENCIA DE JUEGO}

Si algo se puede aproximar a una "intensidad" de juego es la frecuencia con la que se participa en la actividad lúdica: no es igual que el juego se practique de manera ocasional que de manera diaria. A los jugadores que participaron en el estudio se les preguntó por la frecuencia del juego más reciente (véase cuadro 4.7).

Además, como se aborda en el capítulo 5 de esta obra, no se puede perder de vista que entre las principales razones para apostar destacan las opciones de respuestas relacionadas con actividades recreativas y propias del tiempo libre. 
Este libro forma parte del acervo de la Biblioteca Jurídica Virtual del Instituto de Investigaciones Jurídicas de la UNAM

\section{CUADRO 4.7}

\begin{tabular}{l|c}
\hline \multicolumn{2}{c}{ FRECUENCIA DE JUEGO } \\
(PORCENTAJES) \\
\hline Diario & 6.0 \\
\hline Una vez a la semana & 26.8 \\
\hline Una vez al mes & 24.7 \\
\hline Una vez cada seis meses & 8.6 \\
\hline Una vez al año & 6.3 \\
\hline Ocasionalmente & 27.6 \\
\hline
\end{tabular}

Fuente: Encuesta Nacional de Percepciones Sociales de los Juegos de Azar en México, México, UNAM, Instituto de Investigaciones Jurídicas, Departamento de Investigación Aplicada y Opinión, 2016.

Únicamente el 6 por ciento de los entrevistados juega diario; poco más de dos de cada diez una vez a la semana, y poco más de dos de cada diez juega una vez al mes. Únicamente el 6 por ciento de los entrevistados juega una vez al año. El juego ocasional corresponde a tres de cada diez jugadores.

\section{¿QUIÉNES APUESTAN?}

Bajo el paraguas de "juegos de azar" ha quedado cubierta una variedad de actividades que, si bien tienen como común denominador el azar, involucran al mismo tiempo una inversión monetaria, a veces voluntaria, como en las cartas, y otras obligatoria, como cuando se compra un billete de lotería. Entre los jugadores identificados en este estudio se intentó encontrar algún patrón entre los que sí apostaron, independientemente del tipo de juego. Cuatro de cada diez entrevistados expresaron que sí han apostado. En el cuadro se pueden apreciar las diferencias sociodemográficas entre los que sí y los que no apostaron (véase cuadro 4.8).

De entre los que apuestan destacan, con porcentajes superiores a la media nacional, los hombres, y además se observa una tendencia respecto al ingreso familiar: entre más aumenta el ingreso, aumenta el porcentaje de respuesta de quienes dijeron haber apostado. 
Este libro forma parte del acervo de la Biblioteca Jurídica Virtual del Instituto de Investigaciones Jurídicas de la UNAM www.juridicas.unam.mx

CUADRO 4.8

CONDICIÓN DE APUESTA SEGÚN PRINCIPALES VARIABLES SOCIODEMOGRÁFICAS (PORCENTAJES)

\begin{tabular}{|c|c|c|c|}
\hline & & SÍ APUESTA & NO APUESTA \\
\hline \multicolumn{2}{|r|}{ TOTAL NACIONAL } & 39.9 & 59.0 \\
\hline \multirow[t]{2}{*}{ Sexo } & Hombre & 50.5 & 48.9 \\
\hline & Mujer & 24.7 & 73.5 \\
\hline \multirow{6}{*}{ Edad } & De 18 a 24 años & 44.5 & 52.2 \\
\hline & De 25 a 34 años & 28.0 & 70.6 \\
\hline & De 35 a 44 años & 38.6 & 61.4 \\
\hline & De 45 a 54 años & 50.1 & 49.2 \\
\hline & De 55 a 64 años & 61.7 & 38.3 \\
\hline & 65 años y más & 34.4 & 65.6 \\
\hline \multirow{5}{*}{ Escolaridad } & Ninguno & 23.8 & 76.2 \\
\hline & Primaria & 53.4 & 46.6 \\
\hline & Secundaria & 34.4 & 65.0 \\
\hline & Preparatoria o bachillerato & 42.5 & 57.3 \\
\hline & Licenciatura o posgrado & 43.9 & 49.0 \\
\hline \multirow{4}{*}{$\begin{array}{l}\text { Ingreso } \\
\text { familiar }\end{array}$} & Menos de $\$ 4,382$ (hasta 2 SM) & 30.9 & 67.6 \\
\hline & \begin{tabular}{|l|} 
De $\$ 4,383$ a $\$ 8,765$ \\
(más de 2 y hasta 4 SM)
\end{tabular} & 38.6 & 58.9 \\
\hline & \begin{tabular}{|l|} 
De $\$ 8,766$ a $\$ 13,147$ \\
(más de 4 y hasta 6 SM)
\end{tabular} & 42.9 & 57.1 \\
\hline & Más de $\$ 13,147$ (más de 6 SM) & 53.3 & 45.5 \\
\hline \multirow{3}{*}{ Religión } & Católico & 39.6 & 60.1 \\
\hline & Ateo & 41.7 & 58.3 \\
\hline & Otra & 38.3 & 55.2 \\
\hline
\end{tabular}

Fuente: Encuesta Nacional de Percepciones Sociales de los Juegos de Azar en México, México, UNAM, Instituto de Investigaciones Jurídicas, Departamento de Investigación Aplicada y Opinión, 2016.

\section{APROXIMACIÓN ANALÍTICA A LOS JUGADORES EN MÉXICO}

Con los datos recogidos en la primera Encuesta Nacional de Percepciones Sociales de los Juegos de Azar en México se ha propuesto crear una des- 
Este libro forma parte del acervo de la Biblioteca Jurídica Virtual del Instituto de Investigaciones Jurídicas de la UNAM

cripción de las principales características de los jugadores de juegos de azar en México. En este primer ejercicio se busca construir una línea base para conocer a los que participan en este tipo de juegos e identificar nuevas vetas para el estudio de los participantes en los juegos de azar en el país.

Para lograrlo, en primer lugar se presenta una breve explicación sobre los métodos utilizados para caracterizar a los jugadores a partir de los datos recogidos en la encuesta; posteriormente se analiza al grupo de jugadores según las principales variables sociodemográficas y algunas preguntas de opinión. Finalmente, se presentan algunas conclusiones sobre los perfiles de los jugadores en México y sobre cuáles temas profundizar en futuras investigaciones.

Es importante señalar que la encuesta en estudio comparte con el resto de los libros de la Biblioteca Los mexicanos vistos por sí mismos un diseño muestral nacional, robusto, que se apega a los parámetros establecidos para cuestionarios de opinión en México. Como toda encuesta, tiene un error asociado (para el caso de ésta, 4.2 por ciento) que se debe tener siempre en cuenta a la hora de interpretar los resultados. Gracias al ejercicio estadístico que la respalda, los resultados permiten hacer inferencias válidas para todo el país.

\section{¿CÓMO SE IDENTIFICÓ A LOS JUGADORES EN MÉXICO?}

El primer paso fue establecer criterios que permitieran, a partir de los datos de la encuesta, clasificar a los encuestados en dos grupos: jugadores y no jugadores. Para poder caracterizar a los jugadores se utilizaron dos criterios: su participación en juegos de azar y la última fecha de juego. Se utilizó la tabla de juegos del cuestionario y se incluyeron los quince juegos estudiados. Todos aquellos que respondieron en la entrevista haber participado en algún juego de azar fueron seleccionados. Se seleccionó al 52.9 por ciento de los entrevistados, que fueron quienes participaron en algún juego de azar. 
Este libro forma parte del acervo de la Biblioteca Jurídica Virtual del Instituto de Investigaciones Jurídicas de la UNAM www.juridicas.unam.mx

\section{CUADRO 4.9}

\begin{tabular}{l}
\hline \multicolumn{1}{c}{ JUEGOS ESTUDIADOS EN LA ENCUESTA } \\
\hline Lotería Nacional, Zodiaco, El Gordo (comprar boleto) \\
\hline Melate (sorteos en papel, elegir números) \\
\hline Otros sorteos (raspar) \\
\hline Rifa, tómbola \\
\hline Quinielas (deportes) \\
\hline Concursos de preguntas y respuestas o rompecabezas por televisión en los que se envía \\
un mensaje de texto o se llama por teléfono (telejuegos) \\
\hline Juegos por Internet (póker, loterías, etcétera) \\
\hline Bingo \\
\hline Lotería mexicana \\
\hline Máquinas tragamonedas (de peso o de cinco pesos) \\
\hline Asistir al casino \\
\hline Apuestas en carreras de caballos, perros, automóviles, futbol, gallos, frontón, etcétera \\
\hline Juegos de cartas fuera de casinos, como en casas, bares, etcétera \\
(baraja española, póker, dados) \\
\hline Jaripeo o rodeo (montar toros y lazar ganado) \\
\hline Juegos tradicionales (rayuela, dados, cubilete, volado, dominó) \\
\hline
\end{tabular}

Fuente: Encuesta Nacional de Percepciones Sociales de los Juegos de Azar en México, México, UNAM, Instituto de Investigaciones Jurídicas, Departamento de Investigación Aplicada y Opinión, 2016.

En lo que respecta a la temporalidad, se privilegió el juego en el que se había participado el último año con el propósito de excluir del análisis las participaciones que podían ser tan antiguas como, por ejemplo, un caso en el que la práctica de juego había ocurrido 40 años en el pasado. A partir de este criterio se creó un conjunto de encuestados que además de haber jugado algún juego de azar, también jugaron durante el último año previo al levantamiento de la encuesta. La fecha de corte para este propósito fue el 1 de septiembre de 2015. A este conjunto de personas nos referiremos como los jugadores de juegos de azar en México. Así, una vez realizada esta operación se obtuvo que el 48.3 por ciento de los encuestados había participado en algún juego de azar en el último año (véase cuadro 4.10). 
Este libro forma parte del acervo de la Biblioteca Jurídica Virtual del Instituto de Investigaciones Jurídicas de la UNAM

CUADRO 4.10

\begin{tabular}{l|c}
\hline \multicolumn{2}{c}{ DISTRIBUCIÓN DE PORCENTAJES DE CONDICIÓN DE JUEGO } \\
(PORCENTAJES)
\end{tabular}

Fuente: Encuesta Nacional de Percepciones Sociales de los Juegos de Azar en México, México, UNAM, Instituto de Investigaciones Jurídicas, Departamento de Investigación Aplicada y Opinión, 2016.

\section{¿QUIÉNES JUEGAN EN MÉXICO?}

Los datos de la encuesta indican que casi la mitad de los entrevistados en el país ha participado en algún juego de azar. Previo a este estudio no existían datos que tuvieran como propósito específico cuantificar el número de personas que participan en juegos de azar en México. En este sentido, en la Encuesta Nacional de Ingreso y Gasto de los Hogares (ENIGH) se ha estimado que los hogares mexicanos tuvieron un gasto promedio anual en actividades recreativas y culturales de 7,548 pesos por hogar $(231,863.5 \mathrm{mi}$ llones de pesos en términos de gasto anual de los hogares). Esta cantidad representó el 5.2 por ciento del gasto total de los hogares en 2013. Específicamente, el gasto anual en juegos de azar fue de 3,429.7 millones de pesos (112 pesos en promedio por hogar al año), cifra que constituyó el 1.5 por ciento del gasto total en actividades recreativas y de la cultura (INEGI, 2013). ${ }^{2}$

\section{¿QUIÉNES SON LOS JUGADORES EN MÉXICO?}

Las siguientes gráficas muestran los intervalos de confianza derivados de las proporciones obtenidas sobre las características sociodemográficas de los jugadores. Los intervalos de confianza representan el rango de valores den-

2 El análisis del gasto por hogar se presenta detalladamente en el capítulo dedicado al juego problemático. 
Este libro forma parte del acervo de la Biblioteca Jurídica Virtual del Instituto de Investigaciones Jurídicas de la UNAM

tro de los cuales se encuentra el parámetro, con un nivel de confianza del 95 por ciento. La línea horizontal muestra el valor estimado de la media nacional.

Entre más grande sea la distancia entre la media nacional y los límites que contienen el intervalo de confianza, se puede interpretar que las diferencias entre los diversos grupos comparados (por ejemplo, hombres vs. mujeres) son más importantes.

\section{SEXO}

Los datos del estudio muestran que son los hombres quienes juegan en mayor medida que las mujeres. Si bien el 48.3 por ciento de todos los entrevistados en el país son jugadores, el porcentaje aumenta a 60.5 por ciento cuando analizamos a los hombres por separado, y disminuye a 37.5 por ciento cuando calculamos dicho porcentaje entre las mujeres (véase gráfica 4.1).

\section{GRÁFICA 4.1}

INTERVALOS DE CONFIANZA DE LAS PROPORCIONES

DE JUGADORES SEGÚN SEXO

(PORCENTAJES)

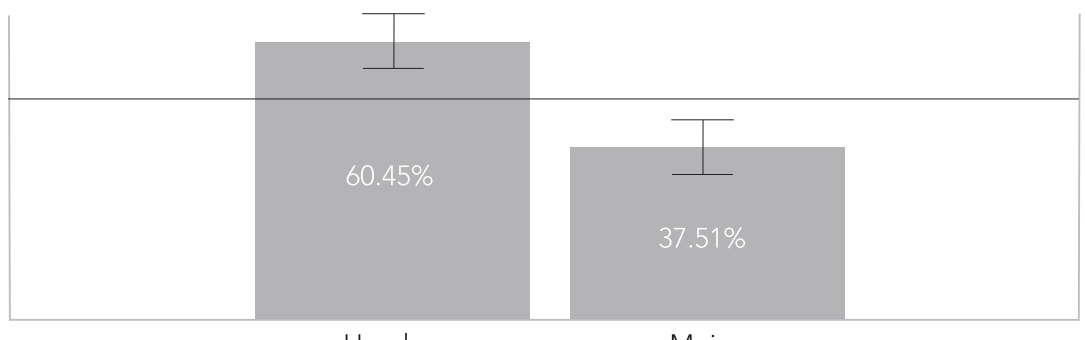

Hombre

Mujer

Sexo

Fuente: Encuesta Nacional de Percepciones Sociales de los Juegos de Azar en México, México, UnAm, Instituto de Investigaciones Jurídicas, Departamento de Investigación Aplicada y Opinión, 2016.

Del análisis de los datos desagregados por sexo se derivan algunas hipótesis: las mujeres prefieren los juegos tradicionales y los que se celebran fuera de los casinos, mientras que los hombres hacen referencia a los deportivos y las quinielas. 
Este libro forma parte del acervo de la Biblioteca Jurídica Virtual del Instituto de Investigaciones Jurídicas de la UNAM

\section{EDAD}

En lo relativo al análisis de los grupos etarios, lo primero que es importante destacar es la participación de los más jóvenes en los juegos de azar. Atendiendo a los porcentajes, se observa una tendencia en la que conforme avanza la edad, aumenta la participación en juegos de azar, hasta alcanzar su máximo entre quienes tienen de 35 a 44 años (véase gáfica 4.2).

\section{GRÁFICA 4.2}

INTERVALOS DE CONFIANZA DE LAS PROPORCIONES

DE JUGADORES SEGÚN GRUPOS DE EDAD

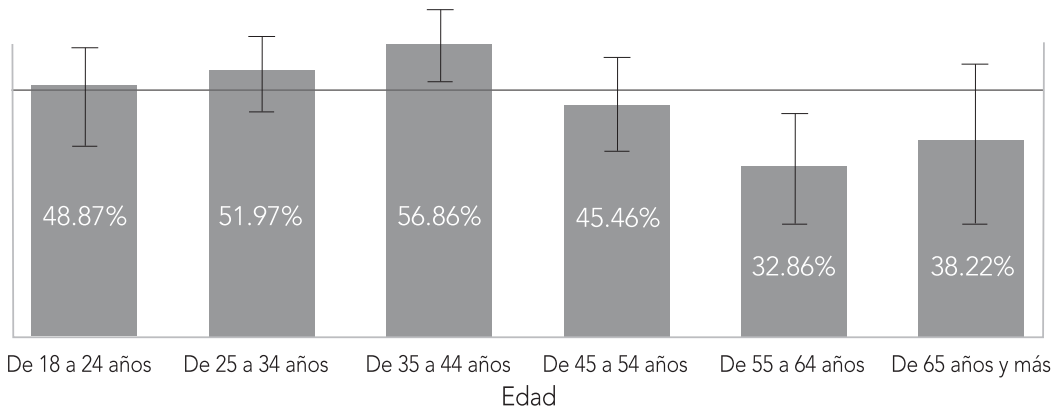

Fuente: Encuesta Nacional de Percepciones Sociales de los Juegos de Azar en México, México, unAm, Instituto de Investigaciones Jurídicas, Departamento de Investigación Aplicada y Opinión, 2016.

Se pueden desprender algunas hipótesis: los más jóvenes (de 18 a 34 años) presentan una preferencia particular por los juegos tragamonedas (de un peso o de cinco pesos), mientras que los de mayor edad (55 años y más) se inclinan por los juegos tradicionales y los de cartas fuera de los casinos.

\section{ESCOLARIDAD}

Se dividió a la población en dos grupos: aquellos que contaban con una escolaridad básica (primaria y secundaria) y aquellos con una educación media superior y superior. De esta manera, los datos se agruparon bajo el supuesto de que existe alguna relación entre estas dos variables, y que dicha relación sería más nítida en una representación gráfica usando estas dos categorías. 
Este libro forma parte del acervo de la Biblioteca Jurídica Virtual del Instituto de Investigaciones Jurídicas de la UNAM

Como se puede observar en la gráfica, la educación básica presenta un efecto negativo sobre la participación en el juego, y la educación media superior y superior, un efecto positivo. En resumen: cuanta más escolaridad se tiene, más se participa en los juegos de azar (véase gráfica 4.3).

\section{GRÁFICA 4.3}

INTERVALOS DE CONFIANZA DE LAS PROPORCIONES SEGÚN ESCOLARIDAD Y LÍNEA DE MEDIA NACIONAL

(PORCENTAJES)

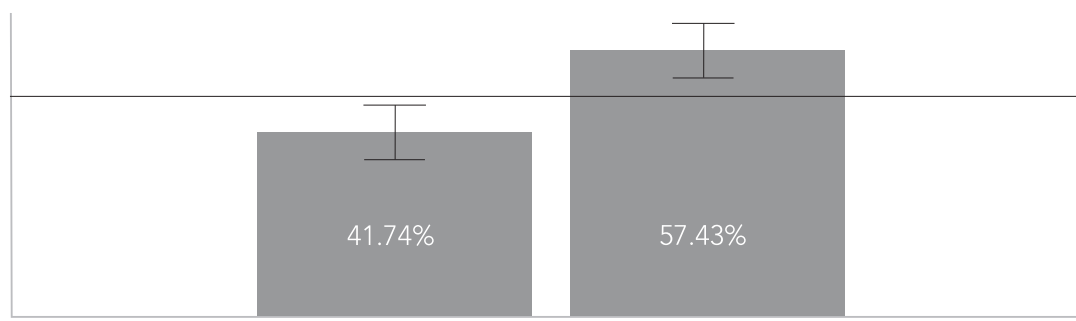

Básica

Pos-básica

Educación

Fuente: Encuesta Nacional de Percepciones Sociales de los Juegos de Azar en México, México, UnAm, Instituto de Investigaciones Jurídicas, Departamento de Investigación Aplicada y Opinión, 2016.

Los datos sugieren la existencia de una relación entre el tipo de juego más reciente y el nivel educativo. La encuesta no puede arrojar resultados concluyentes al respecto; sin embargo, en este caso se advierte que las personas con escolaridad básica tienden a preferir los juegos tradicionales y los que se celebran fuera de los casinos; mientras que aquellos con un grado de escolaridad superior prefieren el juego en casinos.

\section{CONDICIÓN DE ACTIVIDAD}

En relación con la cuestión de si tener o no trabajo afecta la probabilidad de ser jugador, se obtuvo una conclusión esperada: el porcentaje de jugadores es mayor entre los encuestados que sí tienen trabajo que entre los que no lo tienen (véase gráfica 4.4). 
Este libro forma parte del acervo de la Biblioteca Jurídica Virtual del Instituto de Investigaciones Jurídicas de la UNAM

GRÁFICA 4.4

INTERVALOS DE CONFIANZA DE LAS PROPORCIONES SEGÚN CONDICIÓN DE ACTIVIDAD Y LÍNEA DE MEDIA NACIONAL

(PORCENTAJES)

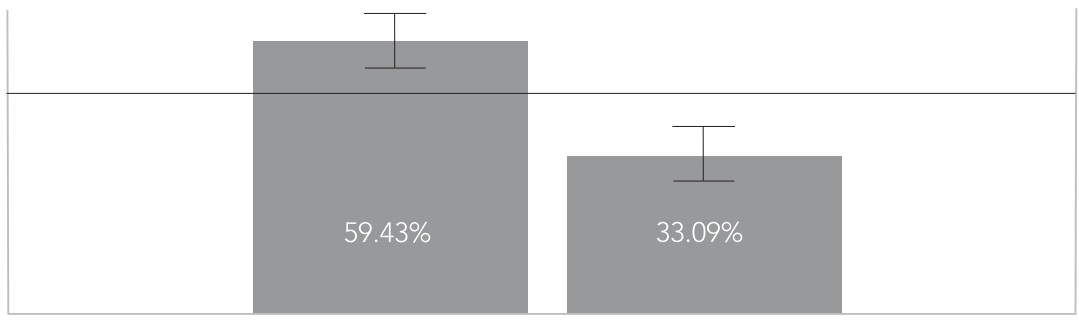

Si trabajó

No trabajó

Condiciones de actividad

Fuente: Encuesta Nacional de Percepciones Sociales de los Juegos de Azar en México, México, unam, Instituto de Investigaciones Jurídicas, Departamento de Investigación Aplicada y Opinión, 2016.

A pesar de los intentos por encontrar alguna característica específica en los datos que pudiera dar una pista más sobre los jugadores en México y su condición de actividad, no hubo ningún hallazgo que mereciera mención.

\section{INGRESO FAMILIAR}

Se decidió analizar a los jugadores según el ingreso familiar mensual que manifestaron en la entrevista. Atendiendo a la distribución de los porcentajes, la información socioeconómica permite dibujar una tendencia interesante en la que conforme aumenta el nivel de ingreso familiar, aumenta el porcentaje de jugadores (véase gráfica 4.5).

También es importante destacar que de los datos puede extraerse una preferencia por los juegos de tipo lotería, sorteos y rifas, conforme aumenta el ingreso. Al mismo tiempo, a medida que disminuye el ingreso familiar, aumenta la predilección por los juegos tradicionales. 
Este libro forma parte del acervo de la Biblioteca Jurídica Virtual del Instituto de Investigaciones Jurídicas de la UNAM

INTERVALOS DE CONFIANZA DE LAS PROPORCIONES SEGÚN CONDICIÓN DE ACTIVIDAD (PORCENTAJES)

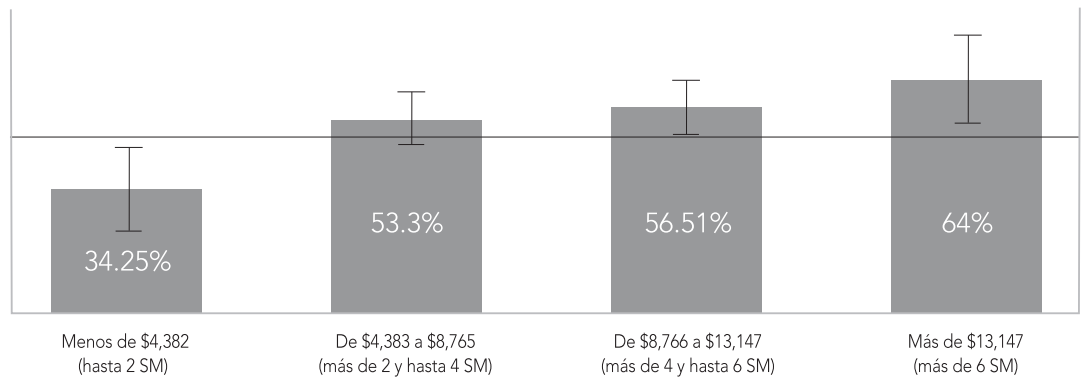

Ingreso familiar

Fuente: Encuesta Nacional de Percepciones Sociales de los Juegos de Azar en México, México, unAm, Instituto de Investigaciones Jurídicas, Departamento de Investigación Aplicada y Opinión, 2016.

\section{¿EXISTE UN SOLO PERFIL DEL JUGADOR EN MÉXICO?}

No es posible construir un único perfil que abarque las características de todos los jugadores de juegos de azar en México. Como se ha podido apreciar en el análisis de cada una de las variables sociodemográficas de los jugadores en México y de las modalidades de participación en los distintos tipos de juego, sería necesario construir varios perfiles. Algunos de los resultados son, en cierta forma, esperados, como el hecho de que juegan más los hombres que las mujeres o que influye tener trabajo para ser jugador. Otros son de carácter contraintuitivo; por ejemplo, los que practican juegos de azar prefieren jugar en compañía.

En este capítulo se han empleado técnicas de análisis estadístico sencillas y muy extendidas en estudios de opinión pública, sociología y ciencias sociales. Además, se han comparado sistemáticamente las proporciones y se ha dado cuenta de las diferencias respecto a la media nacional.

Ahora, cabe preguntarse qué pasaría si el análisis se llevara a cabo no de manera separada, sino conjunta. Es decir, si se analizaran los rasgos más relevantes de los jugadores en México en un solo análisis. Para cumplir con dicho propósito se decidió emplear una técnica de análisis de datos categóricos: un análisis de correspondencias múltiple. 
Este libro forma parte del acervo de la Biblioteca Jurídica Virtual del Instituto de Investigaciones Jurídicas de la UNAM

Como se puede apreciar en la gráfica, el resultado del análisis de correspondencias resume en un solo gráfico los hallazgos de este capítulo. Para leer este gráfico es importante prestar atención a la variable jugador y sus dos posibles respuestas: sí y no. Estos dos puntos serán el inicio de nuestra lectura (véase gráfica 4.6).

\section{GRÁFICA 4.6}

\section{ANÁLISIS DE CORRESPONDENCIAS MÚLTIPLES}

\section{(PORCENTAJES)}

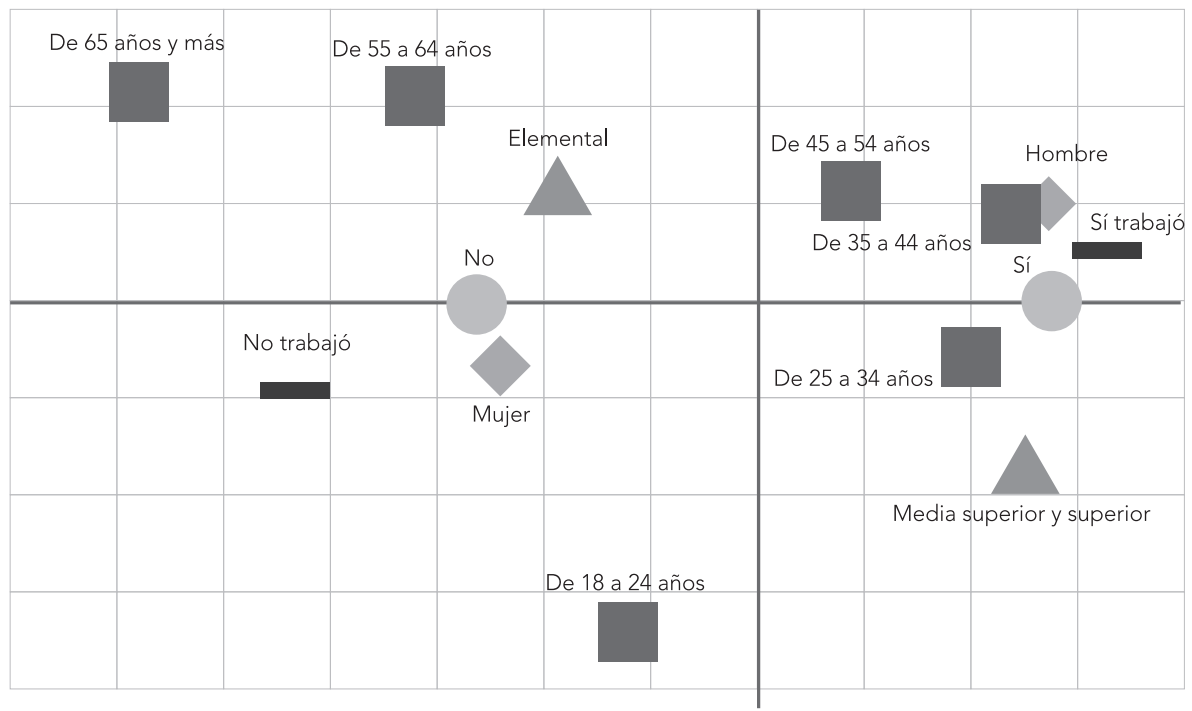

Ser jugador Sexo

Fuente: Encuesta Nacional de Percepciones Sociales de los Juegos de Azar en México, México, UnAM, Instituto de Investigaciones Jurídicas, Departamento de Investigación Aplicada y Opinión, 2016.

Alrededor del sí vemos las características más frecuentes de los jugadores: tener un trabajo, tener de 35 a 44 años, o de 25 a 34 años, y ser hombre. Las distancias son estandarizadas en este gráfico, lo cual permite analizar la distancia entre dos puntos: entre más cercanos son, más guardan cierta relación entre sí. 
Este libro forma parte del acervo de la Biblioteca Jurídica Virtual del Instituto de Investigaciones Jurídicas de la UNAM

El análisis de correspondencias permite interpretar cada uno de los ejes; así, por ejemplo, para este caso, el eje X resume en buena medida el ser o no ser jugador, por lo que si se leen de manera horizontal las distancias entre unos puntos y otros puede observarse que estos resultados son consistentes con los previamente señalados: existe una correspondencia entre ser o no jugador con características tales como el sexo y la condición de actividad, y en menor medida con la edad y la escolaridad. Estos datos ponen de relieve ciertos rasgos de los jugadores en México.

\section{CONCLUSIONES}

En resumen, tras revisar las características sociodemográficas de los jugadores en México, se presentan algunas hipótesis que sugieren los datos analizados.

Entre los hallazgos más relevantes se puede extraer que el 48.3 por ciento de los habitantes del país participó en al menos un juego de azar el último año.

Mediante los datos de esta primera Encuesta Nacional de Percepciones Sociales de los Juegos de Azar en México se han delineado rasgos que caracterizan a los participantes en juegos de azar. En este primer ejercicio exploratorio se busca proponer una línea para guiar futuras investigaciones e identificar nuevas vetas para el estudio de los participantes en los juegos de azar en el país.

En esta etapa del estudio, que es la exploración inicial del fenómeno, los datos permiten empezar a dibujar hipótesis sobre las relaciones que guardan practicar un juego, el tipo de juego y el tipo de juego preferido. Un elemento en común es que todo parece indicar que los jugadores entrevistados en la encuesta comparten algunos rasgos en común.

Entre los principales hallazgos se puede destacar que hay más jugadores entre los hombres (60.4 por ciento) que entre las mujeres (37.5 por ciento). También, que los más jóvenes juegan más: se puede observar que conforme aumenta la edad, crece también la participación en los juegos de azar.

En lo que toca a la escolaridad, se observó que conforme ésta aumenta, también lo hace la participación en los juegos de azar. Esta tenedencia es 
Este libro forma parte del acervo de la Biblioteca Jurídica Virtual del Instituto de Investigaciones Jurídicas de la UNAM

más clara si agrupamos a los entrevistados en dos grupos: educación básica y educación superior; así, el 47.7 por ciento de las personas con educación básica sí juegan, mientras que entre las personas que cuentan con educación superior el porcentaje es de 57.7 por ciento.

Además, según condición de actividad, se observó que entre los que sí tienen una actividad (59.4 por ciento) es más grande la proporción de jugadores que entre los que no tuvieron alguna actividad (33.0 por ciento).

El juego más practicado (ponderado por fecha de juego) es la lotería tradicional mexicana (40.6 por ciento) y la Lotería Nacional (27.8 por ciento), seguido por las máquinas tragamonedas (11.9 por ciento) y las salas de juego (8.2 por ciento).

Sin embargo, algunas preguntas quedaron pendientes, como, por ejemplo: ¿existen patrones que estructuran dichos rasgos?, ¿bajo qué diferentes patrones se estructuran los rasgos comunes?, y ¿qué arreglos y combinaciones de esos elementos se presentan?

El diseño y la ejecución de nuevas investigaciones permitirá ahondar en las distintas modalidades que asumen los jugadores y las prácticas.

Es necesario conocer más elementos acerca del fenómeno del juego en México; no obstante, no queda lugar a dudas de que éste es un tema que abre la puerta a futuras investigaciones, y que estas primeras pesquisas dejan testimonio de lo mucho que aún se puede descubrir. 
Este libro forma parte del acervo de la Biblioteca Jurídica Virtual del Instituto de Investigaciones Jurídicas de la UNAM

\section{CAPÍTULO 5}

\section{EL JUEGO PROBLEMÁTICO EN MÉXICO}

En nuestro país, recientemente se han realizado ejercicios enfocados a medir las prácticas de juego e identificar algunos de sus impactos socioeconómicos. En este sentido, la Encuesta Nacional de Ingreso y Gasto de los Hogares (ENIGH) ha estimado que los hogares mexicanos tuvieron un gasto total anual de 231,863.5 millones de pesos en actividades recreativas y de la cultura. Esto es, un gasto promedio anual de 7,548 pesos por hogar. Esta cantidad representó el 5.2 por ciento del gasto total de los hogares en 2013. Específicamente, el gasto anual en juegos de azar fue de 3,429.7 millones de pesos (112 pesos en promedio por hogar al año), cifra que constituyó el 1.5 por ciento del gasto total en actividades recreativas y de la cultura (INEGI, 2013).

Esta misma encuesta mostró la existencia de diferencias por sexo y por edad en el gasto en juegos de azar en los hogares de México. Al respecto, los hallazgos muestran que mientras los hombres mexicanos gastaban en total 2,776 millones de pesos durante 2013 (124 pesos en promedio por hogar), las mujeres dedicaron 654 millones de pesos a esta actividad (70 pesos en promedio por hogar). En cuanto a la edad, el gasto en juegos de azar tiende a incrementarse con la edad, de tal forma que las personas de 50 
Este libro forma parte del acervo de la Biblioteca Jurídica Virtual del Instituto de Investigaciones Jurídicas de la UNAM

a 64 años gastaron 1,525 millones de pesos. Esto es, las personas de este grupo etario gastaron un promedio anual de 197.5 pesos por hogar.

Por su parte, la Encuesta Nacional sobre el Uso del Tiempo 2014 (ENUT) del INEGI, que recopila información estadística sobre la forma en que las personas mayores de doce años distribuyen su tiempo en diversas actividades como trabajar, estudiar, divertirse, comer y descansar, también ha incluido entre sus variables de estudio e investigación el tiempo dedicado por hombres y mujeres a practicar actividades de esparcimiento, diversión o recreación, tales como la participación en juegos de mesa, azar o video, entre otras. Al respecto, se encontró que el 16.1 por ciento de los mexicanos mayores de doce años participa en juegos y aficiones, y dedica un promedio de 4.6 horas a la semana a estas actividades. La información de esta encuesta también revela que los hombres tienen una mayor tasa de participación en estas actividades que las mujeres (20 y 12.6 por ciento, respectivamente), y que además ellos registran un promedio semanal de 5.1 horas dedicadas a juegos y aficiones, en tanto que las mujeres dedican 4 horas.

Aunque estas dos encuestas ofrecen información valiosa sobre el juego en México, no permiten específicamente estudiar los juegos de azar y, en particular, explorar algunos campos del mismo, como sería el caso del juego problemático. En este sentido, uno de los objetivos de la Encuesta Nacional de Percepciones Sociales de los Juegos de Azar en México fue precisamente incluir algunas variables para la medición del juego problemático, que se analizará en este capítulo.

\section{PARTICIPACIÓN EN LOS JUEGOS DE AZAR}

Para indagar si en la sociedad mexicana existe un comportamiento arraigado en torno a los juegos de azar y apuestas, se preguntó a los participantes en la encuesta nacional sobre su costumbre por apostar. Las costumbres son modalidades evidentes y comunes de comportamiento en situaciones específicas. En este sentido, la costumbre por apostar es una manifestación de un comportamiento habitual que a menudo se considera como natural (Schiffman y Lazar Kanuk, 2010). Al respecto, el 20.9 por ciento de los mexicanos entrevistados afirmó que acostumbra apostar (véase gráfica 5.1). 
Este libro forma parte del acervo de la Biblioteca Jurídica Virtual del Instituto de Investigaciones Jurídicas de la UNAM

GRÁFICA 5.1

¿USTED ACOSTUMBRA APOSTAR?

(PORCENTAJES)

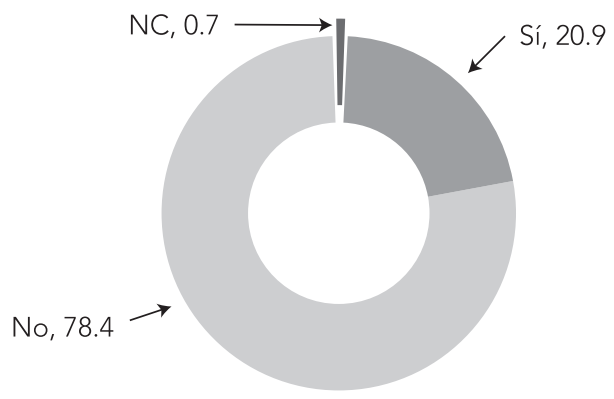

Fuente: Encuesta Nacional de Percepciones Sociales de los Juegos de Azar en México, México, UnAm, Instituto de Investigaciones Jurídicas, Departamento de Investigación Aplicada y Opinión, 2016.

Esta costumbre se presenta como una cuestión masculina, ya que mientras tres de cada diez hombres (31.7 por ciento) afirmaron apostar, sólo una mujer de cada diez (11.4 por ciento) confirma hacerlo. Asimismo, existe una tendencia directamente proporcional entre los niveles de ingreso y la escolaridad y la costumbre a apostar. Esto es, a mayores ingresos personales, mayor proporción de personas manifiesta apostar (40.9 por ciento de quienes perciben más de cuatro salarios mínimos). En este mismo sentido, los mexicanos encuestados con escolaridad de licenciatura y posgrado reportaron también los niveles más altos para la costumbre de apostar (32.8 por ciento).

Habitar en ciertas regiones de México también influye en la costumbre de apostar, ya que el 49.1 por ciento de quienes viven en el noroeste y en el norte confirmaron apostar (25 y 23.6 por ciento, respectivamente).

Otra costumbre que se exploró fue la de participar en rifas y sorteos. Al respecto, el 23.2 por ciento de los encuestados realiza esta actividad (véase gráfica 5.2). El 25.7 por ciento de los varones y el 20.9 por ciento de las mujeres confirmaron participar en rifas y sorteos. Asimismo, quienes perciben más de cuatro salarios mínimos (36.9 por ciento) y aquellos con niveles educativos de licenciatura y posgrado (39.3 por ciento) tuvieron las proporciones más elevadas para participar en rifas y sorteos. 
Este libro forma parte del acervo de la Biblioteca Jurídica Virtual del Instituto de Investigaciones Jurídicas de la UNAM

¿ACOSTUMBRA PARTICIPAR EN RIFAS O SORTEOS?

(PORCENTAJES)

No, 76.2

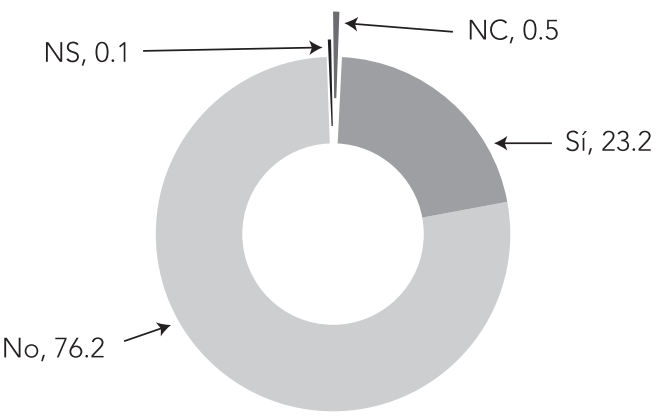

Fuente: Encuesta Nacional de Percepciones Sociales de los Juegos de Azar en México, México, UnAm, Instituto de Investigaciones Jurídicas, Departamento de Investigación Aplicada y Opinión, 2016.

\section{MOTIVACIONES PARA EL JUEGO}

El estudio del juego también permite aproximarnos a su definición tomando como base los motivos que llevan a los individuos a realizar la acción de jugar. En este sentido, el juego puede ser definido como un comportamiento o conducta motivada que está relacionado con la consecución de un objetivo. Identificar la motivación es importante para conocer los factores que atraen la atención y el interés de un individuo en un determinado momento y que lo llevan a jugar para conseguir el objetivo en cuestión (Wong, 2000). Al respecto, a la población encuestada se le planteó la siguiente pregunta: ¿Qué es lo que le motiva principalmente para ir a jugar? Más de la mitad de los encuestados que jugaron expresó que su principal motivación para hacerlo era la diversión y el entretenimiento, mientras que una cuarta parte se decantó por ganar dinero. Aparecen también, aunque en menor medida, las opciones: una invitación, la curiosidad, para no aburrirme y verlo como un reto $(6.5,5.6,1.7$ y 1.1 por ciento, respectivamente) (véase gráfica 5.3).

En una mayor proporción, quienes expresaron el entretenimiento y la diversión como su principal motivación para jugar, fueron los que se encuentran en el grupo de edad de entre 25 y 34 años (64.7 por ciento), los que cuentan con estudios de licenciatura y posgrado (70.8 por ciento), y los 
Este libro forma parte del acervo de la Biblioteca Jurídica Virtual del Instituto de Investigaciones Jurídicas de la UNAM

que habitan el centro y sureste del país. En comparación con la respuesta anterior, la opción ganar dinero fue mencionada en mayor medida por aquellos de 45 a 54 años, quienes tienen estudios de primaria, y los que perciben más de cuatro salarios mínimos individuales.

\section{GRÁFICA 5.3}

¿QUÉ ES LO QUE LE MOTIVA PRINCIPALMENTE PARA IR A JUGAR?

(PORCENTAJES)

El entretenimiento y diversión

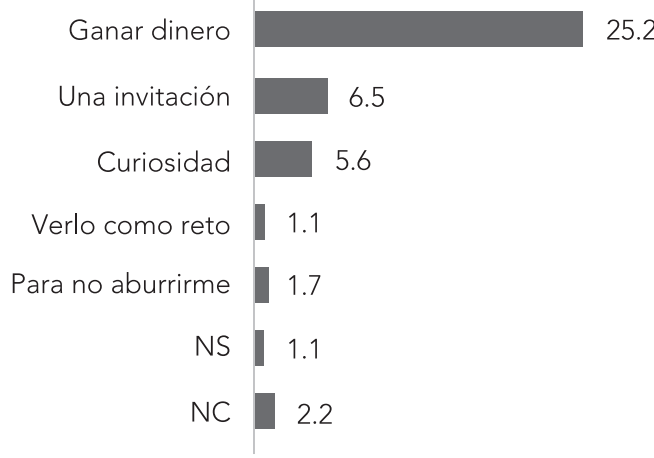

25.2

Fuente: Encuesta Nacional de Percepciones Sociales de los Juegos de Azar en México, México, unam, Instituto de Investigaciones Jurídicas, Departamento de Investigación Aplicada y Opinión, 2016.

Los hallazgos anteriores afirman la hipótesis del papel lúdico del juego, caracterizado por la vivencia de experiencias que hacen referencia a un modo de percibir el juego como entretenimiento y diversión. En este sentido, es pertinente resaltar la función básica del juego en el fomento y disfrute de la emoción (Elías y Dunning, 1988).

\section{AUTOPERCEPCIÓN DE LA CONDUCTA DE JUEGO}

Con la finalidad de indagar sobre la autopercepción acerca de su forma de jugar, a los entrevistados se les planteó la siguiente pregunta: Durante los últimos doce meses, ¿alguna vez ha jugado en exceso? De los entrevistados que alguna vez han jugado, casi la totalidad (94.2 por ciento) mencionó que durante los últimos doce meses no había jugado en exceso, siendo muy 
Este libro forma parte del acervo de la Biblioteca Jurídica Virtual del Instituto de Investigaciones Jurídicas de la UNAM

bajos los porcentajes de entrevistados que afirmaron jugar de forma excesiva (3.9 por ciento).

\section{GRÁFICA 5.4}

DURANTE LOS ÚLTIMOS DOCE MESES, ¿ALGUNA VEZ HA JUGADO EN EXCESO? (PORCENTAJES)

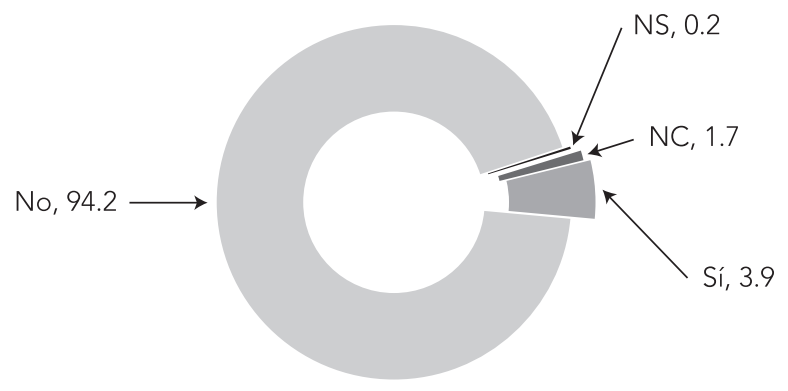

Fuente: Encuesta Nacional de Percepciones Sociales de los Juegos de Azar en México, México, UNAM, Instituto de Investigaciones Jurídicas, Departamento de Investigación Aplicada y Opinión, 2016.

En relación con las características sociodemográficas, el 8.4 por ciento de los jóvenes entre los 18 y los 24 años admitió jugar en exceso. En esta misma situación se encuentran los que tienen estudios de licenciatura y posgrado (9.8 por ciento) y quienes habitan en el sureste del país (9.2 por ciento).

La información presentada muestra claramente que los entrevistados no se perciben como jugadores excesivos, dado que, como se expuso en el apartado anterior, juegan por entretenimiento y diversión, esto es, se acercan al juego desde una perspectiva lúdica y moderada y, al parecer, de una forma positiva.

\section{LA ADICCIÓN AL JUEGO}

Con frecuencia, la vida social permite a los más cercanos registrar aquellos comportamientos ligados al juego que se están convirtiendo en excesivos y permite a los otros registrar aquellas conductas sobre el juego que comprometen o dañan a las personas. De ahí que a los jugadores se les planteó la siguiente pregunta: ¿Alguna vez alguien le ha dicho que tiene una adicción 
Este libro forma parte del acervo de la Biblioteca Jurídica Virtual del Instituto de Investigaciones Jurídicas de la UNAM

al juego? En respuesta, casi todos los entrevistados (93.1 por ciento) que alguna vez han jugado expresaron que no les han dicho que tienen una adicción al juego. Sólo el 4.9 por ciento afirmó que sí le han hecho algún comentario sobre su adicción (véase gráfica 5.5).

\section{GRÁFICA 5.5}

¿ALGUNA VEZ ALGUIEN LE HA DICHO QUE TIENE UNA ADICCIÓN AL JUEGO? (PORCENTAJES)

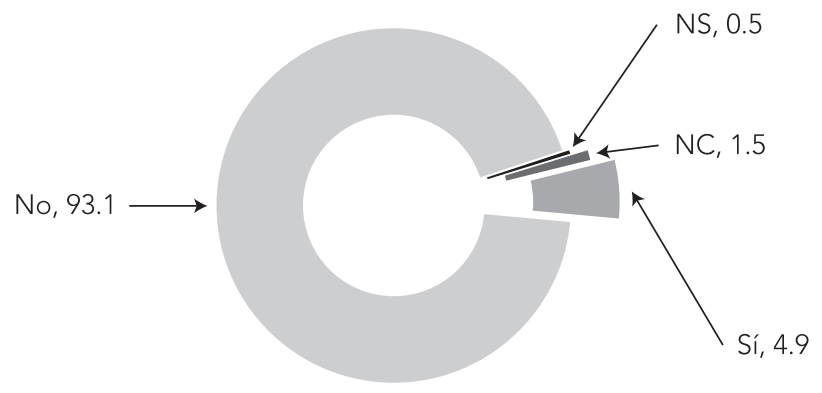

Fuente: Encuesta Nacional de Percepciones Sociales de los Juegos de Azar en México, México, UNAM, Instituto de Investigaciones Jurídicas, Departamento de Investigación Aplicada y Opinión, 2016.

Los jóvenes encuestados entre los 18 y los 24 años de edad son los que señalaron que alguna vez alguien les había dicho que tenían una adicción al juego (8.5 por ciento); esto tiene que ver con su permanencia en el hogar de sus padres. ${ }^{1}$ Quienes tienen estudios de licenciatura y posgrado también han recibido comentarios sobre su adicción al juego (10.0 por ciento), así como los habitantes del sureste del país (7.7 por ciento).

La adicción al juego, al ser considerada un problema de salud, requiere ser diagnosticada y atendida por profesionales, dado que es considerada como un trastorno que tiene efectos negativos en la salud física, psicológica y en las relaciones interpersonales de los individuos. ${ }^{2}$ Por esta razón, a los

1 Al respecto, la Encuesta Nacional de Valores en Juventud mostró que el 70 por ciento de los jóvenes entre los 12 y los 29 años vive con sus padres (INJUVE-UNAM, 2012).

2 Es pertinente hacer notar que existen sólo alrededor de 10 mil profesionales de la salud para el diagnóstico y la atención de este tipo de problemáticas en México (1.6 psiquiatras, 1 médico, 3 enfermeras, 1 psicólogo, 0.53 trabajadores sociales, 0.19 terapeutas y 2 profesionales técnicos en salud por cada 100 mil habitantes) (OPS-OMS, 2011). 
Este libro forma parte del acervo de la Biblioteca Jurídica Virtual del Instituto de Investigaciones Jurídicas de la UNAM

entrevistados que han jugado se les planteó la siguiente pregunta: ¿Alguna vez algún especialista lo ha diagnosticado con adicción al juego? Al respecto, sólo el 1.7 por ciento de los mexicanos que juegan afirmó haber sido diagnosticado por un especialista, por lo tanto, al 95.7 por ciento de los entrevistados que juegan no se les ha diagnosticado una adicción al juego (véase gráfica 5.6).

\section{GRÁFICA 5.6}

Y, ¿ALGUNA VEZ ALGÚN ESPECIALISTA LO HA DIAGNOSTICADO CON ADICCIÓN AL JUEGO? (PORCENTAJES)

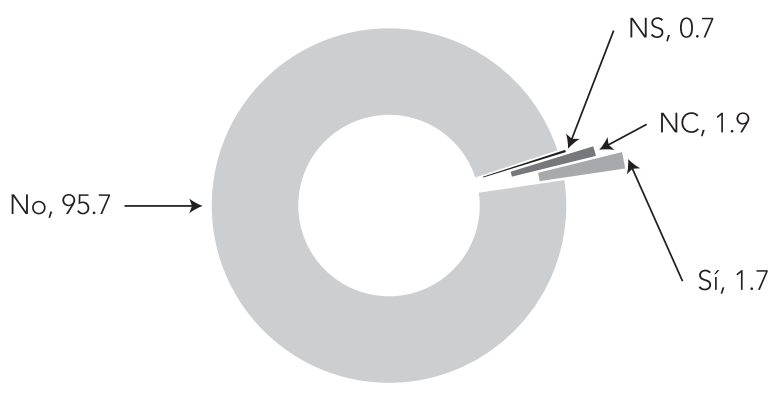

Fuente: Encuesta Nacional de Percepciones Sociales de los Juegos de Azar en México, México, unam, Instituto de Investigaciones Jurídicas, Departamento de Investigación Aplicada y Opinión, 2016.

Los jugadores jóvenes de 18 a 24 años son los que han sido diagnosticados por un especialista (4.3 por ciento), así como los solteros (4.0 por ciento), los que tienen estudios de licenciatura y posgrado (6.8 por ciento) y los que viven en el sureste de México (3.7 por ciento).

En términos generales, se puede señalar que los mexicanos refieren bajos niveles de percepción de la adicción al juego, así como escaso diagnóstico profesional de juego problemático.

\section{EL JUEGO PROBLEMÁTICO}

El juego problemático es un comportamiento persistente y recurrente que involucra un patrón conductual y la presencia de frecuentes y reiterados epi- 
Este libro forma parte del acervo de la Biblioteca Jurídica Virtual del Instituto de Investigaciones Jurídicas de la UNAM

sodios de juegos de apuestas, que afectan la vida social, laboral, material y familiar de la persona (World Health Organization, 1993).

Uno de los objetivos centrales de la Encuesta Nacional de Percepciones Sociales de los Juegos de Azar en México fue realizar una aproximación a la medición del juego problemático. Para ello, se elaboró un modelo de medición empleando, en parte, ${ }^{3}$ al gunos de los ítems utilizados para la detección del juego problemático presentado en el Diagnostic and Statistical Manual of Mental Disorders (DSM-IV) (American Psychiatric Association, 1994). Estos criterios han sido también adaptados y utilizados en la British Gambling Prevalence Survey 2010 (Wardle et al., 2011: 73-74) y en las ocho encuestas nacionales de percepciones sociales del juego de azar en España, realizadas en el periodo 2010-2017 (Cases et al., 2010; Ruíz et al., 2011; Ruíz et al., 2012; Gómez et al., 2013, 2014, 2015, 2016, 2017).

\section{LA MEDICIÓN DEL JUEGO PROBLEMÁTICO}

La Encuesta Nacional de Percepciones Sociales de los Juegos de Azar en México incluyó una batería de preguntas para medir el juego problemático. Estas preguntas se tomaron de la propuesta del DSM-IV para la detección y diagnóstico del juego patológico.

EI DSM-IV sugiere diez preguntas que van desde persiguiendo las pérdidas hasta cometer un crimen para fondear el juego. Estas pautas constituyen una herramienta creada por clínicos especialistas para el diagnóstico del juego patológico, pero no fue diseñado para ser usado como un instrumento de detección entre la población general o para investigaciones de cohorte sociológica. No obstante, algunos de esos criterios han sido utilizados en la serie de encuestas British Gambling Prevalence Survey (BGPS) para la medición de la prevalencia del juego problemático en la población del Reino Unido (NatCen, 2011).

Como tal, no hay una versión de cuestionario estándar propuesta en el DSM-IV. El instrumento usado dentro de la serie del BGPS fue primero desarrollado en 1999 y posteriormente sujeto a desarrollos rigurosos y procesos

3 Solamente se incluyeron siete de los diez ítems correspondientes al DSM-IV y algunas opciones de respuesta tampoco son las mismas que las dictadas por el DSM-IV, dado que se introdujeron cambios para adaptarlas a México. 
Este libro forma parte del acervo de la Biblioteca Jurídica Virtual del Instituto de Investigaciones Jurídicas de la UNAM

de prueba, que incluyeron pruebas cognitivas y ejercicios de piloteo. Cada ítem del DSM-IV es evaluado en una escala de 4 puntos, en el rango de "nunca" a "muy frecuente". Las respuestas a cada ítem pueden ser dicotomizadas para mostrar si una persona reúne los criterios o no para su diagnóstico, o asignando un puntaje a cada ítem para la obtención de un puntaje total de puntajes.

El diagnóstico clínico de juego patológico se confirma por un especialista cuando una persona cumple 5 de los 10 criterios. Muchas encuestas, ${ }^{4}$ al adaptar los criterios del DSM-IV a instrumentos de detección para ser utilizados en encuestas de población general, han incluido una categoría adicional "jugador problemático".

Es importante mencionar que en esta encuesta nacional sólo se incluyeron 7 ítems de los 10 que considera el DSM-IV (véase cuadro 5.1). Los ítems propuestos por el DSM-IV fueron adaptados por varias razones:

1) Los criterios del DSM-IV fueron diseñados pensando en diagnóstico psiquiátrico del juego problemático, y al ser éste un ejercicio sociológico que busca recoger percepciones y opiniones de los mexicanos sobre el tema, se dejaron fuera aquellos ítems que se consideró incluían acepciones sintomatológicas.

2) Se ha reportado que el DSM-IV aplicado tal cual, en ejercicios sociológicos como una encuesta, ha resultado en respuestas incongruentes o alejadas de lo esperado: "Pese a que se utilizan con frecuencia, las distintas versiones del DSM-IV tienen el inconveniente de que están diseñadas desde el ámbito de la psiquiatría, y su aplicación práctica a grandes muestras sociológicas produce a veces resultados extraños" (Gómez et al., 2015: 77).

3) Un factor importante para eliminar los ítems 2, 4 y 8 del DSM-IV es que se trata de temas sensibles y difíciles de preguntar directamente en una encuesta, por tanto, al eliminarlos la intención fue evitar el error por no respuesta (Hayton et al., 2004: 191-195). 
Este libro forma parte del acervo de la Biblioteca Jurídica Virtual del Instituto de Investigaciones Jurídicas de la UNAM

\section{CUADRO 5.1}

\section{ÍTEMS DEL JUEGO PROBLEMÁTICO EN MÉXICO TOMADOS DEL DSM-IV}

\begin{tabular}{|c|c|c|}
\hline & ÍTEMS DSM-IV & $\begin{array}{c}\text { ÍTEMS DE LA ENCUESTA } \\
\text { PERCEPCIONES SOCIALES DE LOS JUEGOS } \\
\text { DE AZAR EN MÉXICO }\end{array}$ \\
\hline 1 & $\begin{array}{l}\text { Preocupación por el juego (por ejemplo, preocu- } \\
\text { pación por revivir experiencias pasadas de juego, } \\
\text { compensar ventajas entre competidores o } \\
\text { planificar la próxima aventura, o pensar formas de } \\
\text { conseguir dinero para jugar). }\end{array}$ & $\begin{array}{l}\text { 53a. Piensa en jugar, es decir, recordando apuestas } \\
\text { anteriores, planificando la próxima vez que jugará. } \\
\text { 53b. Piensa en formas para conseguir dinero para } \\
\text { jugar. } \\
\text { 53g. Ha empeñado o vendido algo para conseguir } \\
\text { dinero para apostar. }\end{array}$ \\
\hline 2 & $\begin{array}{l}\text { Necesidad de jugar cantidades crecientes de } \\
\text { dinero para conseguir el grado de excitación } \\
\text { deseado. }\end{array}$ & \\
\hline 3 & $\begin{array}{l}\text { Fracaso repetido de los esfuerzos para controlar, } \\
\text { interrumpir o detener el juego. }\end{array}$ & $\begin{array}{l}\text { 53h. Ha pensado en dejar de jugar tan seguido } \\
\text { por apostar. }\end{array}$ \\
\hline 4 & $\begin{array}{l}\text { Inquietud o irritabilidad cuando intenta interrum- } \\
\text { pir o detener el juego. }\end{array}$ & \\
\hline 5 & $\begin{array}{l}\text { El juego se utiliza como estrategia para escapar } \\
\text { de los problemas o para aliviar la disforia (por } \\
\text { ejemplo, sentimientos de desesperanza, culpa, } \\
\text { ansiedad, depresión). }\end{array}$ & $\begin{array}{l}\text { 53c. Ha jugado para escapar de sus problemas, } \\
\text { cuando está deprimido, ansioso o mal consigo } \\
\text { mismo. }\end{array}$ \\
\hline 6 & $\begin{array}{l}\text { Después de perder dinero en el juego, se vuelve } \\
\text { otro día para intentar recuperarlo (tratando de } \\
\text { "cazar" las propias pérdidas). }\end{array}$ & $\begin{array}{l}\text { 54. Cuando usted apuesta o juega sorteos, ¿con } \\
\text { qué frecuencia vuelve a apostar para recuperar lo } \\
\text { que perdió? }\end{array}$ \\
\hline 7 & $\begin{array}{l}\text { Se engaña a los miembros de la familia, terapeutas } \\
\text { u otras personas para ocultar el grado de } \\
\text { implicación con el juego. }\end{array}$ & $\begin{array}{l}\text { 53d. Ha mentido a su familia u otros para esconder } \\
\text { el tiempo que dedica a jugar. }\end{array}$ \\
\hline 8 & $\begin{array}{l}\text { Se cometen actos ilegales, como falsificación, } \\
\text { fraude, robo, o abuso de confianza, para financiar } \\
\text { el juego. }\end{array}$ & \\
\hline 9 & $\begin{array}{l}\text { Se han arriesgado o perdido relaciones interper- } \\
\text { sonales significativas, trabajo y oportunidades } \\
\text { educativas o profesionales debido al juego. }\end{array}$ & $\begin{array}{l}\text { 53e. Se ha arriesgado a perder su trabajo o sus } \\
\text { estudios, a causa del juego. } \\
\text { 53i. Se ha preocupado por perder a su familia o } \\
\text { amigos por apostar. }\end{array}$ \\
\hline 10 & $\begin{array}{l}\text { Se confía en que los demás proporcionen dinero } \\
\text { que alivie la desesperada situación financiera } \\
\text { causada por el juego. }\end{array}$ & $\begin{array}{l}\text { 53f. Ha pedido dinero a otras personas para salir } \\
\text { de problemas económicos provocados por el } \\
\text { juego. }\end{array}$ \\
\hline
\end{tabular}

Fuente: Diagnostic and Statistical Manual of Mental Disorders (DSM-IV) (1994), American Psychiatric Association, Washington, DC.

Fuente: Encuesta Nacional de Percepciones Sociales de los Juegos de Azar en México, México, UNAM, Instituto de Investigaciones Jurídicas, Departamento de Investigación Aplicada y Opinión, 2016. 
Este libro forma parte del acervo de la Biblioteca Jurídica Virtual del Instituto de Investigaciones Jurídicas de la UNAM

\section{LA CONSTRUCCIÓN DEL ÍNDICE DEL JUEGO PROBLEMÁTICO}

Los resultados de la encuesta nacional permitieron estimar un índice de juego problemático basado en técnicas estadísticas multivariadas, como el análisis factorial y el análisis de conglomerados de k-medias.

Para la construcción de este índice se utilizó la batería de interrogantes incluidas en las preguntas 53 y 54 del cuestionario en vivienda. Es importante señalar que se consideraron como jugadores sólo a aquellas personas que han jugado al menos un juego de los descritos en el cuestionario en el último año.

Las categorías de estas preguntas fueron clasificadas en una escala Likert, ${ }^{5}$ así, la opción de respuesta siempre se puntuó con "4", casi siempre con "3", algunas veces con " 2 ", casi nunca con "1" y nunca con " 0 ".

Con las variables contenidas en la batería de las preguntas seleccionadas para el índice, y considerando los puntajes de sus categorías, se realizó un análisis factorial confirmatorio, a partir del cual se obtuvo una carga para cada individuo en una escala de valores continuos.

Asimismo, se evaluó la consistencia interna del presente modelo de estimación del juego problemático. Al respecto, se realizó la prueba de alfa de Cronbach para las diez preguntas que conformaron el modelo, y de la cual se obtuvo el valor de 0.88 , con un intervalo de confianza de (0.86-0.89), lo que quiere decir que es un buen modelo para los propósitos de la investigación de juego problemático.

La carga asociada a cada jugador se clasificó en cuatro grupos, mediante un análisis de conglomerados de k-medias. La clasificación de cada individuo depende de su carga asociada, que va desde el jugador sin riesgo alguno

5 En 1990, la Asociación Americana de Psiquiatría introdujo la adicción al juego en su manual estadístico, desarrollando una batería de preguntas (DSM-III) que pudiera servir de instrumento de medida sobre el riesgo de los individuos en encuestas sobre juego. La estandarización de estas preguntas permite, al aplicarse a diversas investigaciones, comparar sus resultados. En 1994 se desarrolló una nueva versión, DSM-IV, consistente en puntuar las respuestas a cada uno de los 10 ítems dicotómicos (Sí/No), aunque en algunas versiones se han utilizado escalas de cuatro puntos sobre la frecuencia con la que el entrevistado se encontraba con un problema de pérdida de control sobre el juego (casi siempre, con frecuencia, algunas veces, nunca) denominadas de Likert (Gómez et al., 2015). 
Este libro forma parte del acervo de la Biblioteca Jurídica Virtual del Instituto de Investigaciones Jurídicas de la UNAM

(-0.42217475 a -0.04193922) hasta el individuo con juego problemático (2.06749884 a 3.77981797) (véase cuadro 5.2).

\section{CUADRO 5.2}

GRUPOS DE JUGADORES SEGÚN EL ÍNDICE

DE JUEGO PROBLEMÁTICO

\begin{tabular}{c|l|c|c}
\hline NO. & \multicolumn{1}{|c|}{ GRUPOS } & LÍMITE INFERIOR & LÍMITE SUPERIOR \\
\hline 1 & Jugador sin riesgo & -0.42217475 & -0.04193922 \\
\hline 2 & Jugador de bajo riesgo & -0.0378204 & 0.71521424 \\
\hline 3 & Jugador de riesgo moderado & 0.78088103 & 2.01777802 \\
\hline 4 & Jugador problemático & 2.06749884 & 3.77981797 \\
\hline
\end{tabular}

Fuente: Encuesta Nacional de Percepciones Sociales de los Juegos de Azar en México, México, UNAM, Instituto de Investigaciones Jurídicas, Departamento de Investigación Aplicada y Opinión, 2016.

La suma de la población encuestada en cada uno de los grupos muestra una tendencia inversamente proporcional a la severidad del tipo de juego en los sujetos que afirmaron haber jugado por lo menos una vez. Es decir, la mayor proporción de población se agrupa en la categoría sin riesgo; le siguen los jugadores con bajo riesgo; posteriormente aquellos con un riesgo moderado, y con el más bajo porcentaje de todos, los jugadores problemáticos.

En términos generales, se podría decir que el 1.1 por ciento de los mexicanos mayores de 18 años son jugadores problemáticos; el 3.3 por ciento se ubica entre los jugadores con un riesgo moderado; el 11.6 por ciento tiene un riesgo bajo; el 31.3 por ciento de los jugadores no tiene riesgo, y el resto, 52.7 por ciento, no ha participado en algún juego.

Del análisis según el sexo de los grupos de jugadores se deduce que existen diferencias de género, dado que seis de cada diez mujeres se consideran no jugadoras, en tanto que cuatro de cada diez hombres están en esta misma condición. Por su parte, aquellos a quienes se clasificó como jugadores sin riesgo, con riesgo bajo y moderado fueron en mayor medida hombres (37.7, 16.3 y 4.4 por ciento, respectivamente). En cambio, de acuerdo con el índice, el 1.2 por ciento de las mujeres fueron consideradas como jugadoras problemáticas, cifra que desciende a 0.9 en el caso de los varones, con una diferencia no estadísticamente significativa (véase gráfica 5.8). 
Este libro forma parte del acervo de la Biblioteca Jurídica Virtual del Instituto de Investigaciones Jurídicas de la UNAM www.juridicas.unam.mx

GRÁFICA 5.7

DISTRIBUCIÓN DE LA POBLACIÓN ENCUESTADA POR GRUPO DE JUGADORES (PORCENTAJES)

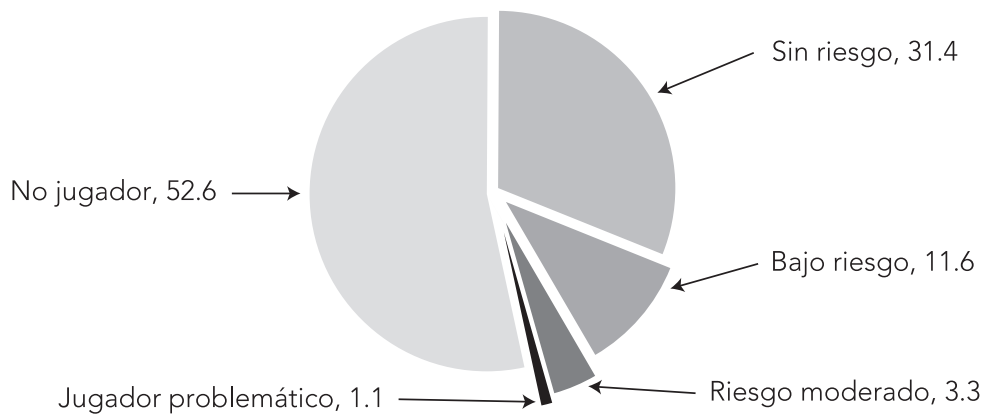

Fuente: Encuesta Nacional de Percepciones Sociales de los Juegos de Azar en México, México, UNAM, Instituto de Investigaciones Jurídicas, Departamento de Investigación Aplicada y Opinión, 2016.

GRÁFICA 5.8

\section{GRUPOS DE JUGADORES POR SEXO}

(PORCENTAJES)

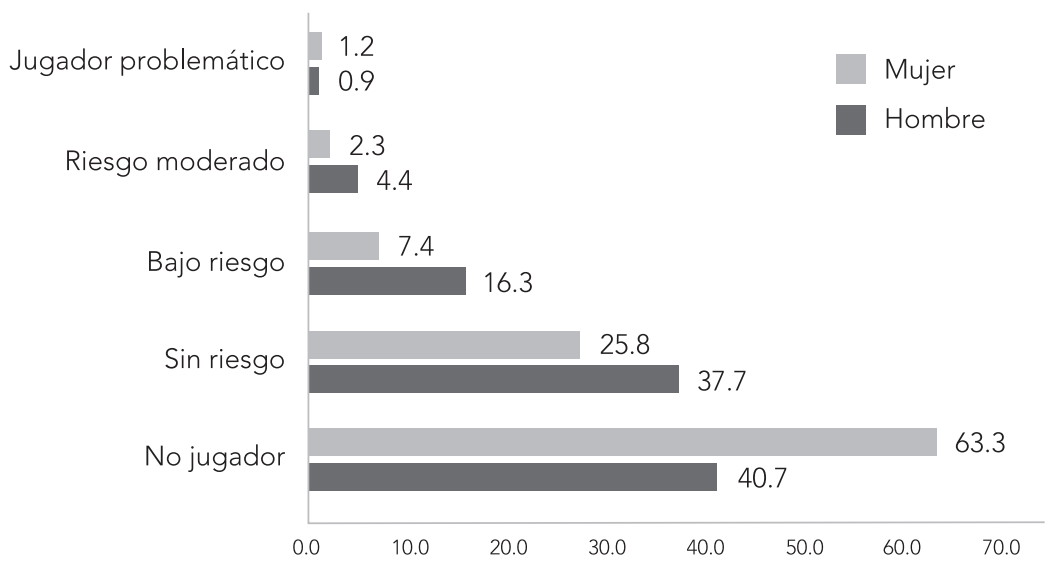

Fuente: Encuesta Nacional de Percepciones Sociales de los Juegos de Azar en México, México, UnAm, Instituto de Investigaciones Jurídicas, Departamento de Investigación Aplicada y Opinión, 2016. 
Este libro forma parte del acervo de la Biblioteca Jurídica Virtual del Instituto de Investigaciones Jurídicas de la UNAM

Al analizar otras características sociodemográficas de quienes se clasificaron con un riesgo moderado, fueron los adultos entre los 45 y los 54 años (4.5 por ciento); aquellos con un nivel de escolaridad de licenciatura o posgrado (9.1 por ciento); con un ingreso mensual individual por encima de los cuatro salarios mínimos (11.5 por ciento) e ingresos familiares superiores a los seis salarios mínimos (8.6 por ciento), así como quienes habitan en las regiones centro y occidente del país (4.2 por ciento y 3.9 por ciento, respectivamente).

Aquellos que fueron considerados como jugadores problemáticos, por encima de la media, son los que tienen una edad entre los 55 y los 64 años (2.4 por ciento); sin escolaridad (3 por ciento); estaban separados, divorciados o viudos (3.6 por ciento); con ingresos familiares superiores a los seis salarios mínimos mensuales (3.3 por ciento), y que viven en la zona noroeste del país (3.4 por ciento).

Si analizamos cada uno de los componentes del modelo para la estimación del juego problemático, esto es, cada una de las interrogantes, se puede observar que a la pregunta ¿Con qué frecuencia usted piensa en jugar, es decir, recordando apuestas anteriores, planificando la próxima vez que jugará?, el 4.3 por ciento de las personas entrevistadas respondió siempre ("4"), mientras que casi uno de cada diez respondió que casi siempre ("3"). Asimismo, a la pregunta ¿Con qué frecuencia usted se ha preocupado por perder a su familia o amigos por apostar?, el 3.8 por ciento de los participantes respondió que siempre ("4"). Finalmente, uno de cada diez encuestados afirmó que casi siempre ("4") piensa en formas para conseguir dinero para jugar.

En general, más de la mitad de los participantes respondió nunca (" 0 ") a las preguntas planteadas en este conjunto de cuestionamientos. Al respecto, los porcentajes variaron entre el 53 y el 82 por ciento; mientras que aquellos que mencionaron haberlo hecho algunas veces ("2") se ubican entre más del 10 y el 2 por ciento. Los que manifestaron la opción casi nunca ("1") se ubicaron entre los 20 y los 6 puntos porcentuales en promedio (véase cuadro 5.3). 
Este libro forma parte del acervo de la Biblioteca Jurídica Virtual del Instituto de Investigaciones Jurídicas de la UNAM www.juridicas.unam.mx

\section{CUADRO 5.3}

¿CON QUÉ FRECUENCIA USTED PIENSA EN JUGAR, ES DECIR, RECORDANDO
APUESTAS ANTERIORES, PLANIFICANDO LA PRÓXIMA VEZ QUE JUGARÁ?
(PORCENTAJES)

Fuente: Encuesta Nacional de Percepciones Sociales de los Juegos de Azar en México, México, UNAM, Instituto de Investigaciones Jurídicas, Departamento de Investigación Aplicada y Opinión, 2016.

Interesantes resultados se encuentran al cruzar la clasificación (tipo) de jugadores con el catálogo de juegos incluidos en la encuesta. ${ }^{6}$ En este sentido, es posible encontrar indicios de cuáles juegos podrían llevar a una persona a convertirse en un jugador problemático y cuáles podrían mantenerla sin riesgo. Al respecto, los juegos que se practican en los casinos casi no tuvieron el mayor porcentaje de jugadores problemáticos (6 por ciento); seguidos por las máquinas tragamonedas — de un peso y cinco pesos- $(4.2$ por ciento) y el bingo, con 1.9 por ciento (véase cuadro 5.4).

6 Lotería Nacional, Zodiaco, El Gordo, Melate, otros sorteos (raspar), rifa, tómbola, quiniela, telejuegos, juegos por Internet, bingo, lotería mexicana, máquinas tragamonedas, casino, apuestas en carreras, juegos de cartas fuera de casinos, jaripeo o rodeo y juegos tradicionales. 
Este libro forma parte del acervo de la Biblioteca Jurídica Virtual del Instituto de Investigaciones Jurídicas de la UNAM

Por otro lado, cabe hacer notar que el 33.4 por ciento de las personas que juegan por Internet se consideran con riesgo moderado; en esta misma categoría estuvo el 23.9 por ciento que juega bingo y el 23.6 por ciento que apostó en el jaripeo o rodeo. Los que participan en juegos por Internet, en quinielas y telejuegos tuvieron un riesgo bajo $(51.4,34.9$ y 33.3 por ciento, respectivamente). Por su parte, casi siete de cada diez de las personas calificadas como sin riesgo juegan cartas fuera de los casinos, y más de seis de cada diez participan en la lotería mexicana y en rifas y tómbolas, lo que indica que estos juegos son una práctica común en los diversos ámbitos de convivencia de los encuestados, pero que no representan un riesgo de juego problemático, al menos en su percepción (véase cuadro 5.4).

\section{CUADRO 5.4}

\begin{tabular}{|c|c|c|c|c|}
\hline \multicolumn{5}{|c|}{$\begin{array}{c}\text { DISTRIBUCIÓN DE JUGADORES DEL MODELO DICOTÓMICO } \\
\text { SEGÚN EL TIPO DE JUEGOS } \\
\text { (PORCENTAJES) }\end{array}$} \\
\hline & \multicolumn{4}{|c|}{ CLASIFICACIÓN DE JUGADOR } \\
\hline TIPO DE JUEGO & SIN PROBLEMA & $\begin{array}{c}\text { BAJO } \\
\text { RIESGO }\end{array}$ & $\begin{array}{c}\text { RIESGO } \\
\text { MODERADO }\end{array}$ & $\begin{array}{c}\text { JUGADOR } \\
\text { PROBLEMÁTICO }\end{array}$ \\
\hline $\begin{array}{l}\text { Lotería Nacional, } \\
\text { Zodiaco, El Gordo }\end{array}$ & 61.4 & 24.9 & 12.4 & 1.3 \\
\hline Melate & 59.5 & 28.9 & 11.6 & \\
\hline Otros sorteos (raspar) & 58.0 & 32.2 & 9.0 & 0.6 \\
\hline Rifa, tómbola & 65.1 & 25.2 & 8.1 & 1.7 \\
\hline Quiniela & 51.8 & 34.9 & 13.3 & \\
\hline Telejuegos & 56.8 & 33.3 & 9.8 & \\
\hline Juegos por Internet & 15.2 & 51.4 & 33.4 & \\
\hline Bingo & 41.5 & 28.8 & 27.9 & 1.9 \\
\hline Lotería mexicana & 65.8 & 27.0 & 6.6 & 0.6 \\
\hline Máquinas tragamonedas & 57.3 & 30.5 & 7.9 & 4.2 \\
\hline Casino & 51.5 & 24.3 & 18.2 & 6.0 \\
\hline Apuestas en carreras & 54.4 & 24.7 & 19.8 & 1.1 \\
\hline $\begin{array}{l}\text { Juegos de cartas fuera } \\
\text { de casinos }\end{array}$ & 69.5 & 21.2 & 7.8 & 1.5 \\
\hline Jaripeo o rodeo & 46.0 & 30.4 & 23.6 & \\
\hline Juegos tradicionales & 62.5 & 27.4 & 8.4 & 1.7 \\
\hline
\end{tabular}

Fuente: Encuesta Nacional de Percepciones Sociales de los Juegos de Azar en México, México, UNAM, Instituto de Investigaciones Jurídicas, Departamento de Investigación Aplicada y Opinión, 2016. 
Este libro forma parte del acervo de la Biblioteca Jurídica Virtual del Instituto de Investigaciones Jurídicas de la UNAM

\section{CONCLUSIONES}

Los resultados de la encuesta en vivienda sobre el tema del juego problemático nos permitieron observar algunas tendencias interesantes y coherentes:

Por ejemplo, que el entretenimiento y la diversión son las principales motivaciones de los mexicanos para jugar, ya que más de la mitad brindó dicha respuesta.

Muy pocos de los encuestados (3.8 por ciento) manifestaron haber jugado en exceso en el último año. En concordancia, un bajo porcentaje (4.8 por ciento) expresó que alguna vez alguien le dijo que tenía una adicción al juego, y un porcentaje mínimo (1.7 por ciento) reconoció haber sido diagnosticado con una adicción al juego por un especialista.

En México, los datos generados a partir de esta Encuesta Nacional de Percepciones Sociales de los Juegos de Azar permiten estimar que el 1.1 por ciento de las personas de 18 años y más son jugadores problemáticos. Esta cifra es similar a la prevalencia reportada para Gran Bretaña en un estudio sobre el comportamiento de los jugadores en 2015. ' Sin embargo, es superior a la reportada en España para ese mismo año, que fue de 0.1 por ciento (Gómez et al., 2015).

Las cifras sobre la prevalencia del juego problemático en el mundo varían en un rango de 0.1 a 5.8 por ciento. Al respecto, se ha señalado que en América del Norte la prevalencia se ubica entre un 2 y un 5 por ciento; en Asia es de 0.5 a 5.8 por ciento; en Oceanía de 0.4 a 0.7 por ciento, y en Europa de 0.1 a 3.4 por ciento (Calado y Griffiths, 2016).

En relación a los jugadores con riesgo, la encuesta nacional permitió detectar que existe un 3.3 por ciento de personas que se ubica en el rango de jugadores con un riesgo moderado, y un 11.6 que presenta un riesgo bajo. Esto es, se estimó que 14.9 ciento son jugadores en riesgo. Estos datos muestran que hay un grupo potencial de jugadores en el que algunos de ellos podrían en un futuro convertirse en problemáticos, de no realizarse las acciones preventivas y educativas pertinentes.

7 Este estudio utilizó información combinada de las encuestas Nacional de Salud de Inglaterra (HSES), de Escocia (SHES) y de Gales, realizadas en población de 16 años y más en 2015. La estimación de la prevalencia del juego problemático utilizó el método de estimación de puntuación continúa empleado en la British Gambling Prevalence Survey (BGPS) (Conelly et al., 2017). 
Este libro forma parte del acervo de la Biblioteca Jurídica Virtual del Instituto de Investigaciones Jurídicas de la UNAM

Los jugadores problemáticos fueron, por encima de la media, los que tienen un nivel de licenciatura o posgrado, los que perciben más de cuatro salarios mínimos individuales al mes, al igual que los que obtienen un ingreso familiar de más de seis salarios mínimos al mes y los que habitan la zona noroeste del país. Mientras que los jugadores con un riesgo moderado fueron los más jóvenes de 18 a 24 años, con un nivel escolar de licenciatura o posgrado y con un ingreso mensual individual por encima de los dos salarios mínimos. Los jugadores problemáticos prefirieron jugar bingo (26.3 por ciento), en casinos (24.1 por ciento) y las apuestas en carreras (22.6 por ciento). Los jugadores con un riesgo moderado prefirieron en mayor medida los juegos por Internet (52.3 por ciento).

Finalmente, es importante señalar que existen en México alrededor de novecientas cuatro mil personas que son jugadores problemáticos y más de 2.7 millones de jugadores en riesgo moderado. Esto, si tomamos en consideración las proyecciones de población del Consejo Nacional de Población (Conapo) para 2016 y las cifras presentadas en este capítulo en relación con el juego problemático y los grupos en riesgo.

En la actualidad, la diversificación de las formas de ocio y la expansión de centros de juegos de azar ha dado lugar a que la población entre en contacto con diferentes tipos de juegos, lo que puede hacer posible un incremento en la incidencia del juego patológico, que la población no identifica como un trastorno del comportamiento o dependencia. Esta falta de conciencia y las carencias de infraestructura y recursos humanos capacitados para informar, prevenir y atender los problemas relacionados con el juego hacen necesaria la acción gubernamental e intersectorial en este tema.

Con base en lo anterior, podemos afirmar que la prevalencia de juego problemático encontrada en nuestro país se ubica en los rangos reportados en diferentes regiones del mundo. Sin embargo, es necesario realizar otros estudios sistemáticos y periódicos para contar con un sistema de encuestas nacionales en esta área, que aporten la información necesaria para delinear tendencias. Por una parte, es urgente la implementación de acciones preventivas dirigidas al grupo de jugadores y, por la otra, que se desplieguen acciones intersectoriales para apoyar y atender a la población detectada con juego problemático. 
Este libro forma parte del acervo de la Biblioteca Jurídica Virtual del Instituto de Investigaciones Jurídicas de la UNAM www.juridicas.unam.mx

Esta encuesta nacional proporciona un buen punto de partida para el desarrollo de futuros estudios sobre los juegos de azar y dar inicio a las acciones para subsanar la carencia de investigaciones sobre esta temática en nuestro país. 
Este libro forma parte del acervo de la Biblioteca Jurídica Virtual del Instituto de Investigaciones Jurídicas de la UNAM

\section{CAPÍTULO 6}

\section{EL JUEGO EN LÍNEA}

\section{ANTECEDENTES}

Los juegos de azar ocupan un espacio vital e importante en el desarrollo de las sociedades y se han estudiado en diferentes momentos históricos. Para Huizinga, los juegos de azar pertenecen "a la esfera de la fiesta o del culto, la esfera de lo sagrado"; es decir, a las actividades gregarias de interacción y enlace con los demás (Huizinga, 2000: 22). Por su parte, Roger Caillois diseñó una clasificación de juegos en donde definió que existen juegos de competición, azar, ficción y vértigo. Éstos se enmarcan en dos formas de manifestación del impulso lúdico: la paidía — juego puro, expresión feliz y desordenada- y el ludus, que implica la necesidad de someter y encauzar el juego a través de reglas y límites.

Hoy, con los avances de la tecnología, las modalidades del juego han cambiado y están transitando de una actividad eminentemente social a una actividad individual. Lo distintivo de esta modalidad es que aunque los jugadores se ubiquen en mesas virtuales grupales, siempre serán solamente el jugador y su interfaz, aislados; es decir, con pulsar una tecla se resuelve la participación en las apuestas a distancia y en tiempo real. 
Este libro forma parte del acervo de la Biblioteca Jurídica Virtual del Instituto de Investigaciones Jurídicas de la UNAM

La modalidad de los juegos de apuesta en línea es una variante que se desarrolló al mismo tiempo que las computadoras, los teléfonos inteligentes o tablets e Internet estuvieron al alcance de una mayoría de la población; cabe señalar que, a diferencia de los juegos de apuesta y sorteo presenciales - a los que es más fácil acceder debido a las máquinas o el material necesario para jugarlos-, para los juegos en línea es necesario un perfil específico de la población. Generalmente se trata de personas con acceso a Internet, a algún equipo como computadora o teléfono celular inteligente, así como una tarjeta de crédito o débito para realizar sus apuestas.

Lo anterior delimita de una manera importante la tipología de estos jugadores. Sin embargo, aunque persisten los juegos de apuesta y sorteo presenciales, lo hacen en competencia con los juegos de apuesta en línea que se han expandido debido al cada vez mayor acceso de la población a Internet y la tecnología. Esta opción electrónica ha hecho que los juegos de azar se hayan masificado y pasen a formar parte de la vida cotidiana:

Hoy se puede apostar y hacer quinielas de fútbol en la farmacia o en la miscelánea de la esquina, por teléfono o por computadoras... Gracias a la tecnología, basta con apretar un simple botón de la computadora o con una llamada telefónica, sin cita previa y a cualquier hora del día, para abandonar la rutina y coquetear con el azar o "navegar" por el entretenimiento de un juego electrónico. Desde la sala de un hogar, mientras se observa el televisor, hoy se puede probar suerte en apuestas que corren del otro lado del globo. Ya no es necesario asistir al hipódromo o a la feria para apostar en las carreras de caballos; tampoco se necesita acudir al casino para jugar a la ruleta. Desde la Ciudad de México se puede apostar a los golpes en Tijuana o participar en una quiniela de una pelea de box que trascurre en Filipinas (González del Rivero, 2000: 170).

Hay modalidades individuales (singles, como el lotto o la ruleta), grupales (como las barajas) y juegos masivos de múltiples jugadores (como World of Warcraft). Entre estos últimos no todos son de azar ni de apuesta, aunque hay quienes buscan sacar ganancias juntando puntos o dinero virtual (Terdiman, 2006: s/p).

En este sentido, los juegos de apuesta y sorteo forman parte de las actividades de la sociedad y han sido parte de ésta desde la Antigüedad; sin 
Este libro forma parte del acervo de la Biblioteca Jurídica Virtual del Instituto de Investigaciones Jurídicas de la UNAM

embargo, la tecnología y la globalización redefinieron la manera en que los juegos de azar se llevan a cabo, dando entrada a los juegos de azar en línea, aunque para jugarlos es necesario tener acceso a los avances tecnológicos e Internet.

La relevancia y el crecimiento que han tenido los juegos de apuesta en línea durante los últimos años, acompañados del desarrollo tecnológico y la generalización del uso del Internet y dispositivos móviles, han hecho necesaria la exploración de este mundo virtual poco conocido. Por eso, en el estudio que se presenta en este libro se incluyó una encuesta en línea con el objetivo de explorar las prácticas de juego de aquellos que juegan y apuestan en Internet, tanto de manera exclusiva como los que también lo hacen en casinos $u$ otros juegos presenciales.

Los resultados de la Primera Encuesta Nacional en Vivienda indican que el 41 por ciento de los mexicanos entrevistados mayores a 18 años conoce los juegos de apuesta por Internet y que el 2 por ciento de ellos los ha jugado. Las estimaciones indican que alrededor de 600 mil mexicanos, en particular los jóvenes, han experimentado los juegos de azar por Internet (gráficas 6.1 y 6.2).

\section{GRÁFICA 6.1}

¿USTED CONOCE O NO CONOCE...?

JUEGOS POR INTERNET (PÓQUER, LOTERÍAS, ETCÉTERA)

(ENCUESTA EN VIVIENDA, PORCENTAJES)

\section{Sí, $41.0 \quad$ No, 59.0}

Fuente: Encuesta Nacional de Percepciones Sociales de los Juegos de Azar en México, México, UNAM, Instituto de Investigaciones Jurídicas, Departamento de Investigación Aplicada y Opinión, 2016.

GRÁFICA 6.2

¿USTED HA PARTICIPADO O COMPRADO UN BOLETO...?

JUEGOS POR INTERNET (PÓQUER, LOTERÍAS, ETCÉTERA)

(ENCUESTA EN VIVIENDA, PORCENTAJES)

Sí, 2.0

No, 98.0

Fuente: Encuesta Nacional de Percepciones Sociales de los Juegos de Azar en México, México, UNAM, Instituto de Investigaciones Jurídicas, Departamento de Investigación Aplicada y Opinión, 2016. 
Este libro forma parte del acervo de la Biblioteca Jurídica Virtual del Instituto de Investigaciones Jurídicas de la UNAM

Aunque no hay una fecha específica, se calcula que los juegos de azar por Internet se originaron en los años noventa del siglo XX, cuando en la isla de Antigua y Barbuda se creó la ley Free Trade \& Processing (Duncan, 2015: 16). Así, se empezaron a dar licencias a empresas que quisieran ofrecer servicios de apuestas por Internet. Las primeras investigaciones se realizaron aproximadamente una década después. Fue en el Reino Unido donde se realizó la primera encuesta sobre la prevalencia del juego por Internet, publicada en 2001. En ese estudio se determinó que los juegos de apuesta en línea podrían ser más atractivos para los jugadores debido a la confidencialidad, accesibilidad e interactividad que garantizaban gracias al desarrollo tecnológico sobre el cual están hechos. Entonces, los resultados de aquella encuesta estimaron que solamente el 1 por ciento de los usuarios de Internet en el Reino Unido habían jugado juegos de azar en línea (Griffiths, 2001). En 2008, el mismo autor publicó otra encuesta en donde se identificó que el 8.8 por ciento de los 8 mil adultos entrevistados dijo haber participado en alguna apuesta remota en el mes anterior a la fecha de la entrevista, cifra que se mantuvo estable con otra encuesta realizada un mes después. Es decir, muy probablemente el número de jugadores aumentó entre 2001 y 2008. Con ese estudio también se verificó que era más probable que los jugadores de apuestas por Internet fueran más hombres que mujeres, y que estuvieran entre los 18 y 34 años de edad. En otro estudio reciente en Gran Bretaña, que recolectó datos a partir de encuestas telefónicas y en línea durante 2016, se encontró que el 17 por ciento de los entrevistados había participado en algún tipo de apuestas por Internet en los últimos cuatro meses anteriores a la fecha del levantamiento (NatCen, 2011).

En Australia también se han realizado estudios nemotécnicos sobre los juegos de azar en línea. En ellos se ha determinado que, si bien los juegos de azar presenciales aún son predominantes a los que se realizan por Internet, la participación en estos últimos ha alcanzado tasas de crecimiento anual de hasta 17 por ciento entre 2004 y 2011 (Gainsbury et al., 2013).

En España, el Instituto de Política y Gobernanza de la Universidad Carlos III de Madrid ha realizado una serie de encuestas para medir la prevalencia de los juegos de azar tanto presenciales como por Internet. En su último estudio de Percepción Social sobre el Juego de Azar 2017 se determinó que 
Este libro forma parte del acervo de la Biblioteca Jurídica Virtual del Instituto de Investigaciones Jurídicas de la UNAM

el número de jugadores en línea ha ido en aumento y se estimó en alrededor de 1.38 millones de clientes activos durante el último año previo al estudio. Los casos de Inglaterra, Australia y España ilustran lo que es una tendencia a nivel mundial. Según las últimas proyecciones, se pronostica que para 2018 el volumen neto de los juegos de apuesta por Internet alcance los 51.96 billones de dólares estadounidenses, lo que duplicaría la estimación de hace apenas diez años, cuando en 2009 éste era apenas de 20.51 billones de dólares (Statista, 2017).

Si bien en estos países, en donde esta práctica de apuestas en línea es común y en donde se han realizado estudios sobre hábitos de consumo, efectos en los jugadores y necesidad de regular estos juegos, el acceso a Internet es mucho mayor que en México (el 81 por ciento para España y el 95 por ciento para Inglaterra), la tasa de crecimiento de su uso en México indica que se podría llegar a esas cifras en algunos años. ${ }^{1}$

Por su parte, la Encuesta Nacional sobre Disponibilidad y Uso de Tecnologías de la Información en los Hogares (ENDUTIH) del INEGI 2016 confirma esta información. Sus principales resultados son que el 47 por ciento de los hogares del país cuenta con conexión a Internet. Además, se registró que el 59.5 por ciento de la población de seis años o más en México es usuaria. Del total de usuarios, el 48.5 por ciento son hombres y el 51.5 por ciento son mujeres. Por otro lado, cabe destacar que el 68.5 por ciento de los que tienen acceso a Internet tienen menos de 35 años.

Los estudios que se han realizado en Inglaterra y España indican que determinar el número exacto de jugadores en línea es complicado debido a las altas y bajas de los mismos en la red; sin embargo, coinciden en que el número ha ido aumentando en los últimos años. A su vez, indicaron que los nuevos hábitos de consumo de la población, principalmente de aquellos más jóvenes, hacen esperar que esta tendencia se mantenga.

1 Datos del Banco Mundial indican que el acceso a Internet en 2006 en España era del 50 por ciento, en Inglaterra del 69 por ciento y en México del 20 por ciento. Mientras que para 2016 los datos arrojados fueron 81 por ciento, 95 por ciento y 60 por ciento, respectivamente, lo que podría indicar que la tasa de crecimiento en el uso de Internet en México ha sido mayor y continuará aumentando. Banco Mundial, disponible en: https://datos.bancomundial.org/indicador/IT.NET. USER.ZS [fecha de consulta: 30 de octubre de 2017]. 
Este libro forma parte del acervo de la Biblioteca Jurídica Virtual del Instituto de Investigaciones Jurídicas de la UNAM

\section{PERFIL SOCIOLÓGICO DE LOS JUGADORES} EN LÍNEA

\section{¿QUIÉNES SON LOS JUGADORES EN LÍNEA?}

De los 10 mil usuarios de los juegos en línea a los que se les envió el correo de invitación a contestar la encuesta en línea, 1,933 lo hicieron. La primera pregunta que se les realizó a estas personas es si habían participado en los últimos seis meses en juegos de apuesta por Internet apostando dinero. Casi cuatro de cada diez de esos 1,933 entrevistados indicaron que sí habían jugado en línea, dando un resultado de 709 jugadores en línea, mientras que el resto dijo que no ha participado en juegos de apuesta por Internet en los seis meses anteriores al levantamiento de la encuesta.

Del conjunto de personas que dijeron haber jugado al menos un juego de apuestas por Internet en los últimos seis meses, casi seis de cada diez resultaron ser hombres. Lo que coincide con la tendencia de que con mayor probabilidad los jugadores en línea sean más varones que mujeres. Con respecto a los grupos de edad de los jugadores, prácticamente cuatro de cada diez resultaron estar entre las edades de 18 a 34 años, otros cuatro de cada diez entre los 35 a 49 años, y únicamente dos de cada diez indicaron tener 50 años o más. Es decir, también se cumplió con el patrón de edad encontrado en España e Inglaterra, en donde los jóvenes suelen ser en mayor medida usuarios de este tipo de juegos que los adultos.

En cuanto al nivel educativo, los jugadores por Internet resultaron tener un porcentaje mayor de estudios de preparatoria y bachillerato, así como de licenciatura y posgrado con respecto al promedio de todos los usuarios que fueron contactados (véase cuadro 6.1). 
Este libro forma parte del acervo de la Biblioteca Jurídica Virtual del Instituto de Investigaciones Jurídicas de la UNAM

\section{CUADRO 6.1}

\begin{tabular}{|c|c|c|c|}
\hline \multicolumn{4}{|c|}{$\begin{array}{l}\text { PERFIL DE LOS USUARIOS QUE CONTESTARON LA ENCUESTA EN LÍNEA } \\
\text { (PORCENTAJES) }\end{array}$} \\
\hline & JUGADORES EN LÍNEA & NO JUGADORES EN LÍNEA & TOTAL \\
\hline Total de entrevistados & 37.7 & 63.3 & 100 \\
\hline (n) & (709) & $(1224)$ & (1933) \\
\hline Hombres & 64.7 & 52.3 & 56.9 \\
\hline Mujeres & 35.3 & 47.7 & 43.1 \\
\hline De 18 a 29 años & 23.4 & 20.0 & 21.2 \\
\hline De 30 a 34 años & 17.8 & 13.0 & 14.8 \\
\hline De 35 a 39 años & 14.2 & 11.6 & 12.6 \\
\hline De 40 a 49 años & 26.1 & 21.5 & 23.1 \\
\hline De 50 años y más & 18.6 & 33.9 & 28.3 \\
\hline Ninguno & 0.8 & 1.0 & 0.9 \\
\hline Primaria & 1.7 & 2.5 & 2.2 \\
\hline Secundaria & 21.3 & 28.3 & 25.7 \\
\hline Preparatoria o bachillerato & 47.5 & 44.0 & 45.3 \\
\hline Licenciatura o posgrado & 28.6 & 24.3 & 25.9 \\
\hline
\end{tabular}

Fuente: Encuesta Nacional de Percepciones Sociales de los Juegos de Azar en México, México, UNAM, Instituto de Investigaciones Jurídicas, Departamento de Investigación Aplicada y Opinión, 2016.

\section{ANÁLISIS DE CORRESPONDENCIAS}

Para delimitar los perfiles de los jugadores en línea se realizó un análisis de correspondencias múltiples. El objetivo de este tipo de análisis es buscar relaciones entre una variable a explicar y las variables suplementarias. En este caso en particular se busca explicar el perfil de los jugadores en línea según su intensidad de juego:

- Intenso.

- Frecuente.

- Ocasional.

Se utilizaron como variables suplementarias las características sociodemográficas de los encuestados. Como se puede apreciar en la gráfica 6.3, el 
Este libro forma parte del acervo de la Biblioteca Jurídica Virtual del Instituto de Investigaciones Jurídicas de la UNAM www.juridicas.unam.mx

resultado del análisis de correspondencias resume en un solo gráfico los hallazgos de este apartado. Para leer este gráfico es importante prestar atención a la variable intensidad de juego y sus tres posibles categorías: intenso, frecuente y ocasional. Estos tres puntos serán el inicio de nuestra lectura.

\section{GRÁFICA 6.3}

BIPLOT DEL ANÁLISIS DE CORRESPONDENCIAS MÚLTIPLES. INTENSIDAD DE JUEGO

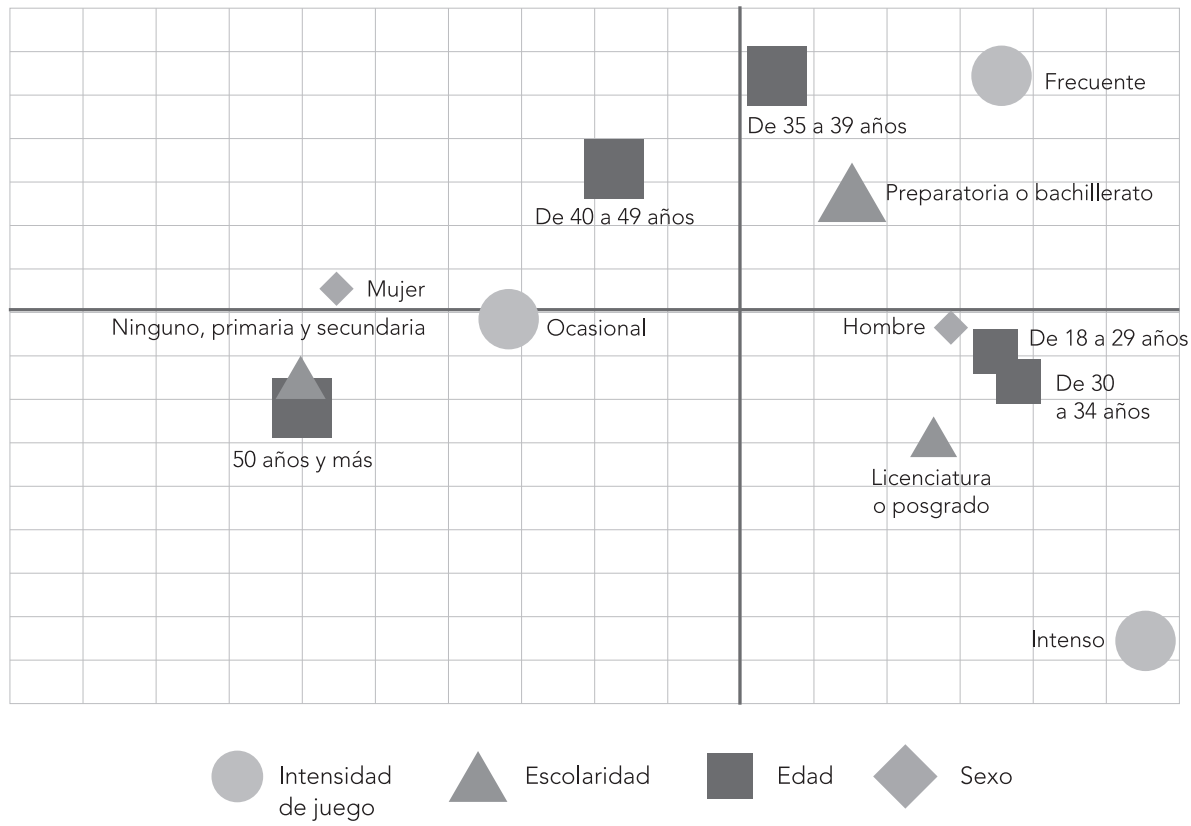

Fuente: Encuesta Nacional de Percepciones Sociales de los Juegos de Azar en México, México, unam, Instituto de Investigaciones Jurídicas, Departamento de Investigación Aplicada y Opinión, 2016.

Alrededor de cada una de las tres categorías se verán las características más frecuentes de cada tipo de jugador:

- Jugador intensivo: aunque lejanos a la categoría, destacan las personas de edad de 30 a 34 años, así como los de 18 a 29 años, con nivel de estudios de licenciatura y posgrado. Los hombres también aparecen en un segundo nivel. 
Este libro forma parte del acervo de la Biblioteca Jurídica Virtual del Instituto de Investigaciones Jurídicas de la UNAM

- Jugador frecuente: se observan cercanos los grupos etarios de 35 a 39 años y los que tienen un nivel de estudios de preparatoria o bachillerato; un poco más lejanos, también sobresalen los hombres y los que tienen entre 40 y 49 años.

- Jugador ocasional: las categorías más colindantes son las mujeres, las personas de 50 años y más, y aquellos con niveles de escolaridad bajos (secundaria o primaria).

Las distancias son estandarizadas en este gráfico, lo cual permite analizar la distancia entre dos puntos: entre más cercanos son, más guardan cierta relación entre sí. El análisis de correspondencias nos permite interpretar cada uno de los ejes que tenemos; por ejemplo, para este caso, el eje X resume en buena medida la intensidad de juego de cada jugador. Por ello, si leemos de manera horizontal las distancias entre unos puntos y otros veremos que estos resultados se corresponden con los previamente señalados. Para este modelo se obtuvo una varianza explicada del 61.7 por ciento.

\section{MOTIVACIONES DEL JUEGO POR INTERNET}

Como se mencionó previamente, investigaciones en el Reino Unido han indicado que las principales motivaciones para participar en juegos de apuesta por Internet son la accesibilidad de poder hacerlo desde cualquier lugar, la confidencialidad y la interacción que permiten. En este estudio no se tienen indicadores para verificar dichas hipótesis - lo que se podrá hacer en el futuro-. No obstante, sí se pudo saber que casi siete de cada diez personas que dijeron apostar por Internet señalaron hacerlo por entretenimiento y diversión. Solamente un poco más de dos de cada diez revelaron hacerlo para ganar dinero, mientras que el resto de las opciones obtuvieron porcentajes por debajo de los tres puntos porcentuales. De esta manera, es posible concluir que, al igual que en el juego presencial, en los juegos en línea la mayoría de los jugadores sujetos de estudio lo hace por entretenimiento y diversión, y la minoría para ganar dinero, lo cual diferencia a los jugadores mexicanos de los de otros países. 
Este libro forma parte del acervo de la Biblioteca Jurídica Virtual del Instituto de Investigaciones Jurídicas de la UNAM

\section{GRÁFICA 6.4}

¿QUÉ ES LO QUE LE MOTIVA PRINCIPALMENTE PARA JUGAR?

(PORCENTAJES)

El entretenimiento y diversión

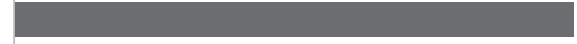

68.1

El ganar dinero

Para no aburrirme

La curiosidad

Verlo como reto

Una invitación

Para no estar solo

\section{4}

2.4

1.8

0.3

0.3

Fuente: Encuesta Nacional de Percepciones Sociales de los Juegos de Azar en México, México, UNAM, Instituto de Investigaciones Jurídicas, Departamento de Investigación Aplicada y Opinión, 2016.

\section{ANÁLISIS DE CORRESPONDENCIAS}

También se realizó un análisis de correspondencias múltiples para delimitar las motivaciones para jugar de los jugadores en línea, buscando a su vez relaciones entre la variable a explicar y las variables suplementarias. En este caso, la variable a explicar fueron las motivaciones principales para jugar y las suplementarias fueron las variables socioeconómicas principales, así como la intensidad de juego de los jugadores en línea. Si se lee el modelo de derecha a izquierda, se puede apreciar que la dimensión 1 explica las motivaciones que llevarían a jugar a las personas que juegan en línea. Para este modelo se obtuvo una varianza explicada del 50.8 por ciento.

Del análisis de correspondencias se pueden observar las siguientes características específicas que motivarían a jugar a cada perfil de los jugadores:

- Entretenimiento: cerca de esta categoría destacan los jugadores frecuentes, las personas de 30 a 39 años de edad, así como los de 30 a 34 años.

- Ganar dinero: sobresalen los hombres, con estudios de licenciatura y posgrado. Por su parte, están más cerca de esta motivación que de 
Este libro forma parte del acervo de la Biblioteca Jurídica Virtual del Instituto de Investigaciones Jurídicas de la UNAM www.juridicas.unam.mx

otra los jugadores intensos y los grupos etarios de 18 a 34 años de edad.

- Otro: destacan las mujeres, los de 50 años y más, y con niveles bajos de escolaridad, que se consideran jugadores ocasionales.

\section{GRÁFICA 6.5}

BIPLOT DEL ANÁLISIS DE CORRESPONDENCIAS MÚLTIPLES. MOTIVACIONES PARA JUGAR POR INTERNET

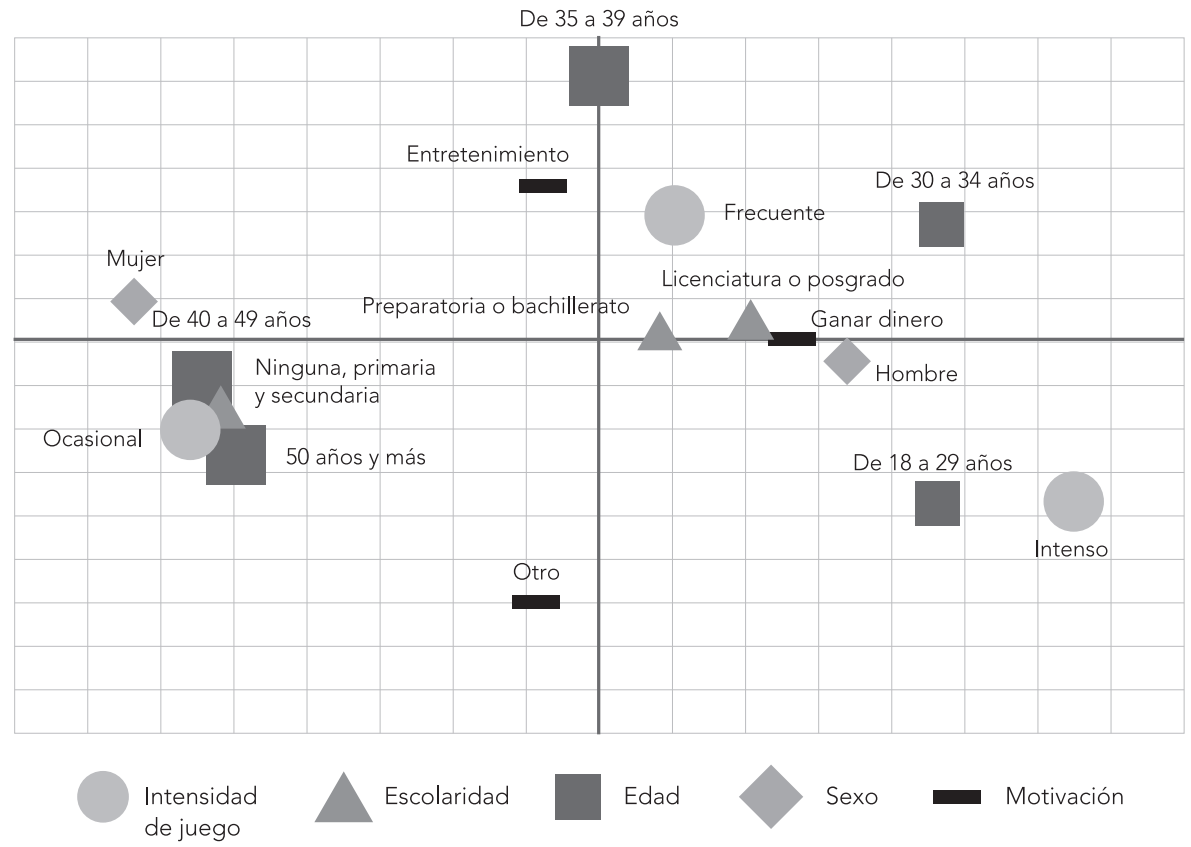

Fuente: Encuesta Nacional de Percepciones Sociales de los Juegos de Azar en México, México, UnAm, Instituto de Investigaciones Jurídicas, Departamento de Investigación Aplicada y Opinión, 2016.

\section{¿A QUÉ JUEGAN POR INTERNET?}

\section{¿CUÁLES SON LOS JUEGOS MÁS CONOCIDOS?}

Para los jugadores de apuestas por Internet que contestaron la encuesta en línea y que dijeron apostar en los últimos seis meses, el juego por Internet más conocido son las máquinas tragamonedas. En segundo lugar se ubica- 
Este libro forma parte del acervo de la Biblioteca Jurídica Virtual del Instituto de Investigaciones Jurídicas de la UNAM

ron los juegos que resultaron ser también los más populares en la encuesta a población abierta en vivienda, tales como la lotería instantánea de pronósticos y la Lotería Nacional o de otro país. Posteriormente aparecieron los juegos más típicos de apuestas en casinos, como el póquer, el bingo, el blackjack y la ruleta. Finalmente, los juegos menos conocidos fueron el craps o pase inglés y la brisca por Internet (véase cuadro 6.2).

\section{CUADRO 6.2}

LOS JUEGOS MÁS CONOCIDOS

(PORCENTAJES)

\begin{tabular}{l|c|c}
\hline & SÍ LOS CONOCE & NÚMERO \\
\hline Máquinas tragamonedas & 78.3 & 555 \\
\hline La lotería instantánea de pronósticos & 77.9 & 552 \\
\hline Lotería Nacional, o lotería de otro país & 74.5 & 528 \\
\hline Póquer por Internet & 71.9 & 510 \\
\hline Bingo por Internet & 71.1 & 504 \\
\hline Blackjack por Internet & 58.1 & 412 \\
\hline Ruleta por Internet & 45.1 & 320 \\
\hline Craps o pase inglés (dados) & 17.3 & 123 \\
\hline Brisca por Internet & 15.8 & 112 \\
\hline Otro juego de apuesta por Internet & 8.0 & 57 \\
\hline Otro juego de cartas por Internet & 7.6 & 54 \\
\hline
\end{tabular}

Fuente: Encuesta Nacional de Percepciones Sociales de los Juegos de Azar en México, México, UNAM, Instituto de Investigaciones Jurídicas, Departamento de Investigación Aplicada y Opinión, 2016.

\section{¿CUÁLES SON LOS JUEGOS MÁS JUGADOS?}

A aquellos que conocían cada uno de los juegos, se les preguntó si efectivamente los jugaban. A continuación se puede observar que no necesariamente los juegos más conocidos son los más jugados por aquellos que los conocen. Las máquinas tragamonedas sí dominan tanto el reconocimiento como el gusto de los usuarios que juegan en línea, siendo las que más se conocen y juegan. Resultó también que prácticamente la mitad de los jugadores que dijo conocer la lotería instantánea de pronósticos, el bingo, el póquer y el blackjack por Internet, indicó también jugarlos. Con un poco menos de correspondencia entre conocimiento y juego resultaron la Lotería 
Este libro forma parte del acervo de la Biblioteca Jurídica Virtual del Instituto de Investigaciones Jurídicas de la UNAM

Nacional o lotería de otro país, y la ruleta por Internet. Finalmente, también coincidió que los juegos menos conocidos fueron los menos jugados, siendo éstos el craps o pase inglés y la brisca por Internet (véase cuadro 6.3).

\title{
CUADRO 6.3
}

\begin{tabular}{l|c|c}
\hline \multicolumn{3}{c}{$\begin{array}{c}\text { LOS JUEGOS MÁS JUGADOS } \\
\text { (PORCENTAJES) }\end{array}$} \\
\hline $\begin{array}{c}\text { Sí LOS HA } \\
\text { JUGADO }\end{array}$ & NÚMERO \\
\hline Máquinas tragamonedas por Internet & 61.6 & 343 \\
\hline Lotería instantánea de pronósticos por Internet & 51.8 & 287 \\
\hline Bingo por Internet & 50.1 & 255 \\
\hline Póquer por Internet & 49.0 & 250 \\
\hline Blackjack por Internet & 46.6 & 193 \\
\hline Lotería Nacional, o lotería de otro país, por Internet & 44.6 & 237 \\
\hline Ruleta por Internet & 43.0 & 139 \\
\hline Craps o pase inglés (dados) por Internet & 34.9 & 45 \\
\hline Brisca por Internet & 33.3 & 39 \\
\hline
\end{tabular}

\section{PERFIL SOCIOLÓGICO DE LOS USUARIOS DE LOS JUEGOS POR INTERNET}

\author{
¿QUIÉNES LOS JUEGAN?
}

La distribución de jugadores entre hombres y mujeres del juego más popular por Internet (las máquinas tragamonedas) es muy similar a la correspondiente del total de jugadores por Internet que contestaron la encuesta en línea. En contraste, tienen una mayor concentración de hombres el craps o pase inglés, la ruleta, el póquer, el blackjack, la brisca y la lotería instantánea de pronósticos por Internet. Por su parte, se observó una mayor agrupación de mujeres en el bingo y la Lotería Nacional o lotería de otro país por Internet.

En términos de edad, los jóvenes de 18 a 29 años estuvieron más agrupados en los siguientes juegos: la ruleta, el blackjack y el póquer por Internet. 
Este libro forma parte del acervo de la Biblioteca Jurídica Virtual del Instituto de Investigaciones Jurídicas de la UNAM

Los de 30 a 34 años destacaron en el craps o pase inglés y la brisca por Internet. Los de 35 a 39 años, así como los de 40 a 49 años, no se concentraron en ninguno de los juegos por Internet. Finalmente, los de 50 años y más se concentraron en la Lotería Nacional o lotería de otro país, en la lotería instantánea de pronósticos y en el bingo por Internet. Los de niveles de escolaridad más altos tuvieron una concentración muy por encima del promedio en la ruleta, el craps o pase inglés y la brisca por Internet.

A partir de este análisis puede indicarse que el perfil del jugador de juegos de azar por Internet arrojado por la presente encuesta está conformado también por más hombres que mujeres, y que los más jóvenes tienden a jugar más juegos de casino que los juegos tradicionales. Asimismo, puede verse la tendencia de que a mayor nivel educativo los juegos que se practican son menos conocidos y más sofisticados (véase cuadro 6.4).

\section{LA FRECUENCIA DEL JUEGO POR INTERNET}

\section{¿CUÁNDO FUE LA ÚLTIMA VEZ QUE COMPRÓ O APOSTÓ TAL JUEGO?}

Cuatro juegos de azar por Internet destacaron por tener a un tercio o un poco más de jugadores que los habían jugado hace menos de una semana. Éstos fueron la lotería instantánea de pronósticos por Internet, la Lotería Nacional o lotería de otro país, las máquinas tragamonedas y el bingo por Internet. De entre aquellos que se habían jugado hace más de una semana, pero menos de un mes, destacaron la Lotería Nacional o lotería de otro país, el craps o pase inglés, y la brisca por Internet. Por su parte, un poco más de dos de cada diez de los jugadores de blackjack indicaron haberlo jugado hacía menos de una semana de la fecha de la entrevista, así como los de póquer y los de ruleta por Internet (véase cuadro 6.5). 
Este libro forma parte del acervo de la Biblioteca Jurídica Virtual del Instituto de Investigaciones Jurídicas de la UNAM

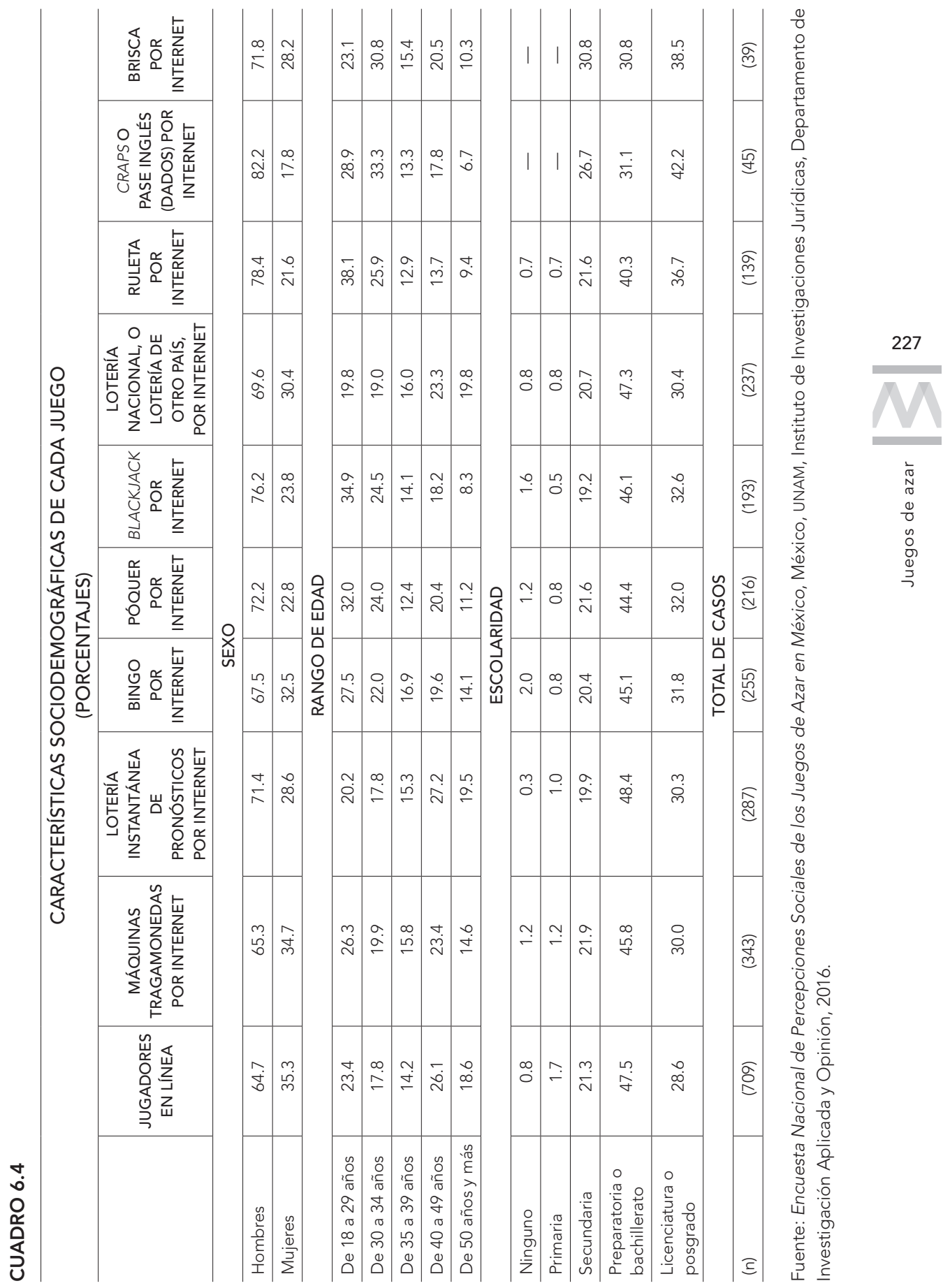


Este libro forma parte del acervo de la Biblioteca Jurídica Virtual del Instituto de Investigaciones Jurídicas de la UNAM

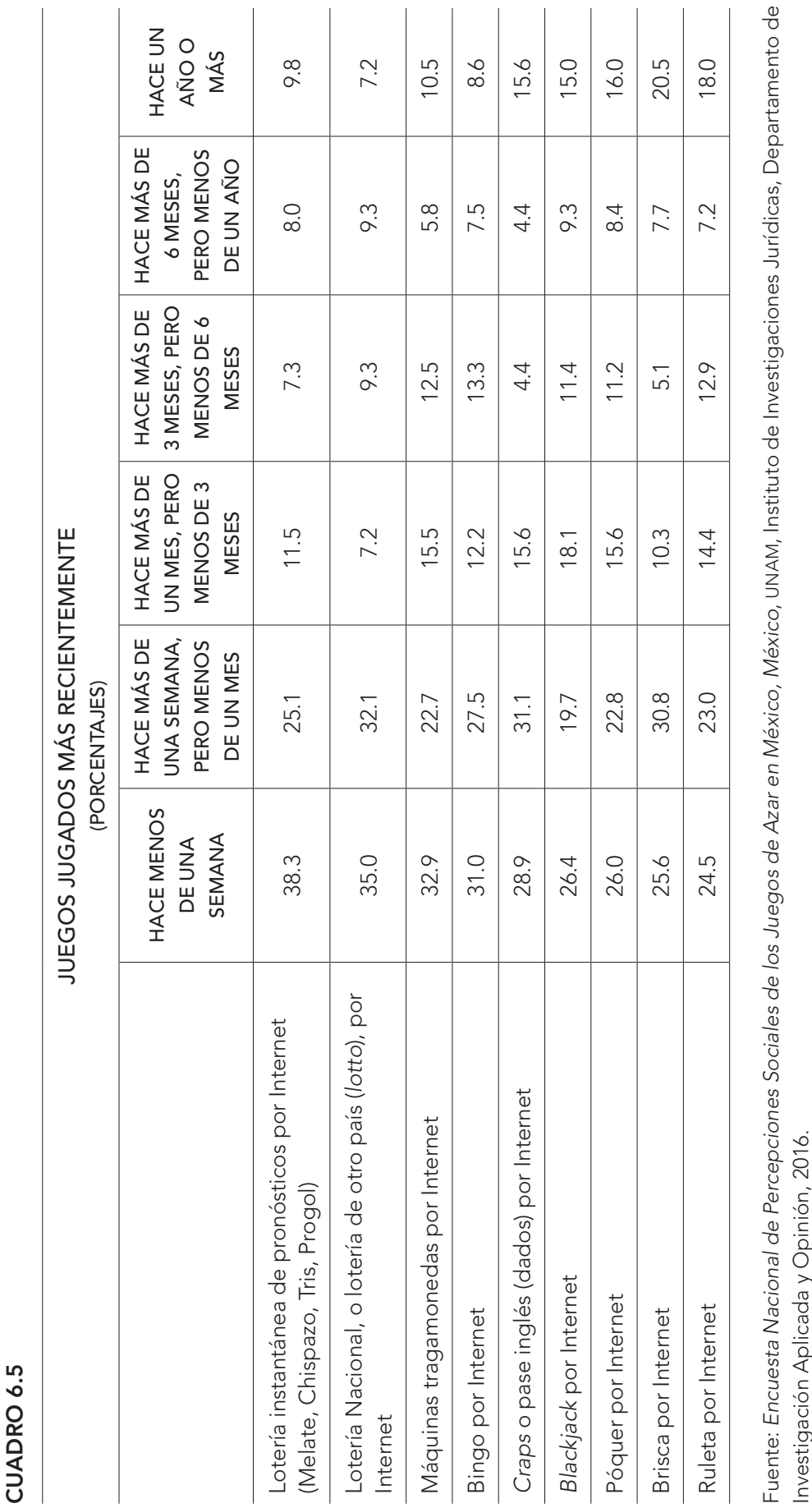


Este libro forma parte del acervo de la Biblioteca Jurídica Virtual del Instituto de Investigaciones Jurídicas de la UNAM

\section{¿CON QUÉ FRECUENCIA SE COMPRA Y JUEGA?}

En términos de frecuencia, las máquinas tragamonedas se juegan principalmente una vez a la semana. Cabe destacar que fueron éstas las que tuvieron el mayor porcentaje de jugadores que indicó jugarlas diariamente. El bingo por Internet también destacó por jugarse una vez a la semana y fue el que tuvo el segundo mayor porcentaje de jugadores que lo hace diariamente. La lotería instantánea de pronósticos y la Lotería Nacional o lotería de otro país destacaron por jugarse en mayor proporción una vez a la semana. La mayor parte de los jugadores del craps o pase inglés dijo jugarlo una vez al mes, así como el blackjack, el póquer, la ruleta y la brisca (véase cuadro 6.6).

\section{CUADRO 6.6}

JUEGOS JUGADOS MÁS FRECUENTEMENTE

(PORCENTAJES)

\begin{tabular}{|c|c|c|c|c|c|c|}
\hline & DIARIO & $\begin{array}{l}\text { UNA VEZ } \\
\text { A LA } \\
\text { SEMANA }\end{array}$ & $\begin{array}{l}\text { UNA } \\
\text { VEZ AL } \\
\text { MES }\end{array}$ & $\begin{array}{l}\text { UNA VEZ } \\
\text { CADA } 6 \\
\text { MESES }\end{array}$ & $\begin{array}{l}\text { UNA } \\
\text { VEZ AL } \\
\text { AÑO }\end{array}$ & OCASIONALMENTE \\
\hline $\begin{array}{l}\text { Máquinas } \\
\text { tragamonedas por } \\
\text { Internet }\end{array}$ & 14.3 & 28.0 & 19.2 & 15.5 & 4.7 & 18.4 \\
\hline Bingo por Internet & 12.9 & 29.0 & 23.5 & 16.9 & 3.1 & 14.5 \\
\hline $\begin{array}{l}\text { Craps o pase inglés } \\
\text { por Internet }\end{array}$ & 8.9 & 22.2 & 28.9 & 11.1 & 6.7 & 22.2 \\
\hline Blackjack por Internet & 8.8 & 24.4 & 26.4 & 15.5 & 3.1 & 21.8 \\
\hline Ruleta por Internet & 8.6 & 20.9 & 21.6 & 12.2 & 5.0 & 31.7 \\
\hline $\begin{array}{l}\text { Lotería instantánea } \\
\text { de pronósticos por } \\
\text { Internet }\end{array}$ & 8.4 & 39.0 & 24.0 & 9.8 & 3.5 & 15.3 \\
\hline Póquer por Internet & 8.4 & 21.2 & 26.4 & 15.2 & 6 & 22.8 \\
\hline $\begin{array}{l}\text { Lotería Nacional, o } \\
\text { lotería de otro país, } \\
\text { por Internet }\end{array}$ & 6.8 & 33.3 & 26.6 & 13.1 & 3.4 & 16.9 \\
\hline Brisca por Internet & 5.1 & 25.6 & 28.2 & 12.8 & 7.7 & 20.5 \\
\hline
\end{tabular}

Fuente: Encuesta Nacional de Percepciones Sociales de los Juegos de Azar en México, México, UNAM, Instituto de Investigaciones Jurídicas, Departamento de Investigación Aplicada y Opinión, 2016. 
Este libro forma parte del acervo de la Biblioteca Jurídica Virtual del Instituto de Investigaciones Jurídicas de la UNAM

\section{CARACTERÍSTICAS DE LOS JUEGOS EN LÍNEA}

\section{¿CON CUÁL JUEGO CONSIDERA QUE SE PUEDE GANAR MÁS DINERO?}

Los jugadores en línea que contestaron la encuesta y que dijeron apostar en los últimos seis meses, consideraron que la lotería instantánea de pronósticos por Internet era el juego con el que podían ganar más dinero. Este juego es también de los más populares entre los juegos presenciales. Para los jugadores por Internet se encontró que en promedio lo juegan más los hombres y que es un juego que se realiza muy frecuentemente. El mayor porcentaje de sus jugadores dijo jugarlo una vez a la semana (véase gráfica 6.6).

\section{GRÁFICA 6.6}

DE ESTOS JUEGOS, ¿CON CUÁL CONSIDERA QUE SE PUEDE GANAR MÁS DINERO? (PORCENTAJES)

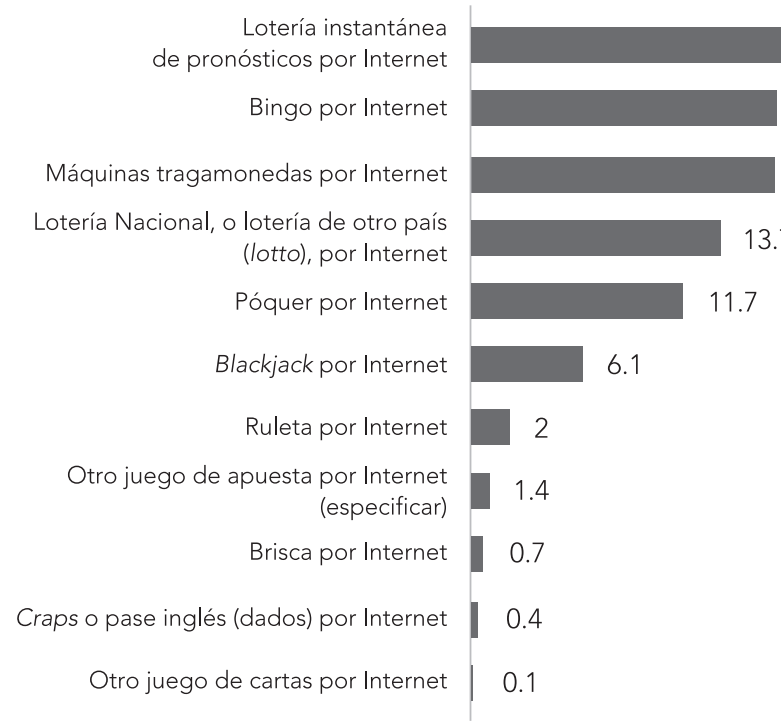

Fuente: Encuesta Nacional de Percepciones Sociales de los Juegos de Azar en México, México, UnAm, Instituto de Investigaciones Jurídicas, Departamento de Investigación Aplicada y Opinión, 2016. 
Este libro forma parte del acervo de la Biblioteca Jurídica Virtual del Instituto de Investigaciones Jurídicas de la UNAM

En segundo lugar, los entrevistados consideraron que con el bingo y las máquinas tragamonedas por Internet se puede ganar más dinero. Aparecieron después la Lotería Nacional o lotería de otro país, y el póquer por Internet. Los demás juegos obtuvieron porcentajes por debajo de los 10 puntos porcentuales.

\section{¿CUÁL ES EL JUEGO QUE MÁS LE GUSTA?}

Coincidiendo con el orden del número de jugadores, de mayor a menor, los primeros tres juegos que los entrevistados indicaron que les gustaban más fueron las máquinas tragamonedas, el bingo y la lotería instantánea de pronósticos por Internet. Seguidos por el póquer por Internet, la Lotería Nacional o lotería de otro país y el blackjack por Internet. El resto de los juegos obtuvo menos de cinco puntos porcentuales de las preferencias (véase gráfica 6.7).

\section{GRÁFICA 6.7}

DE TODOS ESTOS JUEGOS POR INTERNET, ¿CUÁL ES EL QUE MÁS LE GUSTA?

(PORCENTAJES)

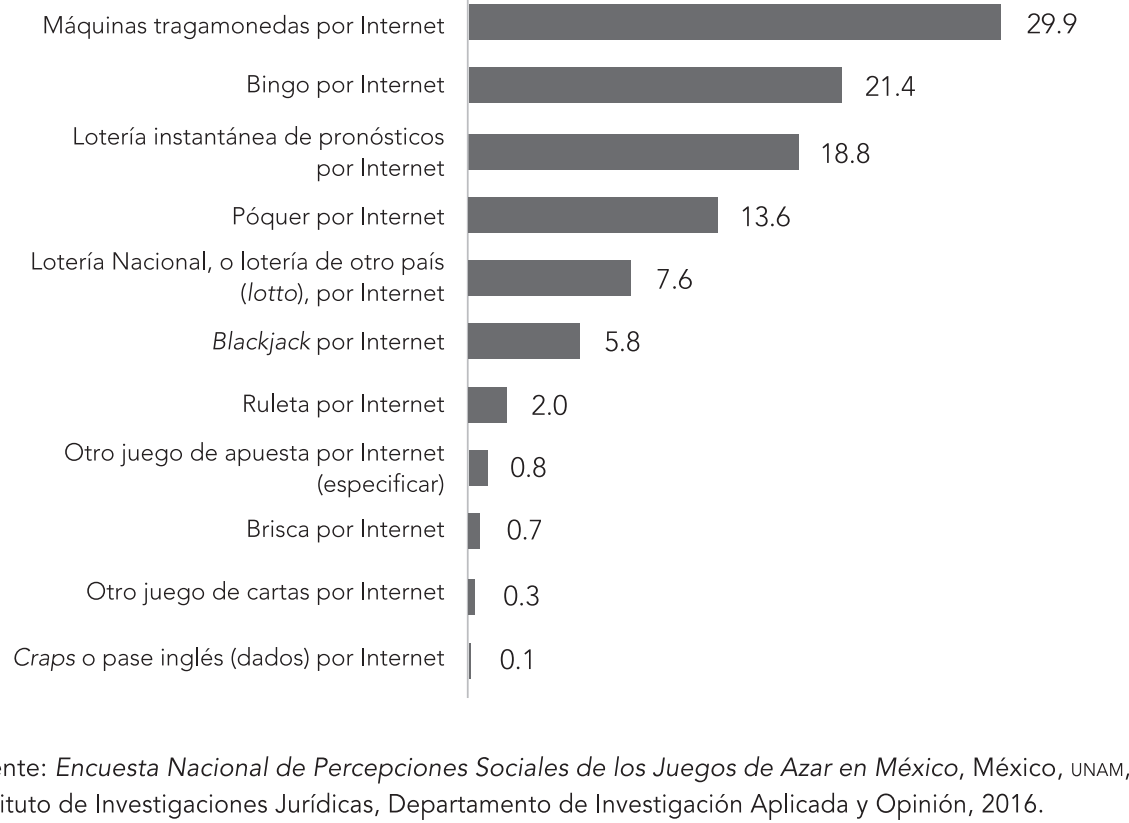

Fuente: Encuesta Nacional de Percepciones Sociales de los Juegos de Azar en México, México,
Instituto de Investigaciones Jurídicas, Departamento de Investigación Aplicada y Opinión, 2016. 
Este libro forma parte del acervo de la Biblioteca Jurídica Virtual del Instituto de Investigaciones Jurídicas de la UNAM

\title{
¿CUÁLES JUEGOS SE JUEGAN DE MANERA PRESENCIAL Y EN LÍNEA?
}

\begin{abstract}
A cada uno de los que dijeron jugar cada juego se les preguntó si lo habían jugado en persona, es decir, asistiendo a locales como casinos, comprando billetes o cupones, con amigos en casa, etcétera. Los juegos que los jugadores han jugado más, tanto de manera presencial como por Internet, son el bingo y las máquinas tragamonedas. Casi siete de cada diez de sus jugadores afirmaron hacerlo de las dos formas. Cuatro de cada diez jugadores de lotería instantánea de pronósticos por Internet dijeron también comprar billetes.

Se observa también que dos de cada diez jugadores de blackjack, póquer y ruleta apuntaron también hacerlo de manera presencial. Los demás juegos están por debajo de los 10 puntos porcentuales (véase gráfica 6.8).
\end{abstract}

\section{GRÁFICA 6.8}

Y DE ESOS JUEGOS, ¿CUÁLES HA JUGADO EN PERSONA, ES DECIR, ASISTIENDO A LOCALES COMO CASINOS, COMPRANDO BILLETES O CUPONES, CON AMIGOS EN CASA, ETCÉTERA?

\section{(PORCENTAJES)}

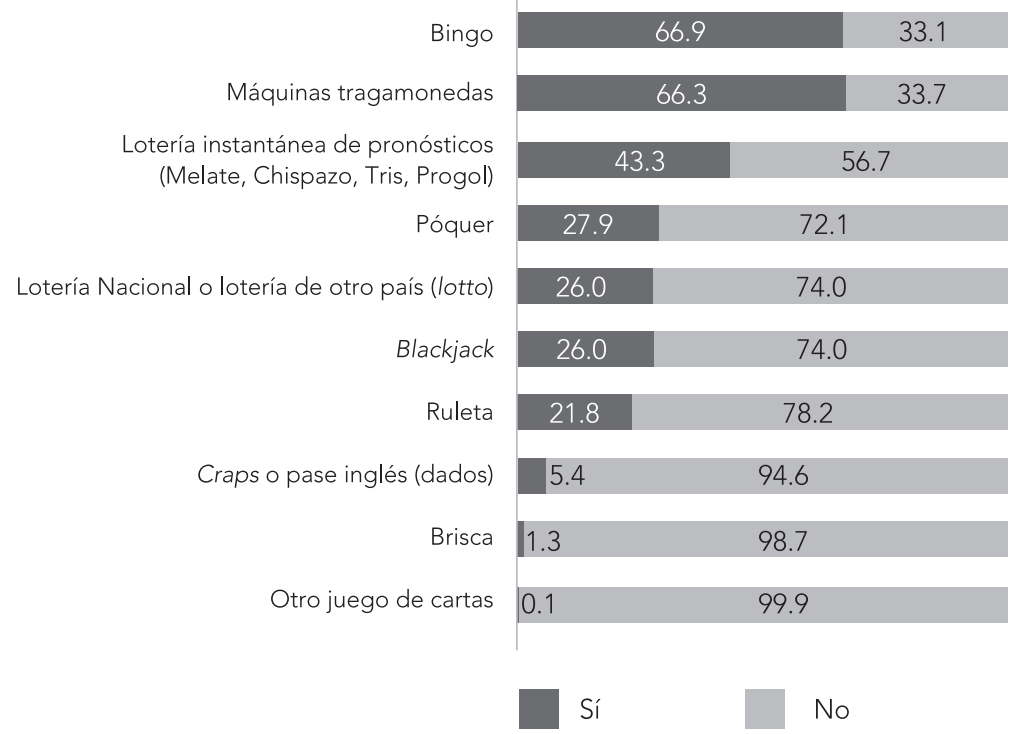

Fuente: Encuesta Nacional de Percepciones Sociales de los Juegos de Azar en México, México, unam, Instituto de Investigaciones Jurídicas, Departamento de Investigación Aplicada y Opinión, 2016. 
Este libro forma parte del acervo de la Biblioteca Jurídica Virtual del Instituto de Investigaciones Jurídicas de la UNAM

\section{MODALIDADES DEL JUEGO EN LÍNEA}

\section{TIEMPO DESTINADO A JUGAR POR INTERNET}

Con respecto al tiempo que dedican a jugar por Internet en los días que lo hacen, tres de cada diez jugadores que contestaron la encuesta en línea y que dijeron ser jugadores de apuesta por Internet indicaron que dedican de una a dos horas a jugar por Internet. En segundo lugar, un poco más de dos de cada diez jugadores indicaron jugar de 30 minutos a una hora. Después siguieron aquellos que indicaron jugar de 15 a 30 minutos, o de dos a tres horas. Muy pocos indicaron jugar de cero a 15 minutos o más de tres horas.

GRÁFICA 6.9

\section{EN UN DÍA EN EL QUE APUESTA, EN PROMEDIO ¿CUÁNTO TIEMPO DEDICA PARA JUGAR EN INTERNET?}

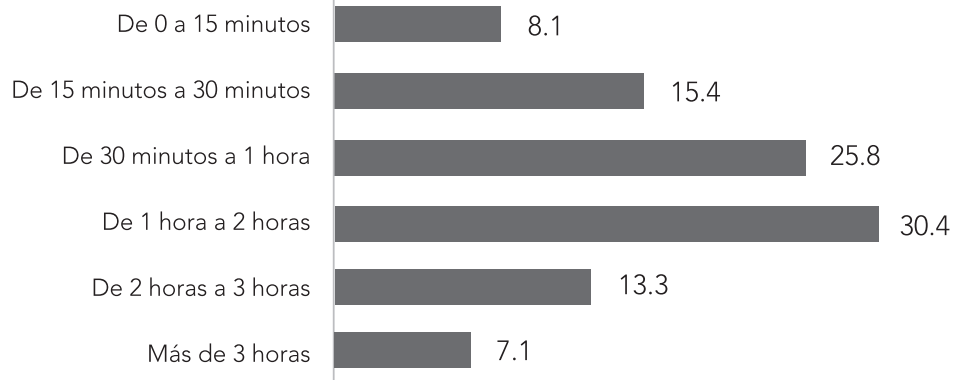

Fuente: Encuesta Nacional de Percepciones Sociales de los Juegos de Azar en México, México, unam, Instituto de Investigaciones Jurídicas, Departamento de Investigación Aplicada y Opinión, 2016.

\section{¿SE JUEGA DURANTE MÁS O MENOS TIEMPO?}

Una de las preguntas más relevantes, ya que refuerza la tendencia comentada de que este tipo de juegos va en aumento, es la estimación que hicieron los encuestados sobre el tiempo que dedican a jugar con respecto al año anterior. La opinión se dividió entre las tres opciones de respuesta. 
Este libro forma parte del acervo de la Biblioteca Jurídica Virtual del Instituto de Investigaciones Jurídicas de la UNAM

Destacó, sin embargo, que cuatro de cada diez jugadores dijeron jugar más que hace un año a la fecha de la entrevista. Por su parte, un poco más de tres de cada diez jugadores dijeron jugar menos tiempo que hace un año, y poco menos de tres de cada diez de ellos indicaron jugar igual que en el año anterior a la entrevista (véase gráfica 6.10).

\section{GRÁFICA 6.10}

RESPECTO AL TIEMPO QUE APUESTA EN INTERNET, ¿DIRÍA QUE...?

(PORCENTAJES)

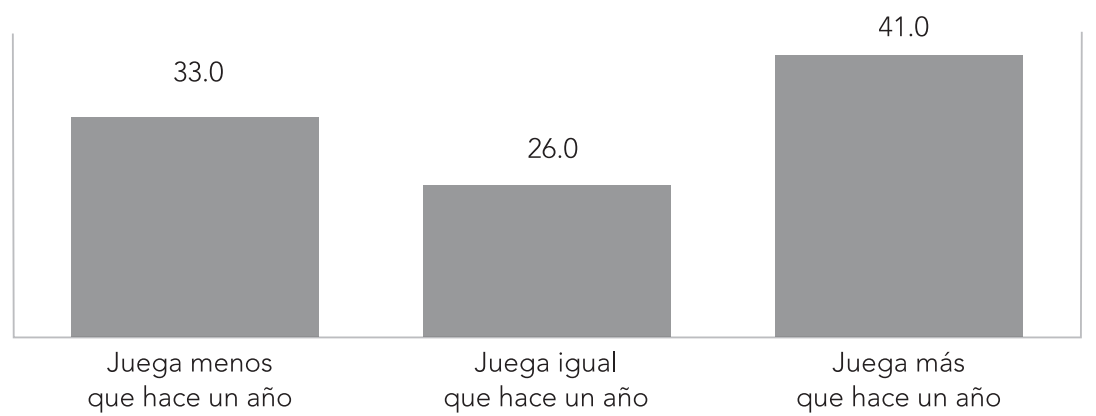

Fuente: Encuesta Nacional de Percepciones Sociales de los Juegos de Azar en México, México, unam, Instituto de Investigaciones Jurídicas, Departamento de Investigación Aplicada y Opinión, 2016.

\section{EN QUÉ LUGAR SE REALIZA EL JUEGO}

Como se mencionó al inicio de este capítulo, se ha dicho que una de las características del juego en línea que lo ha llevado a tener más jugadores es la accesibilidad. Con la siguiente pregunta se pudo constatar que efectivamente los jugadores de apuestas por Internet que contestaron la presente encuesta tienen la facilidad de hacerlo desde sus casas; más de ocho de cada diez de los encuestados que han jugado apostando dinero por Internet en los últimos seis meses así lo indicaron. Muy por debajo, algunos contestaron que lo hacen desde su trabajo o en lugares públicos, como en cibercafés (véase gráfica 6.11). 
Este libro forma parte del acervo de la Biblioteca Jurídica Virtual del Instituto de Investigaciones Jurídicas de la UNAM

\section{GRÁFICA 6.11}

GENERALMENTE, ¿EN QUÉ LUGAR ESTÁ CUANDO APUESTA POR INTERNET?

(PORCENTAJES)

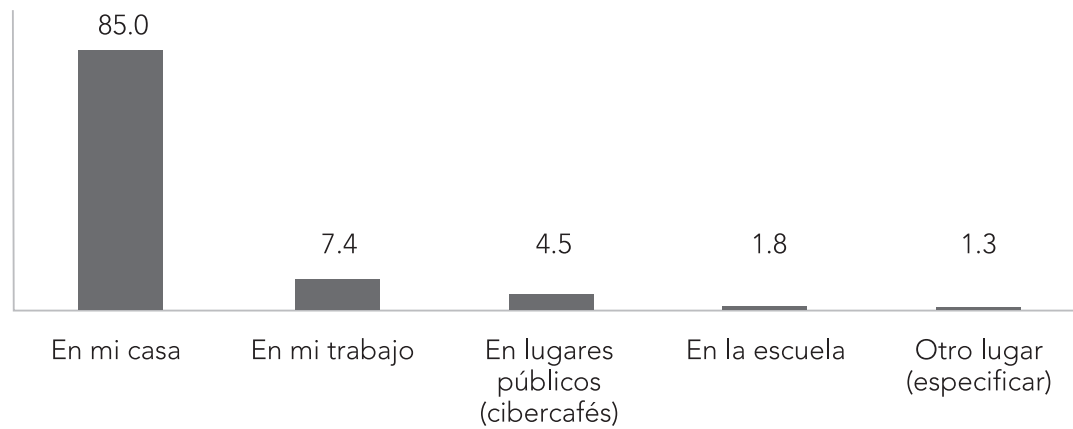

Fuente: Encuesta Nacional de Percepciones Sociales de los Juegos de Azar en México, México, UnAM, Instituto de Investigaciones Jurídicas, Departamento de Investigación Aplicada y Opinión, 2016.

\section{MOMENTOS PREDILECTOS PARA JUGAR}

Otro factor que se suma a la conveniencia y accesibilidad de este tipo de juegos es que se pueden realizar por la noche. Casi siete de cada diez de los jugadores en línea dijeron hacerlo en ese momento del día. Esto contrasta con el juego presencial, en donde más de la mitad de los encuestados en vivienda respondieron que normalmente juegan por la tarde. Por otro lado, los jugadores en línea mencionaron en mayor medida que normalmente juegan tanto entre semana como en fin de semana, mientras que en el caso de las personas entrevistadas en vivienda que acostumbran jugar de manera presencial afirmaron hacerlo mayormente en fines de semana. Esto indica que efectivamente el jugador de juegos de azar por Internet tiene un conjunto mayor de momentos del día y espacios en la semana en los que puede jugar (véanse gráficas 6.12 y 6.13). 
Este libro forma parte del acervo de la Biblioteca Jurídica Virtual del Instituto de Investigaciones Jurídicas de la UNAM www.juridicas.unam.mx

Fuente: Encuesta Nacional de Percepciones Sociales de los Juegos de Azar en México, México, UNAM, Instituto de Investigaciones Jurídicas, Departamento de Investigación Aplicada y Opinión, 2016.

GRÁFICA 6.13

¿NORMALMENTE JUEGA ENTRE SEMANA O EL FIN DE SEMANA? (PORCENTAJES)

Ambos, 44.9

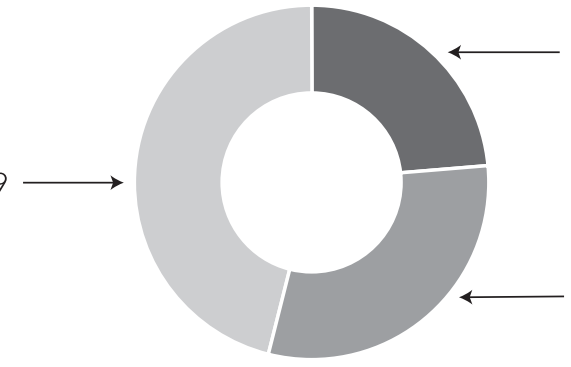

Fin de semana, 30.5

Fuente: Encuesta Nacional de Percepciones Sociales de los Juegos de Azar en México, México, UNAM, Instituto de Investigaciones Jurídicas, Departamento de Investigación Aplicada y Opinión, 2016.

\section{DISPOSITIVO PREFERIDO PARA JUGAR}

El dispositivo electrónico favorito para jugar los juegos de azar en línea resultó ser la computadora o la laptop, seguido muy de cerca por el celular. Esto va también de la mano con la tendencia a hacer del celular el centro de mando de la vida cotidiana (Poushter, 2016). Cabe señalar que según datos 
Este libro forma parte del acervo de la Biblioteca Jurídica Virtual del Instituto de Investigaciones Jurídicas de la UNAM

de la Encuesta Nacional sobre Disponibilidad y Uso de Tecnología de la Información en los Hogares del INEGI (ENDITH, 2016), los usuarios de teléfono celular alcanzan el 73.6 por ciento de la población de seis años o más, además de que tres de cada cuatro usuarios ya cuentan con un teléfono inteligente (INEGI, 2017a). Aproximadamente sólo uno de cada diez entrevistados que apuestan por Internet utiliza una tableta, aunque pudiera deberse a la falta de posesión de la misma (véase gráfica 6.14).

GRÁFICA 6.14

¿EN QUÉ TIPO DE DISPOSITIVO APUESTAS MÁS POR INTERNET?

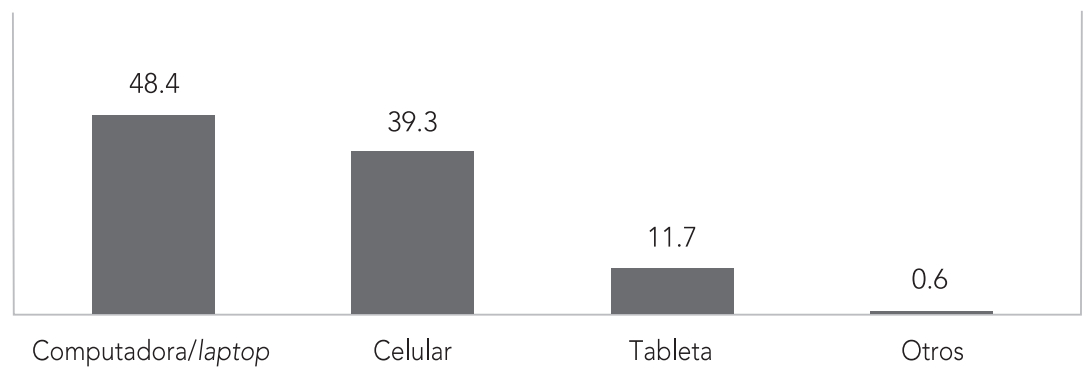

Fuente: Encuesta Nacional de Percepciones Sociales de los Juegos de Azar en México, México, UnAm, Instituto de Investigaciones Jurídicas, Departamento de Investigación Aplicada y Opinión, 2016.

\section{CANTIDADES JUGADAS}

\section{ESTIMACIÓN DEL DINERO GASTADO Y GANADO APOSTANDO POR INTERNET}

Según lo observado en la encuesta en línea, la mayor parte de los jugadores por Internet que fueron entrevistados (46.9 por ciento) gastan más de 500 pesos al mes apostando por Internet. Cabe señalar que un porcentaje parecido de jugadores encuestados (45.1 por ciento) indicó ganar más de 501 pesos por mes apostando por Internet. Por su parte, mientras que un poco más de dos de cada diez de los jugadores entrevistados apuestan entre 251 y 500 pesos, sólo uno de cada diez ha ganado alrededor de esas cantidades. También coincidió que dos de cada deiz jugadores encuestados indicaron 
Este libro forma parte del acervo de la Biblioteca Jurídica Virtual del Instituto de Investigaciones Jurídicas de la UNAM www.juridicas.unam.mx

tanto gastar como ganar entre uno y 250 pesos. Finalmente, mientras que sólo un poco más de uno de cada diez de éstos indicó no apostar nada, dos de cada diez indicaron no ganar nada. Entre aquellos que dijeron no gastar nada, sobresalen las mujeres y las personas de mayor edad (de 50 años en adelante). Destacan los mismos grupos sociodemográficos en aquellos que dijeron no ganar nada (véase gráfica 6.15).

\section{GRÁFICA 6.15}

A. Y EN PROMEDIO EN UN MES, ¿CUÁNTO DINERO GASTA APOSTANDO POR INTERNET? B. Y AL MES, APROXIMADAMENTE, ¿CUÁNTO GANA CON ESTOS JUEGOS

DE APUESTA POR INTERNET? (PORCENTAJES)

De 10,001 a más pesos
De 7501 a 10,000 pesos
De 5001 a 7500 pesos
De 3001 a 5000 pesos
De 2001 a 3000 pesos
De 1501 a 2000 pesos
De 1001 a 1500 pesos
De 501 a 1000 pesos
De 251 a 500 pesos
De 101 a 250 pesos
De 1 a 100 pesos
Nada

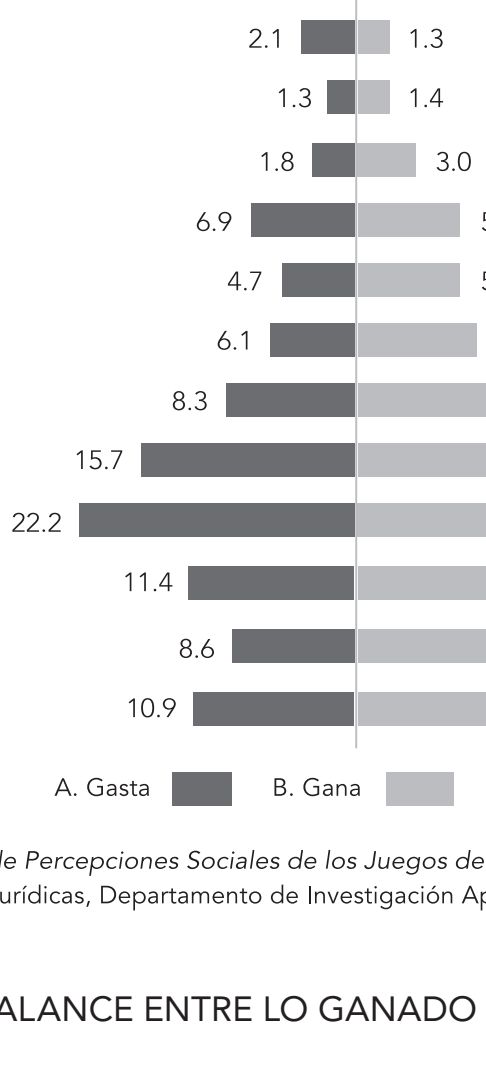

Fuente: Encuesta Nacional de Percepciones Sociales de los Juegos de Azar en México, México, UNAM, Instituto de Investigaciones Jurídicas, Departamento de Investigación Aplicada y Opinión, 2016.

\section{ESTIMACIÓN DEL BALANCE ENTRE LO GANADO Y LO PERDIDO}

Aunque las cantidades señaladas anteriormente dejen ver que aproximadamente existe un balance entre lo ganado y lo perdido, ante la pregunta re- 
Este libro forma parte del acervo de la Biblioteca Jurídica Virtual del Instituto de Investigaciones Jurídicas de la UNAM

lativa a los jugadores sobre si consideran que han perdido más de lo que pensaban gastar jugando/apostando en juegos por Internet, cerca de siete de cada diez entrevistados respondieron afirmativamente, mientras que sólo una tercera parte lo hizo de manera negativa. De los encuestados que respondieron que sí han perdido más de lo que pensaban gastar jugando, destacan las personas de 35 a 39 años y las personas con un nivel de escolaridad de secundaria. En cuanto a los que dijeron que no, sólo resaltan los encuestados de 40 a 49 años, pues en el resto de las variables sociodemográficas no se observaron más particularidades (véase gráfica 6.16).

GRÁFICA 6.16

Y EN SU EXPERIENCIA, ¿HA PERDIDO MÁS DE LO QUE PENSABA GASTAR JUGANDO/APOSTANDO EN JUEGOS POR INTERNET?

(PORCENTAJES)

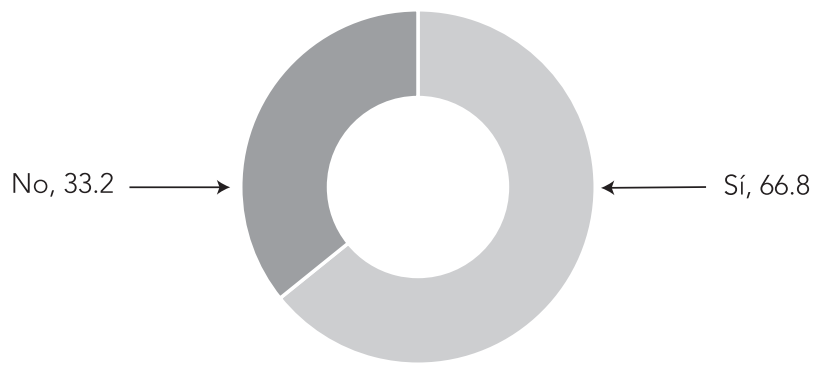

Fuente: Encuesta Nacional de Percepciones Sociales de los Juegos de Azar en México, México, UnAM, Instituto de Investigaciones Jurídicas, Departamento de Investigación Aplicada y Opinión, 2016.

\section{MEDIOS DE PAGO}

Se ha mencionado que un obstáculo al correcto desarrollo de la industria de los juegos de azar por Internet en México es el escaso uso de tarjetas de crédito entre los mexicanos (Castañares, 2017). Las dos encuestas que se realizaron para este estudio dejan ver que efectivamente el uso de tarjetas bancarias no es predominante entre los jugadores mexicanos en general, pero sí entre los jugadores en línea. En primer lugar, la encuesta en vivienda dejó ver que para tres cuartas partes de los asistentes a casinos su forma predilecta de pago es el efectivo, mientras que sólo uno de cada diez en- 
Este libro forma parte del acervo de la Biblioteca Jurídica Virtual del Instituto de Investigaciones Jurídicas de la UNAM

cuestados dijo usar tarjeta de crédito, e incluso menos del diez por ciento dijo utilizar tarjeta de débito. La encuesta en vivienda también mostró que las mujeres pagan en efectivo en una mayor proporción que los hombres, teniendo éstos un relativo uso mayor de las tarjetas de crédito.

Por su parte, en la encuesta en línea a jugadores de apuestas por Internet se observó que poco más de la mitad utiliza una tarjeta de crédito para pagar. Con lo que se puede distinguir que la forma de pago dominante para este tipo de juegos es la tarjeta de crédito. Sin embargo, también señalaron la existencia de otras opciones de pago para jugar, tales como tarjetas de prepago, pago en tiendas de conveniencia, sistemas especiales de pago en línea como Paypal, así como depósitos o transferencias bancarias (véanse gráficas 6.17 y 6.18).

\section{GRÁFICA 6.17}

GENERALMENTE, ¿CUÁL ES SU FORMA DE PAGO EN EL CASINO? (ENCUESTA EN VIVIENDA, PORCENTAJES)

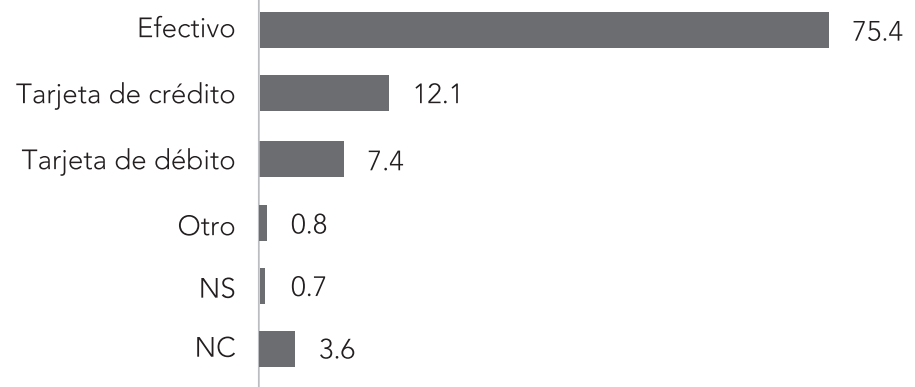

Fuente: Encuesta Nacional de Percepciones Sociales de los Juegos de Azar en México, México, unam, Instituto de Investigaciones Jurídicas, Departamento de Investigación Aplicada y Opinión, 2016. 
Este libro forma parte del acervo de la Biblioteca Jurídica Virtual del Instituto de Investigaciones Jurídicas de la UNAM

GRÁFICA 6.18

GENERALMENTE, ¿CUÁL ES SU FORMA DE PAGO CUANDO COMPRA/APUESTA POR INTERNET? (ENCUESTA EN LÍNEA, PORCENTAJES)

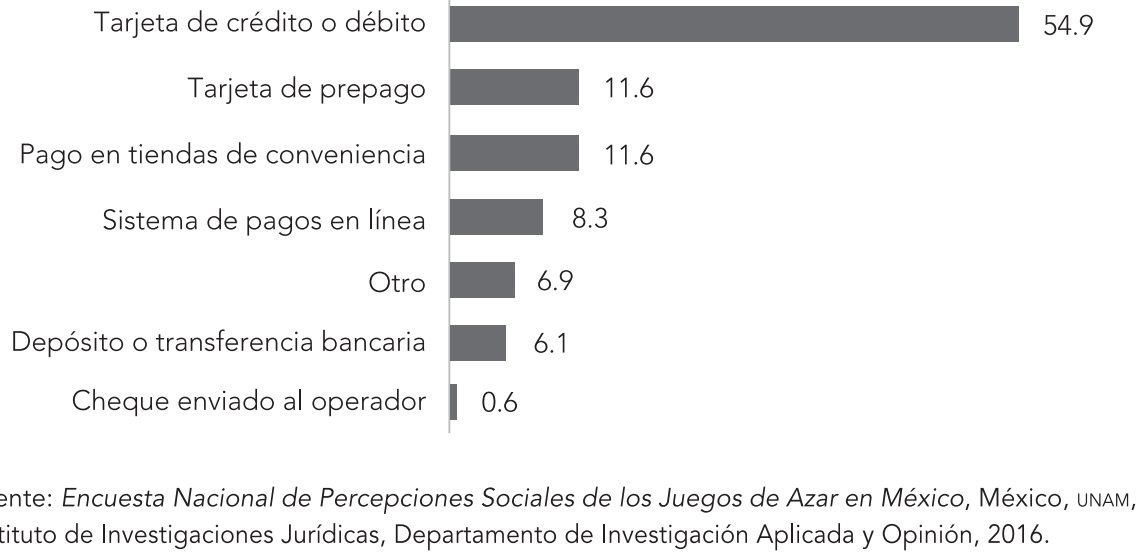

\section{PROBLEMAS TÉCNICOS AL JUGAR POR INTERNET}

Fueron mínimas las observaciones con respecto a problemas técnicos tanto de manera presencial en los casinos como en los juegos de apuesta por Internet. Aun así se reportaron más problemas técnicos al jugar por Internet que de manera presencial. Mientras que los resultados de la encuesta en vivienda nos indican que únicamente tres personas de cien que han asistido a casinos han tenido problemas al jugar dentro de un casino, en la encuesta en línea llegan a ser casi nueve de cada cien jugadores los que los han experimentado. Los problemas que los usuarios indicaron con mayor frecuencia fueron dificultades con el pago de las apuestas o fallas de los sitios web (véanse gráficas 6.19 a 6.21). 
Este libro forma parte del acervo de la Biblioteca Jurídica Virtual del Instituto de Investigaciones Jurídicas de la UNAM www.juridicas.unam.mx

\section{GRÁFICA 6.19}

¿HA TENIDO ALGÚN PROBLEMA O INCONVENIENTE DENTRO DEL CASINO? (ENCUESTA EN VIVIENDA, PORCENTAJES)

NC, 3.4

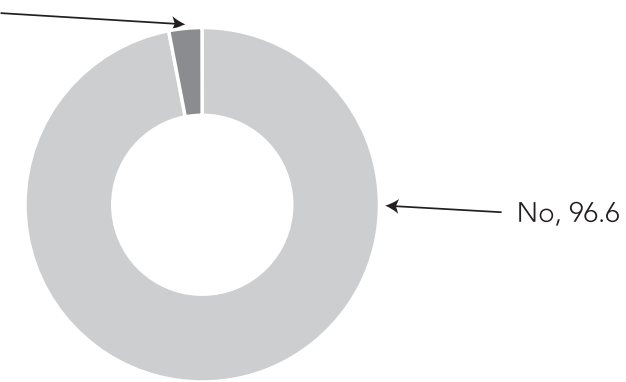

Fuente: Encuesta Nacional de Percepciones Sociales de los Juegos de Azar en México, México, UNAM, Instituto de Investigaciones Jurídicas, Departamento de Investigación Aplicada y Opinión, 2016.

\section{GRÁFICA 6.20}

¿ALGUNA VEZ HA TENIDO ALGÚN PROBLEMA

AL JUGAR SORTEOS O APOSTAR POR INTERNET?

(ENCUESTA EN LÍNEA, PORCENTAJES)

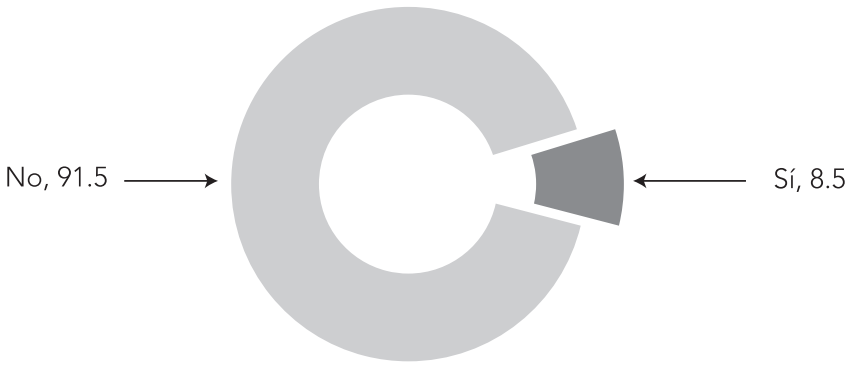

Fuente: Encuesta Nacional de Percepciones Sociales de los Juegos de Azar en México, México, UNAM, Instituto de Investigaciones Jurídicas, Departamento de Investigación Aplicada y Opinión, 2016. 
Este libro forma parte del acervo de la Biblioteca Jurídica Virtual del Instituto de Investigaciones Jurídicas de la UNAM

GRÁFICA 6.21

DEL 8.5 POR CIENTO QUE CONTESTÓ QUE SÍ, ¿CUÁLES PROBLEMAS?

(ENCUESTA EN LÍNEA, PORCENTAJES)

Problemas/dificultades al cobrar la apuesta

Fallas en sitios web de apuestas

Conexión a Internet deficiente

\section{(1)}

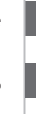

Afición personal al juego

Contraer deudas por el juego

Mención dispersa

Ninguno

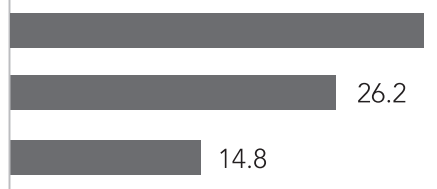

26.2

\section{8}

8.2

Fuente: Encuesta Nacional de Percepciones Sociales de los Juegos de Azar en México, México, UNAM, Instituto de Investigaciones Jurídicas, Departamento de Investigación Aplicada y Opinión, 2016.

\section{CONFIANZA EN LAS CASAS DE APUESTA O CASINOS POR INTERNET}

\section{REGISTRO EN LAS CASAS DE APUESTAS POR INTERNET}

En la encuesta en vivienda sobre los juegos de azar en México, el 0.8 por ciento de los encuestados dijo estar registrado en alguna página de apuestas por Internet, lo que también corresponde a aproximadamente 600 mil usuarios. Nuevamente, este número se deriva de un porcentaje con un margen de error de \pm 4.2 puntos porcentuales, lo que lo hace variable; sin embargo, puede servir de referencia para estudios posteriores. Cuando en la encuesta en vivienda se le preguntó a ese pequeño grupo de encuestados en qué página estaban registrados, un poco más de la mitad señaló estarlo en una página oficial de casinos en México; un poco menos de dos de cada diez dijeron estar registrados en alguna página de apuestas internacional, y el resto no supo o no contestó la pregunta. Por su parte, en la encuesta en línea casi cuatro de cada diez de los encuestados que dijeron apostar por Internet indicaron estar registrados en alguna página de apuestas por Inter- 
Este libro forma parte del acervo de la Biblioteca Jurídica Virtual del Instituto de Investigaciones Jurídicas de la UNAM www.juridicas.unam.mx

net. De éstos, prácticamente seis de cada diez indicaron estar registrados en una página oficial de casinos en México; dos de cada diez seleccionaron alguna página de apuestas internacionales; un poco más de uno de cada diez mencionó algún lugar difícil de identificar, y un porcentaje menor señaló alguna página de lotería instantánea (véanse gráficas 6.22 y 6.23).

\section{GRÁFICA 6.22}

¿USTED ESTÁ REGISTRADO EN ALGUNA PÁGINA DE APUESTAS POR INTERNET?

(ENCUESTA EN VIVIENDA, PORCENTAJES)

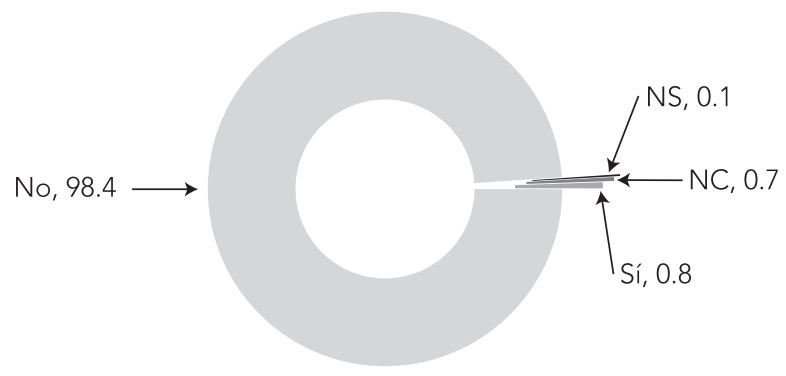

Fuente: Encuesta Nacional de Percepciones Sociales de los Juegos de Azar en México, México, unam, Instituto de Investigaciones Jurídicas, Departamento de Investigación Aplicada y Opinión, 2016.

\section{GRÁFICA 6.23}

\section{¿ESTÁ REGISTRADO EN ALGUNA PÁGINA DE APUESTAS POR INTERNET?}

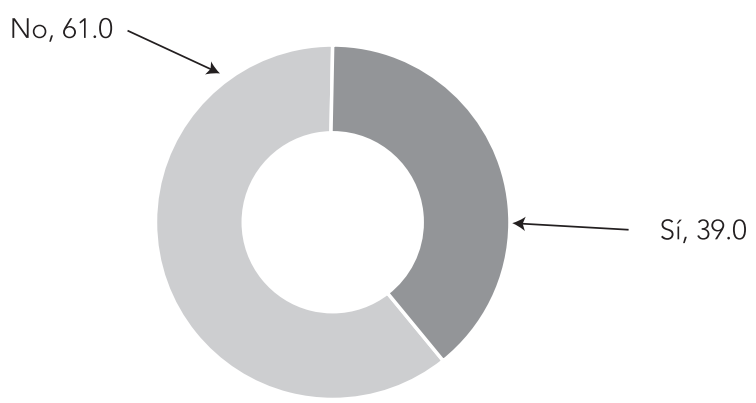

Fuente: Encuesta Nacional de Percepciones Sociales de los Juegos de Azar en México, México, UnAm, Instituto de Investigaciones Jurídicas, Departamento de Investigación Aplicada y Opinión, 2016. 
Este libro forma parte del acervo de la Biblioteca Jurídica Virtual del Instituto de Investigaciones Jurídicas de la UNAM

\section{CONOCIMIENTO DE LA LEGALIDAD DE LAS CASAS DE APUESTA POR INTERNET}

De manera similar a la encuesta en vivienda, la mayor parte de los encuestados en línea y que dijeron haber apostado por Internet en los últimos seis meses consideraron que los juegos de apuesta y sorteo por Internet son legales en México. Cerca de seis de cada diez de los encuestados así lo indicaron. Por otra parte, cerca de cuatro de cada diez señalaron que no lo saben, y muy pocos manifestaron que no lo son. Entre los encuestados que expresaron que sí son legales, destacan los hombres y los que cuentan con licenciatura o posgrado. En contraste, los que dijeron que no son legales fueron, en mayor medida, las personas de 40 a 49 años. En cuanto a los que dijeron que no saben si son legales o no, destacan las mujeres y las personas con nivel de escolaridad de secundaria. El alto porcentaje de personas que indicó no saber si los juegos de apuesta por Internet son legales o no en México deja ver la posible confusión que existe debido a la actual falta de regulación de esta industria (Villalobos, 2017) (véase gráfica 6.24).

\section{GRÁFICA 6.24}

POR LO QUE USTED SABE, ¿LOS JUEGOS DE APUESTA

Y SORTEO POR INTERNET SON LEGALES O NO EN MÉXICO?

(PORCENTAJES)

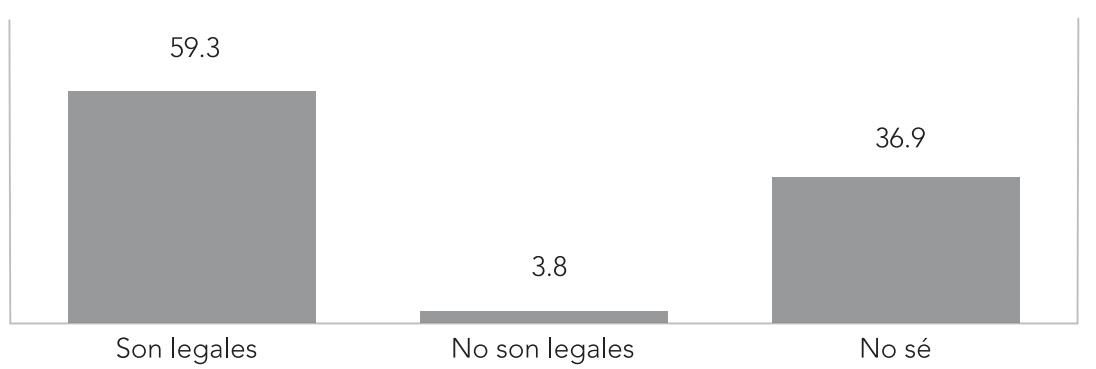

Fuente: Encuesta Nacional de Percepciones Sociales de los Juegos de Azar en México, México, UnAm, Instituto de Investigaciones Jurídicas, Departamento de Investigación Aplicada y Opinión, 2016. 
Este libro forma parte del acervo de la Biblioteca Jurídica Virtual del Instituto de Investigaciones Jurídicas de la UNAM

\section{CONFIANZA EN LAS CASAS DE APUESTA POR INTERNET}

La encuesta en línea mostró que existe más confianza que desconfianza en las casas de apuesta o casinos por Internet entre aquellos que apuestan por esta vía. Aun así la confianza no es total y pareciera que se refleja en la práctica del juego, ya que los perfiles que confían más en las casas de apuesta o casinos por Internet son los que más juegan y viceversa. Por ejemplo, se observó que de entre quienes dijeron que confían mucho, destacaron los hombres y las personas de 30 a 34 años, que corresponden al perfil que más juega por Internet. Por su parte, de los que señalaron que no confían nada, destacaron en mayor medida las mujeres, las personas de 40 a 49 años y las personas con un nivel de escolaridad de secundaria (véase gráfica 6.25).

\section{GRÁFICA 6.25}

EN GENERAL, ¿QUÉ TANTO CONFÍA EN LAS CASAS DE APUESTA O CASINOS POR INTERNET QUE CONOCE?

(PORCENTAJES)

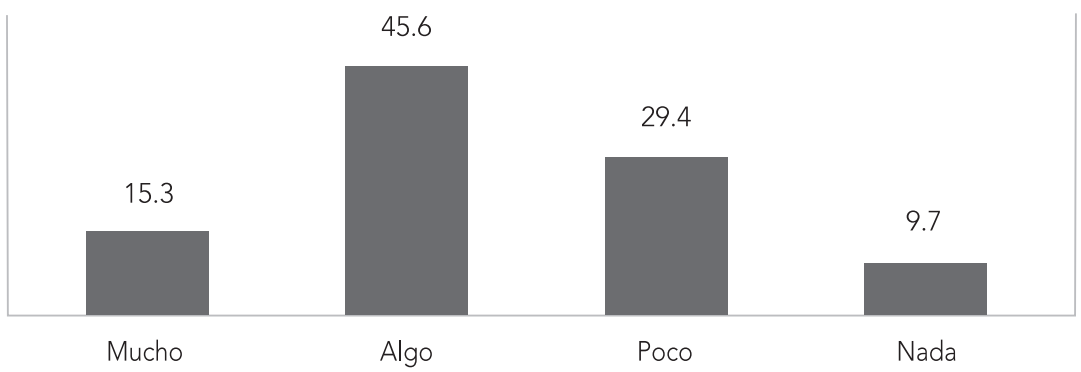

Fuente: Encuesta Nacional de Percepciones Sociales de los Juegos de Azar en México, México, unam, Instituto de Investigaciones Jurídicas, Departamento de Investigación Aplicada y Opinión, 2016.

\section{JUEGO PROBLEMÁTICO EN LÍNEA}

Para analizar el juego problemático en línea se elaboró un índice con base en la misma metodología que se utilizó para elaborar el índice de juego problemático en viviendas (véase Metodología en el capítulo 5). En este sentido, se utilizó la batería de preguntas 22 y 23 incluidas en el cuestionario 
Este libro forma parte del acervo de la Biblioteca Jurídica Virtual del Instituto de Investigaciones Jurídicas de la UNAM

en línea de la Primera Encuesta Nacional de Percepciones Sociales de los Juegos de Azar en México en Línea. Para la construcción del índice se definió como jugadores a aquellas personas que, en los seis meses anteriores al levantamiento de la encuesta, habían jugado al menos un juego de la batería de preguntas 2 del cuestionario en línea.

De acuerdo con los resultados, se observa que la mayoría de las personas entrevistadas son no jugadores; cerca de dos de cada diez son jugadores sin riesgo; 3.7 por ciento son jugadores con riesgo moderado, y solamente uno por ciento son jugadores problemáticos (véase gráfica 6.26).

\section{GRÁFICA 6.26}

ÍNDICE DE JUEGO PROBLEMÁTICO EN LÍNEA (PORCENTAJES)

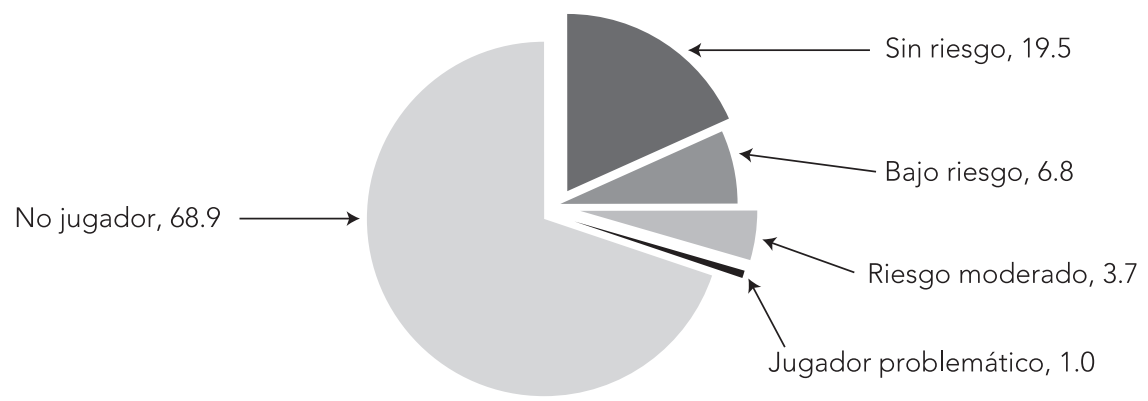

Fuente: Encuesta Nacional de Percepciones Sociales de los Juegos de Azar en México, México, unam, Instituto de Investigaciones Jurídicas, Departamento de Investigación Aplicada y Opinión, 2016.

El perfil de los jugadores muestra que los hombres son quienes con más frecuencia se encuentran en la categoría de juego problemático. La estructura por edad no tiene una tendencia definida del juego problemático, ya que las personas en los grupos de 30 a 34 años y de 40 a 49 años son quienes se identificaron con problemas con el juego. Por su parte, el indicador de escolaridad permite observar que las personas que tienen problemas con el juego son quienes no tienen escolaridad, aunque también resaltan las que tienen preparatoria o bachillerato y licenciatura o posgrado (véase cuadro 6.7). 
Este libro forma parte del acervo de la Biblioteca Jurídica Virtual del Instituto de Investigaciones Jurídicas de la UNAM

CUADRO 6.7

PERFIL DE LAS PERSONAS ENTREVISTADAS EN LÍNEA

(PORCENTAJES)

\begin{tabular}{l|l|c|c|c|c|c}
\hline \multicolumn{2}{c|}{} & $\begin{array}{c}\text { SIN } \\
\text { RIESGO }\end{array}$ & $\begin{array}{c}\text { BAJO } \\
\text { RIESGO }\end{array}$ & $\begin{array}{r}\text { RIESGO } \\
\text { MODERADO }\end{array}$ & $\begin{array}{c}\text { JUGADOR } \\
\text { PROBLEMÁTICO }\end{array}$ & $\begin{array}{c}\text { NO } \\
\text { JUGADOR }\end{array}$ \\
\hline \multirow{3}{*}{ Sexo } & Hombre & 22.2 & 8.2 & 5.0 & 1.2 & 63.4 \\
\cline { 2 - 7 } & Mujer & 15.9 & 5.0 & 2.0 & 0.8 & 76.1 \\
\hline \multirow{5}{*}{ Edad } & De 18 a 29 años & 22.5 & 8.6 & 5.1 & 0.5 & 63.3 \\
\cline { 2 - 7 } & De 30 a 34 años & 22.5 & 7.0 & 6.7 & 2.1 & 61.8 \\
\cline { 2 - 7 } & De 35 a 39 años & 21.5 & 9.1 & 4.1 & 0.8 & 64.5 \\
\cline { 2 - 7 } & De 40 a 49 años & 21.5 & 6.5 & 3.6 & 1.6 & 66.8 \\
\cline { 2 - 7 } & 50 años y más & 13.0 & 4.8 & 0.9 & 0.6 & 80.7 \\
\hline \multirow{5}{*}{ Escolaridad } & Ninguno & 22.2 & - & 5.6 & 5.6 & 66.7 \\
\cline { 2 - 7 } & Primaria & 18.6 & - & 7.0 & - & 74.4 \\
\cline { 2 - 7 } & Secundaria & 14.3 & 8.0 & 3.6 & 0.4 & 73.6 \\
\cline { 2 - 7 } & $\begin{array}{l}\text { Preparatoria o } \\
\text { bachillerato }\end{array}$ & 21.7 & 6.1 & 2.9 & 1.3 & 68.1 \\
\cline { 2 - 7 } & $\begin{array}{l}\text { Licenciatura o } \\
\text { posgrado }\end{array}$ & 20.8 & 7.8 & 5.0 & 1.2 & 65.2 \\
\hline
\end{tabular}

Fuente: Encuesta Nacional de Percepciones Sociales de los Juegos de Azar en México, México, UNAM, Instituto de Investigaciones Jurídicas, Departamento de Investigación Aplicada y Opinión, 2016.

Los jugadores problemáticos en línea con mayor frecuencia juegan por Internet craps o pase inglés, brisca, Lotería Nacional o lotería de otros países (lotto) y algún otro juego de cartas. Aunque con menor frecuencia, los jugadores problemáticos también recurren a otros juegos en línea, como: blackjack, ruleta, lotería instantánea de pronósticos, entre otros juegos de apuestas. Por su parte, las personas jugadoras en línea con riesgo moderado con más frecuencia suelen jugar brisca y craps o pase inglés; mientras que los jugadores de bajo riesgo juegan por Internet ruleta rusa, blackjack, bingo y máquinas tragamonedas, principalmente.

\section{JUGAR EN EXCESO}

La pregunta que cuestionaba a los jugadores si habían sentido que habían jugado en exceso deja ver también el fuerte contraste sobre la presencia de 
Este libro forma parte del acervo de la Biblioteca Jurídica Virtual del Instituto de Investigaciones Jurídicas de la UNAM

juego problemático entre la encuesta en vivienda y en línea. Mientras que en la encuesta en vivienda casi la totalidad de los encuestados que alguna vez había jugado mencionó que en los últimos doce meses no lo había hecho en exceso, poco más de la mitad de los encuestados en línea mencionó que sí lo había hecho.

Fueron los encuestados varones, las personas de 30 a 39 años y aquellos que tienen un nivel escolar de secundaria quienes en mayor medida admitieron haber sentido que habían jugado en exceso (véanse gráficas 6.27 y 6.28).

GRÁFICA 6.27

DURANTE LOS ÚLTIMOS DOCE MESES, ¿ALGUNA VEZ HA JUGADO EN EXCESO? (ENCUESTA EN VIVIENDA, PORCENTAJES)

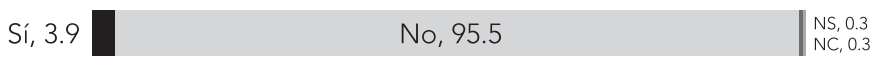

Fuente: Encuesta Nacional de Percepciones Sociales de los Juegos de Azar en México, México, UNAM, Instituto de Investigaciones Jurídicas, Departamento de Investigación Aplicada y Opinión, 2016.

\section{GRÁFICA 6.28}

DURANTE LOS ÚLTIMOS DOCE MESES, ¿ALGUNA VEZ HA SENTIDO QUE HA JUGADO EN EXCESO?

(ENCUESTA EN LÍNEA, PORCENTAJES)

\section{Sí, 53.7}

No, 46.3

Fuente: Encuesta Nacional de Percepciones Sociales de los Juegos de Azar en México, México, UNAM, Instituto de Investigaciones Jurídicas, Departamento de Investigación Aplicada y Opinión, 2016.

\section{DIAGNÓSTICOS DE JUEGO PROBLEMÁTICO}

Cuatro de cada diez entrevistados mencionaron que les han dicho que tienen una adicción al juego, y uno de cada diez admitió que un especialista lo ha diagnosticado.

Entre aquellos a los que les han dicho que tienen adicción al juego, destacan por encima de la media los que pertenecen al grupo de edad de 30 a 
Este libro forma parte del acervo de la Biblioteca Jurídica Virtual del Instituto de Investigaciones Jurídicas de la UNAM www.juridicas.unam.mx

34 años, los que tienen estudios de secundaria, así como los de licenciatura y posgrado. Por su parte, del porcentaje de jugadores que mencionó haber sido diagnosticado por un especialista, sobresalieron los jóvenes de 30 a 34 años (véanse gráficas 6.29 y 6.30).

\section{GRÁFICA 6.29}

\section{¿ALGUNA VEZ ALGUIEN LE HA DICHO QUE TIENE UNA ADICCIÓN AL JUEGO?} (PORCENTAJES)

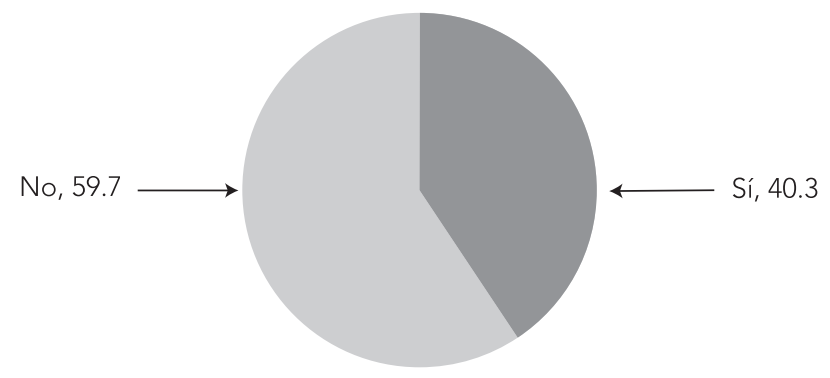

Fuente: Encuesta Nacional de Percepciones Sociales de los Juegos de Azar en México, México, UNAM, Instituto de Investigaciones Jurídicas, Departamento de Investigación Aplicada y Opinión, 2016.

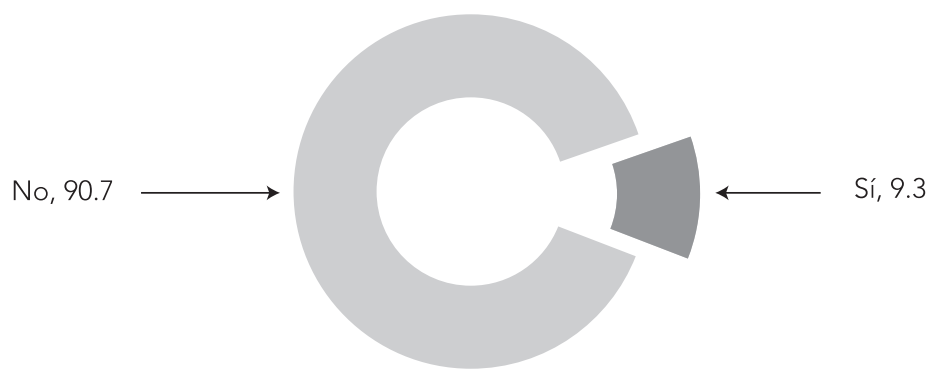

Fuente: Encuesta Nacional de Percepciones Sociales de los Juegos de Azar en México, México, UnAm, Instituto de Investigaciones Jurídicas, Departamento de Investigación Aplicada y Opinión, 2016. 
Este libro forma parte del acervo de la Biblioteca Jurídica Virtual del Instituto de Investigaciones Jurídicas de la UNAM

A partir de estos datos y de las tendencias mostradas en otros estudios, que se confirman con los resultados de la presente encuesta, puede deducirse que existe un riesgo mayor en las personas jóvenes de 30 a 34 años, pues son quienes en mayor medida aceptaron que les han dicho que tienen una adicción al juego, ya fuera cualquier persona o un especialista. Lo anterior sienta las bases para enfocar los esfuerzos de fomento de juego responsable a este grupo etario, incluyendo a los jóvenes de 18 a 29 años, para prevenir y erradicar el juego problemático relacionado con los juegos en línea.

\section{LOS NO JUGADORES POR INTERNET}

\section{MOTIVACIONES PARA NO JUGAR POR INTERNET APOSTANDO DINERO}

De los poco más de seis de cada diez participantes de la encuesta en línea que respondieron que no han apostado por Internet $(1,224)$, señalaron que no lo han hecho principalmente porque no confían en los juegos de apuesta por Internet, porque no los conocen y porque no les interesan. Mencionaron en menor medida que no han participado en estos juegos por falta de tiempo, porque no les gustaría perder y porque no quieren gastar dinero en los juegos de apuesta por Internet. En cuanto al cruce sociodemográfico, se encontró que quienes indicaron más frecuentemente que no han participado en los juegos de apuesta por Internet porque no confían en ellos, fueron los encuestados de 35 a 49 años. Por su parte, el sector más joven de los encuestados, que va de los 18 a 29 y de los 30 a 34 años, señaló en mayor medida que no ha participado en dichos juegos porque no lo conoce. Asimismo, los que dijeron con porcentajes superiores a la media total que no han apostado en juegos por Internet porque no les interesan, fueron las mujeres y quienes tienen 50 años y más (véase gráfica 6.31). 
Este libro forma parte del acervo de la Biblioteca Jurídica Virtual del Instituto de Investigaciones Jurídicas de la UNAM

¿POR QUÉ NO HA PARTICIPADO EN JUEGOS DE APUESTA POR INTERNET APOSTANDO DINERO? (PORCENTAJES)

No confía en los juegos de apuesta por Internet 34.7

No conoce los juegos de apuesta por Internet No le interesan los juegos de apuesta por Internet No ha tenido tiempo de jugar por Internet No le gustaría perder apostando por Internet No quiere gastar dinero apostando por Internet Otro (especificar)

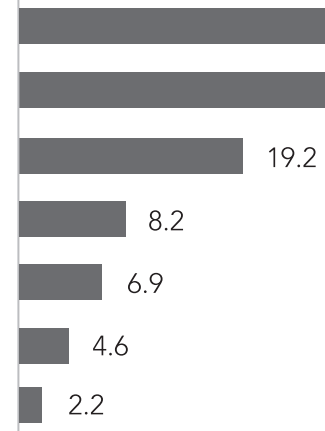
24.1

Fuente: Encuesta Nacional de Percepciones Sociales de los Juegos de Azar en México, México, UNAM, Instituto de Investigaciones Jurídicas, Departamento de Investigación Aplicada y Opinión, 2016.

\section{ANÁLISIS DE CORRESPONDENCIAS}

El tercer análisis de correspondencias múltiples que se realizó para esta sección tuvo el propósito de delimitar las posibles motivaciones a jugar de los no jugadores en línea. De igual forma, se buscaron relaciones entre la variable a explicar y las variables suplementarias. En este caso, la variable a explicar fue las posibles motivaciones que llevarían a jugar a los no jugadores en línea, y las suplementarias fueron únicamente las variables socioeconómicas principales. Si se lee el modelo de derecha a izquierda se puede apreciar que la dimensión 1 explica las motivaciones que llevarían a jugar a las personas que no juegan en línea. Para este modelo se obtuvo una varianza explicada del 59.9 por ciento.

Del análisis de correspondencias se pueden observar las siguientes características específicas que motivarían a jugar a cada perfil de los jugadores:

- Entretenimiento: cercanos a este grupo destacan los que tienen entre 50 años y más.

- Ganar dinero: sobresalen los que cuentan con un nivel de estudios de bachillerato, y los grupos etarios de 40 a 49 años. 
Este libro forma parte del acervo de la Biblioteca Jurídica Virtual del Instituto de Investigaciones Jurídicas de la UNAM

- Curiosidad: están más cercanos los que tienen entre 35 y 39 años de edad. Tanto las mujeres como aquellos con un nivel escolar básico están en medio de la curiosidad y el entretenimiento.

- Para no aburrirse: destacan los varones, entre los 18 y los 34 años de edad; un poco más lejanos se encuentran aquellos con nivel de licenciatura y posgrado (véase gráfica 6.32).

\section{GRÁFICA 6.32}

BIPLOT DEL ANÁLISIS DE CORRESPONDENCIAS MÚLTIPLES. MOTIVACIONES POSIBLES PARA JUGAR

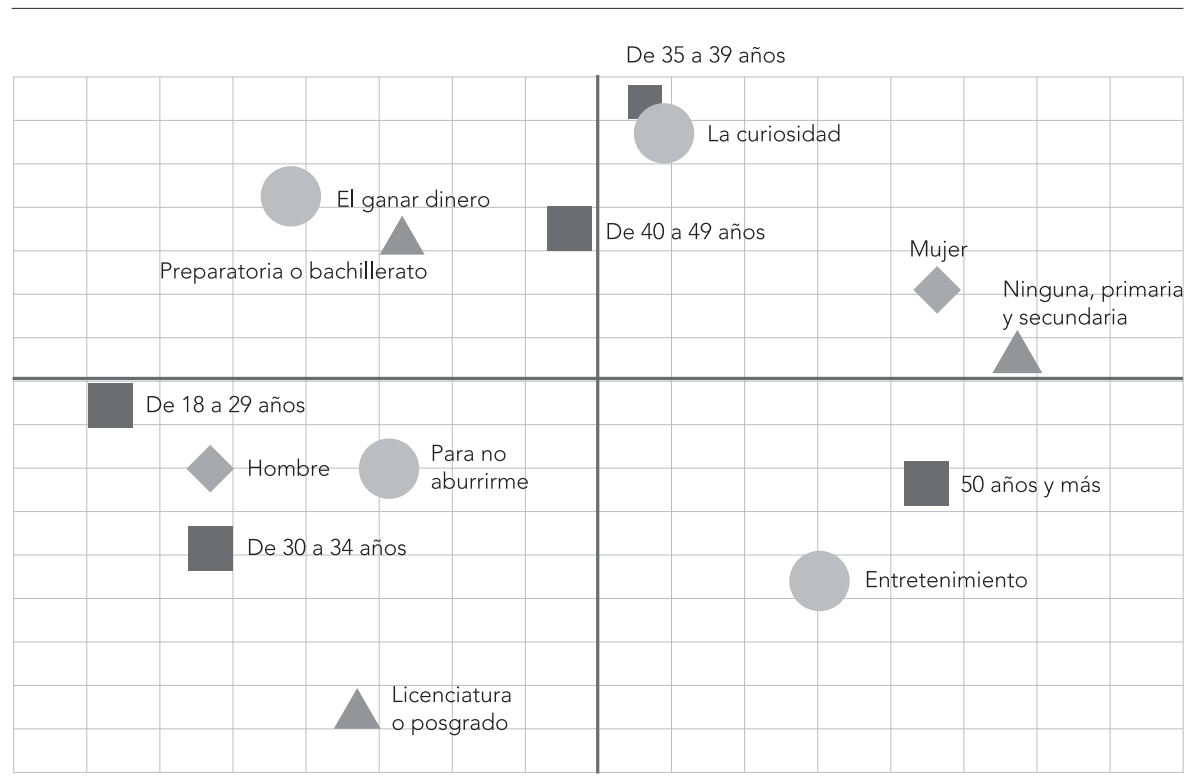

Principal motivación a jugar en Internet

Fuente: Encuesta Nacional de Percepciones Sociales de los Juegos de Azar en México, México, UnAM, Instituto de Investigaciones Jurídicas, Departamento de Investigación Aplicada y Opinión, 2016.

\section{OTRAS CARACTERÍSTICAS DE LOS NO JUGADORES EN LÍNEA}

Es relevante anotar que los encuestados que no han apostado en juegos por Internet señalaron que sí conocían diferentes juegos de apuesta en línea. Los más conocidos por los entrevistados, por orden de mención, fue- 
Este libro forma parte del acervo de la Biblioteca Jurídica Virtual del Instituto de Investigaciones Jurídicas de la UNAM

ron: la lotería instantánea de pronósticos y la Lotería Nacional, seguidos de las máquinas tragamonedas, el póquer y el bingo. También indicaron que conocían —aunque en menor medida—el blackjack y el craps o pase inglés. Los juegos que se consideraron con más probabilidad para ganar coinciden con los juegos más conocidos por los no jugadores participantes en el estudio. Poco más de ocho de cada diez entrevistados dijeron que se podía ganar más dinero en: la lotería instantánea (pronósticos), la lotería por Internet, el bingo por Internet y las máquinas tragamonedas por Internet.

Al preguntar ¿En qué tipo de dispositivo apostaría más por Internet? se observó que poco más de cuatro de cada diez de los individuos que no practican el juego en línea señalaron que jugarían por Internet usando computadora/laptop; poco más de cuatro de cada diez manifestaron que apostarían usando celular, y poco más de uno de cada diez respondió que jugaría usando una tableta. De quienes señalaron que usarían computadora/laptop, destacan los encuestados de 50 años y más. En cuanto a aquellos que dijeron que utilizarían un celular o tableta, resaltaron los individuos de 18 a 39 años (véase gráfica 6.33).

\section{GRÁFICA 6.33}

\section{¿EN QUÉ TIPO DE DISPOSITIVO APUESTAS MÁS POR INTERNET? VS. ¿EN QUÉ DISPOSITIVO APOSTARÍA SI JUGARA?}

\section{(PORCENTAJES)}

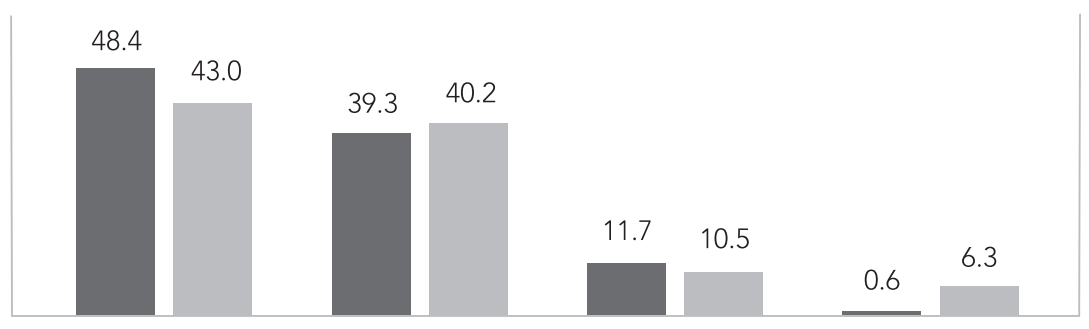

Computadora/laptop

Celular

Tableta

Otros

Sí juega

No juega

Fuente: Encuesta Nacional de Percepciones Sociales de los Juegos de Azar en México, México, UNAM, Instituto de Investigaciones Jurídicas, Departamento de Investigación Aplicada y Opinión, 2016. 
Este libro forma parte del acervo de la Biblioteca Jurídica Virtual del Instituto de Investigaciones Jurídicas de la UNAM

A la pregunta ¿En qué momento del día jugaría?, poco más de siete de cada diez individuos que no practican el juego en línea manifestaron que en la noche. En cambio, poco más de dos de cada diez indicaron que en la tarde. Y menos de uno de cada diez dijo que por la mañana (véase gráfica 6.34).

\section{GRÁFICA 6.34}

\section{¿EN QUÉ MOMENTO DEL DÍA JUEGA NORMALMENTE?} VS. ¿EN QUÉ MOMENTO DEL DÍA JUGARÍA?

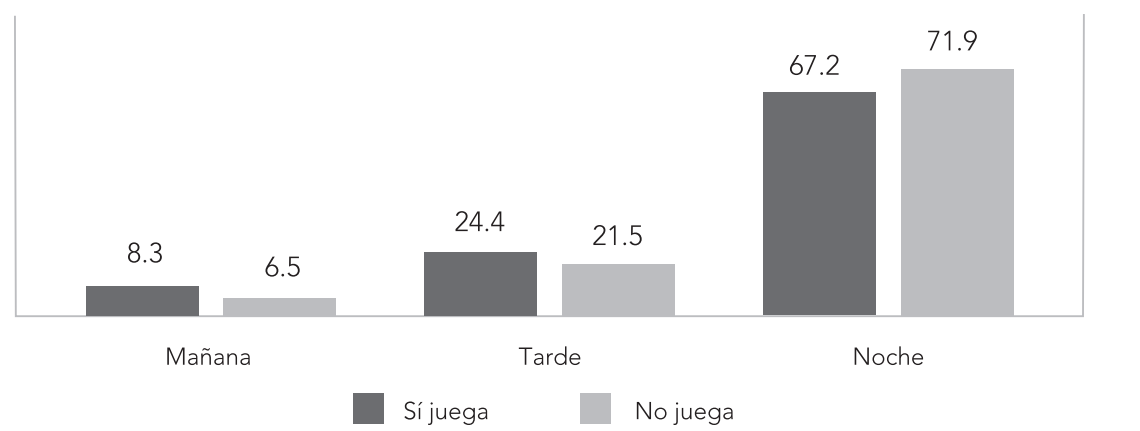

Fuente: Encuesta Nacional de Percepciones Sociales de los Juegos de Azar en México, México, unam, Instituto de Investigaciones Jurídicas, Departamento de Investigación Aplicada y Opinión, 2016.

Por otra parte, poco más de cuatro de cada diez señalaron que jugarían tanto entre semana como en fin de semana. Asimismo, poco más de cuatro de cada diez manifestaron que sólo jugarían el fin de semana. Y cerca de dos de cada diez respondieron que sólo jugarían entre semana (véase gráfica 6.35).

De igual forma que para los encuestados que sí juegan por Internet, para los entrevistados que no lo hacen, el entretenimiento y la diversión serían las principales motivaciones para jugar; un poco más de cuatro entrevistados de cada diez eligieron esta opción. Como segunda opción se encuentra el ganar dinero; casi tres de cada diez opinaron de esta manera. Por su parte, la opción curiosidad fue elegida por un poco más de un entrevistado de cada diez, dejando en los últimos lugares las opciones de no aburrirse, una invitación, o el verlo como un reto (véase gráfica 6.36). 
Este libro forma parte del acervo de la Biblioteca Jurídica Virtual del Instituto de Investigaciones Jurídicas de la UNAM www.juridicas.unam.mx

\section{GRÁFICA 6.35}

¿NORMALMENTE JUEGA ENTRE SEMANA O EL FIN DE SEMANA?

VS. ¿USTED CREE QUE JUGARÍA...?

(PORCENTAJES)

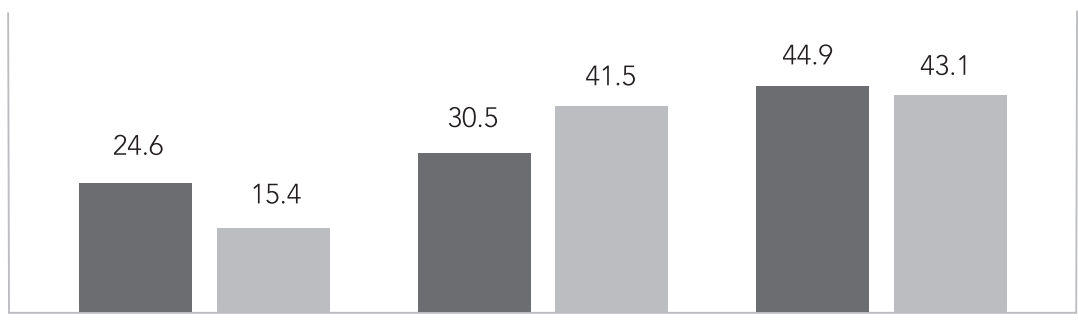

Entre semana

Fin de semana

Ambos

Sí juega

No juega

Fuente: Encuesta Nacional de Percepciones Sociales de los Juegos de Azar en México, México, UnAM, Instituto de Investigaciones Jurídicas, Departamento de Investigación Aplicada y Opinión, 2016.

\section{GRÁFICA 6.36}

DEL 8.5 POR CIENTO QUE CONTESTO QUE SÍ, ¿CUÁLES PROBLEMAS?

(ENCUESTA EN LÍNEA, PORCENTAJES)

El entretenimiento y diversión

El ganar dinero

Para no aburrirme

La curiosidad

Verlo como reto

\begin{tabular}{r|c} 
Una invitación & 0.3 \\
Para no estar solo & 0.3
\end{tabular}

Sí juega

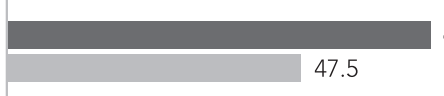

68.1

24.4

29.9

\section{7}

\section{8}

2.4

18

No juega

Fuente: Encuesta Nacional de Percepciones Sociales de los Juegos de Azar en México, México, unam, Instituto de Investigaciones Jurídicas, Departamento de Investigación Aplicada y Opinión, 2016. 
Este libro forma parte del acervo de la Biblioteca Jurídica Virtual del Instituto de Investigaciones Jurídicas de la UNAM

A partir de los grupos sociodemográficos, fueron las mujeres, los jóvenes de 30 a 34 años, los adultos de 50 años y más, y aquellos con un nivel de estudios de secundaria los que opinaron, por encima de la media, que los motivaría a jugar el entretenimiento y diversión. Por otro lado, resultaron ser los hombres y los pertenecientes a los grupos de edad de 35 a 39 y de 40 a 49 años quienes en mayor medida opinaron que los motivaría a jugar el ganar dinero. Grupos que son más parecidos al perfil del jugador de apuestas o sorteos por Internet que se obtuvo a partir de la presente encuesta.

\section{CONCLUSIONES}

Los resultados que se presentaron en el presente capítulo nos indican que en México, a partir de la encuesta en vivienda, los juegos por Internet son conocidos por menos de la mitad de la población estudiada y que son todavía muy pocos los que los han jugado. No obstante, se observó que los juegos en línea son jugados en mayor medida por los hombres y las personas menores de 50 años, así como por quienes tienen una escolaridad de bachillerato y superior. A su vez, se encontró que el principal motivo de los encuestados para jugar en línea fue el entretenimiento y diversión.

En cuanto a los juegos de azar por Internet, resultaron ser las máquinas tragamonedas las más conocidas y jugadas en México. En contraste, los menos conocidos y jugados son el craps o pase inglés, así como la brisca por Internet. El bingo y la lotería por Internet (Nacional o de otro país) son más jugados por las mujeres, mientras que el resto de los juegos por Internet son más practicados por los hombres. La lotería instantánea de pronósticos por Internet es considerada como el juego con el que más se puede ganar dinero. En el mismo sentido, este juego está entre los primeros tres de mayor gusto entre los encuestados, además del bingo y las máquinas tragamonedas (todos en línea).

En promedio, la mayor parte de los encuestados señaló dedicar de 30 minutos a dos horas a jugar por Internet. Los encuestados juegan en su mayoría desde casa, en una computadora y en la noche, sin distinción de días de la semana. En los juegos presenciales predomina el pago en efectivo, sobre todo en las mujeres. En contraste, en los juegos en línea predomina el 
Este libro forma parte del acervo de la Biblioteca Jurídica Virtual del Instituto de Investigaciones Jurídicas de la UNAM

uso de las tarjetas bancarias. Es la minoría de los encuestados la que indicó estar registrada en alguna página de juegos en línea; lo anterior fue rescatado de ambas encuestas. La mayoría indicó que son legales los juegos de apuesta y sorteo en línea, además de que mostró confianza en éstos.

En la encuesta en línea poco más de uno de cada diez encuestados tiene en algúna medida problemas de juego. Solo el 1.0 por ciento de los encuestados resultaron ser jugadores problemáticos.

De quienes dijeron no haber jugado en línea, señalaron que no lo han hecho principalmente porque no confían, además de que no los conocen. No obstante, destaca que tanto los que apuestan como los que no, lo hacen o lo harían principalmente en una computadora y un teléfono inteligente, además de que no habría diferencia en cuanto a motivos para jugar, así como horarios y días de la semana para hacerlo. 
Este libro forma parte del acervo de la Biblioteca Jurídica Virtual del Instituto de Investigaciones Jurídicas de la UNAM

\section{CONCLUSIONES}

Si bien los juegos de azar son frecuentemente relacionados con numerosos estigmas, como el riesgo del juego problemático o el lavado de dinero, igualmente refuerzan espacios de convivencia entre pares. La lectura en conjunto de los datos aquí presentados permite observar tres facetas de los mexicanos entrevistados en relación con las prácticas de juegos de azar:

- En primer lugar, la información analizada pone en entredicho lugares comunes en las percepciones más generalizadas sobre la práctica de los juegos de azar. Las motivaciones de los jugadores que practican juegos de azar no son el aislamiento o la soledad —se juega en compañía, con los amigos o familiares- o la insatisfacción con la vida. Al respecto, se observa que, al contrario de lo que generalmente se piensa, los entrevistados que sienten que les hace falta compañía tienden a jugar en menor medida.

- En segundo lugar, del análisis sociodemográfico de los asistentes a los casinos se desprende información importante que pone en cuestión varios de los tópicos relativos a las personas que asisten a los casinos: en primer lugar, no se trata de adultos mayores, dado que la mayoría 
Este libro forma parte del acervo de la Biblioteca Jurídica Virtual del Instituto de Investigaciones Jurídicas de la UNAM

de quienes asisten (casi tres de cada diez) tienen entre 45 y 54 años, y dos de cada diez tienen de 35 a 44 años y de 55 a 64 años. Igualmente, asisten más hombres que mujeres, y sólo el 4.8 por ciento son personas que se dedican a los quehaceres del hogar.

- En tercer lugar, el trabajo constituye un elemento básico en la vida y los valores de los mexicanos. Si bien la creencia en la suerte está muy extendida, el trabajo duro se considera la condición esencial para tener éxito, para enfrentar el futuro y cumplir los sueños. Incluso entre las asociaciones para la palabra suerte aparece el trabajo. Trabajo y suerte no constituyen elementos separados.

\section{CREENCIAS Y PRÁCTICAS TRADICIONALES}

- La suerte se asocia principalmente con el dinero, la fortuna y las ganancias, pero también con el trabajo. Al contrario de las asociaciones para la palabra azar, que tienen una connotación negativa —el hecho que suceda algo no deseado con consecuencias negativas- para los entrevistados, la suerte es de signo positivo. Su asociación con los juegos de azar queda de relieve; en el habla cotidiana de México, la expresión "sacarse la lotería" es una expresión de buena fortuna que se aplica a todo tipo de situaciones.

- De los resultados del índice de superstición se desprende que si bien las supersticiones y creencias tradicionales están extendidas en la sociedad mexicana, no se sitúan en los extremos. Más de la mitad de la población (53.8 por ciento) se ubica en todo caso en los niveles bajo y medio-bajo. Y se manifiestan por igual entre las poblaciones que dijeron practicar juegos de azar y entre quienes no los practican.

- Mientras más arraigadas están las creencias tradicionales y las supersticiones, crece la disposición a participar en los juegos de azar. Así, las personas que creen en la suerte dijeron en mayor medida haber jugado un juego de azar en el último año. En contraste, quienes no creen en la suerte señalaron con porcentajes más altos no jugar ningún juego.

- Los católicos y los ateos en mayor medida tenderían a participar en juegos de azar que los miembros de otras denominaciones religiosas. 
Este libro forma parte del acervo de la Biblioteca Jurídica Virtual del Instituto de Investigaciones Jurídicas de la UNAM

\section{BIENESTAR SUBJETIVO}

Mucho se ha especulado sobre la relación entre el bienestar subjetivo y la práctica de los juegos de azar. Se ha convertido en un lugar común —principalmente desde algunas visiones- señalar que quienes juegan lo hacen por un vacío existencial: la insatisfacción con su vida o la infelicidad. Los resultados muestran que:

- La satisfacción con la vida no es un elemento relevante para que las personas practiquen juegos de azar. La gran mayoría de los entrevistados dijo estar satisfecho con su vida, por igual entre quienes practican juegos de azar y entre quienes no practican ningún juego.

- Las personas que no juegan ningún juego señalaron en mayor medida que pueden decidir sobre su futuro, en contraste con la media nacional y con quienes han jugado alguna vez en el último año.

- Se considera que lo más importante para tener éxito en la vida es trabajar duro (cuatro de cada diez), mientras que un cuarto de los encuestados indicó que tener una buena educación, y poco más de uno de cada diez dijo que tener buenas conexiones y contactos. Menos del diez por ciento indicó que para tener éxito en la vida era importante contar con una familia unida, nacer en una familia con dinero y tener buena suerte.

\section{SITUACIÓN DEL PAÍS}

- Los entrevistados son pesimistas sobre la situación del país. Es importante mencionar que esta percepción ha sido constante en los últimos años. No obstante, al parecer, la percepción de la situación económica del país no representa un obstáculo para la práctica del juego, dado que de las personas entrevistadas que dijeron que han jugado al menos un juego en el último año, poco menos de ocho de cada diez (77.8 por ciento) consideraron que la situación económica actual del país está igual de mal o peor que la del año pasado, proporción que se encuentra por debajo de la media nacional (80.6 por ciento); mientras 
Este libro forma parte del acervo de la Biblioteca Jurídica Virtual del Instituto de Investigaciones Jurídicas de la UNAM

que las personas que dijeron que no han jugado en el último año y que consideraron que la situación económica del país está igual de mal o peor representan más de ocho de cada diez (83.2 por ciento).

- Asimismo, las personas que han jugado algún juego en el último año se encuentran entre las más optimistas, ya que cerca de tres de cada diez (28.1 por ciento) consideraron que la situación económica del país mejorará o estará igual de bien en el futuro, proporción que se encuentra por encima de la media nacional (24.8 por ciento) y de la proporción de no jugadores, pues estos últimos representan dos de cada diez (21.7 por ciento).

- En concordancia con la percepción sobre la situación económica del país, los resultados sobre la situación económica personal también son poco optimistas. Alrededor de dos terceras partes de la población entrevistada (66.2 por ciento) dijeron que su situación económica actual está igual de mal o peor en relación con el año pasado.

\section{TIEMPO LIBRE}

El tiempo libre ha dado lugar a la creación de una industria de entretenimiento que compite constantemente para atraer la atención de los potenciales clientes.

- Como ya se mencionó, de todos los países miembros de la OCDE, México es el que más horas trabaja al año; sin embargo, resulta paradójico que más de la mitad de la población ocupada vive en la informalidad.

- Dentro de las posibilidades de uso del tiempo libre, se exploró el juego de azar como una actividad que es ubicua en todas las sociedades humanas. En México no existe una tendencia generalizada a estigmatizar los juegos de apuesta como algo propio de tahúres. Esto no quiere decir que los juegos sean percibidos como una actividad virtuosa, simplemente las opiniones son neutrales. 
Este libro forma parte del acervo de la Biblioteca Jurídica Virtual del Instituto de Investigaciones Jurídicas de la UNAM

\section{IMAGINARIOS DE LOS CASINOS}

- El imaginario de los casinos presente entre los entrevistados, registrado a través de las principales asociaciones de palabras, dibujan a los casinos como espacios sujetos a la contingencia, donde los resultados son inciertos: dinero, juego y apuesta, pero también implican diversión. Las pérdidas y ganancias dependen de la suerte: se obtienen en primer lugar ganancias (asociación positiva), pero con la misma intensidad aparecen las pérdidas (asociaciones negativas).

\section{ASISTENCIA A CASINOS}

- La costumbre de asistir a los casinos no ha arraigado todavía en el país. Si bien más de la mitad de los entrevistados en vivienda ha participado alguna vez en un juego de azar, lo ha hecho principalmente en juegos de azar tradicionales. Sólo uno de cada diez ha asistido a un casino y dos de cada diez han realizado apuestas. Es en el noreste del país donde se menciona en mayor medida la presencia de casinos en las cercanías de las viviendas de los entrevistados. Cerca de la mitad de los entrevistados conoce la legalidad de los juegos de azar tanto por Internet como de los casinos.

- La percepción de los juegos de azar en el país, particularmente los casinos, tiende a ser negativa entre los entrevistados, dado que los asocian con los políticos, los narcotraficantes o los empresarios. No obstante, la mayoría de los entrevistados que ha asistido a los casinos dice confiar en ellos. De quienes dijeron haber asistido a un casino, una gran mayoría los califica de manera positiva y mostró satisfacción por el trato recibido. Sólo señaló haber tenido algún problema el 3.4 por ciento del total de quienes asistieron alguna vez.

\section{LEGALIDAD Y REGULACIÓN DE LOS CASINOS}

- El amplio nivel de desconocimiento que existe entre los entrevistados sobre si los juegos están o no regulados, es testimonio de lo ajeno que resultan para la vida cotidiana de las personas (la hipótesis se apuntala 
Este libro forma parte del acervo de la Biblioteca Jurídica Virtual del Instituto de Investigaciones Jurídicas de la UNAM

con el hallazgo de que a mayor participación en juegos de azar, crece el conocimiento de la situación legal de los mismos). Los debates sobre el marco regulatorio de los juegos de azar en México pasan necesariamente por la percepción que tienen los ciudadanos de las implicaciones de esta actividad y cuáles son los riesgos que les son atribuidos en los imaginarios.

\section{¿QUIÉNES JUEGAN EN MÉXICO?}

En esta etapa del estudio, que es la exploración inicial del fenómeno, los datos permiten empezar a dibujar algunas hipótesis sobre las relaciones que guardan el hecho de practicar un juego, el tipo de juego y el tipo de juego preferido. Todo parece indicar que los jugadores entrevistados en la encuesta comparten algunos rasgos en común:

- Entre los hallazgos más relevantes se puede señalar que el 48.3 por ciento de los habitantes del país participó en al menos un juego de azar en el último año.

- Una mayor proporción de hombres (60.4 por ciento) son jugadores en comparación con las mujeres (37.5 por ciento).

- Las personas más jóvenes son quienes con mayor frecuencia se declararon jugadores; además, se pudo observar que conforme aumenta la edad, también crece la participación en los juegos de azar.

- En relación con la escolaridad, se observó que conforme aumenta el nivel educativo se incrementa la participación de los individuos en los juegos de azar.

- De acuerdo con la condición de actividad, una mayor proporción de personas que sí tienen trabajo (59.4 por ciento) se declararon jugadores, mientras que aquellas que no tienen trabajo y son jugadores representan el 33.0 por ciento.

- Los entrevistados señalaron que el juego que más practican es la lotería tradicional mexicana (40.6 por ciento) y la Lotería Nacional (27.8 por ciento); aunque también mencionaron las máquinas tragamonedas (27.8 por ciento) y las salas de juego (8.2 por ciento). 
Este libro forma parte del acervo de la Biblioteca Jurídica Virtual del Instituto de Investigaciones Jurídicas de la UNAM

\section{EL JUEGO PROBLEMÁTICO}

Los resultados de la encuesta en vivienda sobre el tema del juego problemático nos permitieron observar algunas tendencias interesantes y coherentes:

- El entretenimiento y la diversión son las principales motivaciones de los mexicanos para jugar, ya que más de la mitad brindó dicha respuesta.

- Muy pocos de los encuestados (3.8 por ciento) manifestaron haber jugado en exceso en el último año. En concordancia, un bajo porcentaje (4.8 por ciento) expresó que alguna vez alguien le dijo que tenía una adicción al juego, y un porcentaje mínimo (1.7 por ciento) reconoció haber sido diagnosticado con una adicción al juego por un especialista.

- Los datos generados para México a partir de la Encuesta Nacional de Percepciones Sociales de los Juegos de Azar permiten estimar que el 1.1 por ciento de las personas de 18 años y más son jugadores problemáticos. Esta cifra es similar a la prevalencia reportada para Gran Bretaña en un estudio sobre el comportamiento de los jugadores en 2015. Sin embargo, es superior a la reportada en España para este mismo año, que fue de 0.1 por ciento. Las cifras sobre la prevalencia del juego problemático en el mundo varían en un rango de 0.1 a 5.8 por ciento. Al respecto, se ha señalado que en América del Norte la prevalencia se ubica entre 2 y 5 por ciento; en Asia es de 0.5 a 5.8 por ciento; en Oceanía de 0.4 a 0.7 por ciento, y en Europa el rango es de 0.1 a 3.4 por ciento.

- En relación con los jugadores con riesgo, la encuesta nacional permitió detectar que existe un 3.3 por ciento de personas que se ubica en el rango de jugadores con un riesgo moderado, y un 11.6 por ciento que presenta un riesgo bajo. Esto es, se estimó que el 14.9 ciento son jugadores en riesgo.

- Estos datos muestran que hay un grupo potencial de jugadores que podrían en un futuro convertirse en problemáticos, de no realizarse las acciones preventivas y educativas pertinentes. 
Este libro forma parte del acervo de la Biblioteca Jurídica Virtual del Instituto de Investigaciones Jurídicas de la UNAM

- Los jugadores problemáticos fueron, por encima de la media, los que tienen un nivel de licenciatura o posgrado; los que perciben más de cuatro salarios mínimos individuales al mes, al igual que los que obtienen un ingreso familiar de más de seis salarios mínimos al mes, y los que habitan la zona noroeste del país.

- Los jugadores con un riesgo moderado fueron los más jóvenes, de 18 a 24 años, con un nivel escolar de licenciatura o posgrado y con un ingreso mensual individual por encima de los dos salarios mínimos.

- Los jugadores problemáticos prefirieron jugar bingo (26.3 por ciento), en casinos (24.1 por ciento) y las apuestas en carreras (22.6 por ciento). Los jugadores con un riesgo moderado, en cambio, prefirieron en mayor medida los juegos por Internet (52.3 por ciento).

- Finalmente, es importante señalar que existen en México alrededor de novecientas cuatro mil personas que son jugadores problemáticos y más de 2.7 millones de jugadores en riesgo moderado. Esto, si tomamos en consideración las proyecciones de población del Consejo $\mathrm{Na}$ cional de Población (Conapo) para 2016 y las cifras presentadas aquí en relación con el juego problemático y los grupos en riesgo.

\section{ENCUESTA EN LÍNEA}

- Los resultados generados a partir de la encuesta en vivienda nos indican que en México los juegos por Internet son conocidos por menos de la mitad de la población estudiada y son todavía muy pocos los que los han jugado.

- No obstante, se observó que los juegos en línea son jugados en mayor medida por los hombres.

- Un mayor porcentaje de las personas menores de 35 años son jugadores en línea y son quienes tienen algún tipo de riesgo de juego problemático. Estos resultados son relevantes porque se trata de una generación con un mayor acceso a Internet, por lo que están expuestos a un riesgo constante.

- Es decir, cuatro de cada diez jugadores en línea (41.2 por ciento) son jóvenes entre los 18 y los 34 años de edad. 
Este libro forma parte del acervo de la Biblioteca Jurídica Virtual del Instituto de Investigaciones Jurídicas de la UNAM

- De las personas que juegan y presentan algún tipo de riesgo (bajo riesgo y riesgo moderado), el 13.7 por ciento tiene entre 18 y 29 años; un porcentaje similar, de 13.7, se encuentra entre los 30 y los 34 años.

- Se percibe un incremento en la práctica de apostar por Internet, utilizando la computadora, dado que es además una actividad que se practica en casa, en los tiempos libres, principalmente en la noche, tanto entre semana como en fin de semana. Los jugadores en línea admiten dedicar considerables horas de su tiempo - entre los $30 \mathrm{mi}$ nutos y dos horas en un día- y cantidades de dinero a apostar por Internet que van de los $\$ 250.00$ pesos M.N. y los $\$ 1,500.00$ pesos M.N. al mes. En los casinos, los entrevistados señalaron invertir $\$ 1,535.00$ pesos M.N. en un día promedio de juego.

- Los medios preferidos de pago para el juego en línea, tales como la tarjeta de crédito, pagos electrónicos y en tiendas de conveniencia, facilitan la participación de los jugadores, mientras que quienes apuestan de manera presencial acostumbran realizar pagos en efectivo. La mayoría de quienes apuestan, tanto en línea como en vivienda, están conscientes que invierten más de lo que obtienen en el juego.

- Los perfiles de los jugadores entrevistados en vivienda y de quienes juegan en línea tienden a ser similares: se trata principalmente de varones, entre los 18 y los 49 años de edad, con escolaridad media superior o superior, con empleos que suelen brindar cierta estabilidad económica, tales como los profesionistas liberales, comerciantes, funcionarios públicos y empleados administrativos, con ingresos superiores a los cuatro salarios mínimos.

- Las ciudades en donde se obtuvieron más respuestas de jugadores en línea fueron Ciudad de México, Veracruz y el Estado de México.

- El perfil de los entrevistados que no juegan también es similar para las encuestas en vivienda y en línea: son principalmente mujeres, aquellos de más edad (de 55 a 64 años y de 65 años y más), las personas que cuentan con menor escolaridad, los que carecen de ocupación y quienes tienen una religión diferente a la católica.

- El análisis de las características de los jugadores por Internet permitió identificar tres perfiles: los que juegan de manera intensiva, los que juegan de manera frecuente y los que sólo juegan de manera ocasio- 
Este libro forma parte del acervo de la Biblioteca Jurídica Virtual del Instituto de Investigaciones Jurídicas de la UNAM

nal. De acuerdo con la intensidad de juego en línea, juegan con intensidad los hombres jóvenes de 18 a 34 años, muy probablemente vinculados a estos juegos debido a su familiaridad con la tecnología y el uso del Internet.

- En el segundo nivel se encuentran los jugadores frecuentes, entre los que destacan también los varones, aunque éstos se ubican en el rango de edad inmediato superior, es decir, aquellos que tienen entre 35 y 39 años, con estudios de bachillerato.

- Finalmente, entre los jugadores ocasionales predominan las mujeres, las personas de 50 años y más, y quienes cuentan con niveles de escolaridad bajos.

- El nivel de intensidad de juego está vinculado también con las motivaciones para jugar: aquellos que juegan de manera intensiva están motivados a jugar por dinero; los jugadores frecuentes están principalmente motivados por el entretenimiento y la diversión, y los jugadores ocasionales por otro tipo de motivaciones dispersas, tales como la curiosidad, no aburrirse o no sentirse solos.

- El juego favorito para aquellos que juegan en línea son las máquinas tragamonedas por Internet, las cuales, además, corresponden a los juegos que se juegan de manera más frecuente. Dos juegos son preferidos para jugarlos tanto en línea como en vivienda: el bingo y las máquinas tragamonedas; coincide que estos dos juegos también son mencionados, además de la lotería instantánea de pronósticos por Internet (Melate, Chizpazo, Tris y Progol), como aquellos con los que los entrevistados piensan que se puede ganar más dinero.

- En la encuesta en línea, poco más de uno de cada diez encuestados tiene en alguna medida problemas de juego. Sólo el 1.0 por ciento de los encuestados resultaron jugadores problemáticos.

- A diferencia de los jugadores encuestados en vivienda, y en parte debido también al anonimato de una encuesta en línea, se detectó entre los jugadores en línea un número mayor de conductas relacionadas con el juego problemático: poco más de la mitad de los jugadores por Internet sintió, durante los últimos doce meses, que ha jugado en exceso. Al mismo tiempo, cuatro de cada diez entrevistados que juegan en línea señalaron que les han dicho que tienen una adicción al juego; 
Este libro forma parte del acervo de la Biblioteca Jurídica Virtual del Instituto de Investigaciones Jurídicas de la UNAM

mientras que a menos de uno de cada diez jugadores en vivienda le han dicho lo mismo.

- De la misma manera, casi uno de cada diez entrevistados en línea que juegan por Internet mencionó que ha sido diagnosticado con adicción al juego; en contraste, en el caso de los jugadores entrevistados en vivienda, el porcentaje es menor a dos puntos porcentuales.

- De quienes dijeron no haber jugado en línea, señalaron que no lo han hecho principalmente porque no confían, además de que no los conocen. No obstante, destaca que tanto los que apuestan como los que no, lo hacen o lo harían principalmente en una computadora y un teléfono inteligente, además de que no habría diferencia en cuanto a motivos para jugar, así como horarios y días de la semana para hacerlo.

Mediante los datos de esta Primera Encuesta Nacional sobre Percepciones Sociales de los Juegos de Azar en México se han delineado rasgos que caracterizan a los participantes en juegos de azar. En este primer ejercicio exploratorio se busca proponer una línea para guiar futuras investigaciones e identificar nuevas vetas para el estudio de los participantes en los juegos de azar en el país.

En la actualidad, la diversificación de las formas de ocio y la expansión de centros de juegos de azar han dado lugar a que la población entre en contacto con diferentes tipos de juegos, lo que puede hacer posible un incremento en la incidencia del juego patológico que la población no identifica como un trastorno del comportamiento o dependencia. Esta falta de conciencia y las carencias de infraestructura y recursos humanos capacitados para prevenir y atender los problemas relacionados con el juego hacen necesaria la acción gubernamental e intersectorial en este tema.

Con base en lo anterior, podemos afirmar que la prevalencia de juego problemático en nuestro país se encuentra dentro de los rangos reportados en diferentes regiones del mundo. Sin embargo, es necesario realizar otros estudios sistemáticos y periódicos para contar con un sistema de encuestas nacionales en esta área, que aporten la información necesaria para delinear tendencias. Por una parte, es urgente la implementación de acciones preventivas dirigidas al grupo de jugadores y, por la otra, que se desplieguen 
Este libro forma parte del acervo de la Biblioteca Jurídica Virtual del Instituto de Investigaciones Jurídicas de la UNAM

acciones intersectoriales para apoyar y atender a la población detectada con juego problemático.

Esta encuesta nacional proporciona un buen punto de partida para el desarrollo de futuros estudios sobre los juegos de azar y dar inicio a las acciones para subsanar la carencia de investigaciones sobre esta temática en nuestro país. Es necesario conocer más elementos acerca del fenómeno del juego en México; sin embargo, no queda duda de que éste es un tema que abre la puerta a futuras investigaciones, y que estas primeras pesquisas dejan testimonio de lo mucho que aún se puede descubrir. 
Este libro forma parte del acervo de la Biblioteca Jurídica Virtual del Instituto de Investigaciones Jurídicas de la UNAM

\section{BIBLIOGRAFÍA}

Abric, J. C. (1994), Pratique sociales et représentations sociales, París, PUF.

Ai Camp, R. (1997), La política en México, México, Siglo XXI Editores.

American Psychiatric Association (1994), Diagnostic and Statistical Manual of Mental Disorders, $4^{\mathrm{a}}$ ed., Washington, D. C., American Psychiatric Association, disponible en: https://justines 2010blog.files.wordpress.com/2011/03/dsm-iv.pdf.

Angulo, K. M. (2012), "Emociones y sentimientos: coordenadas históricas y multidisciplinares de un campo de estudio clave", Avances en Superstición Educativa. Revista de la Asociación de Inspectores de Educación de España, (16)2.

Arizmendi, M. E. (2012), "El gallo de oro. Entre el texto y el contexto", en Alemany Ferrer, R. y F. Rico Chuco, Literatura y espectáculo, Alicante, Universidad de Alicante-Sociedad Española de Literatura General y Comparada.

Arteaga, J. R. (2013), "Casinos en México, el futuro en juego", Forbes, disponible en: https:// www.forbes.com.mx/casinos-en-mexico-su-futuro-en-juego.

Baermann Steiner, F. (1999), “¿Cómo definir la superstición?", en Adler, J. y R. Fardon (eds.), Taboo, Truth and Religion, Oxford, Berghahn Books.

Ball, J. (2014), "Los estudiantes que les ganaron a los casinos de Las Vegas", BBC Mundo, 27 de mayo, disponible en: http://www.bbc.com/mundo/noticias/2014/05/140526_casino_black jack_estudiantes_mit_ch.

Barbelet, J. (2002), Emotions and Sociology, Nueva York, Wiley-Blackwell.

Barlow, R. (2007), Gambling Had Role in Religious History, Boston, The Boston Globe.

Beezley, W. (1983), "El estilo porfiriano: deportes y diversiones de fin de siglo", Revista Historia Mexicana, 33(2), octubre-diciembre. 
Este libro forma parte del acervo de la Biblioteca Jurídica Virtual del Instituto de Investigaciones Jurídicas de la UNAM www.juridicas.unam.mx

Berger, P. (1977), El dosel sagrado. Para una teoría sociológica de la religión, Buenos Aires, Amorrortu.

Bourdieu, Pierre (1977), Outline of a Theory of Practice, Cambridge, Cambridge University Press.

Caillois, R. (1986), Los juegos y los hombres. La máscara y el vértigo, México, Fondo de Cultura Económica.

Calado, F. y M. D. Griffiths (2016), "Problem Gambling Worldwide: An Update Systematic Review of Empirical Research (2000-2015)", Journal of Behavioral Addicions, DOI: 10.1556/ 2006.5.2016.073

Canchola, A. y P. Villa, (2017), "La emoción de ser un niño gritón", El Universal, 15 de septiembre, recuperado de: http://www.eluniversal.com.mx/nacion/sociedad/la-emocion-de-serun-nino-griton.

Cases, J. I. et al. (2010), Una aproximación a las percepciones sobre el comportamiento y las actitudes sociales respecto al juego y al juego on line en España, Madrid, Instituto de Política y Gobernanza, Universidad Carlos III de Madrid.

Castañares, I. (2017), "Baja bancarización y conectividad, retos de los juegos online en México", El Financiero, 17 de octubre, recuperado de: http://www.elfinanciero.com.mx/empresas/ baja-bancarizacion-y-conectividad-retos-de-los-juegos-online-en-mexico.html.

Castro, P. (2010), "El hipódromo de Constantinopla: encuentros y desencuentros. El imaginario en torno al circo y su poder (ss. VI-VII)", Revista Electrónica Historias de Orbis Terrarum, núm. 4, recuperado de: http://www.orbisterrarum.cl.

Castro, R. (2013), "100 años de casinos en Mexicali. 1903-2013", El Río, Revista de Historia Regional de Mexicali y su Valle, año VI, núm. 19, enero-marzo.

Centini, M. (2003), El libro de las supersticiones: orígenes, significado, interpretación, Barcelona, De Vecchi.

Chinchilla, P. P. (2000), "Lo lúdico y lo profano", en Semo, I. (coord.), La rueda del azar. Juegos y jugadores en la historia de México, México, Pronósticos para la Asistencia Pública.

Cohen, S. (1972), Folk Devils and Moral Panics, Londres, MacGibbon and Kee.

Converse, P. (1964), "The Nature of Belief Systems in Mass Publics", en Apter, D., Ideology and Discontent, Nueva York, The Free Press.

Damasio, A. (2014), "Entrevista con Jason Pontin", The MIT Tecnology Review, 23 de junio.

David, F. N. (1962), Games, Gods \& Gambling: A History of Probability and Statistical Ideas, Nueva York, Hafner.

De Valle A. (1997), "Breve historia de la lotería en México", Artes de México, núm. 13.

Dobbelaere, K. (1992), "Religione e valori morali in Europa a nell' America settentriolale", European Values Study, Italia, Università di Trento.

Duncan, A. M. (2015), Gambling with the Myth of the American Dream, Nueva York, Routledge.

Durkheim, E. (1980), Las reglas del método sociológico, México, Fondo de Cultura Económica.

Durkheim, E. (2002), Educación moral, Madrid, Trotta.

Echeverría, R. et al. (2011), "Los juegos de azar como problema emergente en la investigación social en México: balance preliminar y perspectivas", Revista Científica de Investigaciones Regionales, vol. 33, núm. 2, recuperado de: https://dialnet.unirioja.es/descarga/articulo/ 4156950.pdf. 
Este libro forma parte del acervo de la Biblioteca Jurídica Virtual del Instituto de Investigaciones Jurídicas de la UNAM

Echeverria, R. et al. (2017), "Representaciones sociales de líderes institucionales acerca del juego en casinos mexicanos", Revista de Psicología, vol. 35, núm. 1.

Elías, N. y E. Dunning (1988), Deporte y ocio en el proceso de civilización, México, Fondo de Cultura Económica.

Ferentzy, P. y N. E. Turner (2013), "The History of Gambling and its Intersection with Technology, Religion, Medical Science, and Metaphors", The History of Problem Gambling, Nueva York, Springer.

Forni, F. (1986), "Reflexión sociológica sobre el tema de la religiosidad popular", Sociedad y Religión, núm. 3.

Frey, B. S. (2008), Happiness: A Revolution in Economics, Cambridge, MA, The MIT Press.

Frey, B. S. y A. Stutzer (2002), "What Can Economists Learn from Happiness Research?", Journal of Economic Literature, vol. 40, núm. 2.

Frigerio, A. (1993), "Los estudios sociológicos sobre religión en la Argentina: desarrollo y tendencias actuales", Ciencias sociales y religión en el Cono Sur, Buenos Aires, CEAL.

Gadamer, H. G. (1996), La actualidad de lo bello, Barcelona, Paidós.

Gainsbury, S. M. et al. (2013), "The Impact of Internet Gambling on Gambling Problems: A Comparison of Moderate-Risk and Problem Internet and Non-Internet Gamblers", Psychology of Addictive Behaviors, vol. 27, núm. 4.

García, C. A. (1997), "El lugar de la fortuna. Fiestas del azar en Tlalpan", Revista Artes de México, núm. 13.

García, J. y L. Pérez (2013), "La (inelástica) demanda de juegos de lotto", Revista de Economía Aplicada, vol. XXI, núm. 62, otoño, recuperado de: http://www.revecap.com/revista/12/ 10/2017.

Geertz, C. (2003), La interpretación de las culturas, Barcelona, Gedisa.

Gómez, J. A. et al. (2013), Percepción social sobre el juego de azar en España 2013: IV, Madrid, Instituto de Política y Gobernanza, Universidad Carlos III de Madrid.

Gómez, J. A. et al. (2014), Percepción social sobre el juego de azar en España 2014: V, Madrid, Instituto de Política y Gobernanza, Universidad Carlos III de Madrid, recuperado de: http:// www.codere.com/uploads/media/default/0001/03/6424715e849f43016ad3dbb9775bc b5a25113e1e.pdf.

Gómez, J. A. et al. (2015), Percepción social sobre el juego de azar en España 2015: VI, Madrid, Instituto de Política y Gobernanza, Universidad Carlos III de Madrid, recuperado de: https:// www.fundacioncodere.org/publicaciones/percepcion-social-sobre-el-juego-de-azar-en-espana-2015-vi-informe.

Gómez, J. A. et al. (2016), Percepción social sobre el juego de azar en España 2016: VII, Madrid, Instituto de Política y Gobernanza, Universidad Carlos III de Madrid, recuperado de: http:// www.codere.com/uploads/media/default/0001/03/vii-informe-juego-2016-online.pdf.

Gómez, J. A. et al. (2017), Percepción social sobre el juego de azar en España 2017: VIII, Madrid, Instituto de Política y Gobernanza, Universidad Carlos III de Madrid, recuperado de: https:// www.fundacioncodere.org/wp-content/uploads/2017/07/viii-informe-juego-2017-online. pdf.

González del Rivero, L. (2000), "Las industrias de la suerte", en Semo, I. (coord.), La rueda del azar. Juegos y jugadores en la historia de México, México, Pronósticos para la Asistencia Pública. 
Este libro forma parte del acervo de la Biblioteca Jurídica Virtual del Instituto de Investigaciones Jurídicas de la UNAM

Grañén Porrúa, M. I. (1997), "Hermes y Moctezuma, un tarot mexicano del siglo XVI", Estudios de Cultura Náhuatl, núm. 27, recuperado de: http://www.historicas.unam.mx/publicacio nes/revistas/nahuatl/pdf/ecn27/530.pdf 16/11/2017.

Griffiths, M. (2001), "Internet Gambling: Preliminary Results of the First U.K. Prevalence Study", Journal of Gambling Issues, núm. 5, recuperado de: http://jgi.camh.net//index.php/jgi/ar ticle/view/3590/3550.

Griffiths, M. et al. (2010), "Online Poker Gambling in University Students: Further Findings from an Online Survey", International Journal of Mental Health and Addiction, vol. 8, núm. 1.

Griffiths, M. et al. (2012), "Internet Gambling: An Overview of Psychosocial Impacts", UNLV Gaming Research \& Review Journal, vol. 10, núm. 1.

Gundelach, P. y S. Kreiner (2004), "Happiness and Life Satisfaction in Advanced European Countries", Cross-Cultural Research, vol. 38, núm. 4.

Hayton, J. et al. (2004), "Factor Retention Decisions in Exploratory Factor Analysis: A Tutorial on Parallel Analysis", Organizational Research Methods, vol. 7, núm. 2.

Huesca Morales, Eric (1998), en mesa redonda "La historia de Internet en México", tomado de Gaceta UNAM, México, núm. 2694.

Huizinga, J. (2000), Homo ludens, México, Alianza-Emecé.

Inglehart, R. (1977), The Silent Revolution: Changing Values and Political Styles among Western Publics, Princeton University Press.

Instituto de Investigaciones Legislativas del Senado de la República (2003), Propuestas de reforma a la Ley Federal de Juegos y Sorteos, México, recuperado de: http://bibliodigitalibd. senado.gob.mx/bitstream/handle/123456789/1708/Ley_Juegos_Sorteos.pdf?sequence= 1\&isAllowed=y.

Instituto Mexicano de la Juventud-Universidad Nacional Autónoma de México (2012), Encuesta Nacional de Valores en Juventud 2012, México, INJUVE-UNAM, Instituto de Investigaciones Jurídicas.

Instituto Nacional de Estadística y Geografía (INEGI) (2010), Censo General de Población y Vivienda, 2010, México.

Instituto Nacional de Estadística y Geografía (INEGI) (2013), Encuesta Nacional de Gastos de los Hogares, México.

Instituto Nacional de Estadística y Geografía (INEGI) (2014), Encuesta Nacional sobre Uso del Tiempo, Tabulados básicos, México.

Instituto Nacional de Estadística y Geografía (INEGI) (2016), Encuesta Nacional sobre Disponibilidad y Uso de Tecnologías de la Información en los Hogares (ENDUTIH), México.

Instituto Nacional de Estadística y Geografía (INEGI) (2017a), Estadísticas a Propósito del Día Mundial de Internet, México, 17 de mayo, recuperado de: http://www.inegi.org.mx/salade prensa/aproposito/2017/internet2017_Nal.pdf.

Instituto Nacional de Informática y Geografía (INEGI) (2017b), Tablero de Indicadores Económicos del INEGI, México, recuperado de: http://www.inegi.org.mx/sistemas/tableroindeco/ presentacion.aspx.

Koszla-Szymanska, M. M. (2009), Supersticiones y creencias populares, Varsovia, Instituto de Estudios Ibéricos e Iberoamericanos-Universidad de Varsovia.

La Rosa, J. (1986), Escalas de locus de control y autoconcepto, tesis de doctorado, México, Facultad de Psicología, Universidad Nacional Autónoma de México. 
Este libro forma parte del acervo de la Biblioteca Jurídica Virtual del Instituto de Investigaciones Jurídicas de la UNAM

Lane, R. E. (2000), The Loss of Happiness in Market Democracies, New Haven, CT, Yale University Press.

Lara, L. F. (1996), Diccionario del español usual en México, México, El Colegio de México.

Lechner, N. (2002), "Los desafíos políticos del cambio cultural", Nueva Sociedad, núm. 184.

Liberalesso, N. A. (2002), "Bienestar subjetivo en la vida adulta y en la vejez: hacia una psicología positiva en América Latina", Revista Latinoamericana de Psicología, vol. 34, núm. 1-2.

Lorenzo, M. D. (2014), "De juego prohibido a negocio afortunado. Empresarios y políticos hacia una gestión pública de las loterías en México, 1915-1933", Tzintzun. Revista de Estudios Históricos, núm. 60, julio-diciembre, recuperado de: http://www.scielo.org.mx/scielo. php?script=sci_arttext\&pid=S1870-719X2014000200007.

Lucas, R. E. et al. (1996), "Discriminant Validity of Well-Being Measures", Journal of Personality and Social Psychology, núm. 71.

Malinowsky, B. (1965) [1931], "La Cultura", Encyclopedia of Social Sciences, México, CIESASUAM-UIA, colección Clásicos y Contemporáneos en Antropología, recuperado de: http//: www.ciesas.edu.mx/Publicaciones/Clasicos/Index.html.

Martínez, F. (2014), "Operan en México más casinos que universidades", La Jornada, 15 de septiembre, recuperado de: http://www.jornada.unam.mx/2014/09/15/politica/013n1pol.

Massolo, M. (1994), "El estudio de la religiosidad popular en Latinoamérica y Europa: perspectivas recientes", en Frigerio, A. y M. Carozzi, El estudio científico de la religión a fines del siglo XX, Buenos Aires, CEAL.

Mazur, J. (2010), What's Luck Got to Do with it the History, Mathematics, and Psychology of the Gambler's Illusion, Nueva Jersey, Princeton University Press.

McGurrin, M. C. (1992), Pathological Gambling: Conceptual, Diagnostic, and Treatment Issues, Sarasota, FL, Professional Resource Press.

Menard, A. (2015), "La etnohistoria, el suplemento y la superstición", Diálogo Andino, núm. 46. Morales, L. G. (2000), "El juego de los dioses", en Semo, I. (coord.), La rueda del azar. Juegos y jugadores en la historia de México, México, Pronósticos para la Asistencia Pública.

Mouzo Quintáns, J. (2017), "Los juegos 'online' atrapan al 25\% de los nuevos ludópatas", El País, 21 de octubre, recuperado de: https://elpais.com/ccaa/2017/10/21/catalunya/ 1508605260_498710.html.

NatCen (2011), British Gambling Prevalence Survey 2010, Reino Unido, National Center for Social Research (NatCen).

Nový, M. et al. (2017), "Inglehart's Scarcity Hypothesis Revisited: Is Postmaterialism a Macro-or Micro-Level Phenomenon around the World?", International Sociology, vol. 32, núm. 6.

Nunnally, J. C. y Bernstein, I. H. (1994), Psychometric Theory, Nueva York, McGraw-Hill.

Ochoa, M. (2013), "Radiografía de los casinos en México", Forbes, 13 de mayo, recuperado de: https://www.forbes.com.mx/radiografia-de-los-casinos-en-mexico.

Organización Panamericana de la Salud-Organización Mundial de la Salud (2011), Informe sobre el Sistema de Salud Mental en México, México, OPS-OMS, recuperado de: http://www. who.int/mental_health/who_aims_country_reports/who_aims_report_mexico_es.pdf.

Organización para la Cooperación y el Desarrollo Económicos (OCDE) (2017a), Estudios económicos de la OCDE: México, recuperado de: https://www.oecd.org/eco/surveys/mexico-2017-OECD-Estudios-economicos-de-la-ocde-vision-general.pdf. 
Este libro forma parte del acervo de la Biblioteca Jurídica Virtual del Instituto de Investigaciones Jurídicas de la UNAM

Organización para la Cooperación y el Desarrollo Económicos (OCDE) (2017b), OECD. Data: Hours Worked, recuperado de: https://data.oecd.org/emp/hours-worked.htm.

Phillips, D. L. y K. J. Clancy (1972), "Some Effects of Social Desirability. Survey Studies", American Journal of Sociology, vol. 77, núm. 5.

Poushter, J. (2016), "Smartphone Ownership and Internet Usage Continues to Climb in Emerging Economies", Pew Research Center, 22 de febrero, disponible en: http://www.pewglobal.org /2016/02/22smartphone-ownership-and-internet-usage-continues-to-climb-in-emer ging-economies.

Reith, G. y The Scottish Centre for Social Research (2006), "Research on the Social Impacts of Gambling", Scottish Executive Social Research, recuperado de: www.scotland.gov.uk/so cialresearch.

Rescher, N. (1997), La suerte. Aventuras y desventuras de la vida cotidiana, Santiago de Chile, Andrés Bello.

Reyes, J. J. (1997), Cuestión de suerte, México, Clío.

Rojo, B. F. A. (2009), La ogra de arte como fetiche contemporáneo, Medellín, Instituto Tecnológico Metropolitano.

Rostas, S. y A. Droogers (1995), "El uso popular de la religión popular en América Latina: una introducción", Revista Alteridades, vol. 5, núm. 9.

Rotter, J. B. (1966), "Generalized Expectancies for Internal versus External Control of Reinforcement", Psychological Monographs, núm. 80.

Rueda, E. (2016), ¿Casinos en México? Análisis sobre su apertura, México, Universidad Nacional Autónoma de México, Instituto de Investigaciones Jurídicas, recuperado de: https://archi vos.juridicas.unam.mx/www/bjv/libros/6/2803/6.pdf.

Ruiz, F. J. (coord.) (2012), Tercer informe sobre la percepción social respecto al juego de azar en España, Madrid, Instituto de Política y Gobernanza, Universidad Carlos III de Madrid.

Ruiz, F. J. et al. (2011), Segundo informe sobre la percepción social respecto al juego de azar en España, Madrid, Instituto de Política y Gobernanza, Universidad Carlos III de Madrid.

Sánchez, Y. (2013), "Centros de diversión en Mexicali. Los primeros años", El Río, Revista de Historia Regional de Mexicali y su Valle, año VI, núm. 19, enero-marzo.

Scheff, T. (1990), Microsociology. Discurse, Emotion and Social Structure, Chicago, The University of Chicago Press.

Scheu, D. (1996), "Creencias y mitos en el uso del número en tres culturas europeas", Revista Murciana de Antropología, núm. 3.

Schiffman, L. G. y L. Lazar Kanuk (2010), Comportamiento del consumidor, 10ª ed., México, Pearson.

Semo, I. (2000), "Azar y melancolía", en Semo, I. (coord.), La rueda del azar. Juegos y jugadores en la historia de México, México, Pronósticos para la Asistencia Pública.

Shelley, J. A. (2012), "La trampa mortal de los casinos", Casa del Tiempo, núm. 54, abril, recuperado de: http://www.uam.mx/difusion/casadeltiempo/54_v_abr_2012/casa_del_tiempo_ elV_num_54_36_38.pdf.

Steiner, F. B. (2001), ¿Cómo definir la superstición? De la función al significado, escritos de antropología social, Lima, UNMSM, Fondo Editorial. 
Este libro forma parte del acervo de la Biblioteca Jurídica Virtual del Instituto de Investigaciones Jurídicas de la UNAM

Tépach, M. R. (2004), La instalación y operación de casinos en México: análisis de iniciativas y opinión pública, México, Cámara de Diputados. LIX Legislatura, recuperado de: http:// www. diputados.gob.mx/sedia/sia/se/SIA-DEC-ISS-07-04.pdf.

Tépach, M. R. (2010), "Análisis de las iniciativas en materia de juegos con apuestas presentadas al Congreso de la Unión", en Mora-Donatto, Cecilia (coord.), Juegos de azar. Una visión multidisciplinaria, México, Universidad Nacional Autónoma de México, Instituto de Investigaciones Jurídicas.

Thomas, M. et al. (2011), "How Credit Card Payments Increase Unhealthy Food Purchases: Visceral Regulation ofVices", Journal of Consumer Research, vol. 38, núm. 1, DOI:10.1086/657331.

Thomassen, B. (2014), Liminality and the Modern: Living through the in-between, Copenhague, Ashgate.

Van't Hooft, A. (2016), "Alec Dempster. Lotería Huasteca: Woodblock Prints", Revista de Literaturas Populares, año XVI, núm. 1-2, enero-diciembre, recuperado de: http://www.rlp.cultu raspopulares.org/textos/31/15_vant.pdf.

Vázquez, A. (1989), "Aproximación a la magia, la brujería y la superstición en la Antigüedad", Espacio, Tiempo y Forma, serie II, HF Antigua, t. II.

Vázquez, M. A. (2000), "La república ludens", en Semo I. (coord.), La rueda del azar. Juegos y jugadores en la historia de México, México, Pronósticos para la Asistencia Pública.

Veenhoven, R. (1991), "Is Happiness Relative?", Social Indicators Research, núm. 24.

Veenhoven, R. (2008), "Healthy Happiness: Effects of Happiness on Physical Health and the Consequences for Preventive Health Care", Journal of Happiness Studies, vol. 9, núm. 3.

Velasco, M. P. W. et al. (2015), "Construcción y validación de una escala de locus de control-bienestar subjetivo", Psicología Iberoamericana, vol. 23, núm. 2.

Villalobos, E. (2017), "Apuestas online se regulan con ley de 1947", El Universal, México, 28 de julio, recuperado de: http://www.eluniversal.com.mx/articulo/cartera/economia/2017/07/ 28/apuestas-online-se-regulan-con-ley-de-1947.

Wardle, H. et al. (2011), Britsh Gambling Prevalence Survey 2010, Londres, National Centre for Social Research.

Weber, M. (1998), Economía y sociedad, México, Fondo de Cultura Económica.

Weiss, R. S. (1973), Loneliness: The Experience of Emotional and Social Isolation, Cambridge, The MIT Press.

Williams, R. J. et al. (2011), The Social and Economic Impacts of Gambling. Final Report prepared for the Canadian Consortium for Gambling Research, 11 de marzo.

World Health Organization (1993), ICD-10 Classification of Mental and Behavioural Disorders: Clinical Descriptions and Diagnostic Guidelines, Ginebra, recuperado de: http://www.who. int/classifications/icd/en/GRNBOOK.pdf?ua $=1 \& u a=1$.

Zaller, J. (1992), The Nature and Origins of Mass Opinion, Nueva York, Cambridge University Press. 
Este libro forma parte del acervo de la Biblioteca Jurídica Virtual del Instituto de Investigaciones Jurídicas de la UNAM

\section{ÍNDICE \\ DE GRÁFICAS}

GRÁFICA 2.1

¿A qué religión, creencia o culto pertenece usted?

GRÁFICA 2.2

¿Cree usted en...?

GRÁFICA 2.3

Índice de disponibilidad léxica

Dígame, por favor, tres palabras que asocie con la palabra suerte

GRÁFICA 2.4

Todos tenemos algunas creencias, por ejemplo, ¿usted acostumbra evitar...?

\section{GRÁFICA 2.5}

¿Tiene usted algún objeto que le dé buena suerte?

GRÁFICA 2.6

Índice de supersticiones

GRÁFICA 2.7

Pensando en su vida, ¿qué tan satisfecho o insatisfecho está con la vida que ha llevado hasta hoy?

\section{GRÁFICA 2.8}

Algunas personas piensan que pueden decidir y elegir libremente su futuro; en cambio, otras personas piensan que no tienen influencia sobre su futuro. En una escala de 0 a 10, en donde 0 es nada y 10 es mucho, ¿qué tanto cree usted que puede decidir su futuro? 
Este libro forma parte del acervo de la Biblioteca Jurídica Virtual del Instituto de Investigaciones Jurídicas de la UNAM

\section{GRÁFICA 2.9}

¿Qué tanto cree usted que puede decidir su futuro?

\section{GRÁFICA 2.10}

Según su experiencia, para tener una buena posición en el trabajo, ¿qué cree que sea más importante, el esfuerzo de cada persona

o los contactos que tenga?

GRÁFICA 2.11

Imagine que en las próximas semanas usted tuviera la oportunidad de realizar alguno de sus sueños, ¿cuál sueño realizaría?

GRÁFICA 2.12

¿Qué tan confiado o desconfiado se siente que en el futuro va a poder realizar sus proyectos más anhelados?

\section{GRÁFICA 2.13}

¿Qué tan de acuerdo o en desacuerdo está usted con la siguiente afirmación?

El futuro es tan incierto que es mejor vivir cada día como si fuera el último

GRÁFICA 2.14

De las siguientes condiciones, ¿cuál considera que es más importante para tener éxito en la vida?

GRÁFICA 3.1

Comparada con la situación económica que tenía el país hace un año, ¿cómo diría usted que es la situación económica actual del país: mejor o peor?

\section{GRÁFICA 3.2}

¿Cree usted que en el próximo año la situación económica del país

va a mejorar o va a empeorar?

GRÁFICA 3.3

De las siguientes palabras, ¿con cuál está usted más de acuerdo para describir la situación política del país?

GRÁFICA 3.4

¿Y cree usted que en el próximo año la situación política del país va a mejorar o va a empeorar?

GRÁFICA 3.5

Comparada con la situación económica que tenía usted hace un año, ¿cómo diría que es su situación económica actual: mejor o peor?

\section{GRÁFICA 3.6}

En general, ¿cree usted que en el próximo año su situación económica va a mejorar o va a empeorar?

GRÁFICA 3.7

De lo que usted gana, ¿cuánto aporta para la manutención de su hogar?

GRÁFICA 3.8

¿Si usted tiene un dinero guardado, se lo dice...?

GRÁFICA 3.9

¿Sabe usted o no cuánto gana su...? 
Este libro forma parte del acervo de la Biblioteca Jurídica Virtual del Instituto de Investigaciones Jurídicas de la UNAM

\section{GRÁFICA 3.10}

Si usted tuviera dinero ahorrado para la fiesta de quince años de una hija suya, pero se le presentara un buen negocio, usted: ¿haría la fiesta o invertiría en el negocio?

\section{GRÁFICA 3.11}

Promedio de horas trabajadas en 35 países de la OCDE en 2016

GRÁFICA 3.12

¿Con cuánto tiempo libre cuenta aproximadamente a la semana para hacer las cosas que más le gustan?

GRÁFICA 3.13

Por favor, dígame tres actividades que prefiere hacer en su tiempo libre

GRÁFICA 3.14

Y dígame, ¿usted acostumbra apostar?

GRÁFICA 3.15

¿Acostumbra participar en rifas o sorteos?

GRÁFICA 3.16

¿Usted está registrado en alguna página de apuestas por Internet?

GRÁFICA 3.17

Por lo que usted sabe, ¿los juegos de apuesta y sorteo están o no están regulados por la ley?

GRÁFICA 3.18

¿Quién los regula?

GRÁFICA 3.19

Y, ¿los casinos son o no son legales en México?

GRÁFICA 3.20

Y si se aprobaran estas medidas en nuestro país, ¿usted tendría más confianza

o menos confianza para participar en los juegos de apuesta y sorteos?

\section{GRÁFICA 3.21}

Índice de disponibilidad léxica

Dígame, por favor, tres palabras que asocie con la palabra "CASINO"

GRÁFICA 3.22

¿Y usted cree que ... tengan vínculos o no con los juegos de apuestas y sorteos?

GRÁFICA 3.23

¿Alguna vez ha asistido usted a un casino?

GRÁFICA 3.24

¿Asistió a un casino durante el último año?

GRÁFICA 3.25

Generalmente, ¿cuál es su forma de pago en el casino?

GRÁFICA 3.26

¿Ha tenido algún problema o inconveniente dentro del casino? 
Este libro forma parte del acervo de la Biblioteca Jurídica Virtual del Instituto de Investigaciones Jurídicas de la UNAM

GRÁFICA 4.1

Intervalos de confianza de las proporciones de jugadores según sexo

\section{GRÁFICA 4.2}

Intervalos de confianza de las proporciones de jugadores

según grupos de edad

GRÁFICA 4.3

Intervalos de confianza de las proporciones según escolaridad y línea de media nacional

GRÁFICA 4.4

Intervalos de confianza de las proporciones según condición de actividad y línea de media nacional

GRÁFICA 4.5

Intervalos de confianza de las proporciones según condición de actividad

GRÁFICA 4.6

Análisis de correspondencias múltiples

GRÁFICA 5.1

¿Usted acostumbra apostar?

GRÁFICA 5.2

¿Acostumbra participar en rifas o sorteos?

GRÁFICA 5.3

¿Qué es lo que le motiva principalmente para ir a jugar?

GRÁFICA 5.4

Durante los últimos doce meses, ¿alguna vez ha jugado en exceso?

GRÁFICA 5.5

¿Alguna vez alguien le ha dicho que tiene una adicción al juego?

GRÁFICA 5.6

Y, ¿alguna vez algún especialista lo ha diagnosticado con adicción al juego?

GRÁFICA 5.7

Distribución de la población encuestada por grupo de jugadores

GRÁFICA 5.8

Grupos de jugadores por sexo

GRÁFICA 6.1

¿Usted conoce o no conoce...?

Juegos por Internet (póquer, loterías, etcétera)

(encuesta en vivienda)

GRÁFICA 6.2

¿Usted ha participado o comprado un boleto...?

Juegos por internet (póquer, loterías, etcétera)

(encuesta en vivienda)

GRÁFICA 6.3

Biplot del análisis de correspondencias múltiples

Intensidad de juego 
Este libro forma parte del acervo de la Biblioteca Jurídica Virtual del Instituto de Investigaciones Jurídicas de la UNAM

\section{GRÁFICA 6.4}

¿Qué es lo que le motiva principalmente para jugar?

\section{GRÁFICA 6.5}

Biplot del análisis de correspondencias múltiples

Motivaciones para jugar por Internet

GRÁFICA 6.6

De estos juegos, ¿con cuál considera que se puede ganar más dinero?

GRÁFICA 6.7

De todos estos juegos por Internet, ¿cuál es el que más le gusta?

\section{GRÁFICA 6.8}

Y de esos juegos, ¿cuáles ha jugado en persona, es decir, asistiendo a locales como casinos, comprando billetes o cupones, con amigos en casa, etcétera?

GRÁFICA 6.9

En un día en el que apuesta, en promedio ¿cuánto tiempo dedica para jugar en Internet?

GRÁFICA 6.10

Respecto al tiempo que apuesta en Internet, ¿diría que...?

\section{GRÁFICA 6.11}

Generalmente, ¿en qué lugar está cuando apuesta por Internet?

GRÁFICA 6.12

¿En qué momento del día juega normalmente?

GRÁFICA 6.13

¿Normalmente juega entre semana o el fin de semana?

GRÁFICA 6.14

¿En qué tipo de dispositivo apuestas más por Internet?

GRÁFICA 6.15

A. Y en promedio en un mes, ¿cuánto dinero gasta apostando por Internet?

B. Y al mes, aproximadamente, ¿cuánto gana con estos juegos de apuesta por Internet?

GRÁFICA 6.16

Y en su experiencia, ¿ha perdido más de lo que pensaba gastar jugando/apostando en juegos por Internet?

GRÁFICA 6.17

Generalmente, ¿cuál es su forma de pago en el casino?

(encuesta en vivienda)

GRÁFICA 6.18

Generalmente, ¿cuál es su forma de pago cuando compra/apuesta por Internet?

(encuesta en línea)

GRÁFICA 6.19

¿Ha tenido algún problema o inconveniente dentro del casino?

(encuesta en vivienda) 
Este libro forma parte del acervo de la Biblioteca Jurídica Virtual del Instituto de Investigaciones Jurídicas de la UNAM www.juridicas.unam.mx

\section{GRÁFICA 6.20}

¿Alguna vez ha tenido algún problema al jugar sorteos o apostar por Internet?

(encuesta en línea)

GRÁFICA 6.21

Del 8.5 por ciento que contestó que Sí, ¿cuáles problemas?

(encuesta en vivienda)

GRÁFICA 6.22

¿Usted está registrado en alguna página de apuestas por Internet?

(encuesta en vivienda)

GRÁFICA 6.23

¿Está registrado en alguna página de apuestas por Internet?

(encuesta en línea)

\section{GRÁFICA 6.24}

Por lo que usted sabe, ¿los juegos de apuesta y sorteo por Internet son legales o no en México?

GRÁFICA 6.25

En general, ¿qué tanto confía en las casas de apuesta o casinos

por Internet que conoce?

GRÁFICA 6.26

Índice de juego problemático en línea

GRÁFICA 6.27

Durante los últimos doce meses, ¿alguna vez ha jugado en exceso?

(encuesta en vivienda)

\section{GRÁFICA 6.28}

Durante los últimos doce meses, ¿alguna vez ha sentido que ha jugado en exceso?

(encuesta en línea)

GRÁFICA 6.29

¿Alguna vez alguien le ha dicho que tiene una adicción al juego?

GRÁFICA 6.30

Y, ¿alguna vez algún especialista lo ha diagnosticado con adicción al juego?

GRÁFICA 6.31

¿Por qué no ha participado en juegos de apuesta por Internet apostando dinero?

GRÁFICA 6.32

Biplot del análisis de correspondencias múltiples

Motivaciones posibles para jugar

GRÁFICA 6.33

¿En qué tipo de dispositivo apuestas más por Internet?

vs. ¿En qué dispositivo apostaría si jugara?

GRÁFICA 6.34

¿En qué momento del día juega normalmente?

vs. ¿En qué momento del día jugaría? 
Este libro forma parte del acervo de la Biblioteca Jurídica Virtual del Instituto de Investigaciones Jurídicas de la UNAM www.juridicas.unam.mx

\section{GRÁFICA 6.35}

¿Normalmente juega entre semana o el fin de semana?

vs. ¿Usted cree que jugaría...?

\section{GRÁFICA 6.36}

¿Qué es lo que le motiva principalmente para jugar?

vs. ¿Qué es lo que lo motivaría principalmente a jugar por Internet? 
Este libro forma parte del acervo de la Biblioteca Jurídica Virtual del Instituto de Investigaciones Jurídicas de la UNAM

\section{ÍNDICE \\ DE CUADROS}

CUADRO 2.1

Índice de disponibilidad léxica

Dígame, por favor, tres palabras que asocie con suerte

CUADRO 2.2

Religiones y práctica de juego

CUADRO 2.3

¿Cree usted ...?

CUADRO 2.4

Supersticiones, rituales y prácticas de juego

CUADRO 2.5

¿Tiene usted algún objeto que le dé buena suerte?

CUADRO 2.6

Pensando en su vida, ¿qué tan satisfecho o insatisfecho está con la vida que ha llevado hasta hoy?

\section{CUADRO 2.7}

En orden de importancia, según su experiencia, para tener una buena posición en el trabajo, ¿qué cree que sea más importante?

CUADRO 2.8

Imagine que en las próximas semanas usted tuviera la oportunidad de realizar alguno de sus sueños, ¿cuál sueño realizaría? 
Este libro forma parte del acervo de la Biblioteca Jurídica Virtual del Instituto de Investigaciones Jurídicas de la UNAM

\section{CUADRO 2.9}

¿Qué tan confiado o desconfiado se siente que en el futuro

va a poder realizar sus proyectos más anhelados?

CUADRO 2.10

¿Qué tan de acuerdo o en desacuerdo está usted con la siguiente afirmación?

El futuro es tan incierto que es mejor vivir cada día como si fuera el último

CUADRO 2.11

De las siguientes condiciones, ¿cuál considera que es más importante para tener éxito en la vida?

\section{CUADRO 2.12}

Ahora, pensando en sus relaciones personales, por favor dígame qué tanto se siente...

CUADRO 2.13

¿Qué tanto se siente...? cercano a otras personas

CUADRO 2.14

¿Qué tanto se siente...? que le hace falta compañía

CUADRO 2.15

¿Qué tanto se siente...? parte de un grupo de amigos

CUADRO 3.1

¿Cómo diría usted que es la situación económica actual del país: mejor o peor?

CUADRO 3.2

¿Cree usted que en el próximo año la situación económica del país

va a mejorar o va a empeorar?

\section{CUADRO 3.3}

De las siguientes palabras, ¿con cuál está usted más de acuerdo para describir la situación política del país?

CUADRO 3.4

¿Y cree usted que en el próximo año la situación política del país va a mejorar o va a empeorar?

CUADRO 3.5

Comparada con la situación económica que tenía usted hace un año, ¿cómo diría que es su situación económica actual: mejor o peor?

CUADRO 3.6

¿Cree usted que en el próximo año su situación económica

va a mejorar o va a empeorar?

\section{CUADRO 3.7}

De lo que usted gana, ¿cuánto aporta para la manutención de su hogar?

\section{CUADRO 3.8}

¿Si usted tiene un dinero guardado, se lo dice a...? Jugó al menos un juego en el último año

CUADRO 3.9

¿Sabe usted o no cuánto gana...? Jugó al menos un juego en el último año 
Este libro forma parte del acervo de la Biblioteca Jurídica Virtual del Instituto de Investigaciones Jurídicas de la UNAM

\section{CUADRO 3.10}

Si usted tuviera dinero ahorrado para la fiesta de quince años de una hija suya, pero se le presentara un buen negocio, usted: ¿haría la fiesta o invertiría en el negocio? Según prácticas de juego

CUADRO 3.11

Por favor, dígame tres actividades que prefiere hacer en su tiempo libre

CUADRO 3.12

Y dígame, ¿usted acostumbra apostar?

CUADRO 3.13

¿Usted conoce o no conoce...?

CUADRO 3.14

¿Usted ha participado o comprado un boleto?

CUADRO 3.15

¿Qué tan de acuerdo o en desacuerdo está con las siguientes frases?

CUADRO 3.16

Por lo que usted sabe, ¿los juegos de apuesta y sorteo están o no están regulados por la ley?

CUADRO 3.17

¿Quién los regula?

CUADRO 3.18

Y, ¿los casinos son o no son legales en México?

\section{CUADRO 3.19}

En caso de crearse una nueva ley, ¿usted está de acuerdo o en desacuerdo con las siguientes medidas?

\section{CUADRO 3.20}

En caso de crearse una nueva ley, ¿usted está de acuerdo o en desacuerdo con las siguientes medidas?

\section{CUADRO 3.21}

Y si se aprobaran estas medidas en nuestro país, ¿usted tendría más

confianza o menos confianza para participar en los juegos de apuesta y sorteos?

\section{CUADRO 3.22}

Podría decirme por favor las tres primeras PALABRAS que le vienen a la mente cuando escucha la palabra "CASINO"

CUADRO 3.23

¿Usted cree que ... tengan vínculos o no con los juegos de apuestas y sorteos?

Jugó al menos un juego en el último año

CUADRO 3.24

¿Usted ha asistido a un casino?

CUADRO 3.25

¿Asistió a un casino durante el último año? Distribución sociodemográfica 
Este libro forma parte del acervo de la Biblioteca Jurídica Virtual del Instituto de Investigaciones Jurídicas de la UNAM

\section{CUADRO 3.26}

Asistencia a casinos durante el último año de acuerdo con la condición

de actividad. Jugó en un casino durante el último año

CUADRO 4.1

Clasificación de los tipos de juego

CUADRO 4.2

Porcentaje de participación según el juego más reciente

CUADRO 4.3

Porcentajes de jugadores según tipo de juego: lotería tradicional mexicana, juegos de cartas y juegos tradicionales

CUADRO 4.4

Porcentajes de jugadores según tipo de juego: Lotería Nacional y pronósticos

CUADRO 4.5

Porcentajes de jugadores según tipo de juego: sala de juego

CUADRO 4.6

Porcentajes de jugadores según tipo de juego: sala de juego

CUADRO 4.7

Frecuencia de juego

CUADRO 4.8

Condición de apuesta según principales variables sociodemográficas

CUADRO 4.9

Juegos estudiados en la encuesta

CUADRO 4.10

Distribución de porcentajes de condición de juego

CUADRO 5.1

Ítems del juego problemático en México tomados del DSM-IV

CUADRO 5.2

Grupos de jugadores según el índice de juego problemático

\section{CUADRO 5.3}

¿Con qué frecuencia usted piensa en jugar, es decir, recordando apuestas anteriores, planificando la próxima vez que jugará?

CUADRO 5.4

Distribución de jugadores del modelo dicotómico según el tipo de juegos

CUADRO 6.1

Perfil de los usuarios que contestaron la encuesta en línea

CUADRO 6.2

Los juegos más conocidos

CUADRO 6.3

Los juegos más jugados 
Este libro forma parte del acervo de la Biblioteca Jurídica Virtual del Instituto de Investigaciones Jurídicas de la UNAM www.juridicas.unam.mx

\section{CUADRO 6.4}

Características sociodemográficas de cada juego

\section{CUADRO 6.5}

Juegos jugados más recientemente

\section{CUADRO 6.6}

Juegos jugados más frecuentemente

\section{CUADRO 6.7}

Perfil de las personas entrevistadas en línea 
Este libro forma parte del acervo de la Biblioteca Jurídica Virtual del Instituto de Investigaciones Jurídicas de la UNAM

\section{ANEXO 1 \\ PERFIL SOCIODEMOGRÁFICO}

\section{SEXO}

En la Encuesta Nacional de Percepciones Sociales de los Juegos de Azar en México se entrevistó a un total de 1,200 personas con edades de 18 años y más. El 52.9 por ciento de los entrevistados fueron mujeres y 47.1 por ciento fueron hombres (véase gráfica 1).

\section{EDAD}

En cuanto a la distribución por edad, el mayor porcentaje de las personas entrevistadas se concentró entre los 25 y 34 años (24.6 por ciento), seguido de las personas de entre 35 y 44 años (21.4 por ciento) y las personas de 18 a 24 años de edad (19.4 por ciento). Con porcentajes menores se entrevistó a personas de 45 a 54 años (15.4 por ciento), y un 9.6 por ciento corresponde a personas de 55 a 64 años y personas de 65 años y más, respectivamente (véase gráfica 2). La edad promedio de las personas entrevistadas fue de 39.9 años. 
Este libro forma parte del acervo de la Biblioteca Jurídica Virtual del Instituto de Investigaciones Jurídicas de la UNAM www.juridicas.unam.mx

\section{GRÁFICA 1}

\section{SEXO}

(PORCENTAJES)

Fuente: Encuesta Nacional de Percepciones Sociales de los Juegos de Azar en México, México, UNAM, Instituto de Investigaciones Jurídicas, Departamento de Investigación Aplicada y Opinión, 2016.

\section{GRÁFICA 2}

DISTRIBUCIÓN PORCENTUAL DE LA POBLACIÓN ENCUESTADA SEGÚN GRUPOS DE EDAD (PORCENTAJES)

\section{Promedio: 39.9 años}

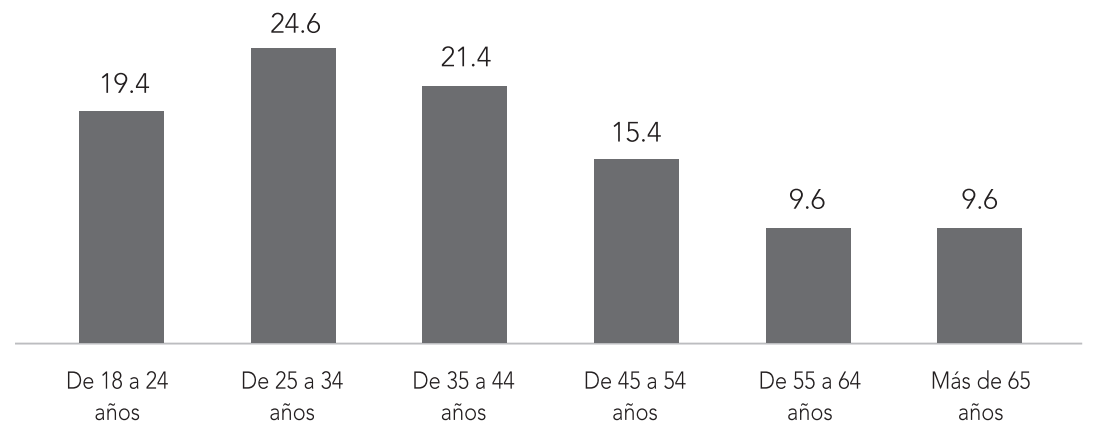

Fuente: Encuesta Nacional de Percepciones Sociales de los Juegos de Azar en México, México, UNAM, Instituto de Investigaciones Jurídicas, Departamento de Investigación Aplicada y Opinión, 2016.

\section{ESCOLARIDAD}

Referente a la escolaridad de las personas entrevistadas, más de la mitad cuenta con educación media y media superior: el 31.9 por ciento tiene pre- 
Este libro forma parte del acervo de la Biblioteca Jurídica Virtual del Instituto de Investigaciones Jurídicas de la UNAM

paratoria o bachillerato y el 28.9 por ciento tiene escolaridad secundaria. En porcentajes menores se entrevistó a personas que cuentan con primaria (14.7 por ciento), con nivel licenciatura (13.5 por ciento) y 7.3 por ciento con carrera técnica (véase gráfica 3).

\section{GRÁFICA 3}

DISTRIBUCIÓN PORCENTUAL DE LA POBLACIÓN ENCUESTADA SEGÚN NIVEL DE ESCOLARIDAD (PORCENTAJES)

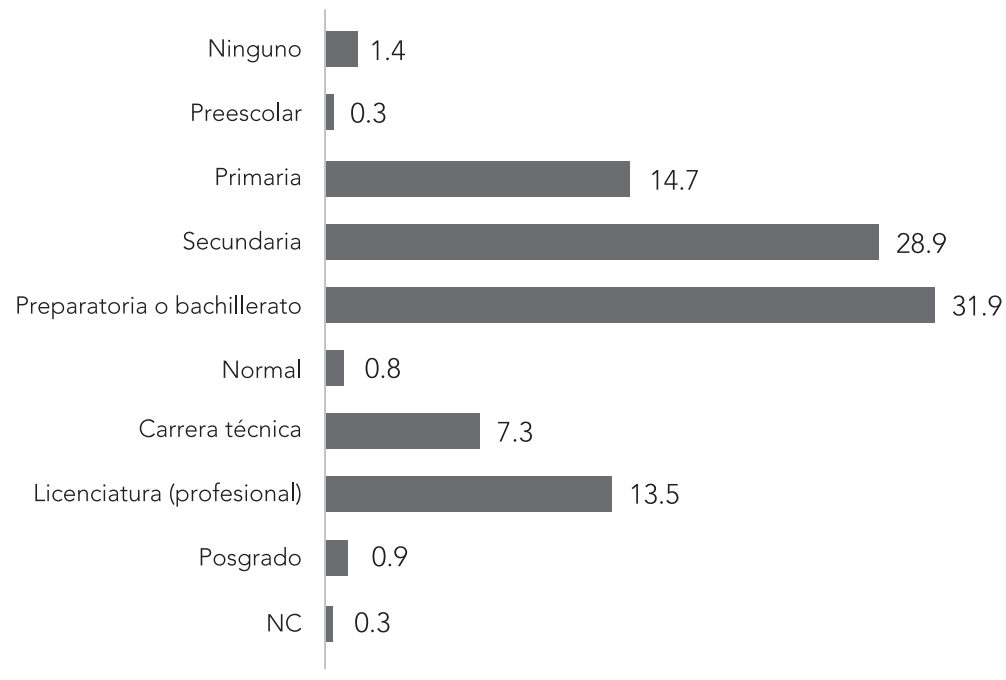

Fuente: Encuesta Nacional de Percepciones Sociales de los Juegos de Azar en México, México, UnAm, Instituto de Investigaciones Jurídicas, Departamento de Investigación Aplicada y Opinión, 2016.

\section{ESTADO CIVIL}

Acerca del estado civil de las personas entrevistadas, casi la mitad dijo estar casado(a) (45.8 por ciento); dos de cada diez, respectivamente, dijeron estar solteros(as) (22.0 por ciento) o que viven con su pareja en unión libre (21.6 por ciento); en porcentajes menores, las personas entrevistadas informaron estar viudos(as), separados(as) o divorciados(as) (véase gráfica 4). 
Este libro forma parte del acervo de la Biblioteca Jurídica Virtual del Instituto de Investigaciones Jurídicas de la UNAM www.juridicas.unam.mx

GRÁFICA 4

DISTRIBUCIÓN PORCENTUAL DE LA POBLACIÓN ENCUESTADA SEGÚN ESTADO CIVIL (PORCENTAJES)

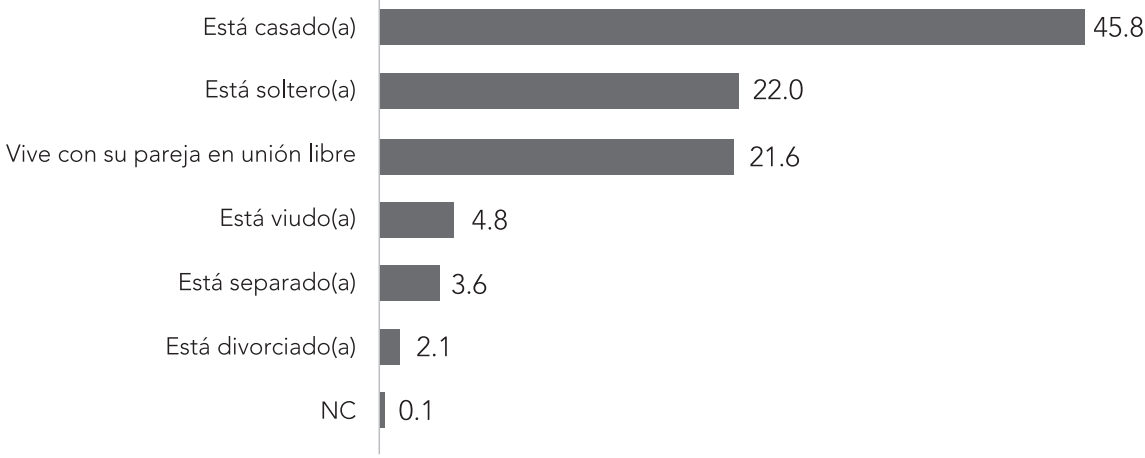

Fuente: Encuesta Nacional de Percepciones Sociales de los Juegos de Azar en México, México, UNAM, Instituto de Investigaciones Jurídicas, Departamento de Investigación Aplicada y Opinión, 2016.

\section{NÚMERO DE HIJOS}

Por su parte, una gran mayoría de las personas entrevistadas informó que sí tiene hijos (71.1 por ciento). De estas personas, una tercera parte tiene 2 hijos(as) (33.1 por ciento); dos de cada diez tienen 1 hijo(a) (22.0 por ciento) y 3 hijos(as) (20.2 por ciento), respectivamente (véase gráfica 5).

\section{CONDICIÓN DE ACTIVIDAD}

El perfil socioeconómico distingue la actividad que desempeñan y el ingreso de las personas entrevistadas. Poco más de la mitad de las personas entrevistadas dijo que la semana pasada trabajo para obtener ingresos (56.5 por ciento), dos de cada diez informaron que se dedican a los quehaceres de su hogar (22.8 por ciento), uno de cada diez es estudiante (9.7 por ciento), y con menores porcentajes dijeron ser jubilados o pensionados (5.3 por ciento) (véase gráfica 6). 
Este libro forma parte del acervo de la Biblioteca Jurídica Virtual del Instituto de Investigaciones Jurídicas de la UNAM www.juridicas.unam.mx

\section{GRÁFICA 5}

\section{DISTRIBUCIÓN PORCENTUAL DE LA POBLACIÓN ENCUESTADA SEGÚN NÚMERO DE HIJOS} (PORCENTAJES)

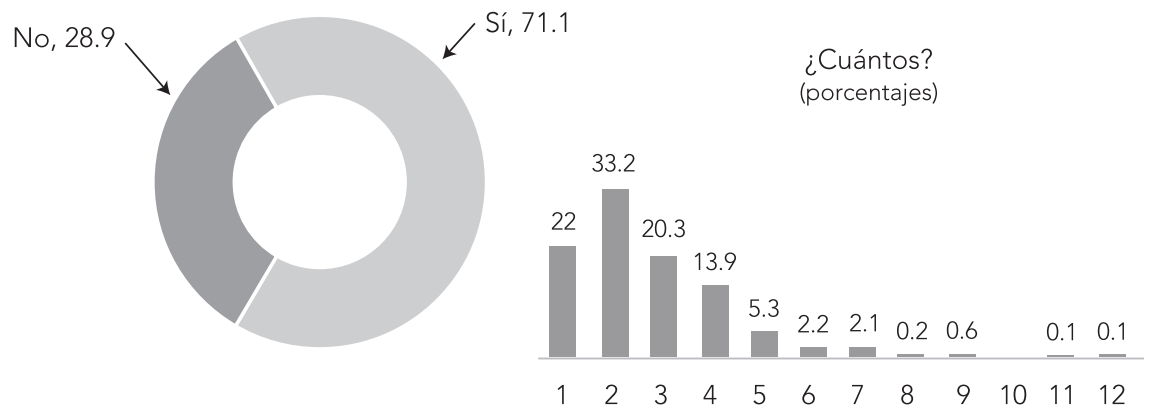

Fuente: Encuesta Nacional de Percepciones Sociales de los Juegos de Azar en México, México, UNAM, Instituto de Investigaciones Jurídicas, Departamento de Investigación Aplicada y Opinión, 2016.

\section{GRÁFICA 6}

\section{DISTRIBUCIÓN PORCENTUAL DE LA POBLACIÓN ENCUESTADA SEGÚN SU CONDICIÓN DE ACTIVIDAD \\ (PORCENTAJES)}

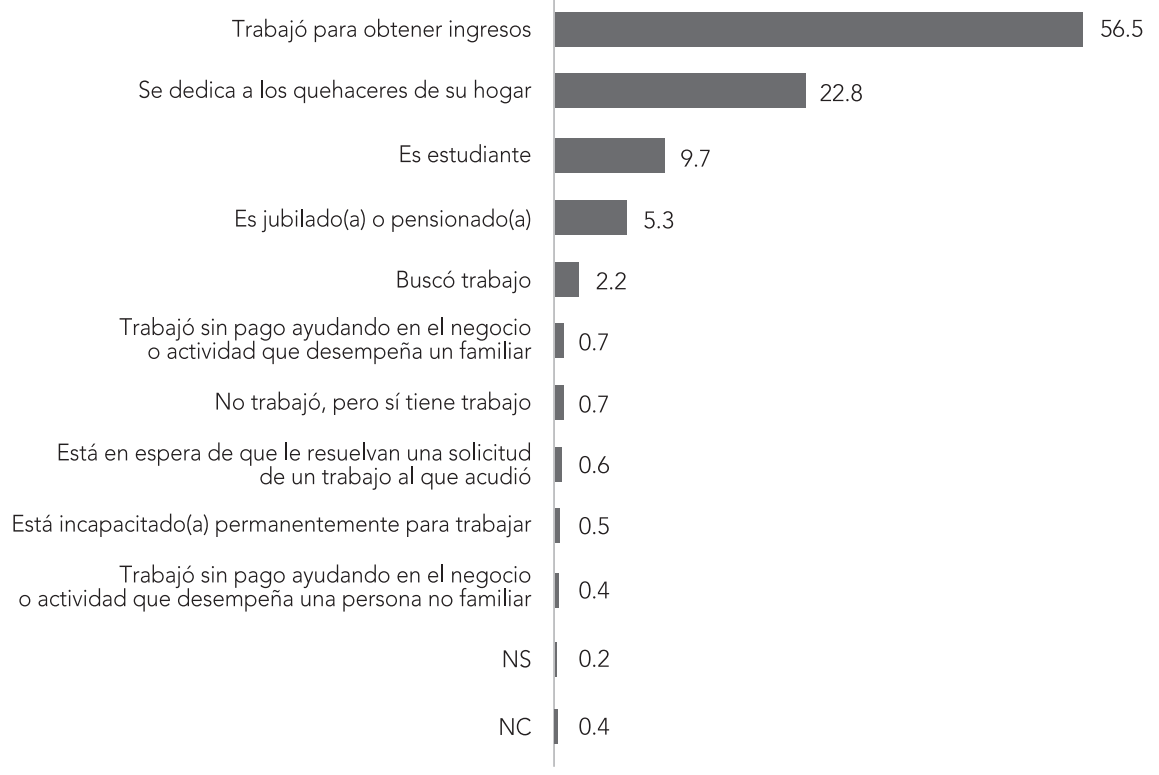

Fuente: Encuesta Nacional de Percepciones Sociales de los Juegos de Azar en México, México, UnAM, Instituto de Investigaciones Jurídicas, Departamento de Investigación Aplicada y Opinión, 2016. 
Este libro forma parte del acervo de la Biblioteca Jurídica Virtual del Instituto de Investigaciones Jurídicas de la UNAM

\section{OCUPACIÓN}

En cuanto al tipo de trabajo, oficio o cargo que desempeñan las personas entrevistadas que dijeron sí trabajar, cuatro de cada diez dijeron ser comerciantes, vendedores y similares (38.1 por ciento); uno de cada diez dijo ser profesionista o técnico (13.8 por ciento) o personal administrativo (13.3 por ciento); los trabajadores en servicios profesionales y conductores de vehículos representan el 13.0 por ciento (véase gráfica 7).

GRÁFICA 7

DISTRIBUCIÓN PORCENTUAL DE LA POBLACIÓN ENCUESTADA

SEGÚN NOMBRE DEL OFICIO, PUESTO O CARGO

(PORCENTAJES)

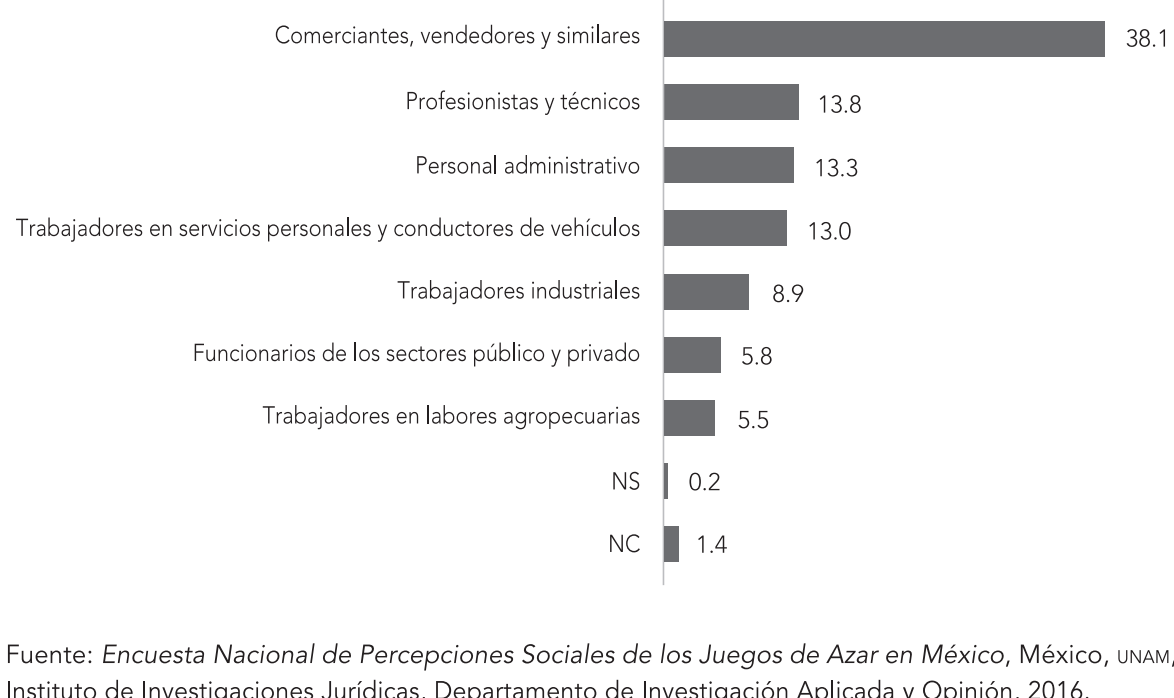
Instituto de Investigaciones Jurídicas, Departamento de Investigación Aplicada y Opinión, 2016.

\section{DISTRIBUCIÓN DE LA POBLACIÓN DE ACUERDO A RAMAS DE ACTIVIDAD}

Para casi la mitad de las personas entrevistadas que trabajan, su empresa, negocio o institución se dedica al comercio (40.5 por ciento), seguido de servicios (25.7 por ciento) e industria (13.9 por ciento) (véase gráfica 8). 
Este libro forma parte del acervo de la Biblioteca Jurídica Virtual del Instituto de Investigaciones Jurídicas de la UNAM www.juridicas.unam.mx

\section{GRÁFICA 8}

\section{DISTRIBUCIÓN PORCENTUAL DE LA POBLACIÓN ENCUESTADA SEGÚN EMPRESA, NEGOCIO O INSTITUCIÓN}

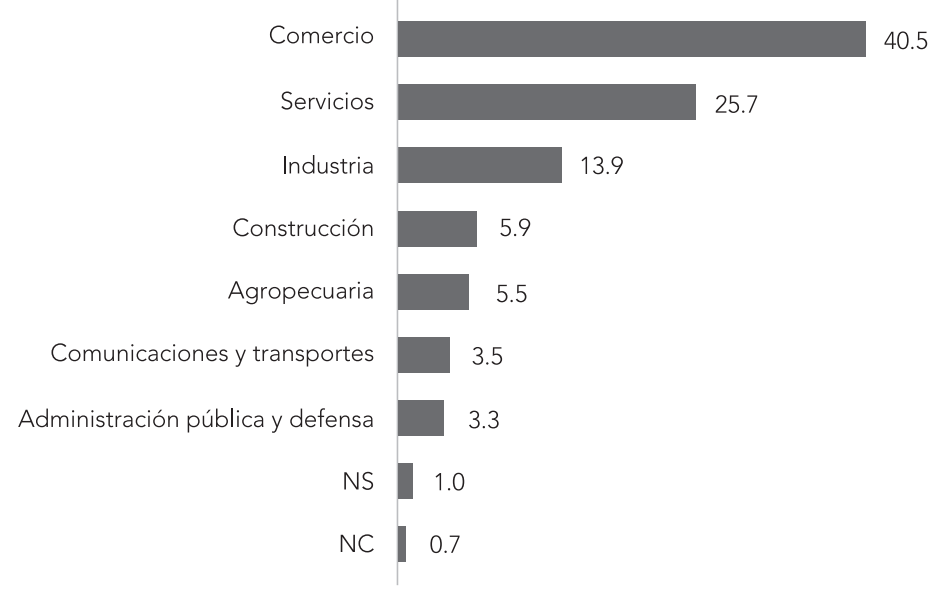

Fuente: Encuesta Nacional de Percepciones Sociales de los Juegos de Azar en México, México, unam, Instituto de Investigaciones Jurídicas, Departamento de Investigación Aplicada y Opinión, 2016.

\section{TIPO DE TRABAJO}

Por su parte, la mitad de las personas dijo ser trabajador a sueldo fijo, salarial o jornal (53.3 por ciento); tres de cada diez dijeron ser trabajadores por su cuenta (29.4 por ciento) y el 6.3 por ciento dijo ser patrón (véase gráfica 9).

Cuatro de cada diez personas entrevistadas reciben sus ingresos cada quince días (39.8 por ciento); tres de cada diez los reciben cada semana (32.6 por ciento), y dos de cada diez los reciben diario (19.9 por ciento) (véase gráfica 10). 
Este libro forma parte del acervo de la Biblioteca Jurídica Virtual del Instituto de Investigaciones Jurídicas de la UNAM www.juridicas.unam.mx

GRÁFICA 9

Trabajador a sueldo fijo, salario o jornal 53.3

Trabajador por su cuenta

Patrón

Trabajador por honorarios

Trabajador a comisión o porcentaje

Trabajador a destajo

Trabajador sin pago

NC

\section{(PORCENTAJES)}

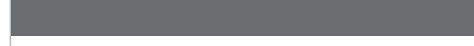

29.4

4.2

3.2

1.8

1.1

0.7

Fuente: Encuesta Nacional de Percepciones Sociales de los Juegos de Azar en México, México, UnAM, Instituto de Investigaciones Jurídicas, Departamento de Investigación Aplicada y Opinión, 2016.

\section{GRÁFICA 10}

\section{¿CADA CUÁNDO OBTIENE USTED SUS INGRESOS O LE PAGAN?}

(PORCENTAJES)

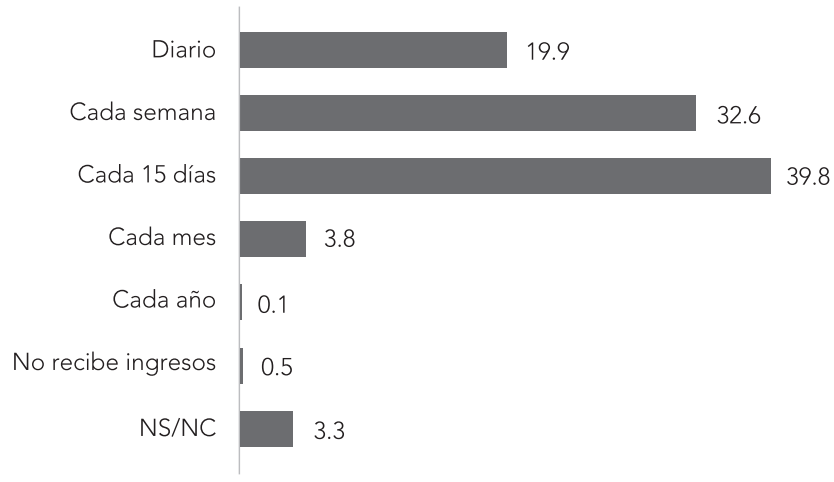

Fuente: Encuesta Nacional de Percepciones Sociales de los Juegos de Azar en México, México, UNAm, Instituto de Investigaciones Jurídicas, Departamento de Investigación Aplicada y Opinión, 2016. 
Este libro forma parte del acervo de la Biblioteca Jurídica Virtual del Instituto de Investigaciones Jurídicas de la UNAM

\section{INGRESO FAMILIAR INDIVIDUAL}

El salario promedio de las personas entrevistadas que dijeron sí trabajar fue de \$6,317.87 pesos M.N. De acuerdo con la distribución porcentual acerca de los ingresos mensuales de las personas entrevistadas, la mayor parte se concentró entre los 2 a 3 salarios mínimos, seguido por los de 1 a 2 salarios mínimos, e ingresos al mes de 3 a 4 salarios mínimos. De manera consecutiva aparecieron los que ganan de 1 salario mínimo, y de 4 a 5 salarios mínimos, y con menores porcentajes quienes ganan de 4 hasta más de 10 salarios mínimos (véase gráfica 11).

\section{GRÁFICA 11}

\section{CLASIFICACIÓN DEL INGRESO MENCIONADO EN LA PREGUNTA ANTERIOR EN LOS SIGUIENTES GRUPOS DE INGRESO

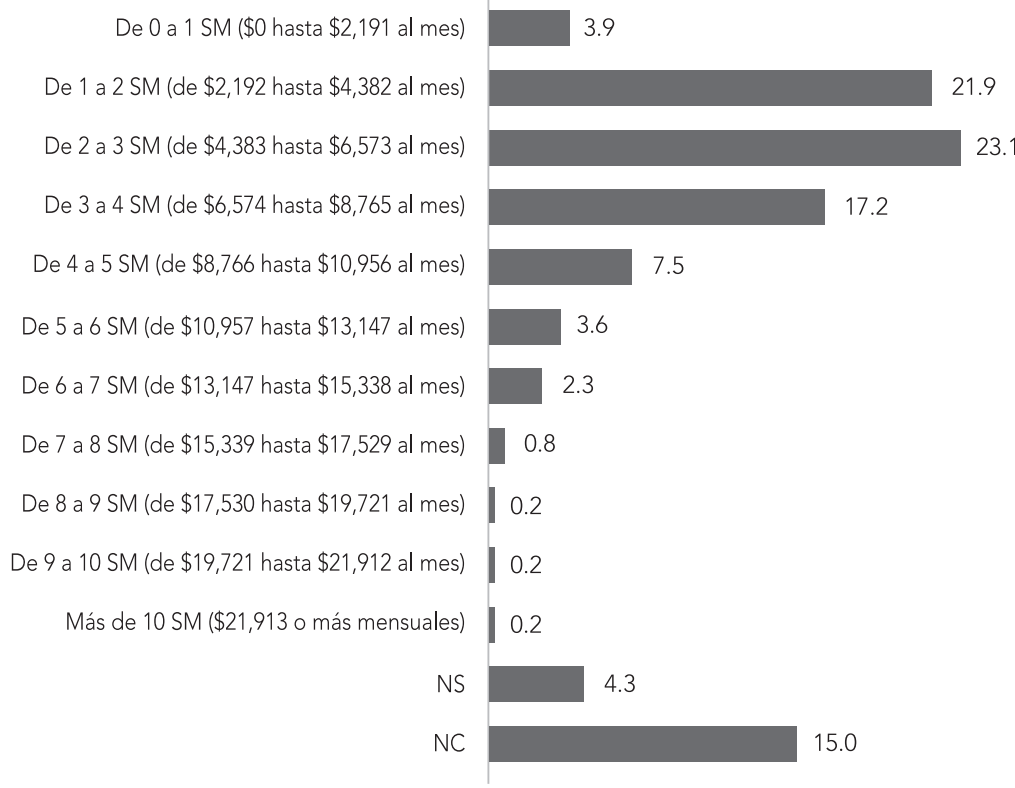

Fuente: Encuesta Nacional de Percepciones Sociales de los Juegos de Azar en México, México, UNAM, Instituto de Investigaciones Jurídicas, Departamento de Investigación Aplicada y Opinión, 2016. 
Este libro forma parte del acervo de la Biblioteca Jurídica Virtual del Instituto de Investigaciones Jurídicas de la UNAM

\section{INGRESO FAMILIAR MENSUAL}

Por otro lado, el promedio mensual de ingreso del hogar de las personas entrevistadas fue de $\$ 8,461.43$ pesos M.N., un promedio de dos mil pesos mayor al ingreso individual. De acuerdo con la distribución porcentual acerca de los ingresos por hogar de las personas entrevistadas, la mayor parte se concentró entre 2 a 4 salarios mínimos, seguido por los de 4 a 6 salarios mínimos, y de 0 a 2 salarios mínimos. Con menores porcentajes aparecieron los de 6 a 8 salarios mínimos, así como los que tienen de 8 hasta más de 20 salarios mínimos (véase gráfica 12).

\section{GRÁFICA 12}

SALARIOS EN SU HOGAR PENSANDO EN EL INGRESO TOTAL DEL MES PASADO

(PORCENTAJES)

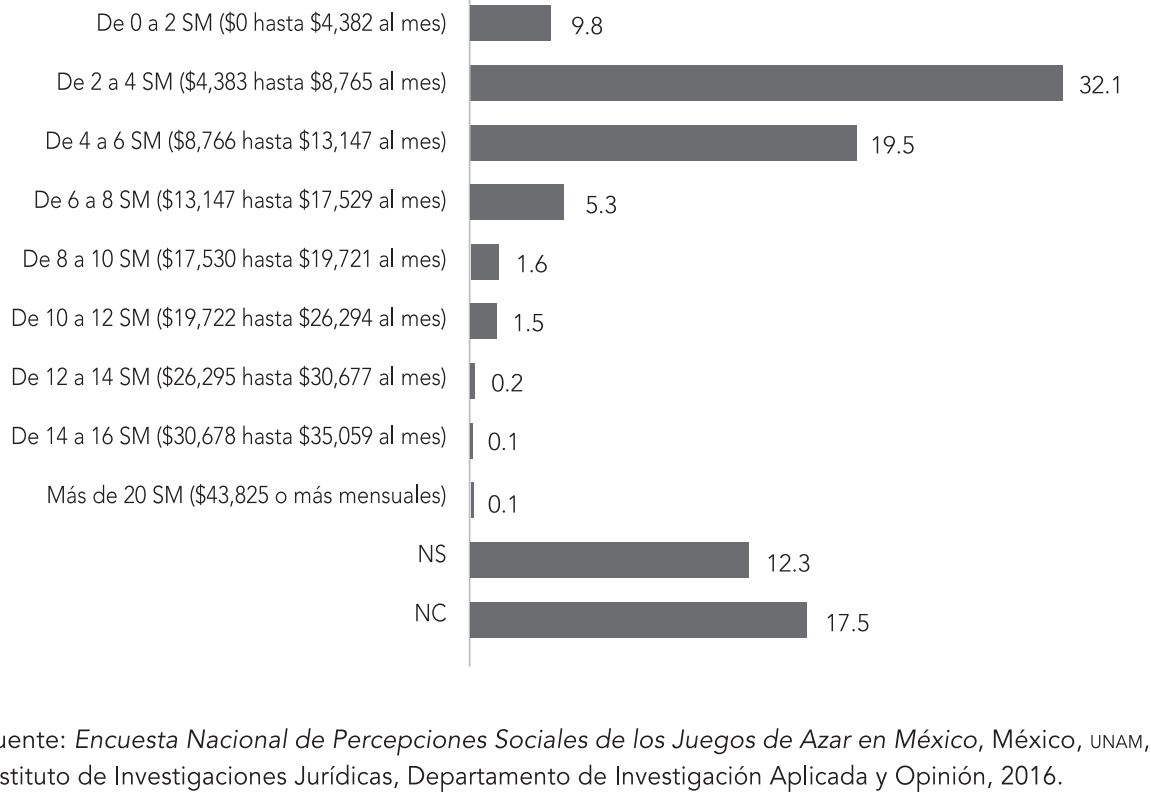

\section{DENOMINACIÓN RELIGIOSA}

Por último, se preguntó a las personas entrevistadas acerca de la religión, culto o creencia a la que pertenecen. En correspondencia con los datos cen- 
Este libro forma parte del acervo de la Biblioteca Jurídica Virtual del Instituto de Investigaciones Jurídicas de la UNAM

sales, la mayor parte de las personas dijo ser católica (71.1 por ciento); una de cada diez dijo ser cristiano no católico (14.5 por ciento), y 7.1 por ciento dijo ser ateo (véase gráfica 13).

\section{GRÁFICA 13}

¿A QUÉ RELIGIÓN, CREENCIA O CULTO PERTENECE USTED?

(PORCENTAJES)

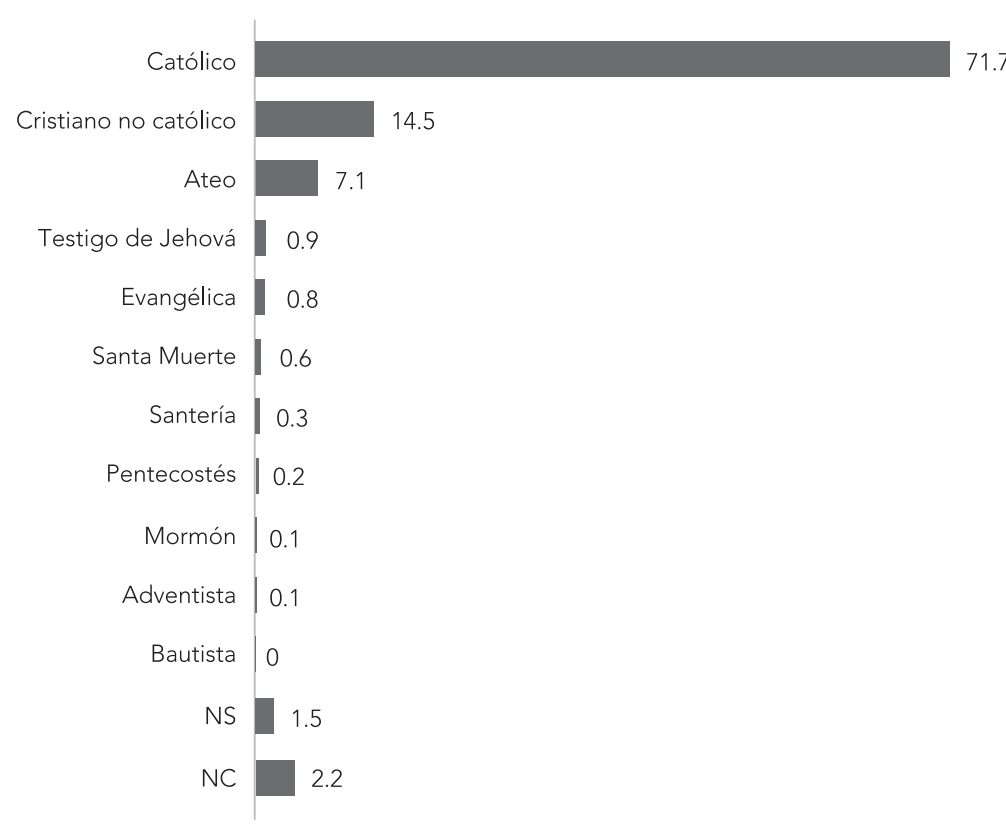

Fuente: Encuesta Nacional de Percepciones Sociales de los Juegos de Azar en México, México, unam, Instituto de Investigaciones Jurídicas, Departamento de Investigación Aplicada y Opinión, 2016. 
Este libro forma parte del acervo de la Biblioteca Jurídica Virtual del Instituto de Investigaciones Jurídicas de la UNAM

\section{ANEXO 2 \\ DISEÑO MUESTRAL}

\section{INTRODUCCIÓN}

Con el fin de conocer las percepciones generales de la población sobre los juegos de azar en México, para la encuesta en vivienda se propuso la elaboración de una muestra probabilística de 1,200 casos a nivel nacional, para personas de 18 años y más, cuyo diseño se presenta en las siguientes líneas.

\section{MARCO MUESTRAL}

Se utilizó el programa Mapa Digital de México versión 6.0.1 y Scince 2010 versión 1.0.2 del Instituto Nacional de Estadística, Geografía e Informática (INEGI) para obtener la georreferenciación de todas las entidades del país, 
Este libro forma parte del acervo de la Biblioteca Jurídica Virtual del Instituto de Investigaciones Jurídicas de la UNAM

así como los datos de población desagregados en el ámbito de localidad ${ }^{1}$ y de Área Geoestadística Básica (AGEB)² urbana.

\section{PERIODO DE LEVANTAMIENTO}

El periodo de levantamiento de la encuesta fue del 23 al 29 de septiembre de 2016.

\section{POBLACIÓN OBJETIVO}

Para esta investigación la población objetivo la constituyeron todas las personas de 18 años cumplidos o más que habitan en el país.

\section{ESTRATIFICACIÓN DEL PAÍS}

Para fines de selección de la muestra, el país fue dividido tanto por regiones geográficas con características comunes como por tamaño de localidad. Las regiones se describen en el cuadro 1.

\section{CUADRO 1}

\begin{tabular}{l|l}
\hline \multicolumn{2}{c}{ REGIONALIZACIÓN DEL PAÍS } \\
\hline REGIÓN & \multicolumn{1}{c}{ ESTADOS DE LA REPÚBLICA } \\
\hline Noroeste & Baja California, Baja California Sur, Chihuahua, Sinaloa, Sonora. \\
\hline Noreste & Coahuila, Durango, Nuevo León, San Luis Potosí, Tamaulipas. \\
\hline Occidente & $\begin{array}{l}\text { Aguascalientes, Colima, Guanajuato, Jalisco, Michoacán de Ocampo, } \\
\text { Nayarit, Querétaro, Zacatecas. }\end{array}$ \\
\hline Centro & $\begin{array}{l}\text { Distrito Federal, Hidalgo, Estado de México, Morelos, Puebla, Tlaxcala. } \\
\text { Sureste }\end{array}$ \\
\hline
\end{tabular}

Fuente: Elaboración propia.

1 Localidad. El INEGI lo define como todo lugar ocupado con una o más viviendas y reconocido por un nombre dado por la ley o la costumbre.

2 AGEB (área geoestadística básica). Extensión territorial delimitada por el INEGI cuyos habitantes comparten características socioeconómicas parecidas. 
Este libro forma parte del acervo de la Biblioteca Jurídica Virtual del Instituto de Investigaciones Jurídicas de la UNAM www.juridicas.unam.mx

De igual manera, el mapa 1 muestra la división del país por región.

\section{MAPA 1}

\section{ESTRATIFICACIÓN DEL PAÍS}

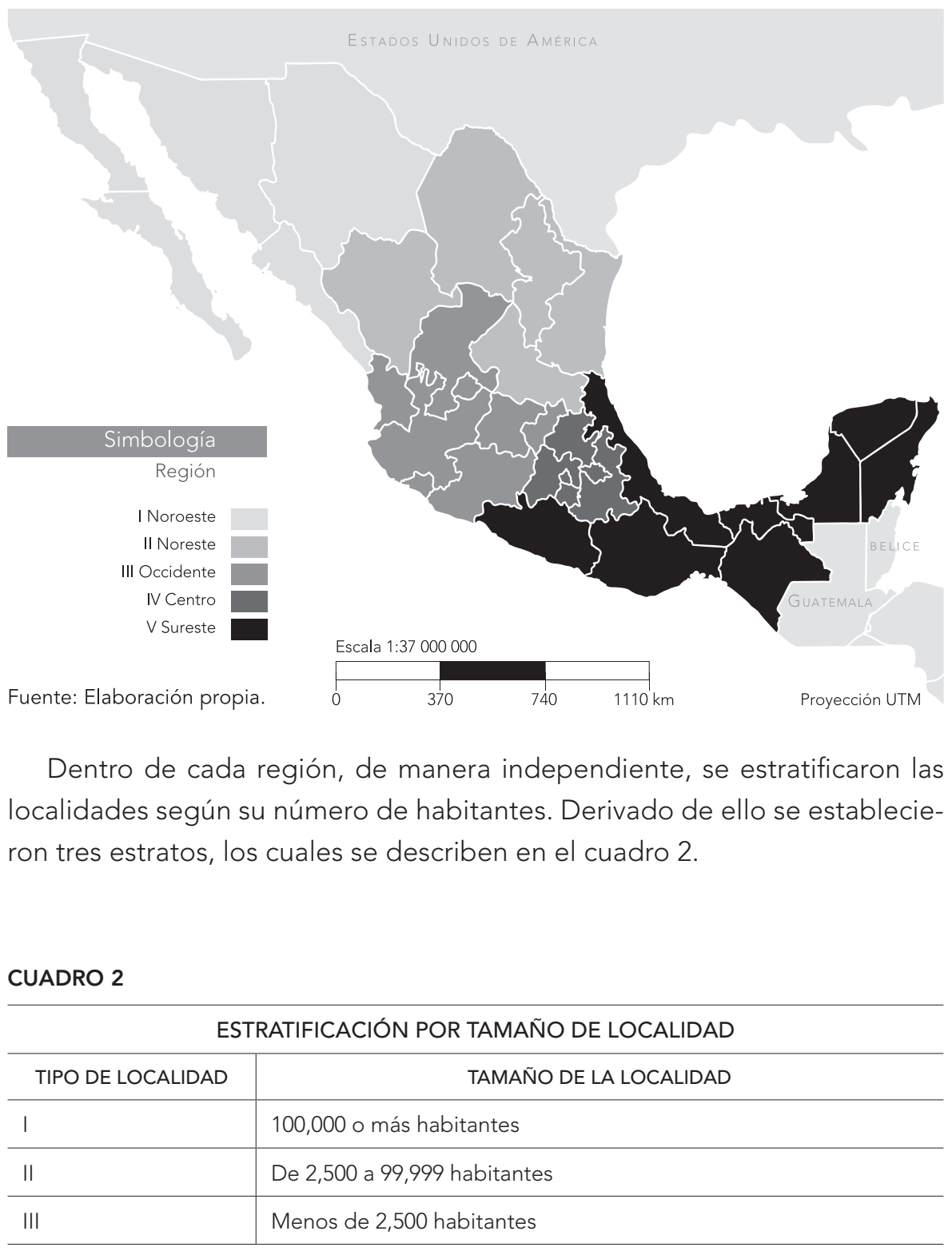


Este libro forma parte del acervo de la Biblioteca Jurídica Virtual del Instituto de Investigaciones Jurídicas de la UNAM www.juridicas.unam.mx

Con los criterios anteriores se obtuvieron quince estratos para todo el país, tal y como se describe en el cuadro 3.

\section{CUADRO 3}

POBLACIÓN DE 18 AÑOS Y MÁS POR ESTRATO³

\begin{tabular}{|c|c|c|c|}
\hline ESTRATO & REGIÓN & TIPO DE LOCALIDAD & $\begin{array}{c}\text { POBLACIÓN } \\
\text { DE } 18 \text { AÑOS Y MÁS }\end{array}$ \\
\hline 1 & Noroeste & I & $5,202,295$ \\
\hline 2 & Noroeste & ॥ & $1,763,647$ \\
\hline 3 & Noroeste & III & $1,254,312$ \\
\hline 4 & Noreste & I & $6,425,721$ \\
\hline 5 & Noreste & II & $1,823,548$ \\
\hline 6 & Noreste & III & $1,462,892$ \\
\hline 7 & Occidente & I & $6,311,964$ \\
\hline 8 & Occidente & II & $5,080,130$ \\
\hline 9 & Occidente & III & $3,502,038$ \\
\hline 10 & Centro & 1 & $14,086,278$ \\
\hline 11 & Centro & II & $6,190,471$ \\
\hline 12 & Centro & III & $3,231,192$ \\
\hline 13 & Sureste & 1 & $4,432,486$ \\
\hline 14 & Sureste & II & $5,757,352$ \\
\hline 15 & Sureste & III & $6,116,571$ \\
\hline
\end{tabular}

Fuente: Censo de Población y Vivienda 2010, INEGI.

\section{ESQUEMA DE SELECCIÓN}

Se realizó un muestreo bajo un esquema probabilístico, polietápico, estratificado, por conglomerados, tal y como se detalla a continuación.

El país fue dividido en estratos geográficos y poblacionales. Posteriormente, la selección de las unidades de muestreo se realizará a través de 
Este libro forma parte del acervo de la Biblioteca Jurídica Virtual del Instituto de Investigaciones Jurídicas de la UNAM

etapas sucesivas y de manera independiente para cada uno de los estratos generados:

- De AGEBS. La selección de AGEBS se realizó con probabilidad proporcional al tamaño (PPT) de la población de la AGEB.

- De manzanas. Se seleccionaron dos manzanas para cada AGEB en la muestra y dicha selección se hizo de forma sistemática, con arranque aleatorio (MSA).

- De viviendas. Se seleccionaron cinco viviendas para cada manzana y dicha selección se hizo de forma sistemática con arranque aleatorio.

- De individuos. Se seleccionó de manera aleatoria (MAS) a un individuo de 18 años cumplidos o más dentro de la vivienda.

\section{TAMAÑO DE MUESTRA}

El tamaño de muestra será de 1,200 casos. Dicho tamaño de muestra será distribuido entre los diferentes estratos, con el fin de generar una disminución de los márgenes de error estadísticos. Para determinarlo se consideró la siguiente fórmula:

$$
n=\frac{\left(z^{2}\right)(p)(1-p)(\text { Deff })}{d^{2}(1-T N R)}
$$

donde:

$n=$ Tamaño de la muestra.

$z^{2}=$ Es el valor en tablas de valores de probabilidad acumulada para la distribución normal estándar. Este valor depende del nivel de confianza asignado $(1-)^{*} 100 \%$.

$p=$ Probabilidad de éxito del evento. Se refiere a la probabilidad de éxito esperada.

$d^{2}=$ es la diferencia entre el valor estimado y el valor poblacional (en este caso, elevado al cuadrado).

$T N R=$ Tasa de no respuesta esperada.

Deff $=$ Efecto de diseño por utilizar un muestreo diferente al muestreo aleatorio simple. 
Este libro forma parte del acervo de la Biblioteca Jurídica Virtual del Instituto de Investigaciones Jurídicas de la UNAM

Considerando un efecto de diseño (Deff) de 2.00, una tasa de no respuesta (TNR) inferior a 5 por ciento y un margen de error (d) de 4.1 puntos porcentuales con un nivel de confianza de 95 por ciento y una $p$ de 0.5 , se calculó para cada encuesta un tamaño de muestra aproximado de 1,200 casos.

\section{CÁLCULO DE LOS PONDERADORES}

Para obtener los ponderadores utilizados dentro del cálculo de los estimadores de los parámetros se utiliza la probabilidad de selección de cada una de las etapas del muestreo.

La probabilidad de selección del individuo m-ésimo que pertenece a la vivienda l-ésima, manzana k- ésima, AGEB j-ésima del estrato i-ésimo se calcula de la siguiente forma:

$$
P\left[X_{j, k, l, m}^{i}\right]=\frac{m_{i} N_{j}^{i}}{N^{i}} \frac{2}{I_{j}^{i}} \frac{5}{I_{j, k}^{i}} \frac{1}{I_{j, k, l}^{i}}
$$

En donde:

$X_{j, k, l, m}^{i}$ es el individuo m-ésimo que pertenece a la vivienda l-ésima, manzana k-ésima, ageb j-ésima del estrato i-ésimo.

$m_{i}$ es el número de ageb seleccionadas para el estrato i-ésimo.

$N_{j}^{i}$ es la población total de personas de 18 años o más que habitan en la ageb j-ésima del estrato i-ésimo.

$N^{i}$ es la población total de personas de 18 años o más que habitan en el estrato i-ésimo.

$I_{j}^{i}$ es el número de manzanas existentes en la ageb j-ésima del estrato i-ésimo.

$I_{j, k}^{i}$ es el número de viviendas particulares habitadas en la k-ésima manzana, en la ageb j-ésima del estrato i-ésimo.

$I_{j, k, l}^{i}$ es el número de personas de 18 años o más que habitan la vivienda I-ésima, en la ageb j-ésima del estrato i-ésimo. 
Este libro forma parte del acervo de la Biblioteca Jurídica Virtual del Instituto de Investigaciones Jurídicas de la UNAM

El recíproco de la probabilidad de selección del individuo da el factor de expansión correspondiente, es decir:

$$
F_{j, k, l, m}^{i}=\frac{1}{P\left[X_{j, k, l, m}^{i}\right]}
$$

\section{AJUSTE DE LOS FACTORES DE EXPANSIÓN}

Se calibraron los factores de expansión de acuerdo con el censo de población y vivienda de 2010 con base en la edad 4 por decenios, sexo y región. Esto, con el fin de que los datos puedan expandir a la población en las proporciones que se presentan en el país. Este ajuste se logra multiplicando el factor de expansión original por una constante (componente de ajuste) que permita alcanzar tal objetivo.

Ajustes de los factores de expansión

$$
F_{r, e, s}^{\prime}=F_{r, e, s} \frac{P_{r, e, s}^{\prime}}{P_{r, e, s}^{\prime \prime}}
$$

donde:

$F_{r, e, s}$ es el factor de expansión en la región región r-ésima, del grupo decenal e y sexo s.

$F_{r, e, s}^{\prime}$ es el factor de expansión corregido en la región r-ésima, del grupo decenal e y sexo s.

$P_{r, e, s}^{\prime}$ es la población total de acuerdo con el censo de población y vivienda de 2010 perteneciente a la región -ésima, grupo decenal y sexo s.

$P_{r, e, s}^{\prime \prime}$ es la población total a la que expande la encuesta en la r-ésima región, del grupo decenal e y sexo s. 
Este libro forma parte del acervo de la Biblioteca Jurídica Virtual del Instituto de Investigaciones Jurídicas de la UNAM

\section{ANEXO 3}

\section{CONFIABILIDAD DE LOS ÍTEMS PARA JUEGO PROBLEMÁTICO}

De los jugadores que participan en al menos un juego, se tomaron los casos completos, es decir, si tenían en una variable un valor perdido se descartaba el caso, considerando los valores de 8 y 9 como perdidos.

El alfa de Cronbach es una medida de confiabilidad interna de los constructos. Típicamente un alfa mayor que 0.7 es deseable (Nunnally y Bernstein, 1994).

El alfa de Cronbach para los 10 ítems es de 0.88 , con un intervalo de confianza de $(0.86 ; 0.89)$, por lo que es un alfa aceptable para los propósitos de la investigación de juego problemático.

\begin{tabular}{ccccccc}
\hline \multicolumn{7}{c}{ CONFIABILIDAD SI UN ÍTEM ES EXCLUIDO } \\
\hline & raw_alpha & std.alpha & G6(smc) & average_r & S/N & alpha se \\
\hline P53_1 & 0.88 & 0.89 & 0.90 & 0.48 & 8.2 & 0.0079 \\
\hline P53_2 & 0.86 & 0.88 & 0.89 & 0.45 & 7.4 & 0.0089 \\
\hline
\end{tabular}


Este libro forma parte del acervo de la Biblioteca Jurídica Virtual del Instituto de Investigaciones Jurídicas de la UNAM www.juridicas.unam.mx

\begin{tabular}{lllllll}
\hline \multicolumn{7}{c}{ (continuación) } \\
\hline P53_3 & 0.86 & 0.88 & 0.89 & 0.45 & 7.4 & 0.0088 \\
\hline P53_4 & 0.86 & 0.88 & 0.89 & 0.44 & 7.2 & 0.0087 \\
\hline P53_5 & 0.87 & 0.88 & 0.89 & 0.45 & 7.4 & 0.0084 \\
\hline P53_6 & 0.86 & 0.88 & 0.89 & 0.45 & 7.3 & 0.0086 \\
\hline P53_7 & 0.86 & 0.88 & 0.89 & 0.45 & 7.2 & 0.0086 \\
\hline P53_8 & 0.86 & 0.88 & 0.89 & 0.45 & 7.5 & 0.0087 \\
\hline P53_9 & 0.87 & 0.89 & 0.90 & 0.47 & 8.1 & 0.0081 \\
\hline P54 & 0.88 & 0.90 & 0.90 & 0.49 & 8.5 & 0.0077 \\
\hline
\end{tabular}

Fuente: Nunnally, J. C. y I. H. Bernstein (1994), Psychometric Theory, Nueva York, McGraw-Hill. 
Este libro forma parte del acervo de la Biblioteca Jurídica Virtual del Instituto de Investigaciones Jurídicas de la UNAM

\section{ANEXO 4}

\section{METODOLOGÍA PARA LA OBTENCIÓN DEL ÍNDICE DE DISPONIBILIDAD LÉXICA}

Se realizó el índice de disponibilidad léxica para la pregunta 1, “Podría decirme por favor las tres primeras palabras que le vienen a la mente cuando escucha la palabra SUERTE?", y la pregunta 26, "¿Podría decirme por favor las tres primeras palabras que le vienen a la mente cuando escucha la palabra CASINO?", del cuestionario en vivienda, cuyo objetivo es el de desencadenar un proceso de evocación libre en los entrevistados.

El propósito inicial del procesamiento de la pregunta de léxico es obtener un vector de tres posiciones, con las frecuencias absolutas de mención de las palabras en primer, segundo y tercer lugar.

El objetivo final es obtener un índice de disponibilidad léxica que se calcula con base en dichas frecuencias.

\section{PROCESO DE NORMALIZACIÓN}

Es necesario someter las respuestas a un proceso de normalización, es decir, definir cierta equivalencia de términos. Se consideran como variantes de la misma palabra y se cuentan como la misma palabra: 
Este libro forma parte del acervo de la Biblioteca Jurídica Virtual del Instituto de Investigaciones Jurídicas de la UNAM

1. Las formas escritas con distinta ortografía o distinta tipografía (incluyendo mayúsculas y minúsculas) que representan la misma palabra.

2. Las variaciones de género y número que corresponden a una misma raíz, siempre y cuando se conserve la clase de palabras (sustantivo o adjetivo).

3. En el caso de verbos, se consideran la misma palabra todas las variantes de modo, tiempo y persona que correspondan a la misma raíz.

4. En el caso de que la respuesta sea una frase, registrar el núcleo de ésta. Eliminar artículos, preposiciones, conjunciones.

5. Si hay frases u oraciones muy complejas, emplear un código que indique que no se pudo registrar.

Una vez que se normalizó la ortografía las palabras deben de ser agrupadas por familias léxicas y se obtienen las frecuencias por cada mención.

Posteriormente se ponderan las cifras por medio de un procedimiento estadístico que otorga una mayor ponderación a las menciones en la primera posición que a las menciones en segunda o tercera posición.

Para la construcción del índice de disponibilidad léxica se utilizó la fórmula de López Chávez y Strassburguer (1987). *

\section{FÓRMULA DE DISPONIBILIDAD LÉXICA}

$$
D\left(P_{j}\right)=\sum_{i=1}^{n}\left(\frac{f_{i j}}{I}\right) e^{-2.3\left(\frac{i-1}{n-1}\right)}
$$

Donde:

$D\left(P_{j}\right)$ disponibilidad de la palabra j.

$i$ es el número de posición de que se trata.

$n$ es la máxima posición alcanzada.

$f_{i j}$ es la frecuencia absoluta de la palabra j en la posición i.

I es el número de informantes que respondieron la pregunta.

Se aplica la fórmula de López Chávez y Strassburger (1987) para obtener un "índice de disponibilidad" que, en principio, puede variar entre 0 y 1. 
Edición

Wendy Vanesa Rocha Cacho

Formación

José Antonio Bautista Sánchez

Apoyo editorial

Carlos Martín Aguilera Ortiz

De la suerte, el juego y otros azares

Encuesta Nacional de Percepciones Sociales

de los Juegos de Azar en México

Editado por el Instituto de Investigaciones Jurídicas de la UNAM, se terminó de imprimir el 29 de junio de 2018 en los talleres de Desarrollo Gráfico Editorial, S. A. de C. V., Municipio Libre 175-A, colonia Portales, delegación Benito Juárez, 03300 Ciudad de México, tel. 56010796. El tiro consta de 1,000 ejemplares impresos mediante offset sobre papel snow de 60 gramos. Para su composición se utilizó la familia tipográfica Avenir LT con cuerpos de 9, 10, 12 y 18 puntos. 
